\title{
Hellenistic Ceramics from Southwestern
}

\section{Paphlagonia}

\section{Ergün Laflı and Gülseren Kan Şahin}

\section{(2) OpenEdition \\ 1 Journals}

\section{Electronic version}

URL: http://journals.openedition.org/anatoliaantiqua/291

DOI: 10.4000/anatoliaantiqua.291

\section{Publisher}

IFEA

Printed version

Date of publication: 1 January 2014

Number of pages: 51-144

ISBN: 9782362450136

ISSN: 1018-1946

\section{Electronic reference}

Ergün Laflı and Gülseren Kan Şahin, « Hellenistic Ceramics from Southwestern Paphlagonia », Anatolia Antiqua [Online], XXII | 2014, Online since 30 June 2018, connection on 18 December 2020. URL : http://journals.openedition.org/anatoliaantiqua/291 ; DOI : https://doi.org/10.4000/anatoliaantiqua. 291 


\section{ANATOLIA ANTIQUA ESKI ANADOLU}

\section{XXII}

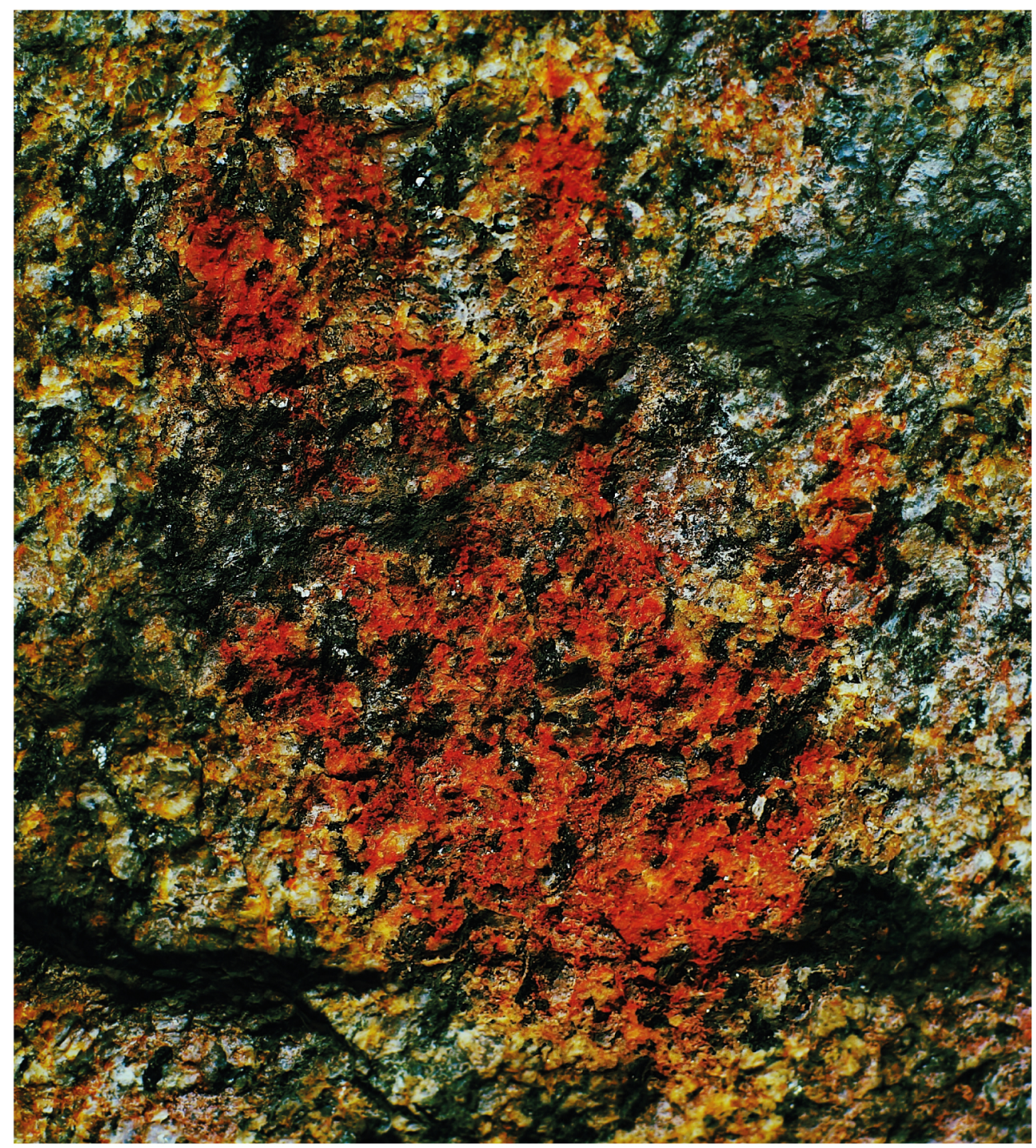

INSTITUT FRANÇAIS D'ETUDES ANATOLIENNES GEORGES-DUMEZIL CNRS USR 3131

DE BOCCARD 


\section{TABLE DES MATIERES}

Emma BAYSAL,

A preliminary typology for beads from the Neolithic and Chalcolithic levels of Barcın Höyük

William ANDERSON, Jessie BIRKETT-REES, Michelle NEGUS CLEARY,

Damjan KRSMANOVIC et Nikoloz TSKVITINIDZE,

Archaeological survey in the South Caucasus (Samtskhe-Javakheti, Georgia):

Approaches, methods and first results

Eda GÜNGÖR ALPER,

Hellenistic and Roman period ceramic finds from the Balatlar Church excavations in

Sinop between 2010-2012

Ergün LAFLI et Gülseren KAN ŞAHİN,

Hellenistic ceramics from Southwestern Paphlagonia

Oğuz TEKIN,

Weights of Lysimachea from the Tekirdağ Museum and various collections

Oğuz TEKIN,

Three weights of Lampsacus

Julie DALAISON et Fabrice DELRIEUX,

La cité de Néapolis-Néoclaudiopolis : histoire et pratiques monétaires

Martine ASSENAT et Antoine PEREZ,

Amida 4. Constance II et Amida

Sencan ALTINOLUK et Nilüfer ATAKAN,

Abrasax: A magical gem in the Istanbul Archaeological Museums

Bahadır DUMAN,

A group of local production Middle Byzantine period pottery from Tripolis:

'Micaceous White Painted Ware'

CHRONIQUES DES TRAVAUX ARCHEOLOGIQUES EN TURQUIE, 2014

Jean-Charles MORETTI,

avec la collaboration de Nicolas BRESCH, Isabel BONORA, Jean-Jacques MALMARY et

Olivier RISS,

Claros, le Temple d'Apollon : travaux réalisés en 2013

Suat ATEŞLIER,

On the excavations of the Zeus Temple of Alabanda 
Olivier HENRY,

avec Ayşe Güliz BİLGIN ALTINÖZ, Jesper BLID, Ömür Dünya ÇAKMAKLI, Andrew DUFTON, Agneta FRECCERO, Linda GOSNER, Ragnar HEDLUND, Pascal LEBOUTEILLER,

Vasilica LUNGU, Felipe ROJAS, Fredrik TOBIN, Baptiste VERGNAUD et

Andrew WATERS,

La mission Labraunda 2013 - Rapport préliminaire

Dominique BEYER, Isabelle CHALIER, Françoise KIRNER,

Françoise LAROCHE-TRAUNECKER et Aksel TIBBET,

Zeyve Höyük - Porsuk. Rapport préliminaire sur la campagne 2013

Çiğdem MANER,

Preliminary report on the first season of the Konya-Ereğli (KEYAR) survey 2013 


\section{Ergün LAFLI* and Gülseren KAN ŞAHINN*}

\section{HELLENISTIC CERAMICS FROM SOUTHWESTERN PAPHLAGONIA}

The Hellenistic and Roman archaeology of Paphlagonia (Map 1) has been studied in a very uneven manner: the south coast of the Black Sea has hardly been touched by comparison with the century and more of sustained excavations and surveys on the other coastlines. Inevitably, the archaeological picture of these coasts in antiquity looks strangely unbalanced, even though our literary texts offer moments of insight into the Classical Antiquity of the Turkish Black Sea coast, spread across centuries and driven by Xenophon's Anabasis, Strabo's Geography and Arrian's Periplus.

Two pottery reports on the finds from southwestern Paphlagonia (Map 2) from the 2005-2008 field seasons of a team from the Dokuz Eylül University already appeared at AnatAnt XX and $\mathrm{XXI}^{1}$; in this following report of the same series general knowledge about the region, field seasons, find situation etc. will therefore not be repeated. Hadrianopolis (Map 3) near the town of Eskipazar in the Turkish Province of Karabük and on its surrounding area, socalled chora $^{2}$, were the major research areas, even though most of the surface remains at Hadrianopolis are from the $6^{\text {th }}$ and $7^{\text {th }}$ cent. A.D. During these field campaigns it has been shown that southwestern $\mathrm{Pa}$ phlagonia was a transitional landscape between $\mathrm{Pa}$ phlagonia, Galatia and Bityhnia that was settled without interruption from the Bronze Age until the $8^{\text {th }}$ century A.D. The earliest pottery from southwestern Paphlagonia originates from the chora of Hadrianopolis and not from the site of Hadrianopolis itself even though some possible pre-Hellenistic finds from Hadrianopolis are known (Fig. 1). In this report pottery finds from the Hellenistic period discovered during these fieldworks will be presented in detail ${ }^{3}$.

At the end of $4^{\text {th }}$ century B.C. Paphlagonia passed under the control of the Macedonian kings, and after the death of Alexander the Great it was assigned, together with Cappadocia and Mysia, to Eumenes ${ }^{4}$. However, it continued to be governed by native princes until it was absorbed by the encroaching power of Pontus. The rulers of that dynasty became masters of the greater part of Paphlagonia as early as the reign of Mithridates Ctistes (302-266 B.C.), but it was not until 183 B.C. that Pharnaces brought the Greek city of Sinope under their control. From that time, the whole province was incorporated into the kingdom of Pontus until the fall of Mithridates VI in 65 B.C. Hellenistic immigrants to the region included the Celtic Galatians who flooded into Anatolia in the $3^{\text {rd }}$ century B.C. ${ }^{5}$. In the surveys carried out by Matthews's team there is at least one hilltop fortified site in the south of the survey area that is probably Galatian in date.

The Hellenistic economy of the coastline of Paphlagonia and Pontus was based on agricultural and industrial activities, and especially on wine and oil production and their international trade. Parallel to the intensive wine and oil production, technologically proficient transport amphorae were produced beginning at the latest in the Late Classical period and continuing into the Middle Byzantine period. Sinope, Heracleia Pontica and Amastris, all in $\mathrm{Pa}-$ phlagonian territories, thus became famous during Hellenistic and Roman times for their wine production and trade.

\footnotetext{
*) Dokuz Eylül Üniversitesi, Edebiyat Fakültesi, Arkeoloji Bölümü, Tınaztepe/Kaynaklar Yerleşkesi, Buca, TR-35160 Izmir, Turkey; <elafli@yahoo.ca>; <gulserenkan@hotmail.com>. 2013.

1) For Roman sigillata and red-slipped ware: Laflı and Kan Şahin 2012; and for Iron Age pottery: Laflı, Kan Şahin and Patacı

2) For its detailed description: Lafl1 and Christof 2012a: 28-31.

3) For a preliminary Iron Age and Hellenistic pottery report of southwestern Paphlagonia: Laflı and Kan Şahin 2015, in print; and a detailed report: Laflı and Kan Şahin 2011.

4) For the history of Paphlagonia in Hellenistic period: Barat 2014: 157-158 and 162-165.

5) Darbyshire, Mitchell and Vardar 2000: 79.
} 


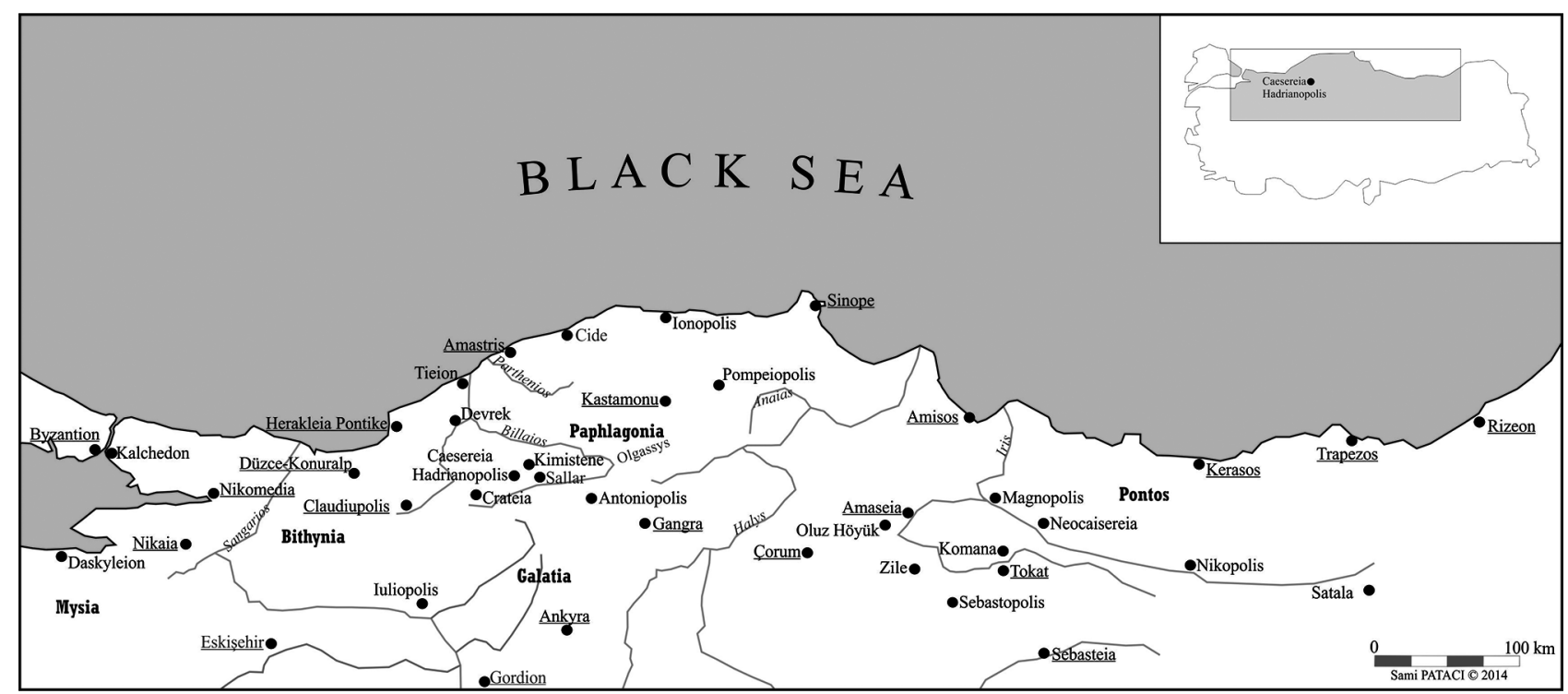

Map 1 : Map of Hellenistic Paphlagonia, Northern and Central Anatolia with the quoted places in the text. Underlined places indicate cities with local museums.
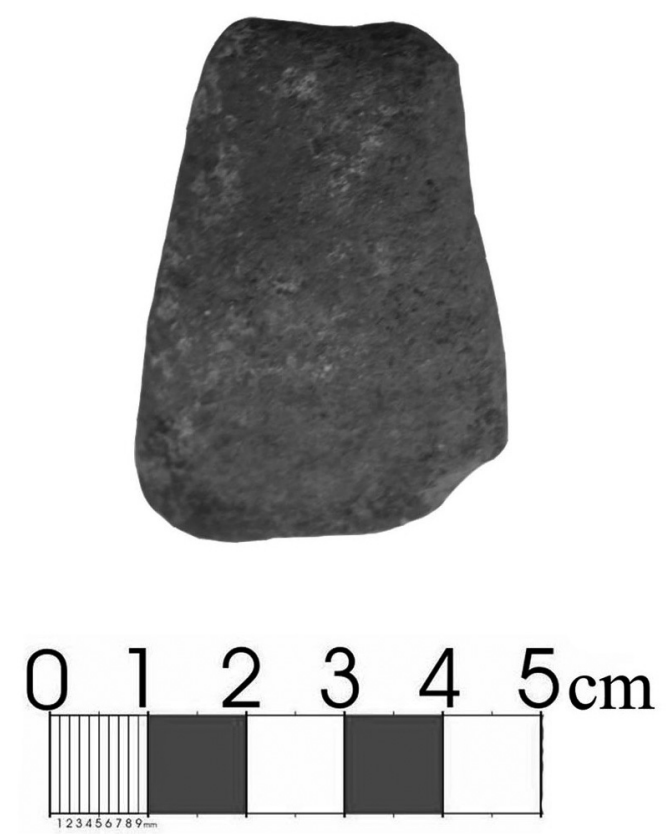

Fig. 1 : A possible pre-Roman stone axe from the Bath $A$, found in 2008 (Museum of Amasra; inv. no. Hdrn.08-08). H $5.3 \mathrm{~cm}$, w $3.7 \mathrm{~cm}$, th $2 \mathrm{~cm}$.

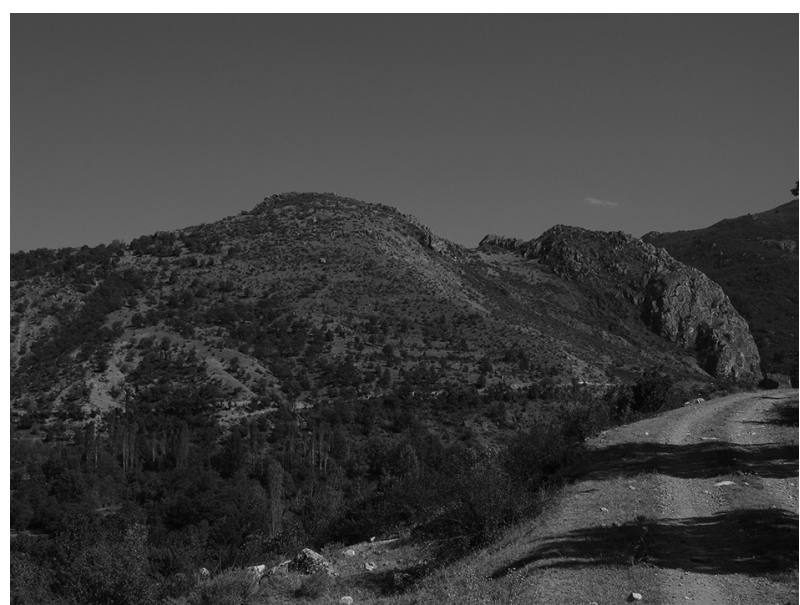

Fig. 2 : Acropolis and the Cistern of Kimistene from the northwest.

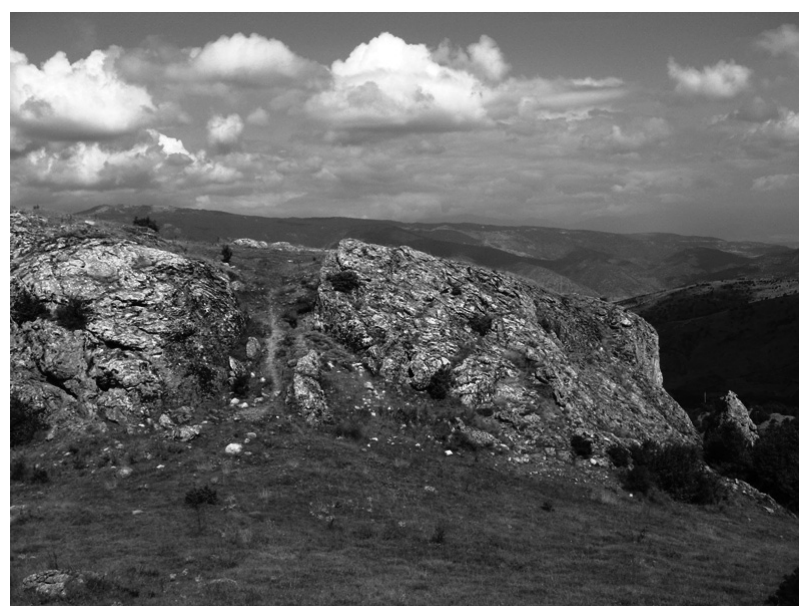

Fig. 3 : Kepez from the south. 


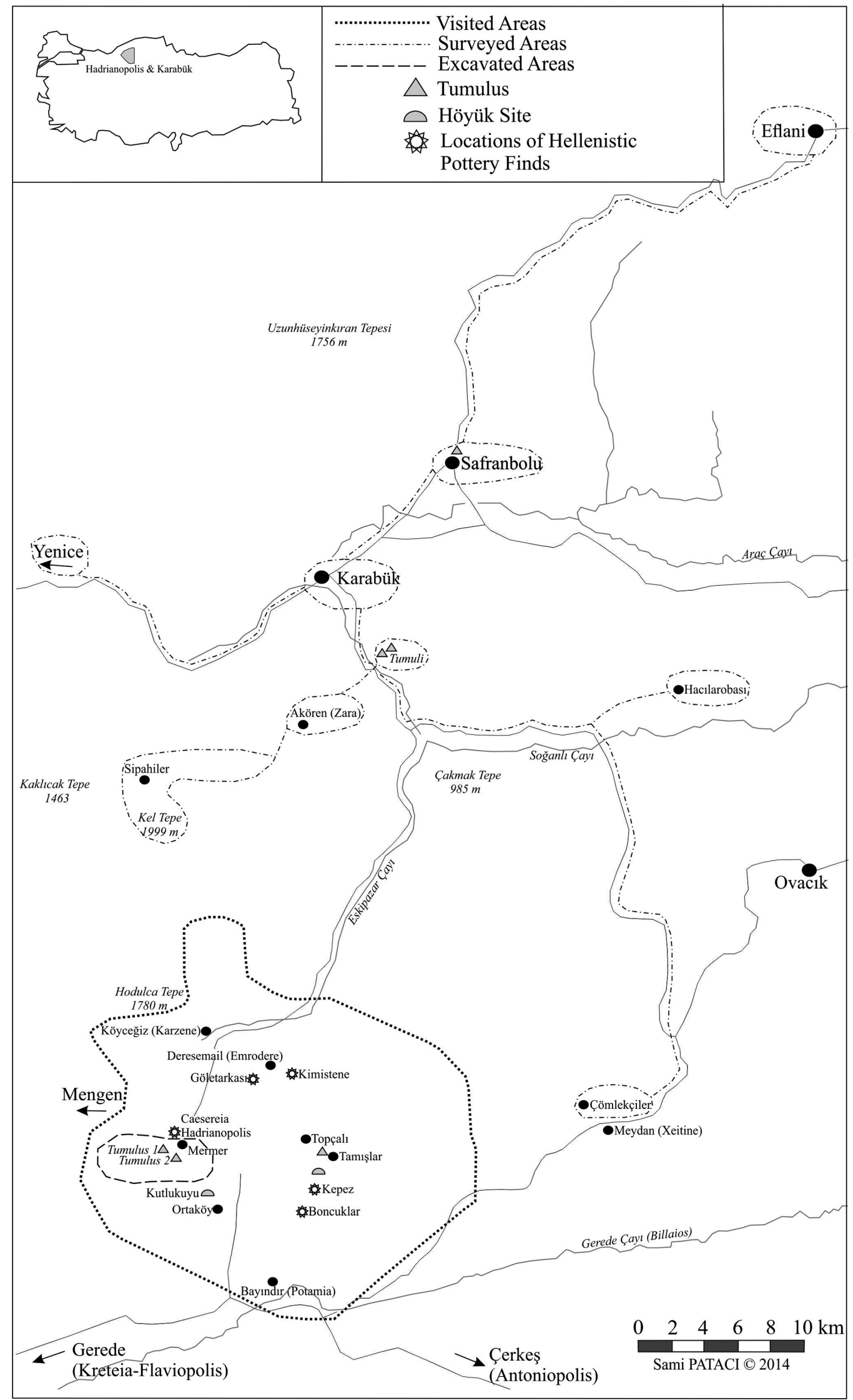

Map 2 : Map of the surveyed areas in southwestern Paphlagonia in 2005 with locations of Hellenistic pottery finds. 


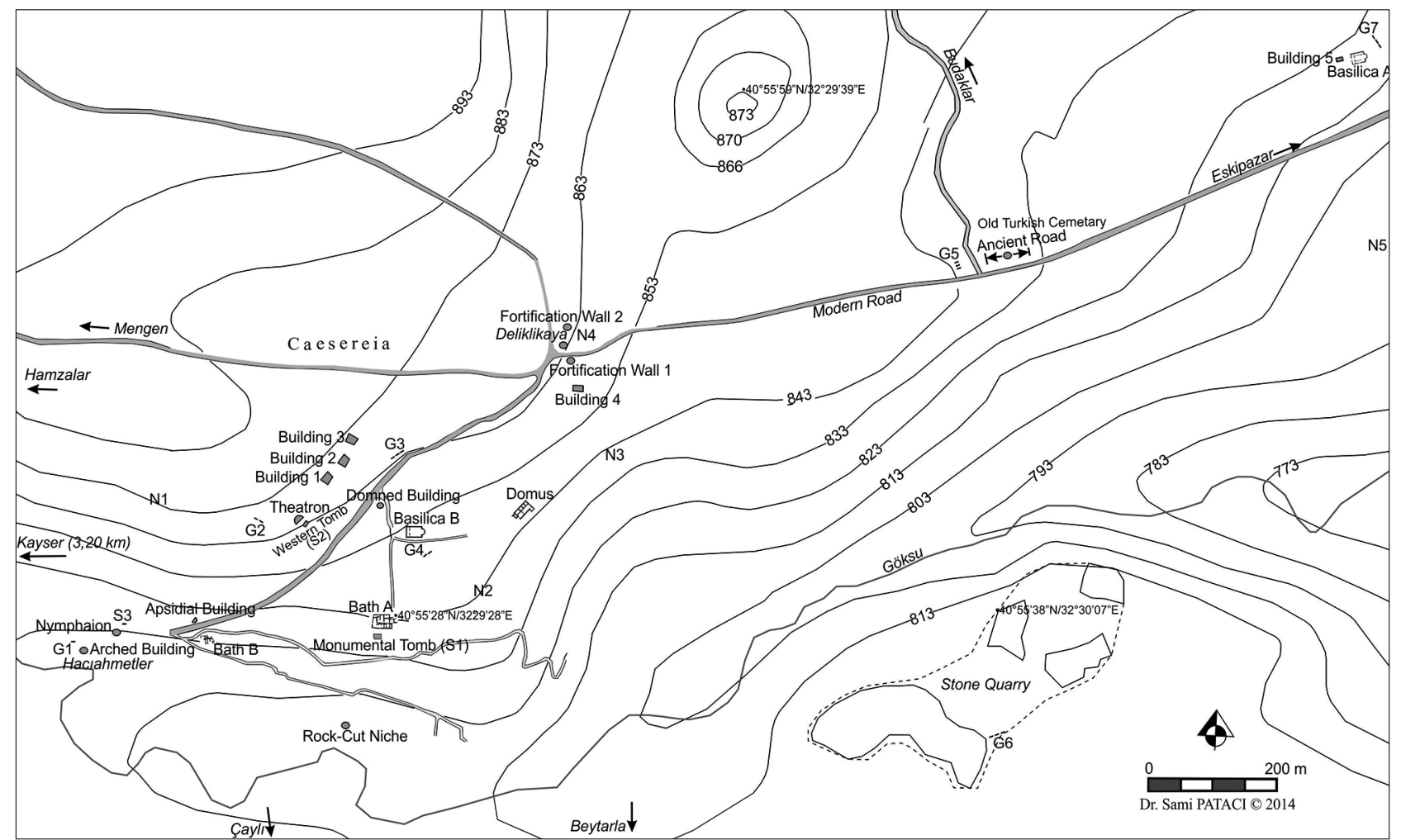

\section{Map 3 : City plan of Hadrianopolis in 2008.}

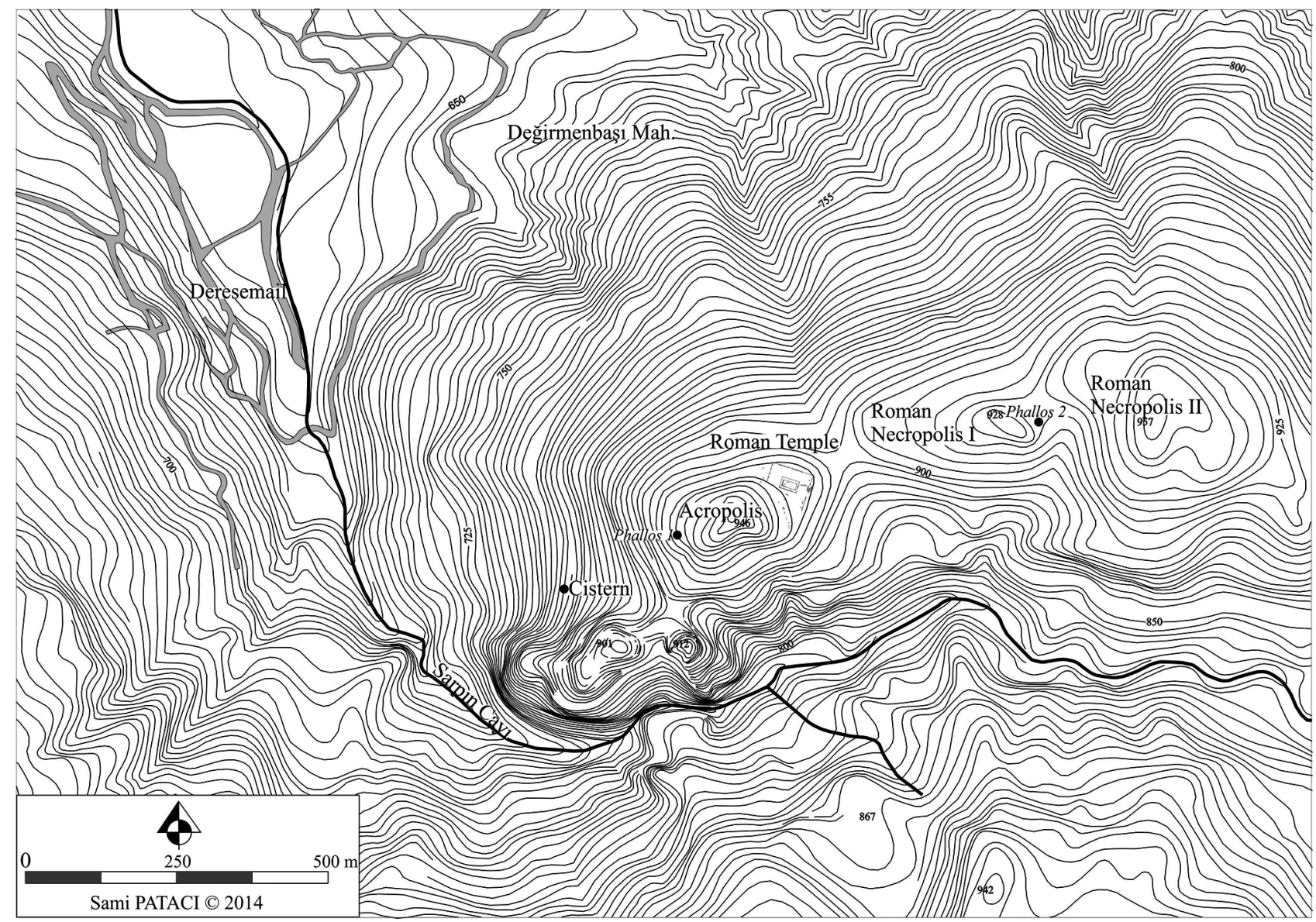

Map 4: Plan of Kimistene in 2008 and find spots of phalloi. 


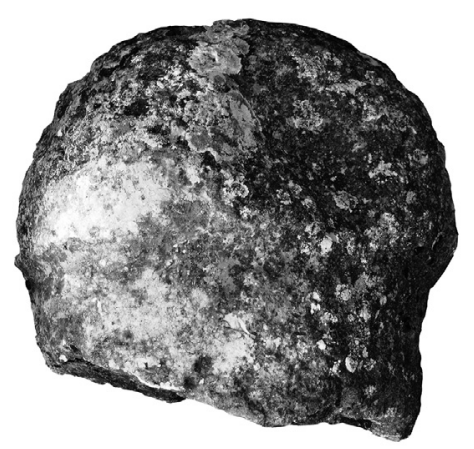

Fig. 4 : A phallos from the Necropolis I area of Kimistene.

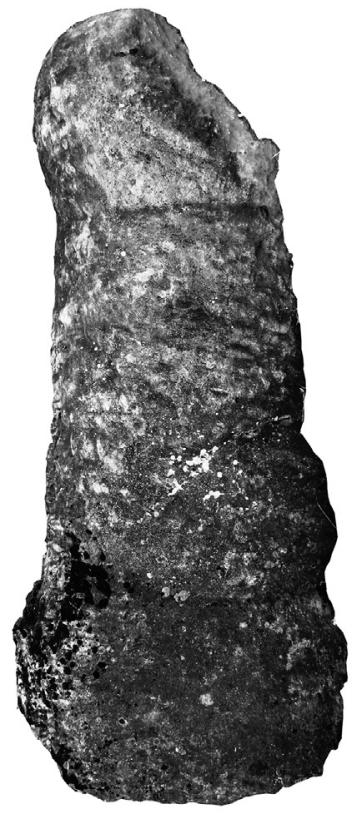

Fig. 5 : A phallos from the western slopes of Kimistene's Acropolis.

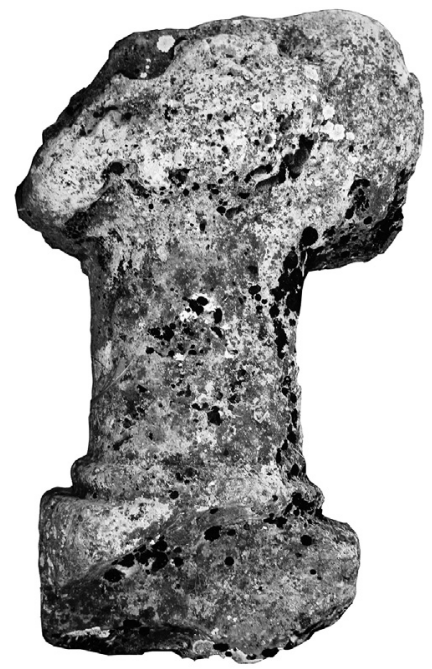

Fig. 6 : A phallos from the modern Turkish cemetery of Ortaköy.
According to D. Magie, however, Hellenistic 'Inner' Paphlagonia had a rural character with a rural type of living ${ }^{6}$. Almost no Hellenistic cities are known in southwestern Paphlagonia. At the same time one should stress the fact that Inner Paphlagonia (southwestern Paphlagonia) was never a heavily urbanized area $^{7}$, and Hellenistic sites are also very rare. The only Hellenistic site in the area that was discovered during the course of Matthews's surveys is PS 066, which is a cemetery site. This is perhaps due to the abandonment of rural settlements ${ }^{8}$. The sole evidence for Hellenistic settlement in the region is the tumuli, the date of which is rather problematic $^{9}$. Other parts of Paphlagonia, especially 'Outer' Paphlagonia are better represented during the Hellenistic period, but their ceramic evidence has not been published to any great extent. A further problem is that we cannot be certain if southwestern Paphlagonia was incorporated with the wider Hellenistic world by a network of roads.

In our 2005 survey in southwestern Paphlagonia we collected Hellenistic sherds from two major sites:
Kimistene (Fig. 2 and Map 4) and Kepez (Fig. 3). The function of Kimistene in the Hellenistic period is unclear ${ }^{10}$. At this site traces of foundations of a Roman temple (of Zeus Kimistenos?), located on the northern artificial edge of its Acropolis and on the southwestern flank of the site should have been built during the $3^{\text {rd }}$ century A.D. and should have been in use until the $4^{\text {th }}$ century A.D. This temple is an indication of some unknown religious activities at a hilltop $^{11}$. As understood from the illegal trenches opened up in its temenos, the foundations of this temple lay in the Iron Age/Hellenistic fill where we have found numerous sherds of Iron Age gray ware, especially open forms, but no painted ware or Hellenistic and Roman pottery. In the illegal excavation trench we documented at least three settlement layers of two metres in height, going deeper than the foundation level of the Roman temple. This is perhaps an indication that this area was a cultic area much earlier than the arrival of the Romans. According to some scholars, Kimistene was a base for the Pontic operations of Mithridates Ctistes as he founded and ex-

6) Magie 1950: 188.

7) Cf. map of Hellenistic Inner Paphlagonia: Matthews, Metcalfe and Cottica 2009: 178, fig. 6.6.

8) Matthews, Metcalfe and Cottica 2009: 177.

9) Laflı and Christof 2012b; as well as tumuli in the region: Matthews 2009: 157-158, table 5.4 and p. 159, fig. 5.8. Three undated phalloi could be associated with these pre-Roman tumuli in the region: Fig. 4-6.

10) For Kimistene during the Hellenistic period: Matthews, Metcalfe and Cottica 2009: 174-177; and for Kimistene generally: Laflı and Christof 2011.

11) $C f$. hilltop sanctuaries in Paphlagonia: Matthews, Metcalfe and Cottica 2009: 174-177. 
panded his kingdom in the years around 300 B.C. ${ }^{12}$. During our survey we were not able to discover any architectural indication for such a Hellenistic fortification. The existing fortification on the Acropolis of Kimistene is dateable to the Middle Byzantine pe$\operatorname{riod}\left(\mathrm{mid} 8^{\text {th }}\right.$ to late $11^{\text {th }}$ cent. A.D.). Kepez is a cemetery site with two rock-cut graves and two cisterns. It is $c a .8 \mathrm{~km}$ southeast of Kimistene and it also located in a cliffy area.

Very few pottery earlier than the $1^{\text {st }}$ cent. B.C. was found in Hadrianopolis, with the exception of a few prehistoric sherds. The first historical sign of this city is that the Caesereia Hadrianopolis region appears to have been annexed to Bithynia already in 63 B.C. ${ }^{13}$. The archaeological evidence currently suggests that Hadrianopolis was a kata komas polis in the $1^{\text {st }}$ century B.C., and it would thus not have had a highly developed urban centre. It was probably only founded in the second quarter of the $1^{\text {st }}$ century B.C. We do not know about the situation at Gangra in the Late Hellenistic period either.

The termination of the $1^{\text {st }}$ century B.C. in the course of Paphlagonian history has a problematic nature as the Romans succeeded in incorporating the region fully into their empire by the end of the $1^{\text {st }}$ century B.C. ${ }^{14}$. It is, therefore, not easy to classify this period either as 'Late Hellenistic' or 'Early Roman'.

Few Hellenistic ceramics have been published from Paphlagonia ${ }^{15}$; on the coastline pottery studies are almost exclusively devoted to amphorae. Excavations in the region, such as at Pompeiopolis in eastern Paphlagonia, and Sinope and Tieion on the coast have so far provided little Hellenistic ceramic evidence ${ }^{16}$. Very few sherds were published in the survey reports of the hinterland region. To date the sole source of information on the Hellenistic pottery from Sinope is derived from the surface survey work of an U.S. American team from the University of Pennsylvania ${ }^{17}$. Although from the very few published sherds it is not possible to draw conclusions on the Hellenistic pottery of the region, it seems that usual types of fine ware are reproduced, such as fishplates, kantharoi and relief skyphoi ${ }^{18}$. At the Cide Survey Project it is reported that the density of Hellenistic sherds is somewhat lower and only few finds could be assigned to the Hellenistic period ${ }^{19}$. In İkiztepe in the northeast examination of the Hellenistic pottery displays generally local characteristics and was used as kitchen ware ${ }^{20}$. The fine mineral tempered fabric is light red, red or orange in colour. Vessels usually have a slip with the same colour as their fabric, and are burnished and well fired.

During the four seasons of field research carried out between 2005 and 2008 in southwestern Paphlagonia a wide range of ceramics was collected from field surveys and excavations; a total of $c a$. 1525 fragments was examined. From these 458 as 'Hellenistic' (47 of which are Hellenistic coarse ware), including Late Hellenistic gray ware and brown-slipped ware. In this article survey finds in particular will be examined, because most of the Hellenistic material was found in the course of 2005 field survey. A major problem is that Iron Age and Hellenistic coarse wares are difficult to distinguish in this landscape ${ }^{21}$.

Through the quantification of material and examination of clay there is a strong evidence to assume that the great majority of these vessels were manufactured in southwestern Paphlagonia. The local origin of the material, however, has not been proven by mineralogical analysis by utilizing $\mathrm{Neu}$ tron Activation Analysis (NAA).

In our pottery study we have classified all the sherds earlier than the Roman period into a 'PreRoman' category, forming nine main groups of Hel-

12) Matthews, Metcalfe and Cottica 2009: 177.

13) Mitchell 1993: 92-93.

14) Matthews, Metcalfe and Cottica 2009: 174.

15) For a list $c f$. Lafl1 2006.

16) Hellenistic pottery from the surveys at Sinop: Doonan 2004: 86, figs. 4-11; as well as from the Acropolis of Tieion: Atasoy 2012: 31; Karaca 2010: 26; Sönmez and Öztürk 2008: 135. For other recent find spots in Paphlagonia: Late Hellenistic pottery in Devrek: Doksanaltı and Karauğuz 2012: 55, fig. 6; fine and coarse ware from the surveys of the Village Beyözü: Anderson 2008: 15; kantharoi and bowls from Cide and Şenpazar in Province Kastamonu: Bakan and Şerifoğlu 2014, in print: figs. 7-8; Kastamonu: Marro, Özdoğan and Tibet 1996: 284 and 294, pl. IV; as well as survey at Pompeiopolis and Gökırmak Valley: Barat et al. 2009.

17) Alexandropoulou 2012: 9.

18) Alexandropoulou 2012: 9 .

19) Düring and Glatz 2010: 209; and Bakan and Şerifoğlu 2014, in print.

20) Bilgi 1999: 38

21) According to the surveys by utilizing Neutron Activation Analysis (NAA) of ceramics from 12 sites across Eskişehir region collected by the Eskișehir archaeological Survey Project, Phrygian regional ceramic productions were highly localized with limited evidence of standardization during the Iron Age and later: Grave et alii 2012: 377f. This situation is also valid for Iron Age and Hellenistic pottery of southwestern Paphlagonia and in Pisidia: $c f$. Vanhaverbeke et alii 2010: 105f. 
lenistic and Late Hellenistic periods. Most of these pre-Roman groups are from Kimistene. Definable wares of these four periods are as follows: Pontic skyphos fragment of northern Black Sea origin $\left(4^{\text {th }}\right.$ century B.C.), Hellenistic painted ware, Hellenistic relief ware, Hellenistic burnished ware, red-painted Kepez group, Late Hellenistic-Early Roman gray ware, Late Hellenistic-Early Roman brown-slipped ware, an unguentarium fragment and Hellenistic coarse ware. Finds in local museums such as those in the Museum of Çankırı, Kastamonu and Amasra which are mostly from graves in the area, have also been considered for our study.

\section{CATALOGUE}

\section{A Pontic Skyphos Fragment \\ (pl. 1, n ${ }^{\circ}$ )}

During the 2005 survey at Kimistene one single fragment of a skyphos was recovered. Its shape, the quality of its slip, and decoration resemble to that of black-glazed vessels, found in the northern Black Sea region, such as Chersonesus ${ }^{22}$. Many of the Atticizing wares found in Early Hellenistic contexts at Gordion were also imported from the Black Sea rather than from Aegean production centers ${ }^{23}$. The fabric is clean and reddish. It has a stamped decoration on the interior surface. It should be dated to the early $4^{\text {th }}$ century B.C. A similar black-glazed fragment of $4^{\text {th }}-3^{\text {rd }}$ centuries B.C. was found at Oluz Höyük ${ }^{24}$ and at Zile ${ }^{25}$. A similar black-glazed trefoil oinochoe (Fig. 7), probably from the same origin and date, is being exhibited today at the Museum of Amasra. A similar bowl sherd from İkiztepe is highly burnished in black suggesting that it may be an import $^{26}$.

1. ( $\mathrm{N}^{\circ}$ 888): Body fragment; Kimistene, Acropolis, southern slope, underground cave, surface find, found in 2005.

pl. 1/1 and pl. 23/1.

Max. h $2.4 \mathrm{~cm}$., max. w $4.3 \mathrm{~cm}$., max. th $0.8 \mathrm{~cm}$.

Black (Gley $12.5 / \mathrm{N}$ ) slip is worn off. Hard, nonporous, thin paste; red (2.5YR 5/8) fabric with no visible inclusions.

\section{Hellenistic Painted Ware (pls. 1-2, $\mathrm{n}^{\text {os }} 2-59$ )}

This group is not a discrete group with common and definable characteristics, but it is clearly a continuation of the Late Iron Age painted ware tradition in the Hellenistic period with Greek forms and local painted features. We have 58 sherds in total, 45 of which are of closed and 13 of open forms. The form repertory of this ware is very limited; mostly they were closed forms with short neck. It is noteworthy that most of the pieces are body sherds with $0.4-1.0 \mathrm{~cm}$ wall thickness so that it was difficult to assign them to any known Hellenistic forms. They seem to be pots for daily use such as storage vessels, or for religious purposes as urns.

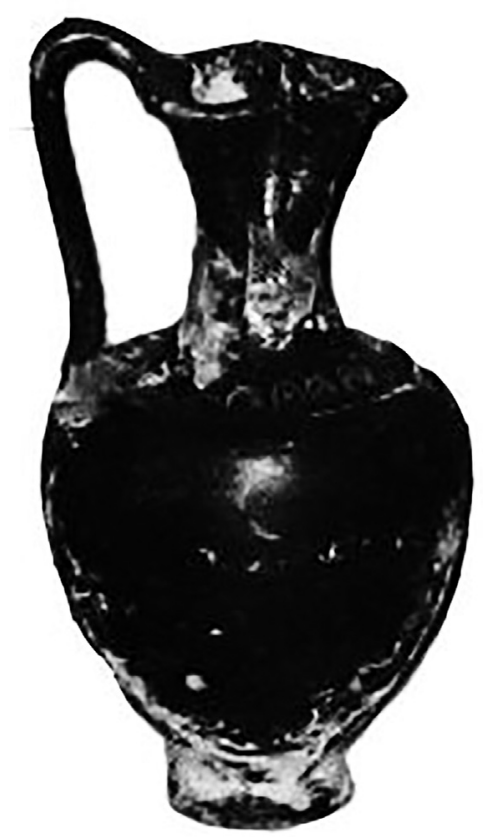

Fig. 7 : A Late Classical (4 ${ }^{\text {th }}$ cent. B.C.) black-glazed trefoil oinochoe from the Museum of Amasra.

22) Zolotarev 2005: 196-197, figs. 4-8.

23) Stewart 2010: 84.

24) Dönmez 2010: 63, fig. 103.

25) Özsait and Özsait 2014: 173, fig. 3, third sherd in the bottom line. Hellenistic sherds from Zile and other parts of Cappadocian Pontus are different than the ones in southwestern Paphlagonia.

26) Bilgi 1999: 38 


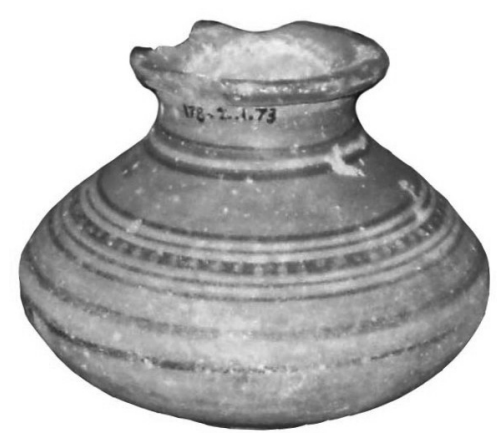

Fig. 8 : A Hellenistic painted belly jug from the Museum of Çankırı (inv. $n^{0}$ 178.2.1.73).

Paste colors are reddish yellow (5YR 6/6-6/8, 7.5YR 6/6-7/6), light red (2.5YR 6/8-6/6), red (2.5YR 5/8-5/6), light brown (7.5YR 6/4), pink (5YR 7/4, 7.5YR 7/4), light reddish brown (5YR $6 / 4)$, very pale brown (10YR 7/4), yellowish red (5YR 5/6-5/8), pale brown (10YR 6/3), brown (7.5YR 5/3), reddish brown (5YR 5/3) and gray (7.5YR 6/1). Inclusions are lime, grog, sand, grit and mica in medium and small dimensions. Their generally hard paste is light and they are well-fired products. In some badly-fired products paste is gray or mottled. Slip colours differ as pink (5YR 7/4-8/3, 7.5YR 7/3-7/4-8/3), very pale brown (10YR 7/3-7/48/2-8/3-8/3), weak red (5R 5/4, 7.5R 4/3, 4/4, 10R 4/4-5/4) red (5R 4/6, 7.5R 5/6, 10R 5/6, 2.5YR 5/6), white (10YR 8/1), reddish yellow (5YR 6/6, 7.5YR 6/6), light red (2.5YR 6/6), pale red (7.5R 6/4), light reddish brown (5YR 6/4), pinkish gray (5YR 7/2) and brown (7.5YR 4/3).

The most important distinctive feature of this group is their cream ground slip. The main decoration pattern is concentric bands in yellowish red (5YR 5/6), reddish brown (2.5YR 4/3, 5YR 5/3), pale red (7.5R 6/4) and weak red (10R 5/4) as well as red (5R 4/6, 10R 5/6-5/8, 2.5YR 5/6). Slips are mostly shinny and smooth; some samples are polished. Decoration is similar to that of Galatian ware in some respects ${ }^{27}$. No distinctive Galatian ware, however, was found in southwestern Paphlagonia. Banded decoration is a widespread ceramic trend in Asia Minor during the Hellenistic period and is produced - or at least used - at sites between Eskişehir to the west and the Halys River to the east ${ }^{28}$. The par-

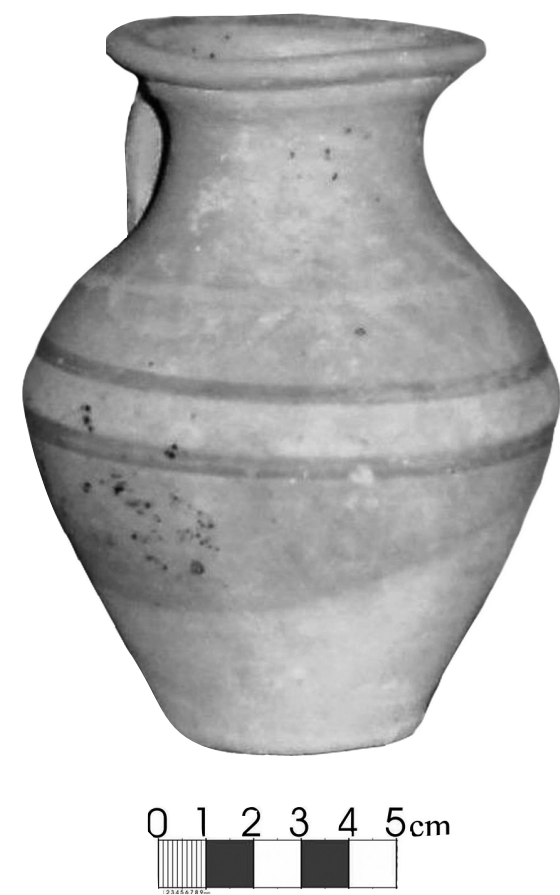

Fig. 9 : A Hellenistic painted, one-handled jug from the Museum of Çankırı.

ticular manifestation of banded pottery that occurs on the Phrygian Plateau (bordered by Eskişehir to the West, the Halys River to the east, possibly the Black Sea coast to the North, and Çatalhöyük to the South) is homogeneous in terms of fabric, form, and decoration ${ }^{29}$.

25 of these sherds were found on the southern slope of the Acropolis at Kimistene and 3 fragments from the cistern of Kimistene. It seems that Hellenistic painted ware has a concentration at Kimistene. Only two sherds were collected from Kepez.

A crater fragment with similar decoration from Oluz Höyük ${ }^{30}$ is dated to the $4^{\text {th }}-3^{\text {rd }}$ centuries B.C. In southwestern Paphlagonia, however, this group should be dated to the $3^{\text {rd }}-2^{\text {nd }}$ centuries B.C. In İkiztepe some pottery were decorated with grooved or fluted geometric patterns, such as parallel grooves or small linear triangles or zigzags ${ }^{31}$.

In the local museums of Paphlagonia, especially in the Museum of Çankırı, there are several similar examples of Hellenistic painted ware ( $c f$. Fig. 8-9) in the exhibition, none of which seems to be the

31) Bilgi 1999: 38, fig. 23, $\mathrm{n}^{\text {os }} 4-5 ; 6-9 ; 11$. 
same in terms of typology and decoration with the ones in southwestern Paphlagonia. Hellenistic painted ware examples from Kimistene seem to be rather very isolated.

$$
\text { Open Forms (pl. 1, nos 2-11) }
$$

\section{Rim Fragments of Open Forms (pl. 1, nos 2-4)}

Most of these sherds cannot be assigned to any known forms. $\mathrm{N}^{\text {os }} 2$ as well as 3 are similar forms in terms of rim profile.

2. ( $\mathrm{N}^{\circ}$ 1275): Rim fragment; Kimistene, Acropolis, southern slope, just below of the summit of Deresemail creek, found in 2005 .

pl. $1 / 2$ and pl. $23 / 2$.

Max. h $1.3 \mathrm{~cm}$. , d of rim $10.4 \mathrm{~cm}$., max. w $4.2 \mathrm{~cm}$., max. th $0.6 \mathrm{~cm}$.

Very pale brown (10YR 8/2) slip on exterior; very pale brown (10YR 7/3) slip on lower interior. Two bands in very dark gray (7.5YR 3/1) on exterior; weak red (10R $5 / 4$ ) on interior rim. Hard, non-porous, thin paste; fine, light brown (7.5YR 6/4) fabric with some sand inclusions.

3. ( $\mathrm{N}^{\circ}$ 544): Rim fragment; Kimistene, Acropolis, southern slope, just below of the summit of Deresemail creek, found in 2005 .

pl. 1/3 and pl. 23/3.

Max. h $1.4 \mathrm{~cm}$. , d of rim $11.2 \mathrm{~cm}$., max. w $4.4 \mathrm{~cm}$., max. th $0.8 \mathrm{~cm}$.

Very pale brown (10YR 8/2) slip on exterior; weak red $(10 \mathrm{R} 4 / 3)$ on interior. Two bands in dark brown (7.5YR 3/3) on exterior. Hard, non-porous, thin paste; fine, pink (7.5YR 7/4) fabric with some lime and sand inclusions.

4. (No 916): Rim fragment; Kimistene, Acropolis, on a rugid area in southeastern terrace (on the way to the Cistern), surface find, found in 2005.

pl. 1/4 and pl. 23/4.

Max. h $1.1 \mathrm{~cm}$. , d of rim $27.4 \mathrm{~cm}$., max. w $5.9 \mathrm{~cm}$., max. th $0.9 \mathrm{~cm}$.

Very pale brown (10YR 8/4) slip on exterior; weak red (7.5R 4/3) slip on interior rim. Hard, thin paste; sparsely porous, light brown (7.5YR 6/4) fabric with occasional micaceous inclusions.

\section{Base Fragment of Open Form (pl. 1, n 5)}

Flat based.

5. (№ 893): Base fragment; Kimistene, Acropolis, southern slope, underground cave, surface find, found in 2005. pl. 1/5 and pl. 23/5.

Max. h $2.0 \mathrm{~cm}$., d of base $4.4 \mathrm{~cm}$., max. w $3.0 \mathrm{~cm}$., $\max$. th $0.6 \mathrm{~cm}$.

Pink (7.5YR 7/3) slip on exterior; weak red (10R 4/4) paint on exterior; red (2.5YR 5/6) slip on interior. Exterior surface is burnished. Hard, non-porous, thin paste; fine, light red (2.5YR 6/8) fabric with some tiny lime inclusions.

\section{Body Fragments of Open Forms (pl. 1, $\mathrm{n}^{\text {os }} 10-11$ )}

6. (No. 902): Body fragment; Kimistene, Acropolis, southern slope, underground cave, surface find, found in 2005.

pl. 23/6.

Max. h $1.6 \mathrm{~cm}$., max. w $1.6 \mathrm{~cm}$., max. th $0.3 \mathrm{~cm}$.

Very pale brown (10YR 8/3) slip on exterior; reddish yellow (5YR 6/6) slip on interior. Two bands in weak red (10R 4/4) and very dark gray (5YR 3/1) on exterior. Interior surface is burnished. Hard, thin paste; non-porous, fine, reddish yellow (5YR 6/6) fabric with no visible inclusions.

7. (No 1364): Body fragment; Kimistene, Acropolis, found in 2005.

pl. 23/7.

Max. h 1.9 cm., max. w $2.4 \mathrm{~cm}$., max. th $0.5 \mathrm{~cm}$.

Pink (7.5YR 7/4) slip on exterior; in red (10R 5/6) on interior. Two bands in black (7.5YR 2.5/1) on exterior. Its below part has been painted in weak red (10R 4/4). Hard, thin paste; non-porous, fine, reddish yellow (5YR 6/6) fabric with occasional sand, frequent tiny lime inclusions.

8. (No 812): Body fragment; Kimistene, Acropolis, southern slope, just below the summit to Deresemail creek, found in 2005 .

pl. 23/8.

Max. h $2.6 \mathrm{~cm}$., max. w $1.8 \mathrm{~cm}$., max. th $0.4 \mathrm{~cm}$.

Very pale brown (10YR 8/2) slip on exterior; reddish yellow (5YR 6/6) slip on interior. Four bands in red (10R $4 / 6)$ and very dark gray (5YR 3/1) on exterior. Interior surface is burnished. Hard, thin paste; non-porous, fine, reddish yellow (5YR 6/6) fabric with rare small lime inclusions.

9. (No 853): Body fragment; Kimistene, Acropolis, southern slope, just below of the summit of Deresemail creek, found in 2005 .

pl. 23/9.

Max. h $2.4 \mathrm{~cm}$. , max. w $2.5 \mathrm{~cm}$., max. th $0.7 \mathrm{~cm}$.

Pink (7.5YR 7/4) slip on exterior and interior. Exterior surface is burnished. Three bands in dark brown (7.5YR 3/2) and red (10R 5/6) on interior. Hard, thin paste; very sparsely porous, fine, yellowish red (5YR 5/6) fabric with occasional small lime inclusions. 

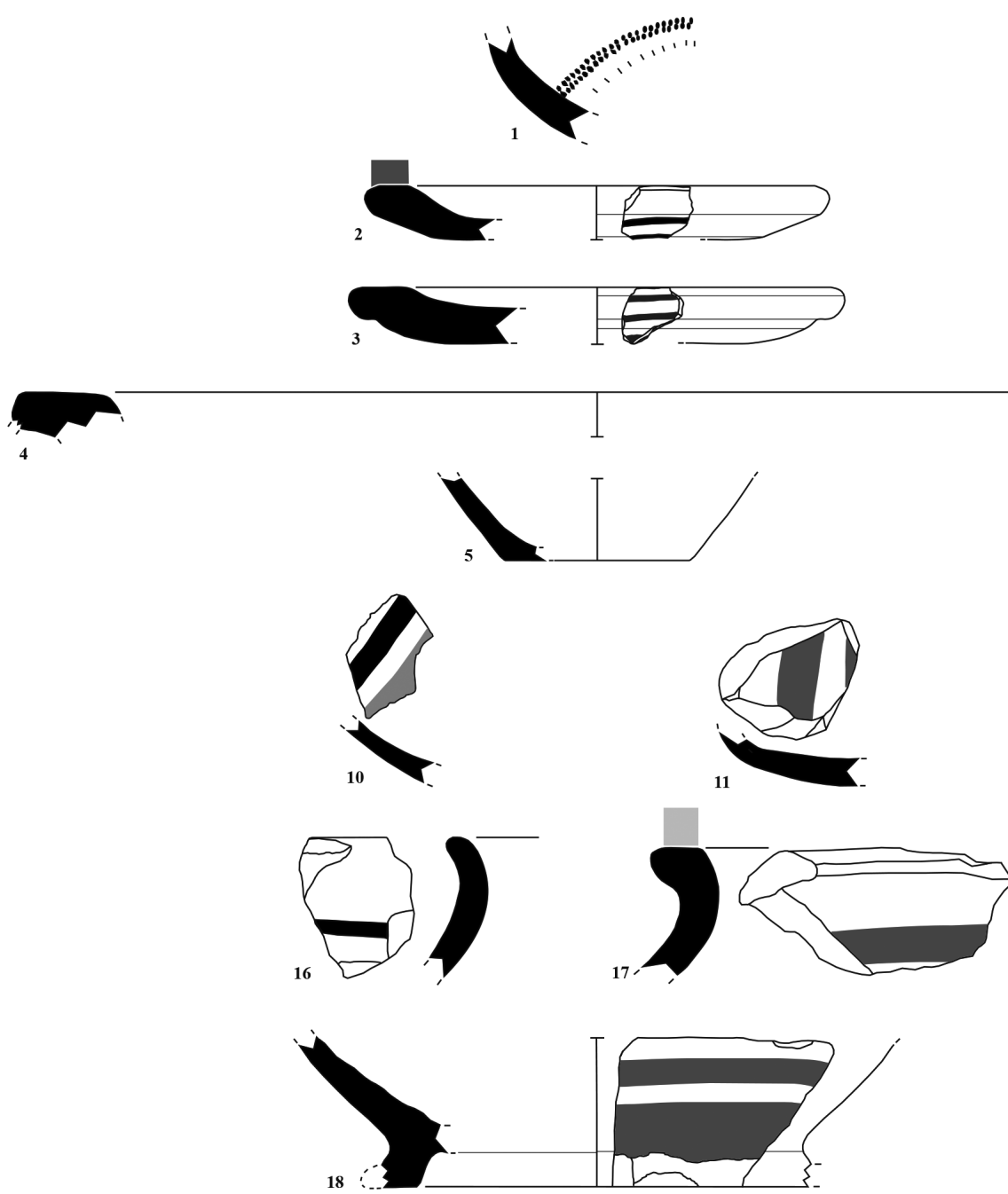
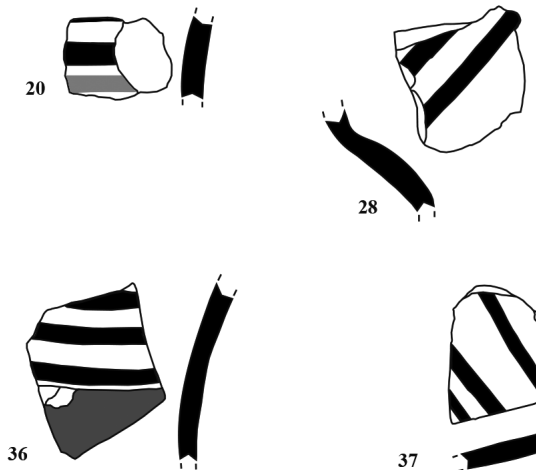

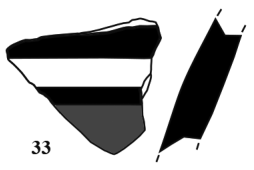

34
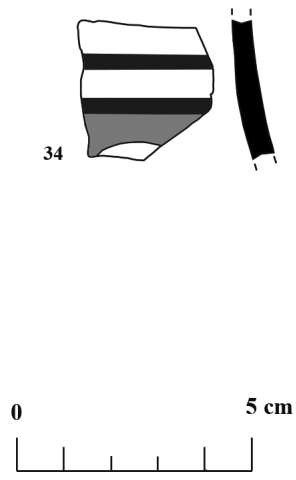

Pl. 1 : No. 1: A Pontic skyphos fragment; $n^{\text {os }} 2-37$ : Hellenistic painted ware; $n^{\text {os }} 2-4$ : Rim fragments of open forms; $n^{0}$ 5: A base fragment of an open form; $n^{\text {os }} 10-11$ : Body fragments of open forms;

$n^{\text {os }}$ 16-17: Rim fragments of closed forms; $n^{\circ} 18$ : A base fragment of a closed form; and $n^{\text {os }}$ 20-37: Body fragments of closed forms. 
10. ( $\left.\mathrm{N}^{\mathrm{o}} 1066\right)$ : Body fragment; Kimistene, Acropolis, southern slope, just below of the summit of Deresemail creek, found in 2005.

pl. 1/10 and pl. 23/10.

Max. h $1.5 \mathrm{~cm}$., max. w $2.1 \mathrm{~cm}$., $\max$. th $0.5 \mathrm{~cm}$.

Reddish yellow (5YR 6/6) unslipped surface on exterior; very pale brown (10YR 8/4) slip on interior. Two bands in red (2.5YR 4/6) and very dark gray (5YR 3/1) on interior. Hard, thin paste; non-porous, fine, light red (2.5YR 6/8) fabric with no visible inclusions.

11. ( $\left.\mathrm{N}^{\circ} 1023\right)$ : Body fragment; Kepez, found in 2005 . pl. 1/11 and pl. 23/11.

Max. h $1.3 \mathrm{~cm}$., max. w $3.4 \mathrm{~cm}$., max. th $0.8 \mathrm{~cm}$.

Very pale brown (10YR 7/3) slip on exterior; light reddish brown (5YR 6/4) slip on interior. Two bands in dusky red (10R 3/2) on interior. Average hardness; nonporous, thin paste; fine, reddish yellow (5YR 6/6) fabric with some tiny lime inclusions.

12. ( $\left.\mathrm{N}^{\circ} 806\right)$ : Body fragment; Kimistene, summit of the Acropolis, western slope, found in 2005.

pl. 23/12.

Max. h $2.6 \mathrm{~cm}$., max. w $3.5 \mathrm{~cm}$., max. th $0.5 \mathrm{~cm}$.

Light red (2.5YR 6/6) unslipped surface on exterior; light red $(2.5 \mathrm{YR} 6 / 6) \mathrm{slip}$ on interior. Interior surface is burnished. On exterior red (2.5YR 5/6) horizontal bands. Interior surface is burnished. Average hardness; nonporous, thin paste; fine, yellowish red (5YR 5/8) fabric with frequent tiny lime inclusions.

13. ( $\mathrm{N}^{\circ}$ 514): Body fragment; Kimistene, Acropolis, southern slope, just below of the summit of Deresemail creek, found in 2005 .

pl. 23/13.

Max. h $4.0 \mathrm{~cm}$., max. w $4.5 \mathrm{~cm}$., max. th $0.7 \mathrm{~cm}$.

Light brown (7.5YR 6/4) unslipped surface on exterior; light red (2.5YR 6/6) slip on interior. Brown (7.5YR $5 / 3$ ) horizontal bands on exterior. Hard, thin paste; nonporous, brown (7.5YR 5/3) fabric with some tiny lime and sand inclusions.

14. ( $\mathrm{N}^{\circ} 438$ ): Body fragment; Kimistene, Acropolis, slope, found in 2005 .

pl. 23/14.

Max. h 4.0 cm., max. w $4.1 \mathrm{~cm}$., max. th $1.0 \mathrm{~cm}$.

Red (10R 5/6) smoothed slip on exterior; weak red (10R 5/4) slip on interior. A band in very dark gray (7.5YR 3/1) on interior. All of surface is burnished. Hard, thin paste; non-porous, red $(2.5 \mathrm{YR} 5 / 8)$ and reddish yellow (5YR 6/6) fabric with some tiny lime inclusions.
Closed Forms (pls. 1-2, nos 16-59)/

Rim Fragments (pl. 1, nos 16-17)

$\mathrm{N}^{\circ} 17$ is narrow and short-necked. Most of the rim fragments are outcurved.

15. (No 1047): Rim fragment; Kepez, found in 2005. pl. 23/15.

Max. h $2.0 \mathrm{~cm}$., max. w $3.5 \mathrm{~cm}$., max. th $0.6 \mathrm{~cm}$

White $(10 \mathrm{YR} 8 / 1)$ slip on exterior and interior rim. Pink (7.5YR 7/4) unslipped surface on lower interior. Average hardness; very sparsely porous, fine, reddish brown (5YR 6/6) fabric with frequent sand and inclusions.

16. ( $\left.\mathrm{N}^{\circ} 1130\right)$ : Rim fragment; Kimistene, Acropolis, found in 2005 .

pl. 1/16 and pl. 23/16.

Max. h 3.4 cm., max. w $2.7 \mathrm{~cm}$., max. th $0.7 \mathrm{~cm}$.

White (10YR 8/1) slip on exterior and interior rim. A band in very dark gray (7.5YR 3/1) on exterior. Hard, thin paste; very sparsely porous, fine, red (2.5YR 5/8) fabric with occasional sand inclusions.

17. ( $\left.\mathrm{N}^{\circ} 881\right)$ : Rim fragment; Kimistene, Acropolis, southern slope, underground cave, surface find, found in 2005 .

pl. 1/17 and pl. 23/17.

Max. h $3.1 \mathrm{~cm}$., max. w $6.5 \mathrm{~cm}$., max. th $0.8 \mathrm{~cm}$.

Pink (7.5YR 7/3) slip on exterior; weak red (10R 5/4) on interior rim. Its below part has a very pale brown (10YR 7/3) unslipped surface on interior. A band in dusky red (10R 3/4) on exterior. Hard, non-porous, thin paste; fine, light brown (7.5YR 6/4) fabric with some tiny lime inclusions.

\section{A Base Fragment of a Closed Form} (pl. 1, no 18)

18. ( $\mathrm{N}^{\circ} 1478$ ): Kimistene, Acropolis, found in 2005. pl. 1/18 and pl. 23/18.

Max. h $3.6 \mathrm{~cm}$., d of base $8.6 \mathrm{~cm}$., max. w $5.3 \mathrm{~cm}$., $\max$. th $0.7 \mathrm{~cm}$.

Pinkish gray (5YR 7/2) slip on the exterior; reddish yellow (5YR 6/6) unslipped surface on the interior. Two parallel horizontal bands on the exterior. The upper and lower bands are weak red ( $5 R \quad 4 / 3$ or $5 R 4 / 2$ ). Hard, nonporous, thin paste; fine, light red (2.5YR 6/6) fabric with some tiny lime and sand inclusions. High-based form with internal wheel-marks. 


\section{Body Fragments of Closed Forms}

(pls. 1-2, $\mathrm{n}^{\text {os }} 20-59$ )

Large carinated forms. No ornemantation. They are either polished, or have strong internal wheelmarks.

19. (No 897): Body fragment; Kimistene, Acropolis, southern slope, underground cave, surface find, found in 2005.

pl. 23/19.

Max. h $2.1 \mathrm{~cm}$., max. w $2.0 \mathrm{~cm}$., max. th $0.5 \mathrm{~cm}$.

Weak red (7.5R 4/4) slip on exterior; reddish yellow (5YR 6/6) unslipped surface on interior. Exterior surface is burnished. Hard, non-porous, thin paste; fine, light red (2.5YR 6/8) fabric with some tiny lime inclusions.

20. ( $\mathrm{N}^{\circ} 442$ ): Body fragment; Kimistene, Acropolis, slope, found in 2005 .

pl. 1/20 and pl. 23/20.

Max. h $1.8 \mathrm{~cm}$., max. w $2.3 \mathrm{~cm}$., max. th $0.6 \mathrm{~cm}$.

Pink (5YR 8/3) slip on exterior; reddish yellow (5YR 7/6) unslipped surface on interior. Two black (5YR 2.5/1) bands on upper exterior. Its below part was painted in weak red (10R 4/4). Average hardness; thin paste; very sparsely porous, fine, light red (2.5YR 6/8) fabric with frequent tiny lime and some sand inclusions.

21. ( $\mathrm{N}^{\circ}$ 950): Body fragment; Kimistene, Acropolis, southern slope, just below of the summit of Deresemail creek, found in 2005 .

pl. 23/21.

Max. h $1.7 \mathrm{~cm}$., max. w $3.5 \mathrm{~cm}$., max. th $0.5 \mathrm{~cm}$.

Red (7.5R 5/6) slip on exterior; pink (7.5YR 7/4) unslipped surface on interior. Hard, thin paste; porous, fine, pink (7.5YR 7/4) fabric with some tiny lime inclusions.

22. ( $\mathrm{N}^{\circ} 1371$ ): Body fragment; Kimistene, Acropolis, southern slope, just below of the summit of Deresemail creek, found in 2005 .

pl. 23/22.

Max. h $2.3 \mathrm{~cm}$., max. w $3.0 \mathrm{~cm}$., max. th $0.4 \mathrm{~cm}$.

Weak red (10R 5/4) slip on exterior; pink (7.5YR 7/4) unslipped surface on interior. Hard, thin paste; very sparsely porous, fine, pink (7.5YR 7/4) fabric with no visible inclusions.

23. ( $\mathrm{N}^{\circ} 1149$ ): Body fragment; Kimistene, Acropolis, northern slope, found in 2005.

pl. 23/23.

Max. h $2.8 \mathrm{~cm}$., max. w $2.3 \mathrm{~cm}$., max. th $0.8 \mathrm{~cm}$.

Weak red (10R 5/4) slip on exterior; pink (7.5YR 7/4) unslipped surface on interior. Average hardness; nonporous, reddish yellow (5YR 6/6) fabric with frequent tiny lime and micaceous inclusions.
24. ( $\left.\mathrm{N}^{\mathrm{o}} 1325\right)$ : Body fragment; Kimistene, summit of the Acropolis, southern slope, found in 2005.

pl. 23/24.

Max. h $1.7 \mathrm{~cm}$., max. w $3.1 \mathrm{~cm}$., max. th $0.6 \mathrm{~cm}$.

Very pale brown (10YR 7/4) slip on exterior; reddish yellow (7.5YR 7/6) unslipped surface on interior. Two bands in reddish brown (5YR 5/4) and very dark gray (10YR 3/1) on exterior. Average hardness; thin paste; nonporous, reddish yellow (7.5YR 7/6-5YR 6/8) fabric with rare tiny lime inclusions.

25. ( $\left.\mathrm{N}^{\circ} 441\right)$ : Body fragment; Kimistene, Acropolis, slope, found in 2005 .

pl. 23/25.

Max. h $1.9 \mathrm{~cm}$. , max. w $3.3 \mathrm{~cm}$. , $\max$. th $0.9 \mathrm{~cm}$.

Red (2.5YR 5/6) slip on exterior; reddish yellow (5YR 6/6) unslipped surface on interior. A dark reddish gray (2.5YR 3/1) band on exterior. Hard, non-porous, thin paste; fine, reddish yellow (5YR 6/6) fabric with occasional tiny lime inclusions.

26. ( $\left.\mathrm{N}^{\mathrm{o}} 1262\right)$ : Body fragment; Kimistene, Acropolis, southern slope, just below of the summit of Deresemail creek, found in 2005 .

pl. 23/26.

Max. h $2.5 \mathrm{~cm}$., max. w $2.9 \mathrm{~cm}$., max. th $0.5 \mathrm{~cm}$.

Pink (7.5YR 8/3) slip on exterior; very pale brown (10YR 8/4) unslipped surface on interior. Two bands in dark brown (7.5YR 3/2) on exterior. These bands are bordered with two reddish brown (2.5YR 4/3) bands. Average hardness; thin paste; non-porous, fine, very pale brown (10YR 7/4) fabric with rare sand and micaceous inclusions.

27. (No 1235): Body fragment; Kimistene, Acropolis, southern slope, just below of the summit of Deresemail creek, found in 2005 .

pl. 23/27.

Max. h $2.9 \mathrm{~cm}$. , max. w $2.7 \mathrm{~cm}$., max. th $0.6 \mathrm{~cm}$

Pink (7.5YR 8/3) slip on exterior; reddish yellow (5YR 6/6) unslipped surface on interior. Three red (2.5YR $5 / 6)$ and dark reddish gray (5YR 4/2) bands on exterior. Hard, thin paste; very sparsely porous, fine, light brown (7.5YR 6/4) fabric with some sand inclusions.

28. ( No 972): Body fragment; Kimistene, Acropolis, southern slope, just below of the summit of Deresemail creek, found in 2005 .

pl. $1 / 28$ and pl. $23 / 28$.

Max. h $2.2 \mathrm{~cm}$., max. w $3.4 \mathrm{~cm}$., max. th $0.5 \mathrm{~cm}$.

Pink (7.5YR 8/3) slip on exterior; light red (2.5YR $6 / 8$ ) unslipped surface on interior. Two bands in very dark gray (7.5YR 3/1) paint on exterior. Hard, thin paste; nonporous, fine, red (2.5YR 5/8) fabric with rare sand, occasional tiny lime inclusions. 
29. ( $\mathrm{N}^{\mathrm{o}} 1011$ ): Body fragment; Kimistene, Acropolis, slope, found in 2005 .

pl. 23/29.

Max. h $2.5 \mathrm{~cm}$., max. w $3.6 \mathrm{~cm}$., $\max$. th $0.8 \mathrm{~cm}$.

Weak red (5R 5/4) slip on exterior; reddish yellow (5YR 6/6) unslipped surface on interior. Average hardness; non-porous, thin paste; fine, light red (2.5YR 6/8) fabric with no visible inclusions.

30. (No 940): Body fragment; Kimistene, Acropolis, found in 2005 .

pl. 23/30.

Max. h $2.8 \mathrm{~cm}$., max. w $2.8 \mathrm{~cm}$., max. th $0.7 \mathrm{~cm}$.

Red (10R 5/6) shiny slip on exterior; light red (2.5YR 6/6) unslipped surface on interior. Exterior surface is burnished. Hard, thin paste; very sparsely porous, fine, red (2.5YR 5/8) fabric with some tiny lime inclusions.

31. ( No 1397): Body fragment; Kimistene, summit of the Acropolis, surface find, found in 2005.

pl. 23/31.

Max. h 2.9 cm., max. w $4.6 \mathrm{~cm}$., max. th $0.4 \mathrm{~cm}$.

Weak red (7.5R 4/3) slip on exterior; reddish yellow (7.5YR 7/6) unslipped surface on interior. Hard, thin paste; non-porous, reddish yellow (5YR 6/8) and reddish yellow (5YR 6/6) fabric with no visible inclusions.

32. ( $\left.\mathrm{N}^{\circ} 1351\right)$ : Body fragment; Kimistene, Cistern, eastern slope, found in 2005.

pl. 23/32.

Max. h $3.4 \mathrm{~cm}$., max. w $3.2 \mathrm{~cm}$., max. th $0.5 \mathrm{~cm}$.

Light reddish brown (5YR 6/3) unslipped surface; reddish yellow (5YR 6/6) unslipped surface on interior. Traces of a reddish brown (5YR 5/4) band. Hard, thin paste; very sparsely porous, fine, reddish yellow (5YR $6 / 8$ ) fabric with some micaceous and sand inclusions.

33. ( $\left.\mathrm{N}^{\circ} 416\right)$ : Body fragment; Kimistene, Necropolis 1 , found in 2005 .

pl. 1/33 and pl. 23/33.

Max. h $2.9 \mathrm{~cm}$., max. w $3.3 \mathrm{~cm}$., max. th $0.8 \mathrm{~cm}$.

Very pale brown (10YR 7/4) slip on exterior; light red (2.5YR 6/8) unslipped surface on interior. Two very dark brown $(7.5 \mathrm{YR} 3 / 2)$ bands on exterior. Its below part is red (2.5YR 5/6). Average hardness; non-porous, red (2.5YR $5 / 8$ ) and pale brown (10YR 6/3) fabric with frequent tiny lime and sand inclusions.

34. ( $\mathrm{N}^{\circ} 1285$ ): Body fragment; Kimistene, found on the steep slopes from the Cistern to the Acropolis in 2005.

pl. 1/34 and pl. 23/34.

Max. h $3.1 \mathrm{~cm}$., max. w $2.7 \mathrm{~cm}$., max. th $0.5 \mathrm{~cm}$.

Very pale brown (10YR 7/4) slip on exterior; very pale brown (10YR 7/4) unslipped surface on interior. Two very dark gray (5YR 3/1) bands. Its below part is yellowish red (5YR 5/6) on exterior. Hard, thin paste; very sparsely porous, fine, very pale brown (10YR 7/4) fabric with rare lime inclusions.
35. ( $\mathrm{N}^{\circ} 889$ ): Body and base fragment; Kimistene, Acropolis, southern slope, underground cave, surface find, found in 2005.

pl. 24/35.

Max. h $2.9 \mathrm{~cm}$., max. w $4.2 \mathrm{~cm}$., $\max$. th $0.7 \mathrm{~cm}$.

Weak red (10R 4/4) slip on upper exterior; pink (7.5YR 7/4) slip around the exterior base. Reddish yellow (5YR 7/6) unslipped surface on interior. Hard, thin paste; non-porous, fine, reddish yellow (5YR 6/8) fabric with no visible inclusions.

36. ( $\mathrm{N}^{\circ}$ 537): Body fragment; Kimistene, Acropolis, southern slope, just below of the summit of Deresemail creek, found in 2005 .

pl. $1 / 36$ and pl. $24 / 36$.

Max. h $3.8 \mathrm{~cm}$., max. w $3.0 \mathrm{~cm}$., max. th $0.4 \mathrm{~cm}$.

Pink (7.5YR 8/3) slip on exterior; reddish yellow (5YR 7/6) unslipped surface on interior. Three very dark gray $(7.5 \mathrm{YR} 3 / 1)$ bands on exterior. Its below part is reddish brown (2.5YR 4/3). Hard, thin paste; non-porous, reddish yellow (5YR 6/8) fabric with no visible inclusions.

37. ( $\left.\mathrm{N}^{\circ} 407\right)$ : Body fragment; Necropolis 1 , found in 2005.

pl. 1/37 and pl. 24/37.

Max. h $1.8 \mathrm{~cm}$., max. w $3.4 \mathrm{~cm}$., max. th $0.4 \mathrm{~cm}$.

Very pale brown (10YR 8/2) slip on exterior; light red (2.5YR 6/8) unslipped surface on interior. Three black (7.5YR 2.5/1) bands on exterior. Hard, thin paste; very sparsely porous, fine, light red (2.5YR 6/8) fabric with no visible inclusions.

38. ( $\mathrm{N}^{\mathrm{o}}$ 1242): Body fragment; Kimistene, Acropolis, southern slope, just below of the summit of Deresemail creek, found in 2005.

pl. 2/38 and pl. 24/38.

Max. h $3.3 \mathrm{~cm}$., max. w $2.6 \mathrm{~cm}$., max. th $0.7 \mathrm{~cm}$.

Red (2.5YR 5/6) slip on exterior, pink (7.5YR 7/4) unslipped surface on interior. A dark reddish gray (2.5YR 3/1) band on upper exterior. Hard, thin paste; very sparsely porous, pink (7.5YR 7/4) and reddish yellow (5YR 6/6) fabric with occasional sand and tiny lime inclusions.

39. (No 400): Body fragment; Kimistene, Acropolis, eastern lowest slope; found in 2005.

pl. 2/39 and pl. 24/39.

Max. h $2.2 \mathrm{~cm}$., max. w $4.2 \mathrm{~cm}$., max. th $0.5 \mathrm{~cm}$

Very pale brown (10YR 8/3) slip on exterior; reddish yellow (5YR 7/6) unslipped surface on interior. A very dark gray (10YR 3/1) band on exterior; its below part is weak red (10R 5/4) on exterior slip. Average hardness; thin paste; very sparsely porous, fine, reddish yellow (5YR 6/8) fabric with occasional tiny lime inclusions. 

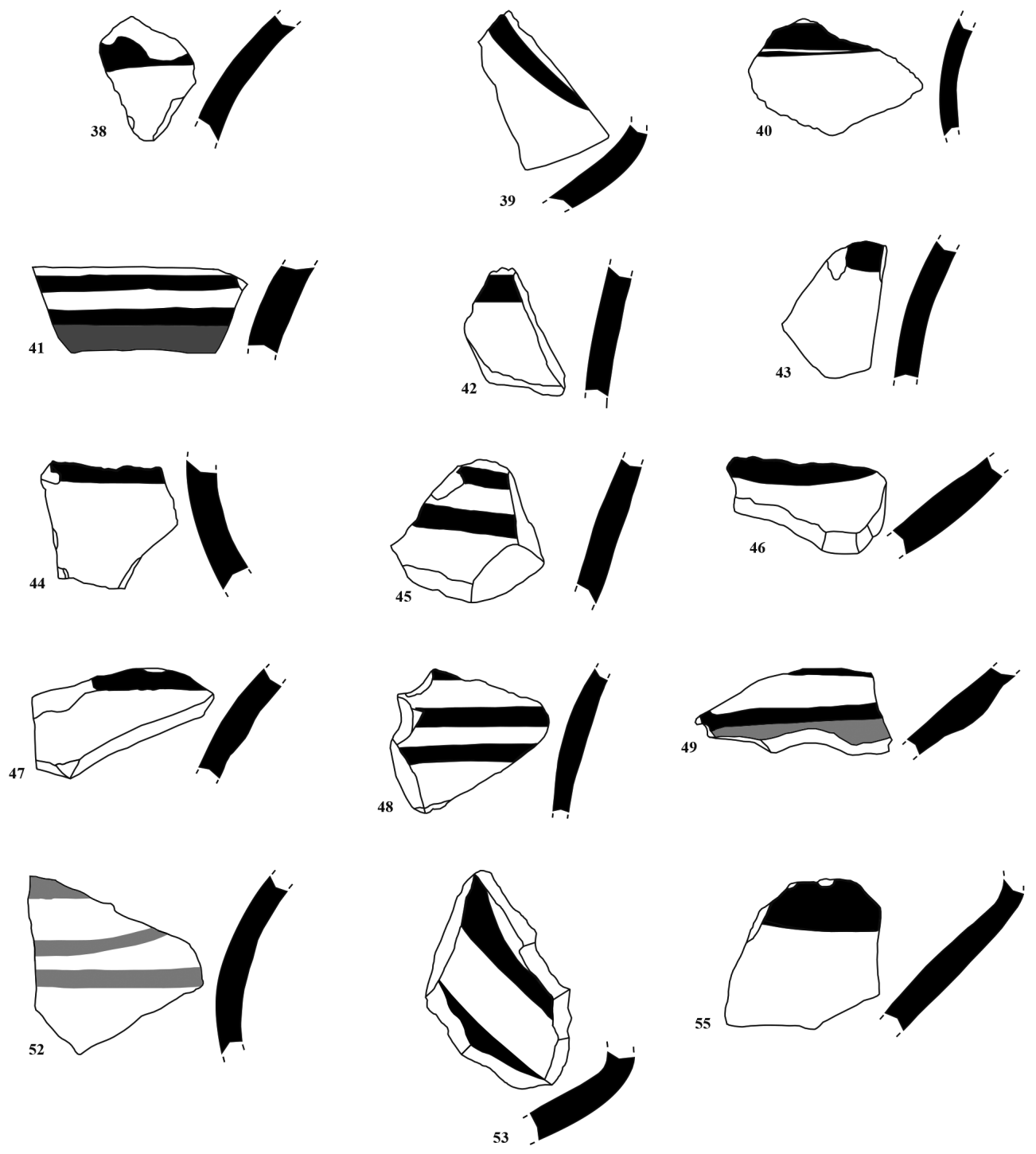

53
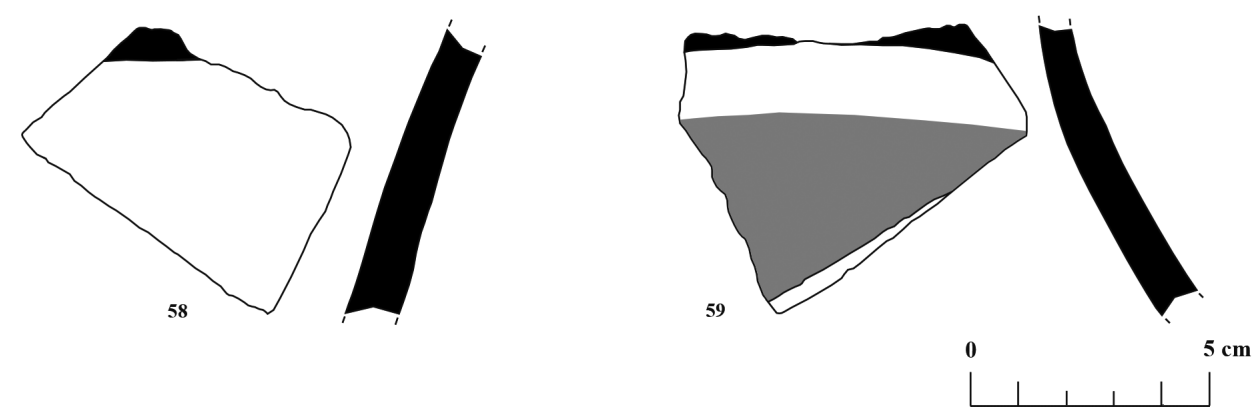

Pl. 2 : Nos 38-59: Hellenistic painted ware, body fragments of closed forms. 
40. ( $\mathrm{N}^{\circ} 731$ ): Body fragment; Kimistene, Acropolis, temple's terrace, illegally excavated area under the temple's podium, found in 2005 .

pl. 2/40 and pl. 24/40.

Max. h $3.1 \mathrm{~cm}$., max. w $4.6 \mathrm{~cm}$., max. th $0.5 \mathrm{~cm}$.

Light reddish brown (2.5YR 6/4) unslipped surface on exterior; light brown (7.5YR 6/4) unslipped surface on interior. A band in very dark gray (5YR 3/1) paint on exterior. Hard, thin paste; non-porous, fine, red (2.5YR 5/6) fabric with rare lime and sand inclusions.

41. ( $\mathrm{N}^{\circ}$ 934): Body fragment of a closed form; Kimistene, Acropolis, found in 2005.

pl. 2/41 and pl. 24/41.

Max. h $2.3 \mathrm{~cm}$., max. w $5.7 \mathrm{~cm}$., max. th $0.8 \mathrm{~cm}$.

White (10YR 8/1) slip on the exterior; light reddish brown (5YR 6/3) unslipped surface on the interior. Two parallel horizontal dark reddish gray $(2.5 \mathrm{YR} 4 / 1)$ bands on the exterior. The lower part is reddish brown (5YR $5 / 3$ ). Hard, non-porous, thin paste; reddish brown (5YR $5 / 3$ ) fabric with some micaceous and sand inclusion.

42. ( $\mathrm{N}^{\circ}$ 444): Body fragment; Kimistene, Acropolis, slope, found in 2005 .

pl. 2/42 and pl. 24/42.

Max. h 3.4 cm., max. w $2.7 \mathrm{~cm}$., max. th $0.6 \mathrm{~cm}$.

Pink (7.5YR 7/4) slip on exterior; reddish yellow (7.5YR 7/6) unslipped surface on interior. A very dark gray $(7.5 Y R 3 / 1)$ band on exterior. Hard, very sparsely porous, fine, light brown (7.5YR 6/4) fabric with rare lime inclusions.

43. ( $\mathrm{N}^{\circ}$ 1360): Body fragment; Kimistene, Cistern, eastern slope, found in 2005.

pl. 2/43 and pl. 24/43.

Max. h $3.6 \mathrm{~cm}$., max. w $2.8 \mathrm{~cm}$., max. th $0.6 \mathrm{~cm}$.

Pink (7.5YR 7/3) slip on exterior; pink (7.5YR 7/3) unslipped surface on interior. A very dark gray (5YR 3/1) band on exterior, its below part is red (10R 5/6) on exterior slip. Hard, thin paste; very sparsely porous, fine, pink (7.5YR 7/4) fabric with occasional micaceous and sand inclusions.

44. (No 1350): Body fragment; Kimistene, Cistern, eastern slope, found 2005.

pl. $2 / 44$ and pl. $24 / 44$.

Max. h 3.4 cm., max. w $3.7 \mathrm{~cm}$., max. th $0.8 \mathrm{~cm}$.

Red (5R 4/6) slip on exterior; reddish yellow (5YR $6 / 6)$ unslipped surface on interior. A dark reddish gray (2.5YR 3/1) band on upper exterior. Exterior surface is burnished. Hard, thin paste; non-porous, fine, red (2.5YR $5 / 8$ ) fabric with some tiny lime inclusions.

45. ( $\mathrm{N}^{\circ}$ 524): Body fragment; Kimistene, Acropolis, southern slope, just below of the summit of Deresemail creek, found in 2005.

pl. 2/45 and pl. 24/45.

Max. h $3.8 \mathrm{~cm}$., max. w $4.0 \mathrm{~cm}$., max. th $0.7 \mathrm{~cm}$.

Pink (7.5YR 8/3) slip on exterior, pink (7.5YR 7/4) unslipped surface on interior. Two bands in very dark gray
(7.5YR 3/1) on exterior. Hard, thin paste; very sparsely porous, fine, reddish yellow (7.5YR 7/6) fabric with occasional tiny lime inclusions.

46. ( $\mathrm{N}^{\circ}$ 939): Body fragment; Kimistene, Acropolis, found in 2005.

pl. 2/46 and pl. 24/46.

Max. h $2.6 \mathrm{~cm}$., max. w $4.2 \mathrm{~cm}$., max. th $0.8 \mathrm{~cm}$.

Red (10R 5/6) shiny slip on exterior; pink (7.5YR $7 / 4$ ) unslipped surface on interior. A very dark gray (5YR 3/1) band on exterior. Exterior surface is burnished. Hard, very sparsely porous, thin paste; fine, red (2.5YR 5/8) fabric with some micaceous, rare lime and grog less than 0.5 $\mathrm{cm}$. inclusions.

47. ( $\mathrm{N}^{\circ}$ 546): Body fragment; Kimistene, Acropolis, southern slope, just below of the summit of Deresemail creek, found in 2005 .

pl. 2/47 and pl. 24/47.

Max. h 2.9 cm., max. w $4.8 \mathrm{~cm}$., max. th $0.7 \mathrm{~cm}$.

Red (2.5YR 5/6) slip on lower exterior; pink (7.5YR 7/4) unslipped surface on interior. A very dark gray (5YR $3 / 1$ ) band on upper exterior. Exterior surface is burnished. Hard, thin paste; non-porous, light brown (7.5YR 6/4) and gray $(7.5 \mathrm{YR} 6 / 1)$ fabric with frequent tiny lime and rare sand inclusions.

48. ( $\mathrm{N}^{\circ} 398$ ): Body fragment; Kimistene, Acropolis, eastern (lowest) slope, found in 2005.

pl. 2/48 and pl. 24/48.

Max. h $4.8 \mathrm{~cm}$., max. w $4.2 \mathrm{~cm}$. , max. th $0.5 \mathrm{~cm}$.

Reddish yellow (7.5YR 7/6) slip on exterior; pink (5YR 7/4) unslipped surface on interior. Interior surface is smoothed. Three black bands (7.5YR 2.5/1) on exterior; its below part is in red (2.5YR 5/6). Hard, thin paste; very sparsely porous, fine, light reddish brown (5YR 6/4) fabric with occasional tiny lime inclusions.

49. (No 924): Body fragment of a closed form; Kimistene, Acropolis, found in 2005.

pl. 2/49 and pl. 24/49.

Max. h $2.3 \mathrm{~cm} .$, max. w $5.2 \mathrm{~cm}$., $\max$. th $0.8 \mathrm{~cm}$.

Pink (7.5YR 8/3) slip on the exterior; pink (5YR 7/4) unslipped surface on the interior. On the exterior there are two horizontal dark reddish gray (10R 4/1) bands. Its lower part is in red (10R 5/8). Hard, thin paste; nonporous, fine, pink (5YR 7/4) fabric with some micaceous and lime inclusion.

50. ( No 919): Body fragment; Kimistene, Acropolis, southeastern slope; surface find, found in 2005.

Max. h $4.1 \mathrm{~cm}$., max. w $4.1 \mathrm{~cm}$., max. th $0.6 \mathrm{~cm}$. pl. 24/50.

Very pale brown (10YR 8/2) slip on exterior; reddish yellow (7.5YR 7/6) unslipped surface on interior. A very dark gray (7.5YR 3/1) band on upper exterior. Exterior surface is burnished. Hard, thin paste; very sparsely porous, fine, reddish yellow (7.5YR 6/6) fabric with no visible inclusions. 
51. ( $\left.\mathrm{N}^{\circ} 1453\right)$ : Body fragment; uncertain.

pl. 24/51.

Max. h $4.5 \mathrm{~cm}$., max. w $4.9 \mathrm{~cm}$., max. th $0.6 \mathrm{~cm}$.

Weak red (10R 4/4) matt slip on exterior; pink (5YR $7 / 4$ ) unslipped surface on interior. Hard, thin paste; very sparsely porous, fine, reddish yellow (5YR 6/6) fabric with no visible inclusions.

52. (No 1237): Body fragment; Kimistene, Acropolis, southern slope, just below of the summit of Deresemail creek, found in 2005 .

pl. 2/52 and pl. 24/52.

Max. h $4.8 \mathrm{~cm}$., max. w $4.6 \mathrm{~cm}$., max. th $0.6 \mathrm{~cm}$.

Very pale brown (10YR 8/2) slip on exterior; pink (7.5YR 7/4) unslipped surface on interior. Three yellowish red (5YR 5/6) bands on exterior. Average hardness; non-porous, thin paste; fine, light brown (7.5YR 6/4) fabric with occasional sand and tiny lime inclusions.

53. ( $\mathrm{N}^{\circ}$ 887): Body fragment; Kimistene, Acropolis, southern slope, underground cave, surface find, found in 2005.

pl. 2/53 and pl. 24/53.

Max. h $2.5 \mathrm{~cm}$., max. w $5.8 \mathrm{~cm}$., max. th $1.0 \mathrm{~cm}$.

Pink (7.5YR 7/4) unslipped surface on exterior; pink (7.5YR 8/4) unslipped surface on interior. Two very dark gray (5YR 3/1) bands on exterior. Hard, thin paste; nonporous, light reddish brown (5YR 6/4) and light red (2.5YR 6/8) fabric with rare tiny lime inclusions.

54. (No 854): Body fragment; Kimistene, Acropolis, northwestern slope of the Temple, found in 2005.

pl. 24/54.

Max. h $4.6 \mathrm{~cm}$., max. w $5.1 \mathrm{~cm}$., max. th $0.9 \mathrm{~cm}$.

Weak red (10R 4/4) slip on exterior; light red (2.5YR 6/6) unslipped surface on interior. Exterior surface is burnished. Hard, thin paste; non-porous, fine, red (2.5YR 5/6) fabric with some tiny lime inclusions.

55. (№ 434): Body fragment; Kimistene, Acropolis, slope, found in 2005 .

pl. 2/55 and pl. 24/55.

Max. h $4.0 \mathrm{~cm}$., max. w $4.1 \mathrm{~cm}$., max. th $0.7 \mathrm{~cm}$.

Pale red (7.5R 6/4) slip on lower exterior; reddish yellow (7.5YR 7/6) unslipped surface on interior. A dark reddish gray (2.5YR 3/1) band on upper exterior. Hard, thin paste; fine, light red (2.5YR 6/8) fabric with some tiny lime inclusions.

56. (№ 439): Body fragment; Kimistene, Acropolis, slope, found in 2005 .

pl. 24/56.

Max. h $4.3 \mathrm{~cm}$. , max. w $4.2 \mathrm{~cm}$., max. th $1.2 \mathrm{~cm}$.

Weak red (10R 5/4) slip on exterior; reddish yellow (7.5YR 7/6) unslipped surface on interior. Hard, thin paste; non-porous, fine, pink (7.5YR 7/4) fabric with rare tiny lime inclusions.
57. (No 771): Body fragment; Kimistene, Acropolis, southern slope, just below of the summit of Deresemail creek, found in 2005.

pl. 24/57.

Max. h $5.7 \mathrm{~cm}$., max. w $5.2 \mathrm{~cm}$., max. th $0.8 \mathrm{~cm}$.

White (10YR 8/1) slip on exterior; pink (5YR 7/4) unslipped surface on upper interior. Pink (5YR 7/4) slip on the lower part on interior. Interior slip is separated with a red (2.5YR 5/6) band. Hard, thin paste; non-porous, reddish yellow (5YR 6/6) fabric with occasional medium grit and rare grog inclusions.

58. ( $\left.\mathrm{N}^{\circ} 443\right)$ : Body fragment; Kimistene, Acropolis, slope, found in 2005.

pl. 2/58 and pl. 25/58.

Max. h $6.0 \mathrm{~cm}$., max. w $6.9 \mathrm{~cm}$., $\max$. th $1.2 \mathrm{~cm}$.

Weak red (10R 5/4) slip on exterior; pink (7.5YR 7/4) unslipped surface on interior. A very dark gray (7.5YR 3/1) band on upper exterior. Hard, thin paste; porous, fine, pink (7.5YR 7/4) fabric with some tiny lime and sand inclusions.

59. ( $\mathrm{N}^{\circ}$ 525): Body fragment; Kimistene, Acropolis, southern slope, just below of the summit of Deresemail creek, found in 2005 .

pl. 2/59 and pl. 24/59.

Max. h $6.1 \mathrm{~cm}$., max. w $7.3 \mathrm{~cm}$., max. th $0.9 \mathrm{~cm}$.

Very pale brown (10YR 8/2) slip on upper exterior; very pale brown (10YR 7/4) unslipped surface on interior. A dark reddish gray $(2.5 \mathrm{YR} 4 / 1)$ band on upper exterior; the lower part is red $(2.5 \mathrm{YR} 5 / 6)$ on exterior. Exterior surface is burnished. Hard, thin paste; very sparsely porous, fine, light reddish brown (5YR 6/4) fabric with some lime inclusions.

\section{Hellenistic Relief Ware (pl. 3, n ${ }^{\text {os }}$ 60-73)}

This mould-made ware consists only of a bowl form whose exterior is decorated with high reliefs in egg-and-dart or degenerated floral decorations, perhaps through the influence of external workshops in western Asia Minor. Their rims are outcurved and their body form must be globular. 14 fragments were collected, 12 of which are from Kepez (mostly perhaps of a single vessel) and two from Kimistene.

Paste is reddish yellow (7.5YR 6/6, 5YR 6/6), light brown (7.5YR 6/4), pale brown (10YR 6/3), very pale brown (10YR 7/4), pale red (10R 6/2) and yellowish red (5YR 5/6). Inclusions are tiny lime, quartz, micaceous and sand small grit. Inclusions are small. Paste is hard and less porous. Slip is red (2.5YR 5/64/6-5/8, 10R 5/6), light red (2.5YR 6/6), reddish yellow (5YR 6/6-7/6), reddish brown (2.5YR 5/4, 5YR 4/4-5/4) and dark brown (7.5YR 3/2). 
Some relief ware examples were also collected in Matthews's surveys of Inner Paphlagonia ${ }^{32}$; these finds differ, though. This bowl type should be dated into $2^{\text {nd }}-1^{\text {st }}$ century B.C.

\section{Open Forms (pl. 3, nos 60-73)}

\section{Rim Fragments of a Bowl Form (pl. 3, $\mathrm{n}^{\mathrm{os}}$ 60-62)} dart ${ }^{33}$.

Some of them bear a rim frieze with egg-and2005.

60. ( $\mathrm{N}^{\circ}$ 1091): Rim fragment; Kepez, found in

pl. $3 / 60$ and $\mathrm{pl} . \mathbf{2 5 / 6 0}$.

Max. h $4.7 \mathrm{~cm}$., max. w $4.4 \mathrm{~cm}$., max. th $0.7 \mathrm{~cm}$.

Everted rim; horizontal leaf-decoration. Red (2.5YR 5/6) slip on the exterior; light red (2.5YR 6/6) slip on the interior. Average hardness; thin paste; very sparsely porous, fine, reddish yellow (5YR 6/6) and light red (2.5YR 6/8) mottled fabric with some lime and rare small grit inclusion.

61. (No 1090): Rim fragment; Kepez, found in 2005. pl. 3/61 and pl. 25/61.

Max. h $3.9 \mathrm{~cm}$., d of rim $14.8 \mathrm{~cm}$., max. w $4.3 \mathrm{~cm}$., max. th $0.6 \mathrm{~cm}$.

Everted rim; in the rim zone, a band of egg-and-dart pattern below the rim $^{34}$. Light red (2.5YR 6/6) matt slip on the exterior and interior. Hard, thin paste; very sparsely porous, fine, reddish yellow (7.5YR 6/6) fabric with frequent tiny lime inclusions.

62. ( $\left.\mathrm{N}^{\circ} 1283\right)$ : Rim fragment; Kimistene, Necropolis 1 , found in 2005 .

pl. 3/62 and pl. 25/62.

Max. h $3.2 \mathrm{~cm}$., d of rim $15.4 \mathrm{~cm}$., max. w $4.2 \mathrm{~cm}$., max. th $0.6 \mathrm{~cm}$.

Everted rim ${ }^{35}$, red (2.5YR 5/6) matt, thick slip on exterior; red (2.5YR 5/6) on interior. A pink (5YR 7/3) band on exterior rim. Average hardness; non-porous, thin paste; fine, reddish yellow (7.5YR 6/6) fabric with some tiny lime inclusions.

\section{Body Fragments of Open Forms (pl. $3, \mathrm{n}^{\mathrm{os}} 68-73$ )}

63. ( $\left.\mathrm{N}^{\circ} 1026\right)$ : Body fragment; Kepez, found in 2005. pl. 25/63.

Max. h $1.8 \mathrm{~cm}$., max. w $2.9 \mathrm{~cm}$., $\max$. th $0.6 \mathrm{~cm}$.

Red (2.5YR 4/6) slip on exterior; light red (2.5YR 6/6) slip on interior. Average hardness; thin paste; nonporous, fine, light brown (7.5YR 6/4) fabric with occasional small grit inclusions.
64. ( $\left.\mathrm{N}^{\circ} 1030\right)$ : Body fragment; Kepez, found in 2005.

pl. 25/64.

Max. h $2.7 \mathrm{~cm}$., max. w $2.3 \mathrm{~cm}$., $\max$. th $0.5 \mathrm{~cm}$.

Reddish brown (5YR 4/4) slip on exterior; red (2.5YR 5/6) slip on interior. Two pinkish white (7.5YR $8 / 2$ ) and dark reddish brown (5YR 3/3) bands on exterior. Hard, thin paste; non-porous, fine, pale brown (10YR 6/3) fabric with some tiny lime and rare sand inclusions.

65. ( $\mathrm{N}^{\circ}$ 1027): Body fragment; Kepez, found in 2005. pl. 25/65.

Max. h $2.4 \mathrm{~cm}$., max. w $2.7 \mathrm{~cm}$., max. th $0.6 \mathrm{~cm}$.

Red $(2.5$ YR $5 / 8)$ slip on exterior and interior. Hard, thin paste; non-porous, reddish yellow (5YR 6/6) fabric with some lime and sand, rare micaceous inclusions.

66. ( $\left.\mathrm{N}^{\circ} 1054\right)$ : Body fragment; Kepez, found in 2005. pl. 25/66.

Max. h $3.2 \mathrm{~cm}$., max. w $2.2 \mathrm{~cm}$., max. th $0.7 \mathrm{~cm}$.

Red (2.5YR 5/6) slip on exterior; very pale brown (10YR 7/3) unslipped surface on interior. Soft, thin paste; non-porous, fine, pale brown (10YR 6/3) fabric with rare lime inclusions.

67. ( $\mathrm{N}^{\circ}$ 1017): Body fragment; Kepez, found in 2005. pl. 25/67.

Max. h $1.8 \mathrm{~cm}$., max. w $3.1 \mathrm{~cm}$., max. th $0.5 \mathrm{~cm}$.

Reddish brown (2.5YR 5/4) slip on exterior; red (2.5YR 5/6) tiny slip on interior. Average hardness; thin paste; non-porous, fine, reddish yellow (7.5YR 6/6) fabric with no visible inclusions. 2005 .

68. ( $\mathrm{N}^{\circ}$ 1019): Body fragment; Kepez, found in

Max. h $3.4 \mathrm{~cm}$., max. w $3.1 \mathrm{~cm}$., max. th $0.5 \mathrm{~cm}$.

Reddish yellow (5YR 6/6) slip on exterior; reddish yellow (5YR 7/6) slip on interior. Small leaf ornamentation on exterior surface. Hard, thin paste; non-porous, very pale brown (10YR 7/4) and light brownish gray (10YR 6/2) fabric with infrequent lime and sand inclusions.

69. (No 921): Body fragment; Kimistene, Acropolis, southeastern slope, on the way to the Cistern, on a rocky slope, surface find, found in 2005.

pl. 3/69 and pl. 25/69.

Max. h $2.8 \mathrm{~cm}$., max. w $3.9 \mathrm{~cm}$., max. th $0.6 \mathrm{~cm}$.

Dark brown (7.5YR 3/2) slip on exterior; red (10R 5/6) slip on interior. Average hardness; thin paste; nonporous, fine, reddish yellow (7.5YR 6/6) fabric with infrequent tiny lime inclusions.

32) Matthews, Metcalfe and Cottica 2009: 220, fig. 6.104, $\mathrm{n}^{\text {os }} 11-14$ (site PS 168).

33) Similar ones: Bilde 2010: 276, pl. 169, F-6 and F-8-9.

34) Similar ones: Rotroff 1982: 48, pls. 6, 73, no. 34

35) Idem. 

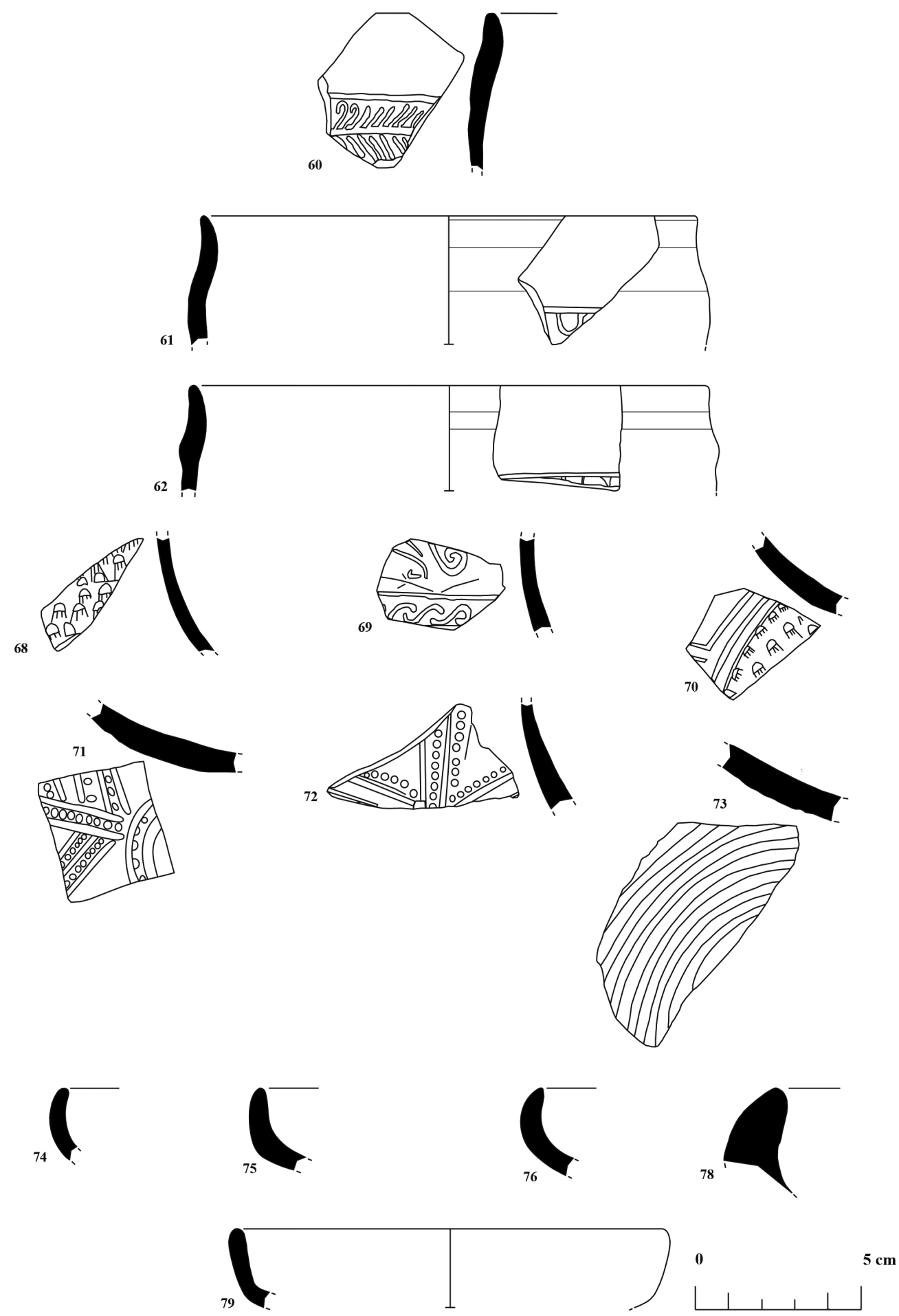

Pl. 3 : Nos 60-73: Hellenistic relief ware; $n^{\text {os }}$ 60-62: Rim fragments of a bowl form; and $n^{\text {os }}$ 68-73: Body fragments of open forms; $n^{\text {os }}$ 74-79: Hellenistic burnished ware, rim fragments of a bowl form. 
70. ( No 1231): Body fragment; Kepez, found in 2005. pl. 3/70 and pl. 25/70.

Max. h $2.4 \mathrm{~cm}$., max. w $3.5 \mathrm{~cm}$., max. th $0.7 \mathrm{~cm}$.

Reddish brown (5YR 5/4) slip on exterior and interior. Small leaf ornamentation on exterior surface. Average hardness; thin paste; sparsely porous, fine, yellowish red (5YR 5/6) fabric with rare sand, frequent tiny lime inclusions.

71. (No 1001): Body fragment; Kepez, found in 2005. pl. 3/71 and pl. 25/71.

Max. h $2.1 \mathrm{~cm}$., max. w $4.9 \mathrm{~cm}$., max. th $0.8 \mathrm{~cm}$.

Red (2.5YR 5/6) slip on exterior and interior. Hard, thin paste; very sparsely porous, fine, light brown (7.5YR $6 / 4$ ) fabric with rare quartz and a little micaceous inclusions.

Raised pattern of rays spreading vertically from bottom of bowl. Each ray consists of one lines. In the space between the rays, series of raised dots are set in vertical rows.

72. ( $\left.\mathrm{N}^{\circ} 1003\right)$ : Body fragment; Kepez, found in 2005. pl. 3/72 and pl. 25/72.

Max. h $3.2 \mathrm{~cm}$., max. w $5.8 \mathrm{~cm}$., max. th $0.7 \mathrm{~cm}$.

Red (2.5YR 5/6) tiny slip on exterior and interior. Hard, thin paste; non-porous, fine, reddish yellow (7.5YR 6/6) fabric with infrequent tiny lime inclusions.

73. (No 1006): Body fragment; Kepez, found in 2005. pl. 3/73 and pl. 25/73.

Max. h $2.4 \mathrm{~cm}$., max. w $6.6 \mathrm{~cm}$., max. th $0.8 \mathrm{~cm}$.

Reddish yellow (5YR 6/6) slip on exterior; its upper part is very pale brown (10YR $8 / 3)$ slip; red (2.5YR 5/6) slip on interior. Average hardness; porous, thin paste; fine, light brown (7.5YR 6/4) fabric with occasional tiny lime inclusions.

\section{Hellenistic Burnished Ware (pls. 3-6, $\mathrm{n}^{\text {os }} 74-128$ )}

Major forms of this ware are incurved rim bowls and fish plates. These are the imitations of some major Hellenistic forms of western Asia Minor. The incurving rim bowl is the most common shape in the Middle Hellenistic period in whole region. At the field surveys at Devrek similar incurved rim bowls dated to Late Hellenistic period were collected. ${ }^{36}$

Paste is reddish yellow (7.5YR 7/6-6/6, 5YR 6/8-6/6-7/6), light brown (7.5YR 6/4), pale brown (10YR 6/3), yellowish red (5YR 5/6), brown (7.5YR
5/4, 10YR 5/3), very pale brown (10YR 7/3-7/4), pink (7.5YR 7/4), light red (2.5YR 6/8), red (2.5YR $5 / 8)$, reddish brown (5YR 5/4) and light yellowish brown (10YR 6/4).

Hard, non-porous and well-fired paste. Bad paste became mottled in gray (7.5YR 6/1), dark gray (7.5YR 4/1) and black (2.5Y 2.5/1). Inclusions are sand, micaceous, small grit, grog, and tiny lime in medium dimensions; some of the fragments are without any inclusions. Their thickness differ between $0.5-1.0 \mathrm{~cm}$. Thin slip mostly in the same colour of paste, ranging from very pale brown (10YR 8/2-8/3-8/4-7/3-7/4) to reddish yellow (5YR 6/6, 7.5YR 6/6-7/6), pink (7.5YR 7/4-7/3-8/4, 5YR $7 / 4$ ), light yellowish brown (10YR 6/4), pale brown (10YR 6/3), light gray (10YR 7/2), reddish brown (5YR 5/4), yellowish red (5YR 5/6), pinkish white (7.5YR 8/2) and red (2.5YR 5/6). Slip was applied on light coloured-paste and polished slightly. Most of them have no decoration, except on $\mathrm{n}^{\mathrm{O}} 122$ whose exterior has engraved linear decoration. In exterior mostly burnished surface and wheel-marks.

There are 60 fragments in total; 48 of them belong to open and 12 to closed forms. 34 fragments were found at Kepez, and 11 on the southern slope of Acropolis at Kimistene.

$2^{\text {nd }}-1^{\text {st }}$ centuries B.C.

$$
\begin{gathered}
\text { Open Forms (pls. 3-6, } \mathrm{n}^{\text {os }} 74-114 \text { ) } \\
\text { Rim Fragments of a Bowl Form } \\
\text { (pls. 3-5, } \mathrm{n}^{\text {os }} 74-92 \text { ) }
\end{gathered}
$$

Incurved and rounded rim bowls are significant surface finds in Hellenistic southwestern Paphlagonia, as at all the major published Hellenistic sites in the Mediterranean. They are the most common and most widely distributed shape at Gordion ${ }^{37}$ and elsewhere ${ }^{38}$. Their size differs between medium (12.8$14 \mathrm{~cm})$ and large $(14.2-30.8 \mathrm{~cm})$ dimensions. Typologically two subgroups of these bowls have been identified: closed rim bowls and simple rim bowls. These bowls would have functioned as accommodating a variety of foods including soups, stews, and mashes, as well as side dishes of fruits and nuts ${ }^{39}$; they could basically be grave goods, too. They have a thin slip; in their interior and exterior faces wheel-marks are very distinctive.

36) Doksanaltı and Karauğuz 2012: 61, fig. 6, n. 32. These examples have a semi-lustrous reddish brown slip which is also a part of Hellenistic tradition.

37) Stewart 2010: 195-196, figs. 218-222, $\mathrm{n}^{\text {os }} 226-281$

38) Meriç 2002: pl. 1, K 1-12; and Abadie-Reynal 2003: 102-103, pl. LXXI, 3.

39) Stewart 2010: 196. 
74. (No 1094): Rim fragment; Kepez, found in 2005. pl. 3/74 and pl. 25/74.

Max. h $2.2 \mathrm{~cm}$., max. w $2.5 \mathrm{~cm}$., max. th $0.5 \mathrm{~cm}$.

Very pale brown (10YR 7/4) unslipped surface on exterior and interior. Hard, thin paste; very sparsely porous, fine, reddish yellow (7.5YR 6/6) fabric with frequent tiny lime inclusions.

75. (No 1079): Rim fragment; Kepez, found in 2005. pl. 3/75 and pl. 25/75.

Max. h $2.5 \mathrm{~cm}$., max. w $3.8 \mathrm{~cm}$., max. th $0.5 \mathrm{~cm}$.

Very pale brown (10YR 8/3) slip on exterior; very pale brown (10YR 7/4) slip on interior. All of surface is burnished. Average hardness; thin paste; very sparsely porous, fine, reddish yellow (5YR 6/6) fabric with frequent tiny lime and some sand inclusions.

76. ( $\mathrm{N}^{\circ} 1085$ ): Rim fragment; Kepez, found in 2005. pl. $3 / 76$ and $\mathrm{pl} .25 / 76$.

Max. h $2.6 \mathrm{~cm}$., max. w $2.5 \mathrm{~cm}$., $\max$. th $0.6 \mathrm{~cm}$.

Light gray (10YR 7/2) slip on exterior; pale brown (10YR 6/3) slip on interior rim. Exterior surface and interior rim are burnished. Hard, thin paste; non-porous, yellowish red (5YR 5/6) and dark grayish brown (10YR 4/2) fabric with some micaceous inclusions.

77. ( $\left.\mathrm{N}^{\circ} 1218\right)$ : Rim fragment; Kimistene, summit of the Acropolis, southern slope, found in 2005.

pl. 25/77.

Max. h $3.2 \mathrm{~cm}$., max. w $5.0 \mathrm{~cm}$., $\max$. th $0.7 \mathrm{~cm}$.

Very pale brown (10YR 7/3) slip on exterior; very pale brown (10YR 7/4) slip on interior. All of surface is burnished. Average hardness; thin paste; very sparsely porous, fine, pale brown (10YR 6/3) fabric with infrequent sand inclusions.

78. ( No 991): Rim fragment; Kepez, found in 2005. pl. 3/78 and pl. 25/78.

Max. h $3.2 \mathrm{~cm}$. , max. w $5.0 \mathrm{~cm}$., max. th $1.6 \mathrm{~cm}$.

Pink (7.5YR 7/4) slip on exterior and interior; light red (2.5YR 6/6) on the rim. Interior surface is burnished. Hard, very sparsely porous, fine, reddish yellow (7.5YR $7 / 6$ ) fabric with frequent tiny lime and large grit inclusions.

79. (No 1180): Rim fragment; Kepez, surface find in the Cistern, found in 2005.

pl. 3/79 and pl. 25/79.

Max. h $2.4 \mathrm{~cm}$., d of rim $12.8 \mathrm{~cm}$., max. w $3.0 \mathrm{~cm}$., $\max$. th $0.5 \mathrm{~cm}$.

Very pale brown (10YR 7/3) slip on exterior; very pale brown (10YR 7/4) slip on interior. Average hardness; thin paste; non-porous, fine, very pale brown (10YR 7/3) fabric with some tiny lime inclusions.

80. (No 1224): Rim fragment; Kimistene, summit of the Acropolis, southern slope, found in 2005. pl. 4/80 and pl. $25 / 80$.

Max. h $2.8 \mathrm{~cm}$., d of rim $13.6 \mathrm{~cm}$., max. w $7.2 \mathrm{~cm}$., max. th $0.5 \mathrm{~cm}$.

Reddish yellow (7.5YR 7/6) slip on exterior and interior. Exterior surface is burnished. Hard, thin paste; very sparsely porous, fine, pink (7.5YR 7/4) fabric with no visible inclusions.

81. (No 1220): Rim fragment; Kimistene, summit of the Acropolis, southern slope, found in 2005.

pl. 4/81 and pl. 25/81.

Max. h $2.7 \mathrm{~cm}$., d of rim $14.0 \mathrm{~cm}$., max. w $6.6 \mathrm{~cm}$., max. th $0.6 \mathrm{~cm}$.

Very pale brown (10YR 7/3) slip on exterior and on interior. As inclusion medium calsite on exterior. Hard, thin paste; non-porous, fine, pink (7.5YR 7/4) fabric with occasio nal tiny lime inclusions.

82. (No 692): Rim fragment; Kimistene, Acropolis, southern slope, just below of the summit of Deresemail creek, found in 2005.

pl. 4/82 and pl. 25/82.

Max. h $3.0 \mathrm{~cm}$., d of rim $14.2 \mathrm{~cm}$., max. w $4.4 \mathrm{~cm}$., max. th $0.6 \mathrm{~cm}$.

Reddish yellow (7.5YR 6/6) slip on exterior, reddish yellow (7.5YR 7/6) slip on interior. All of surface is burnished. Hard, thin paste; non-porous, fine, yellowish red (5YR 5/6) fabric with rare sand and lime inclusions.

83. (No 1078): Rim fragment; Kepez, found in 2005. pl. 4/83 and pl. 25/83.

Max. h $2.4 \mathrm{~cm}$., d of rim $15.0 \mathrm{~cm}$., max. w $5.8 \mathrm{~cm}$., max. th $0.5 \mathrm{~cm}$.

Very pale brown (10YR 7/4) unslipped surface on exterior; pink (5YR 7/4) unslipped surface on interior. Hard, thin paste; very sparsely porous, fine, reddish yellow (7.5YR 6/6) fabric with frequent lime and rare sand inclusions.

84. (No 1077): Rim fragment; Kepez, found in 2005. pl. 4/84 and pl. 25/84.

Max. h $3.4 \mathrm{~cm}$., d of rim $30.8 \mathrm{~cm}$., max. w $6.6 \mathrm{~cm}$., $\max$. th $1.2 \mathrm{~cm}$.

Very pale brown (10YR 7/3) slip on exterior; light yellowish brown (10YR 6/4) unslipped surface on interior. Average hardness; non-porous, fine, light brown (7.5YR 6/4) fabric with some medium grit and lime inclusions.

85. (No 1068): Rim fragment; Kepez, found in 2005. pl. 4/85 and pl. 25/85.

Max. h $3.8 \mathrm{~cm}$., d of rim $16.2 \mathrm{~cm}$., max. w $9.3 \mathrm{~cm}$., $\max$. th $0.7 \mathrm{~cm}$.

Very pale brown (10YR 8/2) slip on exterior and interior of the rim. Very pale brown (10YR 7/4) unslipped surface on lower interior. Exterior surface is burnished. Average hardness; thin paste; sparsely porous, fine, reddish yellow (7.5YR 6/6) fabric with frequent lime and rare small grit inclusion. 

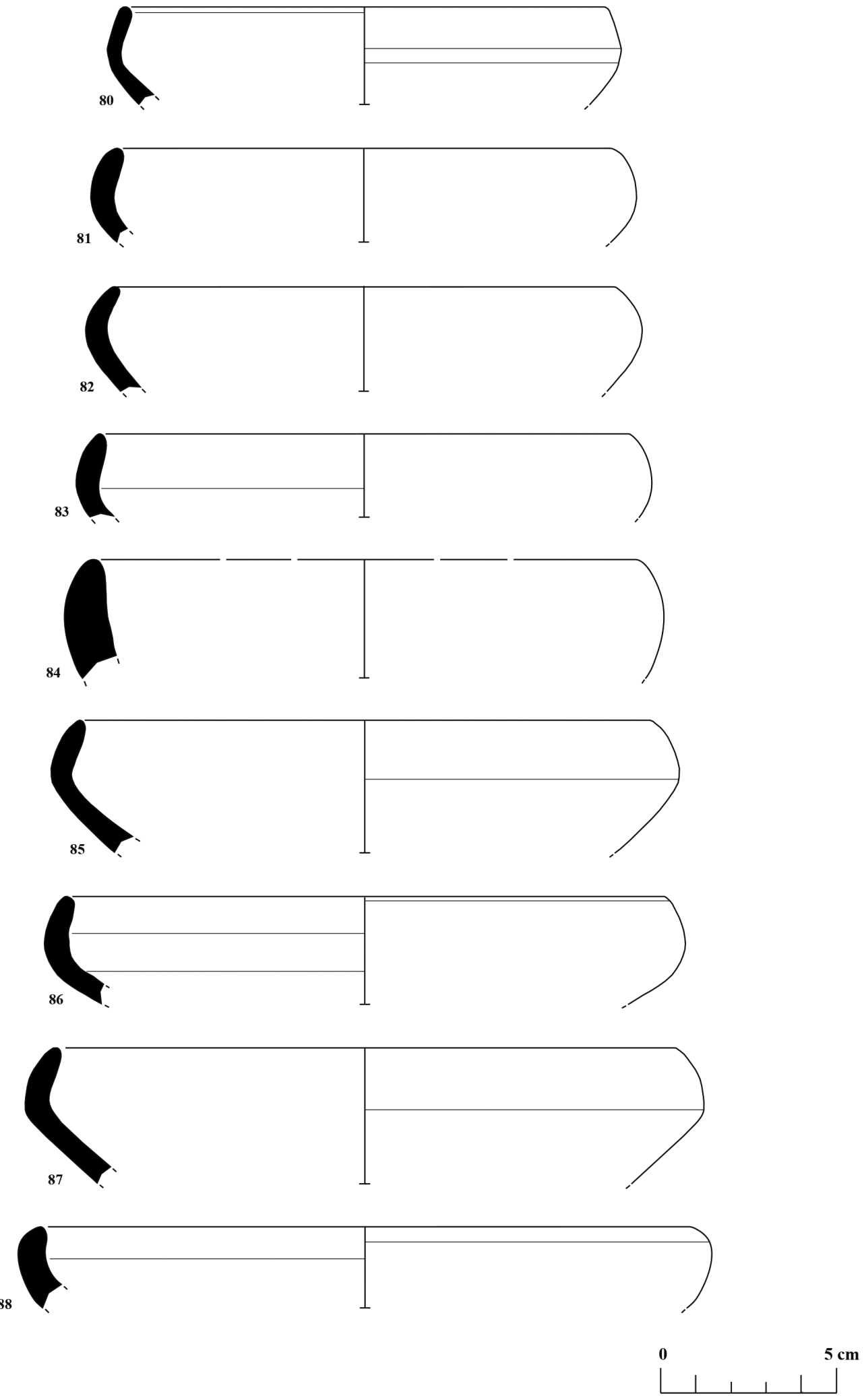

Pl. 4 : Nos 80-88: Hellenistic burnished ware, rim fragments of a bowl form. 
86. ( $\mathrm{N}^{\mathrm{o}} 1070$ ): Rim fragment; Kepez, found in 2005 . pl. $4 / 86$ and pl. $25 / 86$.

Max. h $3.1 \mathrm{~cm}$., d of rim $17.0 \mathrm{~cm}$., max. w $3.8 \mathrm{~cm}$., $\max$. th $0.7 \mathrm{~cm}$.

Thick wheel-marks. Exterior surface is burnished. Pinkish white (7.5YR 8/2) slip on exterior. Reddish yellow (7.5YR 7/6) unslipped surface on interior. Hard, thin paste; non-porous, fine, reddish yellow (5YR 7/6) fabric with frequent micaceous and some sand inclusion.

87. ( $\mathrm{N}^{\circ}$ 1221): Rim fragment; Kimistene, summit of the Acropolis, southern slope, found in 2005.

pl. $4 / 87$ and pl. $26 / 87$.

Max. h $3.9 \mathrm{~cm}$., d of rim $17.6 \mathrm{~cm}$., max. w $5.8 \mathrm{~cm}$., max. th $0.6 \mathrm{~cm}$.

Reddish yellow (7.5YR 7/6) slip on exterior rim and interior. Reddish yellow (7.5YR 7/6) unslipped surface on lower exterior. Exterior rim and interior surface are burnished. Hard, thin paste; very sparsely porous, fine, reddish yellow (7.5YR 6/6) fabric with some sand inclusions.

88. (No 399): Rim fragment; Kimistene, Acropolis, below the Temple's terrace, eastern slope, found in 2005 .

pl. 4/88 and pl. 26/88.

Max. h $2.4 \mathrm{~cm}$., d of rim $18.4 \mathrm{~cm}$., max. w $3.6 \mathrm{~cm}$., max. th $0.9 \mathrm{~cm}$.

Very pale brown (10YR 7/4) slip on exterior; reddish yellow (7.5YR 6/6) slip on interior. Interior surface is burnished. Hard, thin paste; non-porous, fine, reddish yellow (5YR 6/6) fabric with frequent lime and sand, rare micaceous inclusions.

89. ( $\mathrm{N}^{\circ} 1082$ ): Rim fragment; Kepez, found in 2005. pl. 5/89 and pl. 26/89.

Max. h $2.5 \mathrm{~cm}$., d of rim $19.0 \mathrm{~cm}$., max. w $4.1 \mathrm{~cm}$., $\max$. th $0.7 \mathrm{~cm}$.

Very pale brown (10YR 8/2) on exterior and interior rim. Very pale brown (10YR 7/4) unslipped surface on lower interior. Hard, thin paste; non-porous, fine, reddish yellow (7.5YR 7/6) fabric with some tiny lime inclusions.

90. ( $\left.\mathrm{N}^{\circ} 1277\right)$ : Rim fragment; Kimistene, Necropolis, found in 2005 .

pl. 5/90 and pl. 26/90.

Max. h $2.6 \mathrm{~cm}$., d of rim $21.0 \mathrm{~cm}$., max. w $5.2 \mathrm{~cm}$., max. th $0.6 \mathrm{~cm}$.

Reddish yellow (7.5YR 6/6) slip on exterior; pink (7.5YR 7/4) unslipped surface on interior. Exterior surface is burnished. Hard, thin paste; non-porous, reddish yellow (7.5YR 6/6-5YR 6/8) fabric with rare grog, sand and tiny lime inclusions.
91. ( $\mathrm{N}^{\mathrm{o}}$ 1394): Rim fragment; Kimistene, summit of the Acropolis, surface find, found in 2005.

pl. 5/91 and pl. 26/91.

Max. h $5.2 \mathrm{~cm}$., d of rim $25.0 \mathrm{~cm}$., max. w $7.6 \mathrm{~cm}$., $\max$. th $0.8 \mathrm{~cm}$.

Reddish yellow (7.5YR 6/6) slip on exterior; light brown (7.5YR 6/3) unslipped surface on interior. Exterior surface is burnished. Hard, non-porous, light brown (7.5YR 6/4) fabric with frequent tiny lime inclusions.

92. ( $\mathrm{N}^{\mathrm{0}}$ 1214): Rim fragment; Kimistene, summit of the Acropolis, southern slope, found in 2005.

pl. $5 / 92$ and pl. $26 / 92$.

Max. h $6.8 \mathrm{~cm}$., d of rim $25.2 \mathrm{~cm}$., $\max$. w $4.6 \mathrm{~cm}$., $\max$. th $1.1 \mathrm{~cm}$.

Light yellowish brown (10YR 6/4) slip on exterior and interior. Exterior surface is burnished. Hard, nonporous, fine, reddish brown (5YR 5/4) fabric with infrequent lime and small grit inclusions.

\section{Other Rim Fragments (pl. 5, nos $94-100)$}

Some metal imitated shapes, such as carinated and ledge rim bowls are popular. Most of them are polished. In some other excavated sites, such as at Oluz Höyük and Kaman these carinated bowl forms were classified as 'Achaemenid' 40 . However, in southwestern Paphlagonia these vessel forms cannot be assigned to any known group.

93. ( $\mathrm{N}^{\circ}$ 801): Rim fragment; Kimistene, summit of the Acropolis, western slope, found in 2005.

Max. h $2.8 \mathrm{~cm}$., max. w $2.2 \mathrm{~cm}$., max. th $0.7 \mathrm{~cm}$. pl. 26/93.

Light yellowish brown (10YR 6/4) slip on exterior; pale brown (10YR 6/3) slip on interior. All of surface is burnished. Hard, non-porous, fine, pale brown (10YR 6/3) fabric with frequent sand and some small grit inclusions.

94. (No 500): Rim fragment; Kimistene, Acropolis, southern slope, just below of the summit of Deresemail creek, found in 2005 .

pl. 5/94 and pl. $26 / 94$.

Max. h $1.8 \mathrm{~cm}$., max. w $3.1 \mathrm{~cm}$., max. th $0.7 \mathrm{~cm}$.

Light brown (7.5YR 6/4) slip on exterior and interior. All of surface is burnished. Hard, non-porous, fine, brown (7.5YR 5/4) fabric with some sand inclusions.

95. (No 862): Rim fragment; Kimistene, Acropolis, temple slope, illegally excavated pit with boukranion altar, found in 2005 .

40) A similar bowl sherd with the same slip was found in the second Building Layer of Oluz Höyük, dated into $4^{\text {th }}-3^{\text {rd }}$ cent. B.C. Dönmez 2012: 71, fig. 8 (=Dönmez 2014, in print: figs. 15-16). These sherds with dark red slip attract attention with their 's'-shaped profiles, resembling Achaemenid bowls. Close parallels of these bowls are seen at Maşat Höyük and Kuşaklı. 

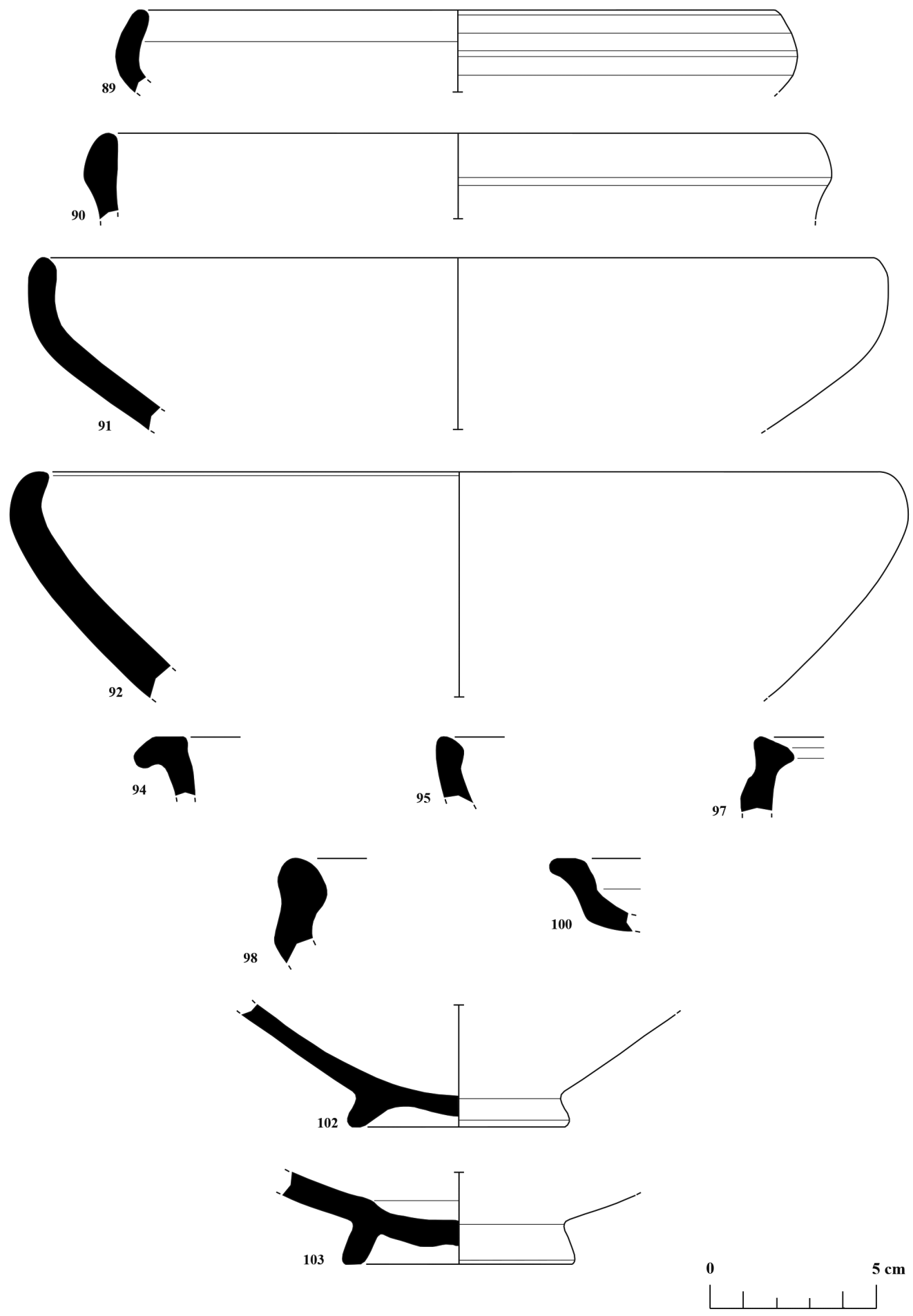

Pl. 5 : $\mathbf{N}^{\text {os }}$ 89-103: Hellenistic burnished ware; $n^{\text {os }}$ 89-92: Rim fragments of a bowl form; $n^{\text {os } 94-100:}$ Other rim fragments; and $n^{\text {os }}$ 102-103: Base fragments of open forms. 
pl. 5/95 and pl. 26/95.

Max. h $2.0 \mathrm{~cm}$., max. w $2.5 \mathrm{~cm}$., max. th $0.7 \mathrm{~cm}$.

Everted rim. Pink (5YR 7/4) slip on exterior and interior. All of surface is burnished. Soft, non-porous, fine, reddish yellow (5YR 6/6) fabric with frequent sand inclusions.

96. ( $\mathrm{N}^{\circ}$ 1299): Rim fragment; Kimistene, Acropolis, temple's terrace, illegally excavated area under the temple's podium, found in 2005.

pl. 26/96.

Max. h $2.1 \mathrm{~cm}$., max. w $2.7 \mathrm{~cm}$., max. th $0.9 \mathrm{~cm}$.

Light yellowish brown (10YR 6/4) slip on exterior and interior. All of surface is burnished. Hard, non-porous, pale brown (10YR 6/3) and black (2.5Y 2.5/1) fabric with frequent tiny lime inclusions.

97. ( $\mathrm{N}^{\circ}$ 955): Rim fragment; Kimistene, Acropolis, found in 2005 .

pl. 5/97 and pl. 26/97.

Max. h $2.3 \mathrm{~cm}$., max. w $4.0 \mathrm{~cm}$., $\max$. th $1.0 \mathrm{~cm}$.

Everted rim. Light brown (7.5YR 6/4) slip on exterior; pink (7.5YR 7/4) slip on interior. Exterior surface is burnished. Hard, non-porous, light brown (7.5YR 6/4) and gray (7.5YR 6/1) fabric with frequent tiny lime and some sand inclusions.

98. ( $\mathrm{N}^{\circ}$ 517): Rim fragment; Kimistene, Acropolis, southern slope, just below of the summit of Deresemail creek, found in 2005 .

pl. 5/98 and pl. 26/98.

Max. h $3.2 \mathrm{~cm}$., max. w $2.3 \mathrm{~cm}$., max. th $1.2 \mathrm{~cm}$.

Knobbed rim. Light brown (7.5YR 6/4) slip on exterior and interior. All of surface is burnished. Hard, nonporous, fine, brown (7.5YR 5/4) fabric with some sand inclusions.

99. ( $\mathrm{N}^{\circ}$ 1075): Rim fragment; Kepez, found in 2005. pl. 26/99.

Max. h $1.8 \mathrm{~cm}$., max. w $3.8 \mathrm{~cm}$., $\max$. th $1.1 \mathrm{~cm}$.

Light brown (7.5YR 6/4) slip on exterior; pink (7.5YR 7/4) unslipped surface on interior. Exterior surface is burnished. Soft, very sparsely porous, fine, yellowish red (5YR 5/6) fabric with frequent tiny lime inclusions.

100. ( $\mathrm{N}^{\circ}$ 1457): Rim fragment; uncertain. pl. 5/100 and pl. 26/100.

Max. h $2.2 \mathrm{~cm}$., max. w $4.4 \mathrm{~cm}$., max. th $0.7 \mathrm{~cm}$.

Rim with carination. Reddish brown (5YR 5/4) slip on exterior and interior. All of surface is burnished. Hard, non-porous, fine, brown (10YR 5/3) fabric with occasional sand and grog inclusions.

\section{Base Fragments of Open Forms \\ (pls. 5-6, $\mathrm{n}^{\text {os } 102-105)}$}

Foots with high-ring profiles.

101. ( No 1165): Base fragment; Kepez, Cistern, found in 2005.

pl. 26/101.

Max. h $2.8 \mathrm{~cm}$., max. w $7.5 \mathrm{~cm}$., $\max$. th $0.8 \mathrm{~cm}$.

Very pale brown (10YR 7/4) slip on exterior and interior. Average hardness; thin paste; very sparsely porous, fine, light brown (7.5YR 6/4) fabric with frequent tiny lime and rare small grit inclusions.

102. ( $\left.\mathrm{N}^{\circ} 1158\right)$ : Base fragment; Kepez, Cistern, found in 2005 .

pl. 5/102 and pl. 26/102.

Max. h $3.7 \mathrm{~cm}$., d of base $6.4 \mathrm{~cm}$., $\max$. w $11.5 \mathrm{~cm}$., max. th $0.7 \mathrm{~cm}$.

Surface is smoothed on the exterior. A red $(2.5 \mathrm{YR}$ 5/6) tiny slip on the exterior. Reddish yellow (5YR 6/67.5YR 7/6) unslipped surface on interior. Average hardness; sparsely porous, thin paste; fine, light red (2.5YR $6 / 8$ ) fabric with frequent lime and some small grit inclusion.

103. ( $\mathrm{N}^{\circ} 988$ ): Base fragment; Kepez, found in 2005. pl. 5/103 and pl. 26/103.

Max. h $2.8 \mathrm{~cm}$., d of base $6.8 \mathrm{~cm}$., max. w $6.9 \mathrm{~cm}$., $\max$. th $0.7 \mathrm{~cm}$.

Pink (7.5YR 7/4) slip on exterior; exterior surface thinly slipped. Reddish yellow (5YR 6/6) slip on interior. It is burnished on the middle of interior. Hard, non-porous, thin paste; reddish yellow (5YR 6/6) fabric with no visible inclusions.

104. ( $\mathrm{N}^{\circ}$ 1322): Base fragment; Kimistene, summit of the Acropolis, southern slope, found in 2005.

pl. 6/104 and pl. 26/104.

Max. h $2.8 \mathrm{~cm}$., d of base $7.4 \mathrm{~cm}$., max. w $4.9 \mathrm{~cm}$., $\max$. th $0.7 \mathrm{~cm}$.

Very pale brown (10YR 8/2) slip on exterior and interior. Interior surface is burnished. Hard, thin paste; nonporous, reddish yellow (5YR 6/8) and pale brown (10YR $6 / 3$ ) fabric with no visible inclusions.

105. ( $\mathrm{N}^{\circ} 466$ ): Base fragment; Kimistene, Acropolis, southern slope, just below of the summit of Deresemail creek, found in 2005.

pl. 6/105 and pl. 26/105.

Max. h $2.4 \mathrm{~cm}$., d of base $7.6 \mathrm{~cm}$., max. w $5.7 \mathrm{~cm}$., max. th $0.8 \mathrm{~cm}$.

Very pale brown (10YR 8/2) slip on exterior; pink (7.5YR 7/4) slip on interior. Interior surface is burnished. Hard, thin paste; non-porous, fine, reddish yellow (5YR 6/6) fabric with infrequent tiny lime inclusions. 

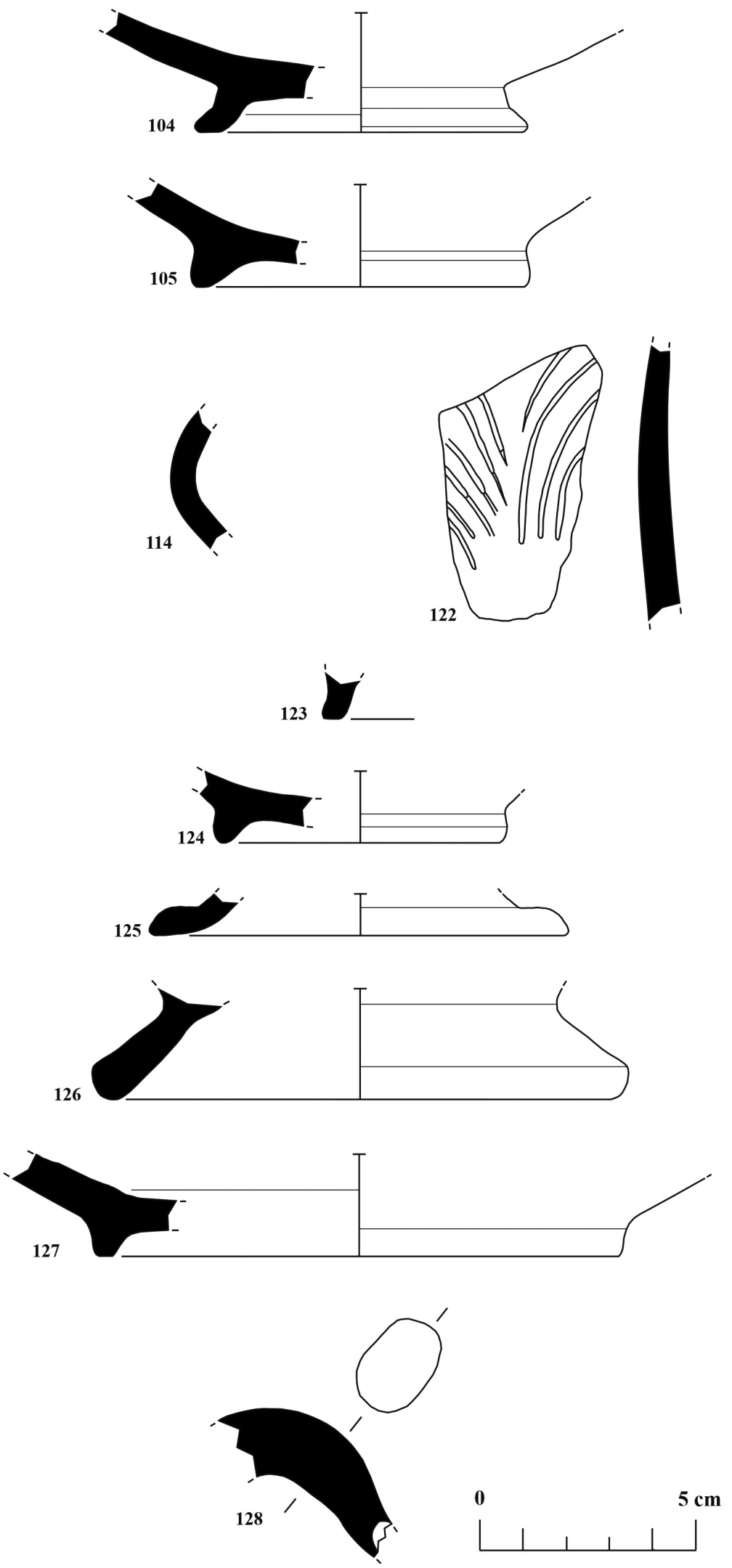

Pl. 6 : Nos 104-128: Hellenistic burnished ware; $n^{\text {os }}$ 104-105: Base fragments of open forms; no. 114: A body fragment of an open form; $n^{0}$ 122: A body fragment of a rhyton; $n^{\text {os }}$ 123-127: Base fragments of closed forms; and $n^{0} 128$ : A handle fragment of a closed form. 


\section{Body Fragments of Open Forms}

(pl. 6, $n^{\circ} 114$ )

Mostly with no decoration, whereas some examples are burnished in their interior surface.

106. ( $\mathrm{N}^{\circ} 1193$ ): Body fragment; Kepez, Cistern, found in 2005 .

pl. 26/106.

Max. h $1.5 \mathrm{~cm}$., max. w $1.6 \mathrm{~cm}$., max. th $0.5 \mathrm{~cm}$.

Reddish yellow (5YR 6/6) slip on exterior; reddish yellow (7.5YR 7/6) slip on interior. Hard, thin paste; nonporous, fine, reddish yellow (5YR 6/8) fabric with frequent micaceous, rare sand inclusions. 2005.

107. ( $\mathrm{N}^{\circ}$ 1057): Body fragment; Kepez, found in

pl. 26/107.

Max. h $2.3 \mathrm{~cm}$., max. w $2.6 \mathrm{~cm}$., max. th $0.5 \mathrm{~cm}$.

Pink (7.5YR 8/4) slip on exterior; reddish yellow (5YR 6/6) unslipped surface on interior. Hard, thin paste; non-porous, fine, reddish yellow (5YR 6/6) fabric with no visible inclusions. 2005.

108. $\left(\mathrm{N}^{\circ} 1058\right)$ : Body fragment; Kepez, found in

pl. 26/108.

Max. h $2.5 \mathrm{~cm}$., $\max$. w $2.5 \mathrm{~cm}$., max. th $0.5 \mathrm{~cm}$.

Yellowish red (5YR 5/6) slip on upper exterior. Upper exterior is burnished. Its below part has a pink (7.5YR 7/4) unslipped surface. Reddish yellow (5YR 6/6) slip on interior; Hard, thin paste; non-porous, fine, light red (2.5YR 6/8) fabric with some tiny lime and rare sand inclusions. 2005.

109. ( $\mathrm{N}^{\circ}$ 1024): Body fragment; Kepez, found in

pl. 27/109.

Max. h $2.6 \mathrm{~cm}$., max. w $2.6 \mathrm{~cm}$., max. th $0.6 \mathrm{~cm}$.

Very pale brown (10YR 7/3) slip on exterior; very pale brown (10YR 7/4) thin slip on interior. All of surface is burnished. Hard, thin paste; non-porous, fine, yellowish red (5YR 5/6) fabric with rare sand inclusions.

110. ( $\left.\mathrm{N}^{\circ} 841\right)$ : Body fragment; Kimistene, Cistern, eastern slope, found in 2005 .

pl. 27/110.

Max. h $2.3 \mathrm{~cm}$., max. w $2.9 \mathrm{~cm}$., $\max$. th $0.6 \mathrm{~cm}$.

Pink (7.5YR 7/3) slip on exterior; pink (7.5YR 7/4) slip on interior. Hard, thin paste; non-porous, reddish yellow (7.5YR 6/6) and brown (7.5YR 5/2) mottled fabric with no visible inclusions. 2005.

111. ( $\mathrm{N}^{\circ}$ 1036): Body fragment; Kepez, found in

pl. 27/111.

Max. h $2.7 \mathrm{~cm}$., max. w $2.3 \mathrm{~cm}$., max. th $0.7 \mathrm{~cm}$.
Very pale brown (10YR 7/4) thin slip on exterior and interior. Average hardness; thin paste; non-porous, fine, light brown (7.5YR 6/4) fabric with rare sand inclusions.

112. (№ 759): Body fragment; Kimistene, Acropolis, temple's terrace, illegally excavated area under the temple's podium, found in 2005 .

pl. 27/112.

Max. h $3.5 \mathrm{~cm}$., max. w $2.4 \mathrm{~cm}$., max. th $0.7 \mathrm{~cm}$.

Pink (7.5YR 8/4) slip on exterior; pink (7.5YR 7/4) slip on interior. Average hardness; thin paste; non-porous, fine, light brown (7.5YR 6/4) fabric with frequent tiny lime inclusions.

113. ( $\mathrm{N}^{\circ}$ 1028): Body fragment; Kepez, found in 2005.

pl. 27/113.

Max. h $2.5 \mathrm{~cm}$., max. w $3.3 \mathrm{~cm}$., max. th $0.7 \mathrm{~cm}$.

Very pale brown (10YR 8/3) slip on exterior and interior. All of surface is burnished. Hard, thin paste; nonporous, fine, light brown (7.5YR 6/4) fabric with no visible inclusions.

114. ( $\left.\mathrm{N}^{\circ} 814\right)$ : Body fragment; Kimistene, summit of the Acropolis, western slope, found in 2005.

pl. 6/114 and pl. 27/114.

Max. h $3.2 \mathrm{~cm}$., max. w $4.0 \mathrm{~cm}$., max. th $0.5 \mathrm{~cm}$

Reddish yellow (5YR 7/6) unslipped surface on exterior; very pale brown (10YR 7/4) unslipped surface on interior. Hard, thin paste; non-porous, fine, light brown (7.5YR 6/4) fabric with some sand inclusions.

115. ( $\left.N^{\circ} 1160\right)$ : Body fragment; Kepez, Cistern, found in 2005 .

pl. 27/115.

Max. h $1.9 \mathrm{~cm}$., max. w $4.3 \mathrm{~cm}$., max. th $1.0 \mathrm{~cm}$.

Reddish yellow (7.5YR 6/6) slip on exterior and interior. The connecting area of its base and belly is burnished and slipped on the exterior. Average hardness; thin paste; very sparsely porous, fine, yellowish red (5YR 5/6) fabric with frequent tiny lime inclusions.

116. ( $\mathrm{N}^{\circ} 436$ ): Body fragment; Kimistene, Acropolis, slope, found in 2005.

pl. 27/116.

Max. h $1.3 \mathrm{~cm}$., max. w $4.6 \mathrm{~cm}$., max. th $0.7 \mathrm{~cm}$.

Pale brown (10YR 6/3) slip on exterior and interior. All of surface is burnished. Average hardness; thin paste; non-porous, brown (10YR 5/3) and grayish brown (10YR $5 / 2$ ) fabric with no visible inclusions.

117. ( $\left.\mathrm{N}^{\circ} 995\right)$ : Body fragment; Kepez, found in 2005. pl. 27/117.

Max. h $3.9 \mathrm{~cm}$., max. w $4.5 \mathrm{~cm}$., max. th $0.6 \mathrm{~cm}$.

Light gray (10YR 7/2) thin slip on exterior and interior. Hard, thin paste; non-porous, grayish brown (10YR $5 / 2$ ) fabric with no visible inclusions. 
118. ( $\left.N^{\circ} 1013\right)$ : Body fragment; Kepez, found in 2005. pl. 27/118.

Max. h $2.9 \mathrm{~cm}$., max. w $5.7 \mathrm{~cm}$., max. th $0.5 \mathrm{~cm}$.

Very pale brown (10YR 8/4) slip on exterior; reddish yellow (5YR 6/6) slip on interior. Interior surface is burnished. Hard, thin paste; non-porous, fine, reddish yellow (7.5YR 6/6) fabric with no visible inclusions.

119. ( ${ }^{\circ}$ 1173): Body fragment; Kepez, Cistern, found in 2005 .

pl. 27/119.

Max. h $3.4 \mathrm{~cm}$., max. w $4.3 \mathrm{~cm}$., max. th $0.7 \mathrm{~cm}$.

Very pale brown (10YR 7/3) slip on exterior and interior. Exterior surface is burnished. Average hardness; thin paste; very sparsely porous, fine, pale brown (10YR $6 / 3$ ) fabric with some micaceous inclusions.

120. $\left(\mathrm{N}^{\circ} 1166\right)$ : Body fragment; Kepez, Cistern, found in 2005 .

pl. 27/120.

Max. h $4.0 \mathrm{~cm}$., max. w $6.8 \mathrm{~cm}$., $\max$. th $0.7 \mathrm{~cm}$.

Very pale brown (10YR 7/4) thin slip on exterior and interior. Hard, thin paste; non-porous, fine, light brown (7.5YR 6/4) fabric with occasional tiny lime and sand inclusions.

121. ( $\mathrm{N}^{\circ}$ 1168): Body fragment; Kepez, Cistern, found in 2005 .

pl. 27/121.

Max. h $4.3 \mathrm{~cm}$., max. w $5.7 \mathrm{~cm}$., $\max$. th $0.5 \mathrm{~cm}$.

Very pale brown (10YR 7/4) slip on exterior and interior. Exterior surface is burnished. Hard, thin paste; nonporous, fine, pale brown (10YR 6/3) fabric with some sand inclusions.

Closed Forms (pl. 6, n ${ }^{\text {os }}$ 122-128)

A Body Fragment of a Rhyton (pl. 6, no 122)

122. ( $\left.N^{\circ} 1170\right)$ : Body fragment; Kepez, Cistern, found in 2005 .

pl. 6/122 and pl. 27/122.

Max. h $6.4 \mathrm{~cm}$., max. w $4.1 \mathrm{~cm}$., max. th $0.8 \mathrm{~cm}$.

Very pale brown (10YR 7/3) slip on exterior; very pale brown (10YR 7/4) unslipped surface on interior. Engraved linear decoration on the exterior. Soft, thin paste; non-porous, fine, pale brown (10YR 6/3) fabric with occasional tiny lime and frequent sand inclusions.

\section{Base Fragments of Closed Forms (pl. 6, $\mathrm{n}^{\mathrm{os}} 123-127$ )}

Foots with high-ring profiles; some of them were polished.

123. ( $\left.\mathrm{N}^{\circ} 1197\right)$ : Base fragment; Kepez, Cistern, found in 2005 . pl. 6/123 and pl. 27/123.

Max. h $1.1 \mathrm{~cm}$., max. w $2.0 \mathrm{~cm}$., max. th $0.7 \mathrm{~cm}$.

Pink (7.5YR 8/4) unslipped surface on exterior and interior. Hard, thin paste; very sparsely porous, fine, reddish yellow (5YR 6/6) fabric with some sand and rare tiny lime inclusions.

124. ( $\mathrm{N}^{\circ}$ 1396): Base fragment; Kimistene, summit of the Acropolis, found in 2005.

pl. 6/124 and pl. 27/124.

Max. h $1.7 \mathrm{~cm}$., d of rim $6.4 \mathrm{~cm}$., max. w $3.3 \mathrm{~cm}$., $\max$. th $0.7 \mathrm{~cm}$.

Reddish yellow (5YR 6/6) slip on exterior; reddish yellow (5YR 7/6) unslipped surface on interior. Exterior surface is burnished. Hard, thin paste; sparsely porous, yellowish red (5YR 5/6) and reddish yellow (7.5YR 6/6) mottled fabric with rare small grit inclusions.

125. ( $\left.N^{o} 1109\right)$ : Base fragment; Kepez, Cistern, found in 2005 .

pl. 6/125 and pl. 27/125.

Max. h $1.0 \mathrm{~cm}$., d of rim $9.4 \mathrm{~cm}$., max. w $3.3 \mathrm{~cm}$., max. th $0.6 \mathrm{~cm}$.

Very pale brown (10YR 7/3) slip on exterior; very pale brown (10YR 7/4) slip on interior. Hard, thin paste; very sparsely porous, fine, light brown (7.5YR 6/4) fabric with no visible inclusions.

126. ( $\mathrm{N}^{\circ}$ 503): Base fragment; Kimistene, Acropolis, southern slope, just below of the summit of Deresemail creek, found in 2005.

pl. 6/126 and pl. 27/126.

Max. h $2.6 \mathrm{~cm}$., d of rim $11.6 \mathrm{~cm}$., max. w $7.5 \mathrm{~cm}$., $\max$. th $1.0 \mathrm{~cm}$.

Pink (7.5YR 7/4) slip on exterior and interior. Exterior surface is burnished. Hard, thin paste; very sparsely porous, brown (7.5YR 5/4) fabric with some tiny lime and sand inclusions.

127. ( $\mathrm{N}^{\circ}$ 665): Base fragment; Kimistene, Cistern, eastern slope, found in 2005.

pl. 6/127 and pl. 27/127.

Max. h $2.4 \mathrm{~cm}$., d of rim $12.0 \mathrm{~cm}$., max. w $6.6 \mathrm{~cm}$., max. th $0.8 \mathrm{~cm}$.

Reddish yellow (7.5YR 7/6) slip on exterior. Reddish yellow (5YR 6/6) unslipped surface on the exterior of connecting area between base and belly. Reddish yellow (7.5YR 7/6) unslipped surface on interior. The area between base and belly is also burnished. Hard, thin paste; sparsely porous, fine, reddish yellow (7.5YR 6/6) fabric with rare lime, infrequent sand inclusions. 


\section{A Handle Fragment of a Closed Form}

(pl. $\left.6, \mathrm{n}^{\mathrm{os}} 128\right)$

Exterior is burnished.

128. ( $\mathrm{N}^{\circ} 709$ ): Handle fragment; Kimistene, Acropolis, temple slope, eastern slope, surface find, found in 2005.

pl. 6/128 and pl. 27/128.

Max. h $3.5 \mathrm{~cm}$., max. w $4.5 \mathrm{~cm}$., max. th $1.6 \mathrm{~cm}$.

Very pale brown (10YR 7/4) slip on exterior; very pale brown (10YR 7/3) unslipped surface on interior. Exterior surface is burnished. Hard, thin paste; non-porous, fine, very pale brown (10YR 7/4) fabric with frequent tiny lime inclusions.

\section{Body Fragments of Closed Forms (pl. 27, $\mathrm{n}^{\text {os }} 129-133$ )}

All of them have a light slip.

129. ( $\mathrm{N}^{\circ}$ 1236): Body fragment; Kepez, found in 2005.

pl. 27/129.

Max. h 2.0 cm., max. w $3.3 \mathrm{~cm}$., max. th $0.6 \mathrm{~cm}$.

Reddish yellow (5YR 6/6) slip on exterior; red (2.5YR 5/6) unslipped surface on interior. Hard, thin paste; non-porous, red $(2.5 \mathrm{YR} 5 / 8)$ and light brown (7.5YR 6/3) fabric with frequent tiny lime and occasional sand inclusions.

130. ( $\mathrm{N}^{\circ}$ 1181): Body fragment; Kepez, Cistern, found in 2005 .

pl. 27/130.

Max. h $2.2 \mathrm{~cm}$., max. w $4.5 \mathrm{~cm}$., max. th $0.6 \mathrm{~cm}$.

Very pale brown (10YR 8/3) slip on exterior; reddish yellow (5YR 7/6) unslipped surface on interior. Average hardness; thin paste; non-porous, fine, reddish yellow (7.5YR 6/6) fabric with frequent tiny lime and rare small grit inclusions. 2005

131. ( $\mathrm{N}^{\mathrm{1}}$ 1232): Body fragment; Kepez, found in

pl. 27/131.

Max. h $1.3 \mathrm{~cm}$., max. w $6.2 \mathrm{~cm}$., max. th $1.1 \mathrm{~cm}$.

Reddish yellow (7.5YR 6/6) slip on exterior. Reddish yellow (5YR 6/6) unslipped surface on interior. Exterior surface is burnished. Average hardness; thin paste; very sparsely porous, fine, reddish yellow (5YR 6/6) fabric with rare micaceous and sand inclusions.

132. ( $\mathrm{N}^{\circ}$ 1172): Body fragment; Kepez, Cistern, found in 2005 .

pl. 27/132.

Max. h $5.5 \mathrm{~cm}$., max. w $4.0 \mathrm{~cm}$., $\max$. th $0.6 \mathrm{~cm}$.

Very pale brown (10YR 7/4) slip on exterior and interior neck. The other part has a very pale brown (10YR 7/4) unslipped surface on interior. Exterior surface is bur- nished. Hard, thin paste; non-porous, fine, very pale brown (10YR 7/4) fabric with some sand inclusions.

133. ( $N^{\circ} 1161$ ): Body fragment; Kepez, surface find in the Cistern, found in 2005.

pl. 27/133.

Max. h $5.0 \mathrm{~cm}$., max. w $5.6 \mathrm{~cm}$., max. th $0.9 \mathrm{~cm}$

Very pale brown (10YR 8/3) slip on exterior; reddish yellow (5YR 6/6) unslipped surface on interior. Average hardness; thin paste; non-porous, fine, light yellowish brown (10YR 6/4) fabric with infrequent sand and some tiny lime inclusions.

\section{Red-Painted Kepez Group (pls. 7-13, nos 134-266)}

During the pre-Roman period there should had been numerous local workshops of painted pottery in northern and central Asia Minor, such as the one discovered at Oluz Höyük. We have discovered a further unique and homogenous group of such pottery in a Hellenistic cemetery site, called Kepez, $c a$. $5 \mathrm{~km}$ far from Hadrianopolis. In any case this is a local group and should be assigned to southwestern Paphlagonia. Our Kepez group consists mostly of small sherds which have frequently one or two red or brownish bands in the interior and thin bands around the rim. Especially on the shoulders and interior faces this type of decoration had been applied by means of a compass. The most common form of Kepez group is hemispherical bowls with thin walls and smoothed surface that are partially slipped. Similar examples are found at Pompeipolis and this group comprises of table vessels, mainly plates, dishes and bowls, but also of some closed shapes, most probably jugs. Also BIAA' surveys at Sallar in the Province of Çankırı provided two similar sherds (Fig. 10a-b)

Some of them are incurved rim bowls ( $c f . \mathrm{n}^{\text {os }} 151$ and 164) with a thickness of $0.4-1.0 \mathrm{~cm}$ and fish plates with downturned rims ( $\mathrm{n}^{\text {os }} 180$ and 185) are also attested. $\mathrm{N}^{\circ} 146$ is a hemispherical form with two grooves on the upper exterior of its rim. Most of the sherds are of bases and rims.

Paste is reddish yellow (5YR 6/6-6/8-7/6-7/8, 7.5YR 6/6-7/6), light red (2.5YR 6/8-6/6), light brown (7.5YR 6/3-6/4), red (10R 5/8, 2.5YR 5/65/8), pink (5 YR 7/4, 7.5YR 7/3-7/4), yellowish red (5YR 5/6), very pale brown (10YR 7/3-7/4), reddish brown (5YR 4/4-5/4), brown (7.5YR 4/4-5/3-5/4), light reddish brown (5YR 6/4) and light yellowish brown (10YR 6/4). Hard paste with lime, sand, grit, micaceous, grog and quartz inclusions in small dimensions. In some examples there is no inclusion. The slip is red (10R 4/6-5/6-5/8, 2.5 YR 4/6-4/8-5/6- 

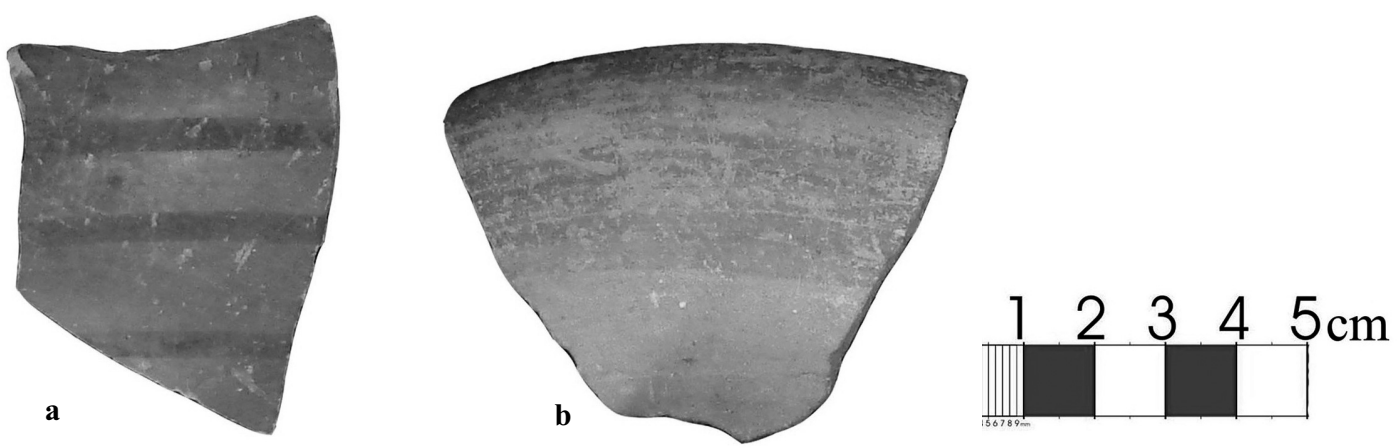

Fig. 10a-b : Two Hellenistic sherds from the BIAA'surveys at Salman, in Province Çankırı.

5/8), reddish yellow (5YR 6/6-6/8-7/6, 7.5YR 6/6$7 / 6)$, very pale brown (10YR 8/2-8.5/2-8/3-8/4- 7/37/4), pink (5YR 7/4-8/3, 7.5YR 7/4-8/3), light red (2.5YR 6/6-6/8), reddish brown (2.5YR 4/4-5/4, $5 Y R$ 4/3-5/4), weak red (10R 4/4-5/4), brown (7.5YR 4/2-4/3-5/4, 10YR 5/3), light brown (7.5YR 6/4), yellowish red (5YR 5/6), light gray (10YR 7/2) and yellow (10YR 7/6). Due to the changing fire conditions or brush use the slip colors can be changed to be mottled. It is non-porous.

The decoration was primarily slipping, applied in bands. These decorative bands with $0.7-2.0 \mathrm{~cm}$ were applied in red (10R 5/8-5/6, 2.5YR 4/6-5/6$5 / 8)$, pinkish white $(7.5 \mathrm{YR} 8 / 2,5 \mathrm{YR} 8 / 2)$, weak red (7.5R 4/4, 10R 5/4-4/2, 2.5YR 4/2), light red (2.5YR 6/6-6/8), reddish brown (2.5YR 5/4-4/3, 5YR 5/44/4-4/3), reddish yellow (5YR 6/6, 7.5YR 7/6-7/8$6 / 6)$, dusky red (2.5YR 3/2), very dark gray (7.5YR $3 / 1$ ), very pale brown (10YR 8/2), black (5YR 2.5/1, 7.5YR 2.5/1), light brown (7.5YR 6/4), yellowish red (5YR 5/6), dark grayish brown (10YR 4/2), light reddish brown (5YR 6/4), dark reddish gray (2.5YR $3 / 1$ ) and white (5YR 8/1).

134 sherds belonging to this group were collected in total. 112 fragments are open forms and 22 closed forms.

90 of them were found at Kepez and 30 of them were from the southern slope of the Acropolis at Kimistene. This ware could be associated with Hellenistic burial traditions.

$2^{\text {nd }}-1^{\text {st }}$ centuries B.C.

$$
\text { Open Forms (pls. 7-12, } \left.\mathrm{n}^{\text {os }} 134-244\right)
$$

Bowl Form 1 (pls.7-8, nos 134-156)

This bowl type is an incurved rim bowl with a deep interior and a ring or false ring foot. Most of them were decorated with red and red-brown bands. Their rim parts were painted in red with brush. These thin bands continue also in the vessels itself. Some of them do not have any slip on their bottom part.
Their surfaces are dull. Their dimensions differ between 12.0 and $27.2 \mathrm{~cm}$. In some samples there are two grooves on the upper exterior just below the rim.

134. (No 586): Rim fragment; Kimistene, Acropolis, southern slope, just below of the summit of Deresemail creek, found in 2005.

pl. $7 / 134$ and pl. $28 / 134$.

Max. h $1.2 \mathrm{~cm}$., w $1.8 \mathrm{~cm}$., $\max$. th $0.3 \mathrm{~cm}$.

Red (10R 5/8) on exterior and interior rims; their below parts have light red (2.5YR 6/6) unslipped surface. Hard, non-porous, thin paste; fine, red (2.5YR 5/6) fabric with some micaceous inclusions.

135. (No 1105): Rim fragment; Kepez, found in 2005. pl. $7 / 135$ and pl. $28 / 135$.

Max. h 1.7 cm., max. w $1.7 \mathrm{~cm}$., max. th $0.5 \mathrm{~cm}$.

Red (2.5YR 5/6) slip on exterior and interior. Average hardness; very sparsely porous, thin paste; non-porous, fine, reddish yellow (5YR 7/8) fabric with rare micaceous and lime inclusions.

136. ( $\left.\mathrm{N}^{\mathrm{o}} 1062\right)$ : Rim fragment; Kepez, found in 2005. pl. $7 / 136$ and pl. 28/136.

Max. h $1.9 \mathrm{~cm}$., max. w $1.7 \mathrm{~cm}$., max. th $0.5 \mathrm{~cm}$.

Weak red (10R 5/4) on exterior rim; its below part has pink (7.5YR 7/4) unslipped surface on exterior. Reddish yellow (7.5YR 7/6) slip on interior. Hard, thin paste; non-porous, fine, reddish yellow (7.5YR 7/6) fabric with no visible inclusions.

137. ( No $\left.^{\circ} 1086\right)$ : Rim fragment; Kepez, found in 2005. pl. $7 / 137$ and pl. 28/137.

Max. h $2.1 \mathrm{~cm}$., max. w $2.3 \mathrm{~cm}$., max. th $0.6 \mathrm{~cm}$.

Light red (2.5YR 6/6) on exterior rim; its below part has pink (7.5YR 7/4) unslipped surface. Red (2.5YR 5/6) on interior. Average hardness; non-porous, thin paste; fine, reddish yellow (5YR 6/6) fabric with some sand, lime and micaceous inclusions.

138. ( $\left.\mathrm{N}^{\circ} 885\right)$ : Rim fragment; Kimistene, Acropolis, southern slope, just below of the summit of Deresemail creek, found in 2005 . 

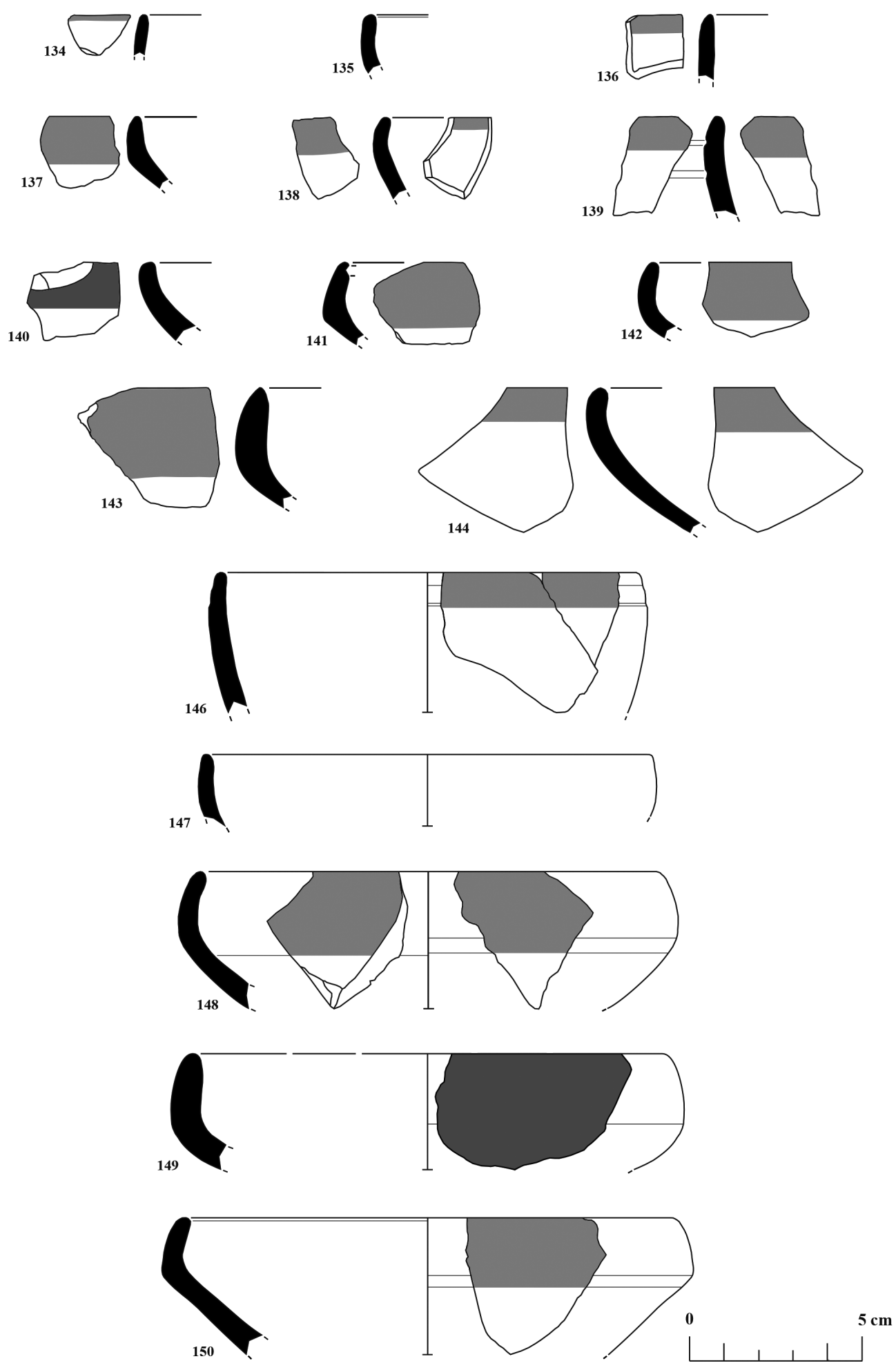

Pl. 7 : Nos 134-150: Red-painted Kepez group, bowl form 1. 
pl. $7 / 138$ and pl. $28 / 138$.

Max. h $2.4 \mathrm{~cm}$., max. w $2.0 \mathrm{~cm}$., $\max$. th $0.5 \mathrm{~cm}$.

Yellowish red (5YR 5/6) on exterior rim; its below part has very pale brown (10YR 7/4) on unslipped surface. Light red (2.5YR 6/6) on interior rim; its below part has pink (7.5YR 7/3) on unslipped surface. Hard, nonporous, thin paste; light brown (7.5YR 6/3) and gray (10YR 5/1) fabric with some tiny lime inclusions.

139. (No 953): Rim fragment; Kimistene, Acropolis, found in 2005 .

pl. 7/139 and pl. 28/139.

Max. h $2.9 \mathrm{~cm}$., max. w $2.6 \mathrm{~cm}$., max. th $0.6 \mathrm{~cm}$.

Reddish brown (2.5YR 5/4) on exterior rim and interior rim. Their below parts have pink (7.5YR 7/4) unslipped surface. Two shallow groove enclose all of exterior rim. Hard, thin paste; non-porous, fine, reddish yellow (7.5YR 6/6) fabric with rare lime inclusions.

140. (No 1190): Rim fragment; Kepez, Cistern, found in 2005 .

pl. $7 / / 140$ and pl. 28/140.

Max. h $2.3 \mathrm{~cm}$., max. w $2.7 \mathrm{~cm}$., $\max$. th $0.7 \mathrm{~cm}$.

Reddish brown (2.5YR 4/3) on exterior rim; its below part has reddish yellow (5YR 7/6) unslipped on exterior. Light brown (7.5YR 6/4) slip on interior. It is burnished on interior surface. Hard, thin paste; sparsely porous, fine, yellowish red (5YR 5/6) fabric with some lime inclusions.

141. ( $\mathrm{N}^{\circ} 802$ ): Rim fragment; Kimistene, summit of the Acropolis, western slope, found in 2005.

pl. $7 / 141$ and pl. $28 / 141$.

Max. h $2.4 \mathrm{~cm}$., max. w $3.1 \mathrm{~cm}$., max. th $0.6 \mathrm{~cm}$.

Light red (2.5YR 6/6) on exterior rim and interior. Lower exterior has a pink (7.5YR 7/4) unslipped surface. This part is burnished. Hard, non-porous, thin paste; fine, reddish brown (5YR 5/4) fabric with occasional tiny lime and sand inclusions.

142. ( $\mathrm{N}^{\circ} 1093$ ): Rim fragment; Kepez, found in 2005. pl. $7 / 142$ and pl. 28/142.

Max. h $2.2 \mathrm{~cm}$., max. w $3.1 \mathrm{~cm}$., max. th $0.5 \mathrm{~cm}$.

Reddish yellow (5YR 6/6) on exterior and interior rim. Very pale brown (10YR 7/4) slip on lower interior. Reddish brown (5YR 4/3) band on middle of the interior. Hard, thin paste; non-porous, fine, brown (7.5YR 5/4) fabric with infrequent sand inclusions.

143. ( $\mathrm{N}^{\circ}$ 645): Rim fragment; Kimistene, Acropolis, western slope, found in 2005.

pl. $7 / 143$ and pl. $28 / 143$.

Max. h $3.5 \mathrm{~cm}$., max. w $4.1 \mathrm{~cm}$., max. th $0.9 \mathrm{~cm}$.

Red $(2.5$ YR $5 / 8)$ on exterior rim and interior rim. Their below parts have reddish yellow (5YR 6/6) unslipped surface. Exterior surface is burnished. Hard, thin paste; very sparsely porous, fine, light red (2.5YR 6/8) fabric with frequent tiny lime inclusions.
144. ( $N^{\circ}$ 966): Rim fragment; Kimistene, the surface find of the Cistern, eastern slope, found in 2005.

pl. $7 / 144$ and pl. 28/144.

Max. h $4.2 \mathrm{~cm}$., max. w $4.6 \mathrm{~cm}$., max. th $0.6 \mathrm{~cm}$.

Red $(2.5$ YR $5 / 6)$ band on exterior rim and interior rim; their below parts have a reddish yellow (7.5YR 7/6) slip. Interior surface is burnished. Average hardness; sparsely porous, thin paste; fine, reddish yellow (7.5YR 7/6) fabric with no visible inclusions.

145. (No 999): Rim fragment; Kepez, found in 2005. pl. 28/145.

Max. h $4.6 \mathrm{~cm}$., max. w $4.5 \mathrm{~cm}$., max. th $1.0 \mathrm{~cm}$.

Red (2.5YR 5/6) band on exterior and interior rim. Their below parts have a reddish yellow (5YR 6/6) unslipped surface. Average hardness; very sparsely porous, fine, reddish yellow (5YR 6/6) fabric with some small lime and small grit inclusions.

146. ( $\mathrm{N}^{\circ} 1071$ ): Rim fragment; Kepez, found in 2005. pl. 7/146 and pl. 28/146.

Max. h $4.1 \mathrm{~cm}$., d of rim $12.0 \mathrm{~cm}$., max. w $5.2 \mathrm{~cm}$., max. th $0.6 \mathrm{~cm}$.

Two shallow grooves enclose all of the exterior rim; reddish brown $(2.5 \mathrm{YR} 5 / 4) \mathrm{slip}$ on exterior rim. Its lower part has a very pale brown (10YR 7/4) unslipped interior and exterior surface. Hard, non-porous, fine, reddish yellow (7.5YR 6/6) fabric with infrequent sand inclusions and with traces of mica.

147. ( $N^{\circ}$ 852): Rim fragment; Kimistene, found in 2005.

pl. $7 / 147$ and pl. $28 / 147$.

Max. h $2.1 \mathrm{~cm}$., d of rim $12.8 \mathrm{~cm}$., max. w $2.4 \mathrm{~cm}$., $\max$. th $0.5 \mathrm{~cm}$.

Red (2.5YR 5/6) slip on exterior and interior. Hard, thin paste; non-porous, fine, pink (7.5YR 7/4) fabric with no visible inclusions.

148. (No 1227): Rim fragment; Kimistene, summit of the Acropolis, southern slope, found in 2005.

pl. 7/148 and pl. 28/148.

Max. h $4.0 \mathrm{~cm}$., d of rim $13.2 \mathrm{~cm}$., max. w $4.1 \mathrm{~cm}$., max. th $0.6 \mathrm{~cm}$.

Red $(2.5 \mathrm{YR} 5 / 6)$ on exterior rim and interior rim. Their below parts have reddish yellow (7.5YR 7/6), thin slip. Hard, non-porous, thin paste; fine, reddish yellow (7.5YR 6/6) fabric with occasional sand and micaceous, some tiny lime inclusions.

149. ( $\left.\mathrm{N}^{\circ} 1204\right)$ : Rim fragment; Kimistene, summit of the Acropolis, southern slope, found in 2005.

pl. 7/149 and pl. 28/149.

Max. h $3.4 \mathrm{~cm}$., d of rim $27.2 \mathrm{~cm}$., max. w $5.7 \mathrm{~cm}$., $\max$. th $0.8 \mathrm{~cm}$.

Reddish brown (5YR 5/4) on exterior rim; its below part has a light brown (7.5YR 6/4) unslipped surface on exterior and interior rim. Light brown (7.5YR 6/4) slip on lower interior. This part is burnished. Hard, thin paste; 

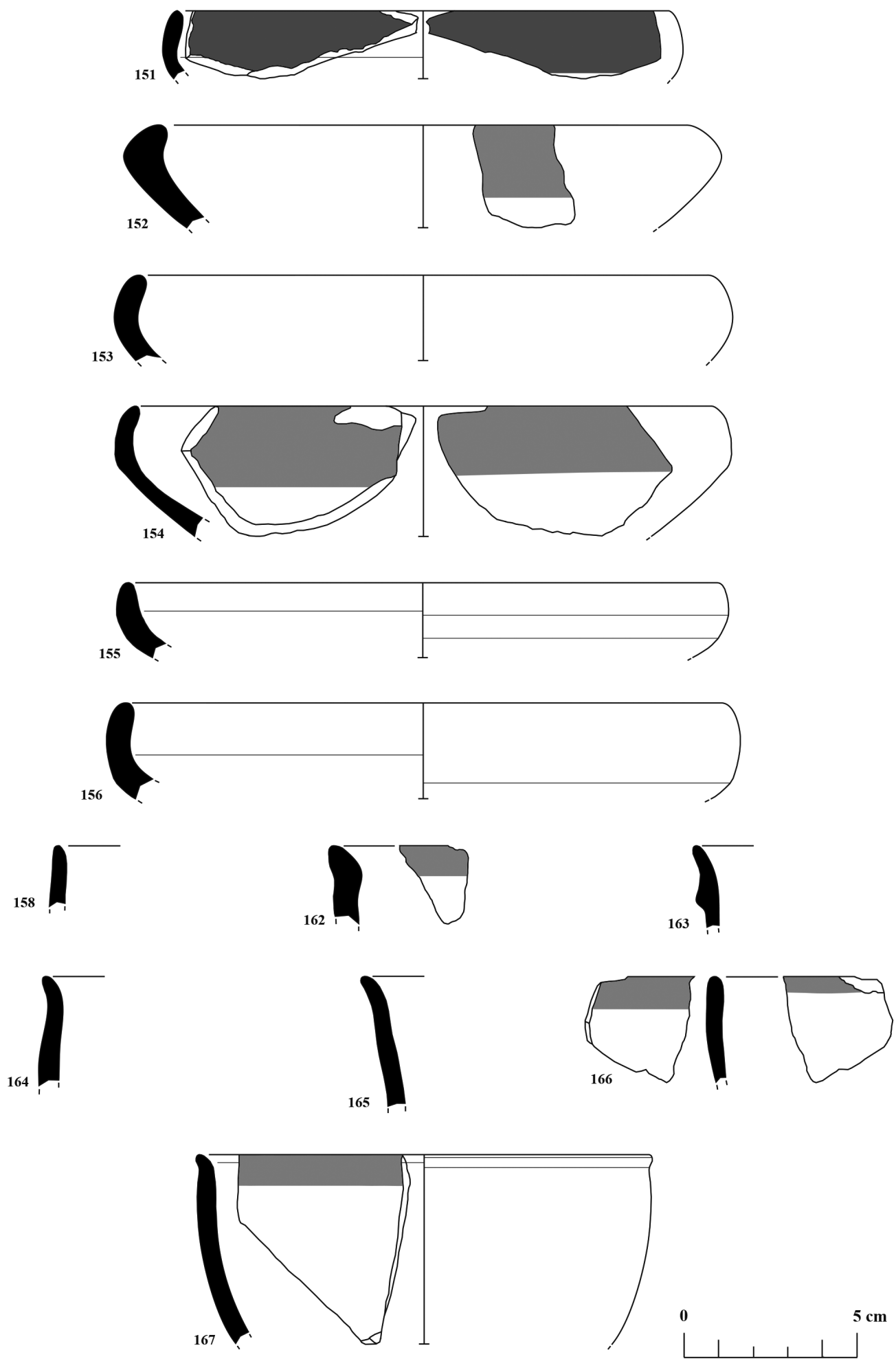

Pl. 8 : $\mathbf{N}^{\text {os }}$ 151-167: Red-painted Kepez group; ${ }^{\text {os }}$ 151-156: Bowl form 1; and $\mathbf{n}^{\text {os }}$ 158-167: Bowl form 2. 
non-porous, fine, brown (7.5YR 5/4) fabric with frequent tiny lime, infrequent medium grit inclusions.

150. ( $\left.N^{\circ} 1217\right)$ : Rim fragment; Kimistene, summit of the Acropolis, southern slope, found in 2005.

pl. $7 / 150$ and pl. $28 / 150$.

Max. h $4.0 \mathrm{~cm}$., d of rim $14.0 \mathrm{~cm}$., max. w $4.1 \mathrm{~cm}$., $\max$. th $0.7 \mathrm{~cm}$.

Red $(2.5 \mathrm{YR} 5 / 6)$ on exterior rim and interior. Its below part has a very pale brown (10YR 7/3) slip on exterior. This part is burnished. Hard, thin paste; non-porous, fine, yellowish red (5YR 5/6) fabric with some tiny lime inclusions.

151. ( $\left.\mathrm{N}^{\circ} 1095\right)$ : Rim fragment of an incurved rim bowl; Kepez, found in 2005.

pl. 8/151 and pl. 28/151.

Max. h $2.0 \mathrm{~cm}$., d of rim $14.2 \mathrm{~cm}$., max. w $6.9 \mathrm{~cm}$., $\max$. th $0.5 \mathrm{~cm}$.

Incurved rim fragment; reddish yellow (7.5YR 7/6) and brown (7.5YR 4/2) mottled slip on exterior; brown (10YR 5/3) and yellow (10YR 7/6) mottled slip on interior. Hard, thin paste; non-porous, fine, light yellowish brown (10YR 6/4) fabric with occasional sand and lime inclusions.

152. ( $\left.\mathrm{N}^{\circ} 1412\right)$ : Rim fragment; Kepez, surface find, found in 2005 .

pl. 8/152 and pl. 28/152.

Max. h $3.0 \mathrm{~cm}$., d of rim $15.2 \mathrm{~cm}$., max. w $2.8 \mathrm{~cm}$., $\max$. th $1.1 \mathrm{~cm}$.

Red (2.5YR 5/6) on exterior rim; its below part a has pink (7.5YR 7/4) unslipped surface. Same color as the interior. Hard, porous, thin paste; fine, reddish yellow (5YR 6/6) fabric with some sand, frequent lime inclusions.

153. ( $\mathrm{N}^{\circ}$ 838): Rim fragment; Kimistene, Cistern, eastern slope, found in 2005.

pl. 8/153 and pl. 28/153.

Max. h $2.5 \mathrm{~cm}$., d of rim $16.4 \mathrm{~cm}$., max. w $4.3 \mathrm{~cm}$., $\max$. th $0.7 \mathrm{~cm}$.

Light red (2.5YR 6/8) slip on exterior; red (2.5YR $5 / 8$ ) slip on interior. All of surface is burnished. Hard, thin paste; non-porous, fine, reddish yellow (5YR 6/8) fabric with some tiny lime inclusions.

154. ( $\mathrm{N}^{\circ} 1069$ ): Rim fragment; Kepez, found in 2005. pl. 8/154 and pl. 28/154.

Max. h $3.8 \mathrm{~cm}$., d of rim $16.6 \mathrm{~cm}$., $\max$. w $6.8 \mathrm{~cm}$., $\max$. th $0.5 \mathrm{~cm}$.

Red (2.5YR 5/6) slip on the exterior and interior rim. Their lower parts have a yellow (10YR 7/6) unslipped surface on exterior and interior. The exterior surface is burnished, hard, sparsely porous, thin paste; fine, reddish yellow (5YR 6/6) fabric with some tiny lime inclusions.
155. ( $\left.\mathrm{N}^{\circ} 1106\right)$ : Rim fragment; Kepez, found in 2005. pl. 8/155 and pl. 28/155.

Max. h $2.2 \mathrm{~cm}$., d of rim $17.0 \mathrm{~cm}$., max. w $3.9 \mathrm{~cm}$., $\max$. th $0.6 \mathrm{~cm}$.

Reddish yellow (5YR 6/8) slip on exterior and interior rim. Reddish yellow (5YR 7/6) unslipped surface on interior. Exterior surface and interior rim are burnished. Average hardness; thin paste; very sparsely porous, fine, reddish yellow (5YR 6/8) fabric with infrequent sand inclusions.

156. ( $\left.\mathrm{N}^{\mathrm{o}} 1369\right)$ : Rim fragment; Kepez, Necropolis, found in 2005.

pl. 8/156 and pl. 28/156.

Max. h $2.8 \mathrm{~cm}$., d of rim $17.2 \mathrm{~cm}$., max. w $6.0 \mathrm{~cm}$., $\max$. th $0.8 \mathrm{~cm}$.

Light brown (7.5YR 6/4) unslipped surface on exterior; pale brown (10YR 6/3) unslipped surface on interior. Hard, thin paste; non-porous, fine, light brown (7.5YR $6 / 4$ ) fabric with some medium grit and rare tiny lime inclusions.

Bowl Form 2 (pls. 8-9, nos $158-172$ )

This is an outturned rim bowl shape with perhaps a hemispherical body and thin or medium walls. At Gordion four similar drinking vessels have been classified as 'hemispherical bowls' where they have been interpreted as 'local variants' ${ }^{41}$.

157. ( $\mathrm{N}^{\circ} 1061$ ): Rim fragment; Kepez, found in 2005 . pl. 28/157.

Max. h 1.7 cm., max. w 1.4 cm., max. th $0.4 \mathrm{~cm}$.

Red (10R 5/8) thin slip on exterior and interior. Soft, thin paste; non-porous, fine, red (10R 5/8) fabric with rare quartz inclusions.

158. ( $\left.\mathrm{N}^{\circ} 1195\right)$ : Rim fragment; Kepez, Cistern, found in 2005 .

pl. 8/158 and pl. 28/158.

Max. h $1.8 \mathrm{~cm}$., max. w $1.6 \mathrm{~cm}$., max. th $0.5 \mathrm{~cm}$.

Red (2.5YR 5/8) slip on exterior and interior. Soft, thin paste; non-porous, fine, light red (2.5YR 6/8) fabric with rare sand inclusions.

159. ( $\mathrm{N}^{\circ}$ 581): Rim fragment; Kimistene, Acropolis, southern slope, just below of the summit of Deresemail creek, found in 2005 .

pl. 28/159.

Max. h 1.4 cm., max. w $2.4 \mathrm{~cm}$., max. th $0.6 \mathrm{~cm}$.

Red (2.5YR 5/8) shiny slip on exterior; light red (2.5YR 6/8) slip on interior. Hard, thin paste; non-porous, fine, red (2.5YR 5/8) fabric with frequent tiny lime and rare sand inclusions. 

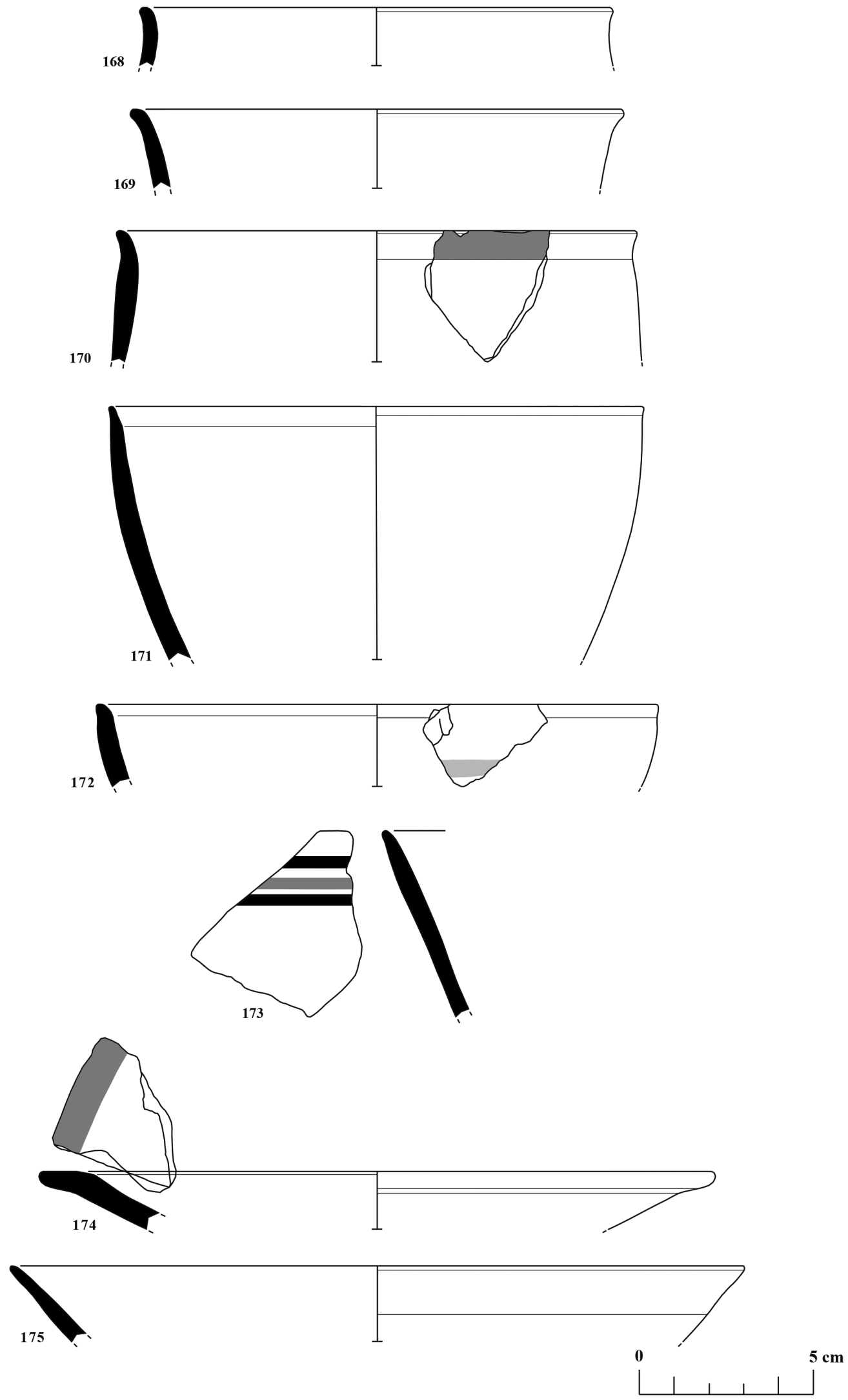

Pl. 9 : $\mathbf{N}^{\text {os }}$ 168-175: Red-painted Kepez group; $\mathrm{n}^{\text {os }}$ 168-172: Bowl form 2; and $\mathrm{n}^{\text {os }}$ 173-175: Dish form 1. 
160. ( $\mathrm{N}^{\circ}$ 582): Rim fragment; Kimistene, Acropolis, southern slope, just below of the summit of Deresemail creek, found in 2005.

pl. 28/160.

Max. h $2.0 \mathrm{~cm}$., max. w $2.2 \mathrm{~cm}$., max. th $0.4 \mathrm{~cm}$.

Weak red (10R 5/4) slip on exterior and interior. Hard, thin paste; non-porous, fine, red (2.5YR 5/8) fabric with no visible inclusions.

161. (No 685): Rim fragment; Kimistene, Acropolis, southern slope, just below of the summit of Deresemail creek, found in 2005 .

pl. 28/161.

Max. h $2.0 \mathrm{~cm}$., d of base $7.8 \mathrm{~cm}$., max. w $2.3 \mathrm{~cm}$., $\max$. th $0.5 \mathrm{~cm}$.

Red (10R 4/6) slip on exterior and interior. Soft, thin paste; non-porous, fine, reddish brown (5YR 4/4) fabric with frequent micaceous and some lime inclusions.

162. (No 1099): Rim fragment; Kepez, found in 2005. pl. 8/162 and pl. 28/162.

Max. h $2.3 \mathrm{~cm}$., max. w $2.0 \mathrm{~cm}$., max. th $0.8 \mathrm{~cm}$.

Red (10R 5/8) on exterior and interior rim. Its below part has a reddish yellow (5YR 7/6) unslipped surface on interior. Average hardness; very sparsely porous, thin paste; fine, reddish yellow (5YR 6/6) fabric with rare lime inclusions.

163. (No 1087): Rim fragment; Kepez, found in 2005. pl. 8/163 and pl. 28/163.

Max. h $2.5 \mathrm{~cm}$., max. w $2.1 \mathrm{~cm}$., max. th $0.4 \mathrm{~cm}$.

Red (2.5YR 5/6) slip on exterior and interior. Average hardness; thin paste; non-porous, fine, light brown (7.5YR 6/4) fabric with infrequent sand inclusions.

164. ( $\mathrm{N}^{\circ} 1020$ ): Rim fragment; Kepez, found in 2005. pl. 8/164 and pl. 28/164.

Max. h $3.2 \mathrm{~cm}$., max. w $2.8 \mathrm{~cm}$., max. th $0.6 \mathrm{~cm}$.

Red (10R 5/6) slip on exterior and interior. Hard, thin paste; non-porous, light reddish brown (10YR 6/3) and reddish yellow (5YR 6/6) fabric with some tiny lime and occasional sand inclusions.

165. ( $\left.\mathrm{N}^{\circ} 1188\right)$ : Rim fragment; Kepez, Cistern, found in 2005 .

pl. 8/165 and pl. 28/165.

Max. h $3.8 \mathrm{~cm}$., max. w $2.8 \mathrm{~cm}$., $\max$. th $0.5 \mathrm{~cm}$.

Red (2.5YR 5/8) slip on exterior and interior. Average hardness; thin paste; non-porous, fine, red (2.5YR 5/6) fabric with some sand inclusions.

166. ( $\mathrm{N}^{\circ} 1128$ ): Rim fragment; Kimistene, Acropolis, southern slope, just below of the summit of Deresemail creek, found in 2005 .

pl. 8/166 and pl. 28/166.

Max. h $3.1 \mathrm{~cm}$., max. w $3.2 \mathrm{~cm}$., max. th $0.4 \mathrm{~cm}$.

Red (10R 5/8) on exterior rim and interior rim. Their below parts have a reddish yellow (7.5YR 7/6) unslipped surface. Average hardness; non-porous, thin paste; fine, reddish yellow (5YR 6/6) fabric with no visible inclusions.

167. (No 1015): Rim fragment; Kepez, found in 2005. pl. 8/167 and pl. 29/167.

Max. h $5.5 \mathrm{~cm}$., d of rim $13.0 \mathrm{~cm}$., max. w $4.9 \mathrm{~cm}$., $\max$. th $0.5 \mathrm{~cm}$.

Brown (7.5YR 4/3) and reddish yellow (5YR 6/6) mottled slip on exterior; reddish yellow (5YR 6/6) band on interior rim. Its below part has a pink (7.5YR 7/4) slip on interior. Hard, thin paste; non-porous, fine, pink (7.5YR 7/4) fabric with infrequent sand and rare lime inclusions.

168. ( $\left.\mathrm{N}^{\circ} 1111\right)$ : Rim fragment; Kepez, Cistern, found in 2005 .

pl. 9/168 and pl. 29/168.

Max. h $1.7 \mathrm{~cm}$., d of rim $13.4 \mathrm{~cm}$., max. w $2.9 \mathrm{~cm}$., $\max$. th $0.5 \mathrm{~cm}$.

Red (2.5YR 5/6) slip on exterior and interior. Average hardness; thin paste; non-porous, fine, reddish yellow (5YR 6/6) fabric with rare tiny lime inclusions.

169. ( $\mathrm{N}^{\circ}$ 1206): Rim fragment; Kimistene, summit of the Acropolis, southern slope, found in 2005.

pl. 9/169 and pl. 29/169.

Max. h $2.3 \mathrm{~cm}$., d of rim $14.0 \mathrm{~cm}$., max. w $5.4 \mathrm{~cm}$., $\max$. th $0.5 \mathrm{~cm}$.

Red (2.5YR 5/6) slip on exterior; reddish yellow (5YR 6/6) slip on interior. Average hardness; thin paste; non-porous, fine, light brown (7.5YR 6/4) fabric with frequent tiny lime inclusions.

170. (No 796): Rim fragment; Kimistene, Acropolis, southern slope, just below of the summit of Deresemail creek, found in 2005 .

pl. 9/170 and pl. 29/170.

Max. h $3.8 \mathrm{~cm}$., d of rim $14.8 \mathrm{~cm}$., max. w $3.6 \mathrm{~cm}$., $\max$. th $0.5 \mathrm{~cm}$.

Red $(2.5 \mathrm{YR} 5 / 6)$ on exterior rim and interior rim. Their below parts have a reddish yellow (7.5YR 7/6) unslipped surface. Hard, very sparsely porous, thin paste; fine, reddish yellow (5YR 6/6) fabric with frequent lime inclusions. in 2005 .

171. ( $\left.\mathrm{N}^{\circ} 1159\right)$ : Rim fragment; Kepez, Cistern, found pl. 9/171 and pl. 29/171.

Max. h $7.3 \mathrm{~cm}$., d of rim $15.2 \mathrm{~cm}$., max. w $5.4 \mathrm{~cm}$., $\max$. th $0.6 \mathrm{~cm}$.

Reddish yellow (7.5YR 7/6) and red (2.5YR 5/8) mottled slip on the exterior. Red (2.5YR 5/6) slip on the interior. Hard, very sparsely porous, thin paste; fine, reddish yellow (7.5YR 6/6) fabric with infrequent small grit and lime inclusion. 

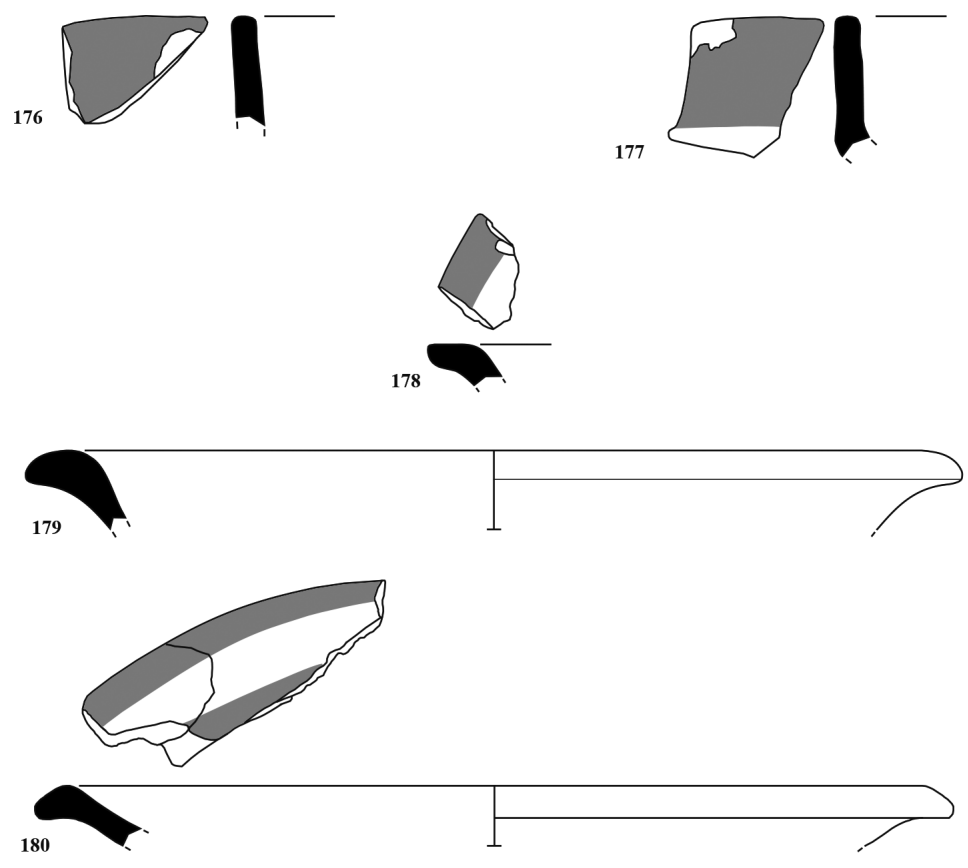

181
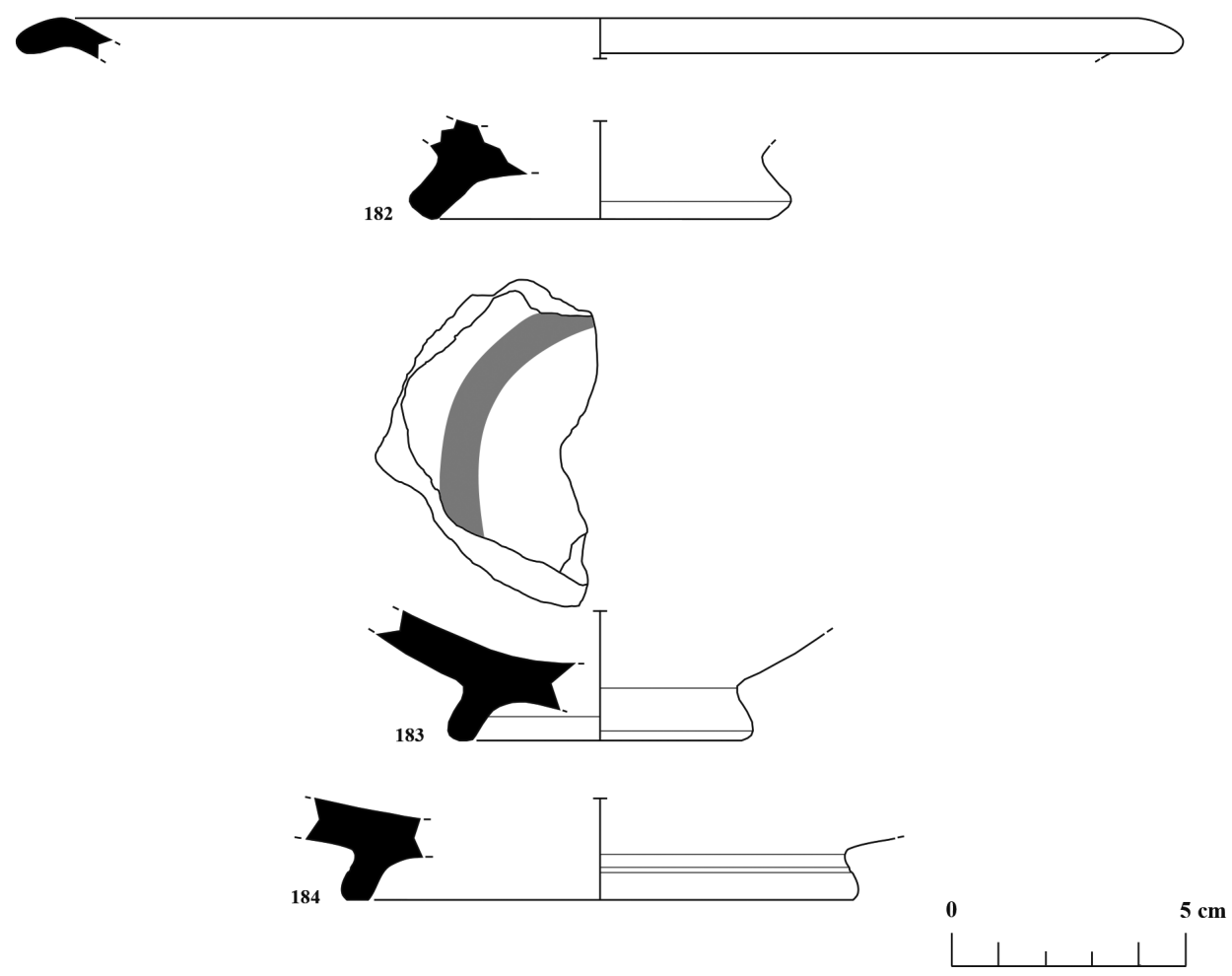

Pl. 10 : Nos 176-184: Red-painted Kepez group; $n^{\text {os }}$ 176-177: Dish form 2; ${ }^{\text {os }}$ 178-181: Plate; and $n^{\text {os }}$ 182-184: Base fragments of open forms. 
172. ( No 1112): Rim fragment; Kepez, Cistern, found in 2005 .

pl. 9/172 and pl. 29/172.

Max. h $2.4 \mathrm{~cm}$., d of rim $16.0 \mathrm{~cm}$., max. w $3.5 \mathrm{~cm}$., max. th $0.6 \mathrm{~cm}$.

Reddish yellow (5YR 6/6), thin slip on exterior and interior. Very pale brown (10YR 8/2) band on interior. Hard, thin paste; non-porous, fine light brown (7.5YR 6/4) fabric with rare tiny lime inclusions.

$$
\text { Dish Form } 1 \text { (pl. 9, ñ } 173-175)
$$

Represented with a rounded rim of a deep dish form.

173. ( No 1000): Rim fragment; Kepez, found in 2005 . pl. 9/173 and pl. 29/173.

Max. h $5.4 \mathrm{~cm}$., max. w $4.8 \mathrm{~cm}$., max. th $0.4 \mathrm{~cm}$.

Very pale brown (10YR 8/2) slip on exterior; reddish yellow (7.5YR 7/6) slip on interior. Two parallel horizontal bands are very dark gray (7.5YR 3/1). There is a red (2.5YR 5/6) horizontal band between two bands on exterior. Hard, thin paste; very sparsely porous, reddish yellow (7.5YR 7/6) and reddish yellow (5YR 6/8) fabric with rare micaceous and sand inclusions.

174. (No 936): Rim fragment; Kimistene, Acropolis, found in 2005 .

pl. 9/174 and pl. 29/174.

Max. h 1.7 cm., d of rim $19.2 \mathrm{~cm}$., max. w $3.5 \mathrm{~cm}$., $\max$. th $0.7 \mathrm{~cm}$.

Very pale brown (10YR 7/4) unslipped surface on exterior; red (2.5YR 5/6) painted interior rim, reddish yellow (5YR 6/6) slip on interior. Hard, thin paste; very sparsely porous, fine, reddish yellow (5YR 6/6) fabric with some micaceous and tiny lime inclusions.

175. ( $\mathrm{N}^{\circ} 1092$ ): Rim fragment; Kepez, found in 2005. pl. 9/175 and pl. 29/175.

Max. h $2.2 \mathrm{~cm}$., d of rim $21.0 \mathrm{~cm}$., max. w $7.9 \mathrm{~cm}$., max. th $0.5 \mathrm{~cm}$.

Entire surface slightly slipped. Red (2.5YR 5/6) slip on the exterior; red (2.5YR 5/6) slip on the interior. Hard, very sparsely porous, thin paste; fine, reddish yellow (5YR 6/8) fabric with rare tiny lime inclusion.

Dish Form 2 (pl. 10, nos 176-177)

Represented with two rounded rims. They should have had a straight edge and shallow surface. Their exterior is slipped with light colours.
176. ( $\left.\mathrm{N}^{\circ} 1100\right)$ : Rim fragment; Kepez, found in 2005. pl. 10/176 and pl. 29/176.

Max. h $2.3 \mathrm{~cm}$., max. w $3.1 \mathrm{~cm}$., max. th $0.5 \mathrm{~cm}$.

Pink (7.5YR 7/4) slip on exterior and interior; red (2.5YR 5/6) on interior slip. Average hardness; nonporous, thin paste; fine, pink (7.5YR 7/4) fabric with infrequent lime inclusions.

177. (No 1107): Rim fragment; Kepez, Cistern, found in 2005 .

pl. 10/177 and pl. 29/177.

Max. h $3.0 \mathrm{~cm}$., max. w $3.3 \mathrm{~cm}$., max. th $0.6 \mathrm{~cm}$.

Light brown (7.5YR 6/4) slip on exterior and lower interior; red (2.5YR 5/6) on interior rim. Exterior surface is burnished. Hard, non-porous, thin paste; fine, pink (7.5YR 7/4) fabric with rare lime inclusions.

$$
\text { Plate (pl. 10, } \left.\mathrm{n}^{\mathrm{os}} 178-181\right)
$$

These are plate fragments with an outcurved rim and shallow body, similar to the shape of a fish plate, which was a fairly popular shape in the eastern Mediterranean during the Hellenistic period ${ }^{42}$.

178. (№ 1476): Rim fragment; Kimistene, Acropolis, southern slope, just below of the summit of Deresemail creek, found in 2005.

pl. 10/178 and pl. 29/178.

Max. h 0.9 cm., max. w $3.5 \mathrm{~cm}$., max. th $0.5 \mathrm{~cm}$.

Pink (5YR 7/4) slip on all of its surface; reddish brown $(2.5 Y R 5 / 4)$ on interior rim. Hard, thin paste; very sparsely porous, red (2.5YR 5/6) and light brown (7.5YR $6 / 4$ ) fabric with rare lime inclusions.

179. (No 1336): Rim fragment; Kimistene, Cistern, eastern slope, found in 2005.

pl. 10/179 and pl. 29/179.

Max. h $1.7 \mathrm{~cm}$., d of rim $18.0 \mathrm{~cm}$., max. w $4.4 \mathrm{~cm}$., $\max$. th $0.5 \mathrm{~cm}$.

Red (2.5YR 6/8) slip on exterior; red (2.5YR 5/8) shiny slip on interior. Hard, thin paste; non-porous, fine, red (2.5YR 6/8) fabric with no visible inclusions.

180. ( $\mathrm{N}^{\circ}$ 1088): Rim fragment; Kepez, found in 2005. pl. 10/180 and pl. 29/180.

Max. h $1.3 \mathrm{~cm}$., d of rim $18.0 \mathrm{~cm}$., max. w $7.0 \mathrm{~cm}$., max. th $0.5 \mathrm{~cm}$.

Its rim curves downward ${ }^{43}$. Very pale brown (10YR $7 / 3)$ thin slip on exterior; red (2.5YR 5/6) slip on interior. Pinkish white (7.5YR 8/2) band on interior. Average hardness; very sparsely porous, thin paste; fine, light reddish brown (5YR 6/4) fabric with some sand and lime. A little micaceous inclusion.

42) Stewart 2010: 179.

43) A similar example is: Stewart 2010: 203, fig. 232, n. 356 (P 4186; Middle Hellenistic). 

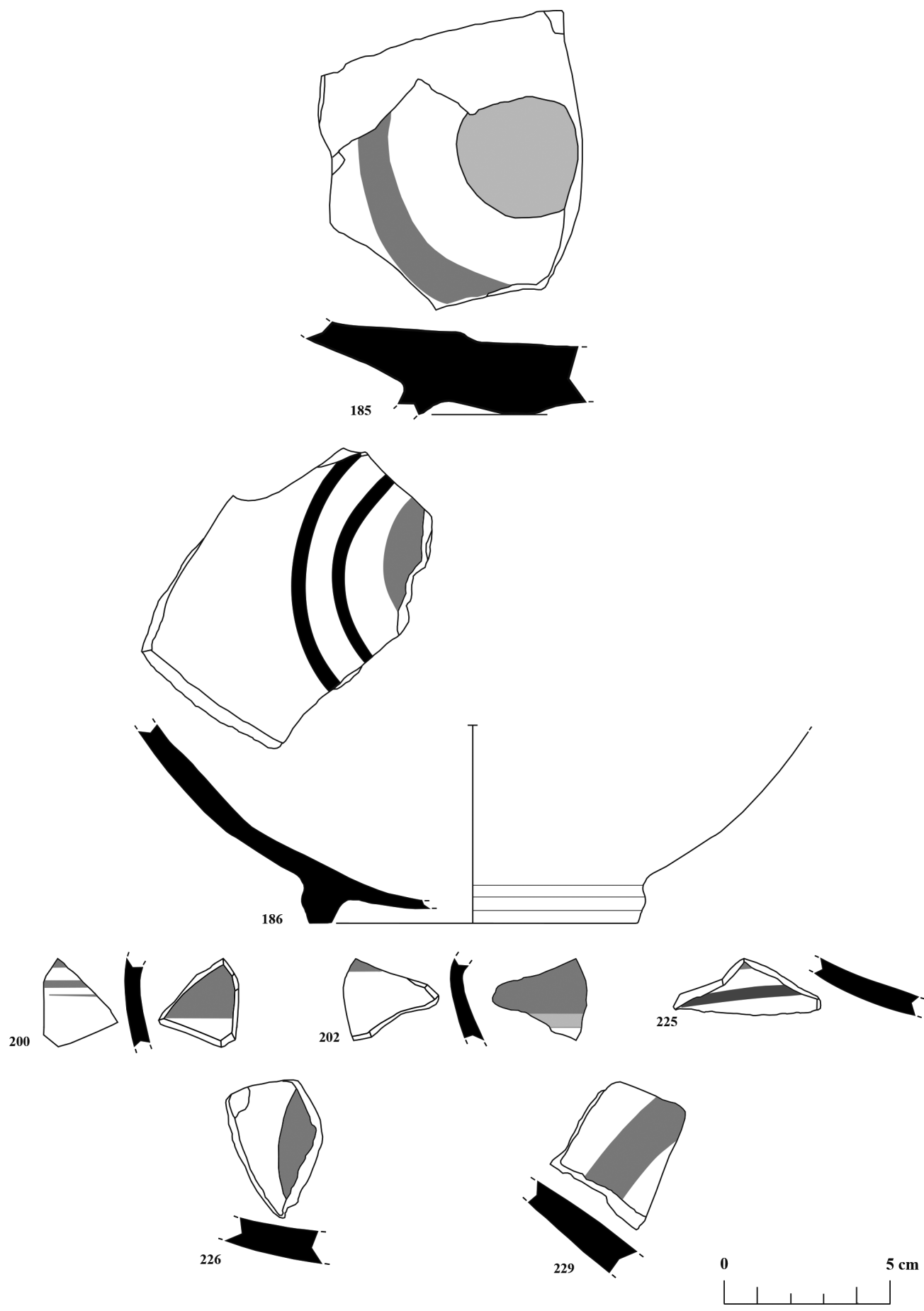

Pl. 11 : Nos 185-229: Red-painted Kepez group; $\mathbf{n}^{\text {os }}$ 185-186: Base fragments of open forms; and ${ }^{\text {os }}$ 200-229: Body fragments of open forms. 
181. ( $\left.\mathrm{N}^{\circ} 1081\right)$ : Rim fragment; Kepez, found in 2005. pl. 10/181 and pl. 29/181.

Max. h $0.9 \mathrm{~cm}$., d of rim $23.0 \mathrm{~cm}$., max. w $3.4 \mathrm{~cm}$., $\max$. th $0.6 \mathrm{~cm}$.

Red (2.5YR 5/8) slip both on exterior and interior. Average hardness; thin paste; non-porous, fine, reddish yellow (7.5YR 6/6) fabric with rare lime inclusions.

\section{Base Fragments of Open Forms} (pls. $10-11, \mathrm{n}^{\text {os }} 182-186$ )

Their forms cannot be assigned; most of them should, however, be belonging to bowls. The most important characteristic of this form is a band decoration. Their measurements are similar to each other. 2005.

182. ( $\mathrm{N}^{\circ} 1009$ ): Base fragment; Kepez, found in

pl. 10/182 and pl. 29/182.

Max. h $2.1 \mathrm{~cm}$., d of base $7.2 \mathrm{~cm}$., max. w $4.3 \mathrm{~cm}$., max. th $1.1 \mathrm{~cm}$.

Pink (5YR 7/4) and thin slip on exterior; red (2.5YR 5/6) slip on interior. Average hardness; non-porous, thin paste; fine, reddish yellow (5YR 6/6) fabric with some small sand, frequent lime inclusions.

183. ( $\mathrm{N}^{\circ}$ 1157): Base fragment; Kepez, Cistern, found in 2005 .

pl. 10/183 and pl. 29/183.

Max. h $2.8 \mathrm{~cm}$., d of base $6.0 \mathrm{~cm}$., max. w $7.0 \mathrm{~cm}$., max. th $0.9 \mathrm{~cm}$.

Reddish yellow (7.5YR 7/6) slip on the exterior; very pale brown (10YR 7/4) unslipped surface on the interior. There is a reddish yellow (7.5YR 7/6) concentric band on the interior surface. Hard, sparsely porous, fine, light red (2.5YR 6/6) fabric with frequent lime inclusions. 2005

184. ( $\mathrm{N}^{\circ}$ 1016): Base fragment; Kepez, found in

pl. 10/184 and pl. 29/184.

Max. h $2.2 \mathrm{~cm}$., d of base $10.8 \mathrm{~cm}$., max. w $6.4 \mathrm{~cm}$., $\max$. th $0.9 \mathrm{~cm}$.

Pink (7.5YR 8/4) unslipped surface on exterior; red (10R 5/6) slip on interior. Hard, thin paste; non-porous, fine, reddish yellow (5YR 7/8) fabric with rare sand inclusions.

185. (No 1198): Base fragment; Kepez, Cistern, found in 2005 .

pl. 11/185 and pl. 29/185.

Max. h $2.8 \mathrm{~cm}$., max. w $9.0 \mathrm{~cm}$., max. th $1.2 \mathrm{~cm}$.

Very pale brown (10YR 7/3) slip on the exterior; very pale brown (10YR 7/3) slip on the centre of the bottom. Very pale brown (10YR 8/2) on the interior surface. A red (2.5YR 5/8) and dusky red (2.5YR 3/2) mottled-painted concentric band on the interior surface. Stripe caused by careless execution. Hard, very sparsely porous, thin paste; fine, pink (5YR 7/4) fabric with frequent micaceous and grit inclusions.
186. ( $\left.\mathrm{N}^{\circ} 829\right)$ : Base fragment; Kimistene, Cistern, eastern slope, found in 2005.

pl. 11/186 and pl. 29/186.

Max. h $6.0 \mathrm{~cm}$., d of base $9.8 \mathrm{~cm}$., max. w $9.5 \mathrm{~cm}$., max. th $0.6 \mathrm{~cm}$.

Reddish yellow (5YR 6/6) and thin slip on the exterior; light red (2.5YR 6/8) slip on the interior. Weak red (7.5R 4/4) on the centre of the bottom; two concentric bands in dark reddish gray (2.5YR 3/1) and very dark gray (7.5YR 3/1) paint on the interior. Hard, non-porous, thin paste; fine, light red (2.5YR 6/8) fabric with occasional tiny lime and a little micaceous inclusion.

\section{Body Fragments of Open Forms (pls. 11-12, nos 200-244)}

187. ( $\mathrm{N}^{\circ}$ 1064): Body fragment; Kepez, found in 2005.

pl. 30/187.

Max. h $1.4 \mathrm{~cm}$., max. w $1.6 \mathrm{~cm}$., max. th $0.4 \mathrm{~cm}$.

Red (10R 5/8) slip on exterior and interior. Hard, thin paste; non-porous, fine, light red (2.5YR 6/8) fabric with frequent tiny sand and rare micaceous inclusions. 2005

188. ( $\mathrm{N}^{\circ} 1063$ ): Body fragment; Kepez, found in

Max. h $1.5 \mathrm{~cm}$. max. w $2.0 \mathrm{~cm}$. $\max$ th $0.5 \mathrm{~cm}$.

Red (10R 5/8) slip on exterior and interior. Average hardness; thin paste; non-porous, fine, light red (2.5YR 6/8) fabric with no visible inclusions.

189. ( $\mathrm{N}^{\circ}$ 1189): Body fragment; Kepez, Cistern, found in 2005 .

pl. 30/189.

Max. h $2.2 \mathrm{~cm}$., max. w $1.4 \mathrm{~cm}$., max. th $0.4 \mathrm{~cm}$.

Very pale brown (10YR 8.5/2) slip on exterior; reddish yellow (7.5YR 7/6) unslipped surface on interior. A band in reddish brown (2.5YR 4/3) on exterior. Average hardness; thin paste; very sparsely porous, fine, reddish yellow (7.5YR 7/6) fabric with some micaceous inclusions.

190. ( $\mathrm{N}^{\circ}$ 1243): Body fragment; Kepez, found in 2005.

pl. 30/190.

Max. h $1.4 \mathrm{~cm}$., max. w $2.2 \mathrm{~cm}$., max. th $0.3 \mathrm{~cm}$.

Very pale brown (10YR $8 / 2)$ slip on lower exterior. A band in reddish brown (2.5YR 5/4) on upper exterior and interior. Hard, thin paste; non-porous, fine, pink (5YR 7/4) fabric with no visible inclusions.

191. ( $\mathrm{N}^{\circ}$ 1192): Body fragment; Kepez, Cistern, found in 2005 .

pl. 30/191.

Max. h 2.1 m., max. w 1.9 cm., max. th $0.6 \mathrm{~cm}$.

Red (10R 5/8) slip on exterior and interior. Average hardness; thin paste; non-porous, reddish yellow (5YR 7/8-7.5YR 6/6) fabric with some lime and sand inclusions. 
192. ( $\left.\mathrm{N}^{\mathrm{o}} 1050\right)$ : Body fragment; Kepez, found in 2005.

pl. 30/192.

Max. h $1.8 \mathrm{~cm}$., max. w $2.2 \mathrm{~cm}$., $\max$. th $0.3 \mathrm{~cm}$.

Reddish brown (5YR 5/4) and reddish yellow (5YR 6/6) mottled slip on exterior. Reddish yellow (5YR 6/6) slip on interior. Two bands in pinkish white (7.5YR 8/2) on exterior slip. Hard, thin paste; non-porous, fine, pink (7.5YR 7/4) fabric with frequent tiny lime inclusions.

193. ( $\mathrm{N}^{\circ}$ 1241): Body fragment; Kepez, found in 2005.

pl. 30/193.

Max. h $2.1 \mathrm{~cm}$., max. w $1.9 \mathrm{~cm}$., max. th $0.5 \mathrm{~cm}$.

Red (2.5YR 5/8) shiny slip on exterior and interior. Hard, thin paste; sparsely porous, fine, light red (2.5YR 6/6) fabric with rare micaceous inclusions. 2005 .

194. ( $\mathrm{N}^{\circ}$ 1035): Body fragment; Kepez, found in pl. 30/194.

Max. h $2.1 \mathrm{~cm}$., max. w $2.3 \mathrm{~cm}$., max. th $0.8 \mathrm{~cm}$.

Red (10R 5/8) slip on exterior; light red (2.5YR 6/8) slip on interior. Average hardness; very sparsely porous, thin paste; non-porous, fine, reddish yellow (5YR 6/6) fabric with no visible inclusions.

195. ( $\mathrm{N}^{\circ}$ 1025): Body fragment; Kepez, found in 2005.

pl. 30/195.

Max. h $2.4 \mathrm{~cm}$., max. w $2.1 \mathrm{~cm}$., max. th $0.5 \mathrm{~cm}$.

Red (2.5YR 5/8) slip on exterior and interior. Average hardness; thin paste; non-porous, fine, reddish yellow (5YR 6/6) fabric with infrequent sand inclusions. 2005 .

196. ( $\mathrm{N}^{\circ}$ 1022): Body fragment; Kepez, found in

pl. 30/196.

Max. h $2.0 \mathrm{~cm}$., max. w $3.1 \mathrm{~cm}$., $\max$. th $0.6 \mathrm{~cm}$.

Red (2.5YR 5/6) slip on exterior and interior. Hard, thin paste; non-porous, fine, very pale brown (10YR 7/3) fabric with no visible inclusions.

197. ( $\mathrm{N}^{\circ}$ 1148): Body fragment; Kimistene, Acropolis, temple slope, first slope on the north, found in 2005.

pl. 30/197.

Max. h $2.1 \mathrm{~cm}$., max. w $2.6 \mathrm{~cm}$., max. th $0.6 \mathrm{~cm}$.

Red (2.5YR 5/6) slip on exterior and interior. Hard, thin paste; non-porous, fine, very pale brown (10YR 7/4) fabric with no visible inclusions.

198. ( $\mathrm{N}^{\circ}$ 1021): Body fragment; Kepez, found in 2005.

pl. 30/198.

Max. h $2.4 \mathrm{~cm}$., max. w $2.5 \mathrm{~cm}$., max. th $0.6 \mathrm{~cm}$.

Red (2.5YR 5/8) slip on exterior and interior. Hard, thin paste; non-porous, reddish yellow (5YR 6/6) and light red (2.5YR 6/8) mottled fabric with occasional sand inclusions.
199. ( $\left.\mathrm{N}^{\circ} 1184\right)$ : Body fragment; Kepez, surface find in the Cistern, found in 2005.

Max. h 3.0 cm., max. w $2.0 \mathrm{~cm}$., max. th $0.5 \mathrm{~cm}$.

Weak red (10R 5/4) slip on exterior. Pink (7.5YR 7/4) slip on interior. Interior surface is burnished. Hard, thin paste; non-porous, fine, red (2.5YR 5/8) fabric with no visible inclusions.

200. ( $\mathrm{N}^{\mathrm{o}}$ 1053): Body fragment; Kepez, found in 2005 .

pl. 11/200 and pl. 30/200.

Max. h $2.7 \mathrm{~cm}$., max. w $2.4 \mathrm{~cm}$., max. th $0.5 \mathrm{~cm}$

Reddish yellow (7.5YR 7/6) slip on exterior and interior. Three bands in red (2.5YR 5/6) on upper exterior and upper interior. Hard, thin paste; non-porous, fine, reddish yellow (7.5YR 6/6) fabric with rare sand inclusions. 2005 .

201. ( $\mathrm{N}^{\circ}$ 1029): Body fragment; Kepez, found in

Max. h $2.4 \mathrm{~cm}$., max. w $2.7 \mathrm{~cm}$., $\max$, th $0.4 \mathrm{~cm}$.

Shiny red $(2.5$ YR 5/6) and reddish brown $(2.5 \mathrm{YR}$ $4 / 4)$ mottled slip on exterior; red (2.5YR 4/8) slip on interior; its below part has reddish brown (5YR 4/3) slip on interior. Hard, thin paste; non-porous, red (2.5YR 5/6) and light red (2.5YR 6/6) mottled fabric with rare lime inclusions.

202. ( $\mathrm{N}^{\circ}$ 1040): Body fragment; Kepez, found in 2005.

pl. 11/202 and pl. 30/202.

Max. h $2.5 \mathrm{~cm}$., max. w $2.9 \mathrm{~cm}$., max. th $0.5 \mathrm{~cm}$.

Light red (2.5YR 6/8) on upper exterior; its below part slipped in reddish yellow (5YR 7/6). Exterior surface is burnished. Light red (2.5YR 6/6) on upper interior; pinkish white $(7.5 \mathrm{YR} 8 / 2)$ band on interior slip. Its below part has a very pale brown (10YR 7/4), unslipped surface on interior. Hard, very sparsely porous, thin paste; fine, reddish yellow (5YR 6/8) fabric with frequent tiny lime inclusions. 2005 .

203. ( $\mathrm{N}^{\circ}$ 1056): Body fragment; Kepez, found in

.

Max. h $2.8 \mathrm{~cm}$., max. w $2.8 \mathrm{~cm}$., max. th $0.9 \mathrm{~cm}$.

Very pale brown (10YR 7/4) unslipped surface on exterior; red (2.5YR 5/6) slip on interior. Hard, thin paste; non-porous, fine, very pale brown (10YR 7/4) fabric with occasional lime inclusions.

204. ( $\mathrm{N}^{\circ}$ 1032): Body fragment; Kepez, found in 2005.

pl. 30/204.

Max. h $3.2 \mathrm{~cm}$., max. w $2.4 \mathrm{~cm}$., max. th $0.5 \mathrm{~cm}$

Very pale brown (10YR 8/4) slip on exterior; red (2.5YR 5/8) slip on interior. A band in red (2.5YR 5/6) on exterior. Hard, thin paste; very sparsely porous, fine, reddish yellow (5YR 6/8) fabric with no visible inclusions. 
205. ( $\mathrm{N}^{\mathrm{o}}$ 1238): Body fragment; Kepez, found in 2005.

pl. 30/205.

Max. h 3.4 cm., max. w $2.7 \mathrm{~cm}$., max. th $0.6 \mathrm{~cm}$.

Red (2.5YR 5/6) and yellow (10YR 7/6) mottled slip on exterior; reddish yellow (5YR 6/6) slip on interior. Hard, thin paste; non-porous, fine, reddish yellow (7.5YR $6 / 6$ ) fabric with rare micaceous, quartz and sand inclusions.

206. ( $\mathrm{N}^{\mathrm{o}}$ 1176): Body fragment; Kepez, Cistern, found in 2005 .

pl. 30/206.

Max. h $2.8 \mathrm{~cm}$., max. w $2.8 \mathrm{~cm}$., max. th $0.7 \mathrm{~cm}$.

Red (2.5YR 5/6) slip on exterior; pink (5YR 7/4) unslipped surface on interior. A band in red (2.5YR 5/8) on interior. Hard, thin paste; non-porous, fine, light red (2.5YR 6/6) fabric with some sand and lime inclusions.

207. (No 518): Body fragment; Kimistene, Acropolis, southern slope, just below of the summit of Deresemail creek, found in 2005 .

pl. 30/207.

Max. h $3.2 \mathrm{~cm}$., max. w $2.2 \mathrm{~cm}$., $\max$. th $0.8 \mathrm{~cm}$.

Reddish brown (2.5YR 5/4) slip on exterior; light red (2.5YR 6/6) slip on interior. Hard, thin paste; very sparsely porous, fine, reddish yellow (5YR 6/6) fabric with some tiny lime inclusions. 2005.

208. ( $\mathrm{N}^{\circ}$ 1045): Body fragment; Kepez, found in pl. 30/208.

Max. h $3.2 \mathrm{~cm}$., max. w $2.3 \mathrm{~cm}$., $\max$. th $0.5 \mathrm{~cm}$.

Very pale brown (10YR 7/4), thin slip on exterior; red (2.5YR 5/6) slip on interior. Hard, thin paste; non-porous, reddish yellow (5YR 6/8) fabric with rare tiny lime inclusions. 2005

209. ( $\mathrm{N}^{\circ}$ 1034): Body fragment; Kepez, found in pl. 30/209.

Max. h $2.5 \mathrm{~cm}$., max. w $3.4 \mathrm{~cm}$., max. th $0.5 \mathrm{~cm}$.

Reddish brown (5YR 5/4) unslipped surface on exterior; reddish yellow (7.5YR 6/6) slip on interior. Interior surface is burnished. Hard, thin paste; non-porous, yellowish red (5YR 5/6) fabric with rare small grit and lime inclusions.

210. ( No $^{\circ}$ 611): Body fragment; Kimistene, Acropolis, southern slope, just below of the summit of Deresemail creek, found in 2005.

pl. 30/210.

Max. h $2.4 \mathrm{~cm}$., max. w $3.6 \mathrm{~cm}$., max. th $0.6 \mathrm{~cm}$.

Pink (7.5YR 7/4) thin slip on exterior; red (2.5YR $5 / 6)$ slip on interior. Hard, thin paste; non-porous, fine, yellowish red (5YR 5/6) fabric with some lime inclusions.
211. ( $\mathrm{N}^{\circ} 813$ ): Body fragment; Kimistene, summit of the Acropolis, western slope, found in 2005.

pl. 30/211.

Max. h $2.5 \mathrm{~cm}$., max. w $3.6 \mathrm{~cm}$., max. th $0.5 \mathrm{~cm}$.

Reddish brown (5YR 5/4) slip on exterior; light red (2.5YR 6/8) slip on interior. Hard, thin paste; very sparsely porous, fine, pink (7.5YR 7/4) fabric with no visible inclusions.

212. (No 1127): Body fragment; Kimistene, Acropolis, found in 2005 .

pl. 30/212.

Max. h 2.4 cm., max. w $3.6 \mathrm{~cm}$., max. th $0.6 \mathrm{~cm}$.

Pink (7.5YR 7/4) unslipped surface on exterior; red (2.5YR 5/6) slip on interior. Hard, thin paste; non-porous, fine, reddish brown (5YR 5/4) fabric with occasional lime and rare sand inclusions.

213. ( $\left.\mathrm{N}^{\circ} 1475\right)$ : Body fragment; Kepez, in a disturbed grave assemblage, found in 2005 .

pl. 30/213.

Max. h $2.5 \mathrm{~cm}$., max. w $3.2 \mathrm{~cm}$., $\max$. th $0.7 \mathrm{~cm}$

Light red (2.5YR 6/6) unslipped surface on exterior and interior. A band in light red (2.5YR 6/8) on interior. Hard, thin paste; very sparsely porous, yellowish red (5YR 5/8) and light brown (7.5YR 6/4) fabric with occasional sand inclusions.

214. (No 511): Body fragment; Kimistene, Acropolis, southern slope, just below of the summit of Deresemail creek, found in 2005.

pl. 30/214.

Max. h $3.2 \mathrm{~cm}$., max. w $2.7 \mathrm{~cm}$., max. th $0.7 \mathrm{~cm}$.

Shiny red (10R 5/6) slip on exterior; matt weak red (10R 5/4) slip on interior. Hard, thin paste; non-porous, fine, reddish brown (5YR 5/4) fabric with frequent tiny lime inclusions.

215. ( $\mathrm{N}^{\mathrm{o}}$ 1234): Body fragment; Kepez, found in 2005 .

pl. 30/215.

Max. h $3.1 \mathrm{~cm} .$, max. w $2.7 \mathrm{~cm} .$, max. th $0.7 \mathrm{~cm}$.

Gray (7.5YR 5/4) unslipped surface on exterior; light brown (7.5YR 6/4) unslipped surface on interior. A band in reddish brown $(2.5 \mathrm{YR} 5 / 4)$ on interior slip. Interior surface is burnished. Average hardness; sparsely porous, thin paste; brown (7.5YR 5/3) fabric with some sand and occasional micaceous inclusions.

216. ( $\left.\mathrm{N}^{\circ} 764\right)$ : Body fragment; Kimistene, Acropolis, southern slope, just below of the summit of Deresemail creek, found in 2005 .

pl. 30/216.

Max. h 3.3 cm., max. w 2.9 cm., max. th $0.6 \mathrm{~cm}$.

Reddish yellow (5YR 6/6) slip on exterior and interior. All of surface is thinly slipped. Exterior surface is burnished. Hard, thin paste; non-porous, fine, yellowish red (5YR 5/6) fabric with infrequent tiny lime and micaceous inclusions. 
217. (No 513): Body fragment; Kimistene, Acropolis, southern slope, just below of the summit of Deresemail creek, found in 2005.

pl. 30/217.

Max. h $3.0 \mathrm{~cm}$., max. w $3.2 \mathrm{~cm}$., $\max$. th $0.5 \mathrm{~cm}$.

Pink (5YR 7/4) unslipped surface on exterior, red (10R 5/6) slip on interior. Hard, sparsely porous, thin paste; fine, light red (2.5YR 6/6) fabric with some sand inclusions.

218. ( $\mathrm{N}^{\circ}$ 1187): Body fragment; Kepez, surface find in the Cistern, found in 2005.

pl. 30/218.

Max. h $3.2 \mathrm{~cm}$., max. w $3.0 \mathrm{~cm}$., max. th $0.6 \mathrm{~cm}$.

Red (2.5YR 5/6) slip on exterior, light red (2.5YR $6 / 6)$ slip on interior. Two thin bands in reddish yellow (7.5YR 7/8). Hard, very sparsely porous, thin paste; fine, reddish yellow (5YR 6/6) fabric with rare sand inclusions. 2005 .

219. ( $\mathrm{N}^{\mathrm{1}}$ 1018): Body fragment; Kepez, found in

pl. 30/219.

Max. h $3.7 \mathrm{~cm}$., max. w $3.2 \mathrm{~cm}$., max. th $0.5 \mathrm{~cm}$.

Very pale brown $(10 \mathrm{YR} 8 / 2)$ slip on exterior, in red (2.5YR 4/6) paint on exterior slip, red (10R 4/6) slip on interior. Average hardness; thin paste; very sparsely porous, fine, reddish yellow (7.5YR 7/6) fabric with some lime and sand inclusions.

220. (No 490): Body fragment; Kimistene, Acropolis, southern slope, just below of the summit of Deresemail creek, found in 2005.

pl. 30/220.

Max. h 2.4 cm., max. w $3.6 \mathrm{~cm}$., max. th $0.6 \mathrm{~cm}$.

Light gray (10YR 7/2) slip on exterior; red (2.5YR 4/6) slip on interior. Exterior surface is burnished. Average hardness; thin paste; very sparsely porous, fine, light brown $(7.5$ YR $6 / 3)$ fabric with no visible inclusions. 2005 .

221. ( $\mathrm{N}^{\circ}$ 1031): Body fragment; Kepez, found in pl. 30/221.

Max. h $2.2 \mathrm{~cm}$., max. w $4.8 \mathrm{~cm}$., max. th $0.5 \mathrm{~cm}$.

Pink (7.5YR 7/4) unslipped surface on exterior; weak red (10R 4/4) slip on exterior. Hard, thin paste; nonporous, fine, reddish yellow (5YR 6/8) fabric with no visible inclusions.

222. ( $\left.\mathrm{N}^{\circ} 1467\right)$ : Rim fragment; Kimistene, Acropolis, southern slope, just below of the summit of Deresemail creek, found in 2005.

pl. 30/222.

Max. h $3.0 \mathrm{~cm}$., max. w $4.1 \mathrm{~cm}$., max. th $0.6 \mathrm{~cm}$.

Pink (7.5YR 8/3) slip on exterior; red (2.5YR 5/6) slip on interior. Hard, sparsely porous, thin paste; fine, light red (2.5YR 6/6) fabric with rare micaceous inclusions.
223. ( $\mathrm{N}^{\mathrm{o}} 504$ ): Body fragment; Kimistene, Acropolis, southern slope, just below of the summit of Deresemail creek, found in 2005 .

pl. 30/223.

Max. h 2.9 cm., max. w $3.9 \mathrm{~cm}$., $\max$. th $1.0 \mathrm{~cm}$

Red (2.5YR 4/6) slip on exterior and interior. Hard, non-porous, fine, reddish yellow (5YR 6/6) fabric with rare tiny lime inclusions.

224. ( $\mathrm{N}^{\circ}$ 1014): Body fragment; Kepez, found in 2005.

pl. 30/224.

Max. h 1.9 cm., max. w 3.9 cm., max. th $0.7 \mathrm{~cm}$.

Red (2.5YR 5/6) and reddish yellow (7.5YR 7/6) mottled slip on exterior; red (2.5YR 5/6) slip on interior. Hard, thin paste; non-porous, fine, light reddish brown (5YR 6/4) fabric with frequent tiny lime inclusions.

225. ( $\mathrm{N}^{\mathrm{o}}$ 1179): Body fragment; Kepez, Cistern, found in 2005 .

pl. 11/225 and pl. 30/225.

Max. h $1.8 \mathrm{~cm}$., max. w $4.3 \mathrm{~cm}$., max. th $0.6 \mathrm{~cm}$.

Very pale brown (10YR 8/4) slip on exterior; very pale brown (10YR 7/4) slip on interior. A band in dusky red (2.5YR 3/2) on lower exterior. Exterior surface is burnished. Average hardness; thin paste; non-porous, fine, reddish yellow (7.5YR 6/6) fabric with some tiny lime and occasional sand inclusions.

226. ( $\mathrm{N}^{\mathrm{o}}$ 1005): Body fragment; Kepez, found in 2005.

pl. 11/226 and pl. 30/226.

Max. h $1.4 \mathrm{~cm}$., max. w $4.1 \mathrm{~cm}$., $\max$. th $1.0 \mathrm{~cm}$.

Very pale brown (10YR 7/4) unslipped surface on exterior and interior. A band in reddish brown (5YR 5/4) on interior. Hard, thin paste; non-porous, fine, very pale brown (10YR 7/3) fabric with infrequent tiny grog and lime inclusions.

227. ( $\mathrm{N}^{\circ}$ 1185): Body fragment; Kepez, Cistern, found in 2005 .

Max. h $3.0 \mathrm{~cm}$., max. w $3.6 \mathrm{~cm}$., max. th $0.6 \mathrm{~cm}$.

Pink (7.5YR 7/4) slip on exterior; red (2.5YR 5/6) slip on interior. Hard, very sparsely porous, thin paste; fine, reddish yellow (7.5YR 6/6) fabric with rare micaceous and some sand inclusions.

228. ( $\mathrm{N}^{\circ}$ 1324): Body fragment; Kimistene, summit of the Acropolis, southern slope, found in 2005.

pl. 30/228.

Max. h $3.1 \mathrm{~cm}$., max. w $4.3 \mathrm{~cm}$., max. th $0.9 \mathrm{~cm}$.

Reddish yellow (5YR 6/6) unslipped surface on exterior; red (2.5YR 4/6) slip on interior. Hard, thin paste; non-porous, fine, reddish yellow (5YR 6/6) fabric with occasional sand and rare micaceous inclusions. 
229. ( $\mathrm{N}^{\circ}$ 668): Body fragment; Kimistene, Acropolis, southern slope, just below of the summit of Deresemail creek, found in 2005.

pl. 11/229 and pl. 30/229.

Max. h $2.8 \mathrm{~cm}$., max. w $3.9 \mathrm{~cm}$., max. th $1.0 \mathrm{~cm}$.

Very pale brown (10YR 7/3) slip on exterior; reddish yellow (7.5YR 6/6) slip on interior. A band in reddish brown (5YR 5/4) on interior. All of surface is burnished. Hard, thin paste; porous, fine, reddish yellow (5YR 6/6) fabric with some tiny lime and micaceous inclusions.

230. ( $\mathrm{N}^{\circ}$ 1131): Body fragment; Kimistene, Acropolis, southern slope, just below of the summit of Deresemail creek, found in 2005.

pl. 31/230.

Max. h $3.7 \mathrm{~cm}$., max. w $4.1 \mathrm{~cm}$., max. th $0.7 \mathrm{~cm}$.

Red (10R 5/6) slip on exterior and interior. Hard, thin paste; non-porous, fine, light red (2.5YR 6/6) fabric with some tiny and rare small lime inclusions.

231. ( $\mathrm{N}^{\mathrm{o}}$ 1175): Body fragment; Kepez, Cistern, found in 2005 .

pl. 31/231.

Max. h $3.8 \mathrm{~cm}$., max. w $3.9 \mathrm{~cm}$., max. th $0.8 \mathrm{~cm}$.

Yellowish red (5YR 5/6) slip on exterior and interior. All of surface is burnished. Average hardness; thin paste; non-porous, yellowish red (5YR 5/6) fabric with frequent tiny lime inclusions. 2005 .

232. ( $\mathrm{N}^{\mathrm{o}}$ 1010): Body fragment; Kepez, found in

pl. 12/232 and pl. 31/232.

Max. h $2.2 \mathrm{~cm}$., max. w $3.4 \mathrm{~cm}$., $\max$. th $0.9 \mathrm{~cm}$.

Very pale brown (10YR 7/3) slip on exterior; light gray (10YR 7/2) slip on interior. A band in light reddish brown (5YR 6/4) on interior, bordered with two thin bands in reddish brown (5YR 5/4). Average hardness; thin paste; non-porous, fine, yellowish red (5YR 5/6) fabric with no visible inclusions.

233. (No 484): Body fragment; Kimistene, Acropolis, southern slope, just below of the summit of Deresemail creek, found in 2005.

pl. 31/233.

Max. h $4.5 \mathrm{~cm}$., max. w $3.3 \mathrm{~cm}$., max. th $1.0 \mathrm{~cm}$.

Red (2.5YR 5/6) slip on exterior; reddish brown (2.5YR 4/4) slip on interior. Hard, non-porous, thin paste; fine, reddish yellow (5YR 6/6) fabric with some tiny lime inclusions.

234. ( $\mathrm{N}^{\mathrm{1}}$ 1169): Body fragment; Kepez, Cistern, found in 2005 .

pl. 12/234 and pl. 31/234.

Max. h $2.0 \mathrm{~cm}$., max. w $3.5 \mathrm{~cm}$., max. th $0.6 \mathrm{~cm}$.

Very pale brown (10YR 7/3) slip on exterior; pink (7.5YR 7/4) unslipped surface on interior. Interior surface separated with a band in light red (2.5YR 6/6). Hard, thin paste; non-porous, fine, reddish yellow (5YR 6/6) fabric with some tiny sand and lime inclusions.
235. ( $\left.\mathrm{N}^{\mathrm{o}} 1183\right)$ : Body fragment; Kepez, Cistern, found in 2005 .

pl. 12/235 and pl. 31/235.

Max. h $1.7 \mathrm{~cm}$., max. w $4.5 \mathrm{~cm}$., max. th $0.6 \mathrm{~cm}$.

Light red (2.5YR 7/6) slip on exterior and interior. Surface is thinly slipped. Two bands in red (2.5YR 5/8) on interior. Hard, thin paste; sparsely porous, fine, light red (2.5YR 6/6) fabric with frequent sand and micaceous inclusions.

236. ( $\left.\mathrm{N}^{\circ} 1368\right)$ : Body fragment; Kepez, Necropolis, found in 2005.

pl. 31/236.

Max. h $5.2 \mathrm{~cm}$., max. w $4.4 \mathrm{~cm}$., max. th $0.5 \mathrm{~cm}$.

Red (10R 5/6) slip on exterior and interior. Average hardness; thin paste; very sparsely porous, fine, reddish yellow (5YR 6/8) fabric with no visible inclusions. 2005 .

237. ( $\mathrm{N}^{\circ}$ 1043): Body fragment; Kepez, found in

pl. 12/237 and pl. 31/237.

Max. h $5.2 \mathrm{~cm}$., max. w $3.2 \mathrm{~cm}$., max. th $0.6 \mathrm{~cm}$.

Yellowish red (5YR 5/6) slip on exterior; light gray (10YR 7/2) slip on interior. Interior surface is burnished. Pinkish white (7.5YR 8/2) band on exterior slip. Hard, thin paste; very sparsely porous, fine, light brown (7.5YR 6/4) fabric with occasional sand inclusions.

238. ( $\mathrm{N}^{\mathrm{0}} 561$ ): Body and base fragment; Kepez, found in 2005 .

pl. 12/238 and pl. 31/238.

Max. h 2.4 cm., max. w $5.1 \mathrm{~cm}$., max. th $1.0 \mathrm{~cm}$.

Very pale brown (10YR 7/4) slip on exterior; reddish yellow (7.5YR 7/6) unslipped surface on interior. A concentric band in red (2.5YR 5/6) on interior. Average hardness; very sparsely porous, thin paste; reddish yellow (7.5YR 6/6) and yellowish red (5YR 5/6) fabric with rare lime inclusions. 2005 .

239. ( $\mathrm{N}^{\circ}$ 1007): Body fragment; Kepez, found in

pl. 12/239 and pl. 31/239.

Max. h $3.0 \mathrm{~cm}$., max. w $6.1 \mathrm{~cm}$., max. th $0.9 \mathrm{~cm}$

Very pale brown (10YR 7/3) thin slip on exterior and interior. A band in yellowish red (5YR 5/6) on interior. Average hardness; non-porous, thin paste; fine, very pale brown (10YR 7/3) fabric with infrequent micaceous inclusions.

240. ( $\mathrm{N}^{\circ}$ 1167): Body fragment; Kepez, Cistern, found in 2005.

pl. 12/240 and pl. 31/240.

Max. h $2.1 \mathrm{~cm}$., max. w $6.5 \mathrm{~cm}$., max. th $1.1 \mathrm{~cm}$.

Very pale brown (10YR 7/4) slip on exterior; reddish yellow (7.5YR 7/6) slip on interior. Two bands in light red (2.5YR 6/8) on interior. Hard, thin paste; sparsely porous, fine, reddish yellow (5YR 6/6) fabric with some tiny lime, occasional small grit and micaceous inclusions. 

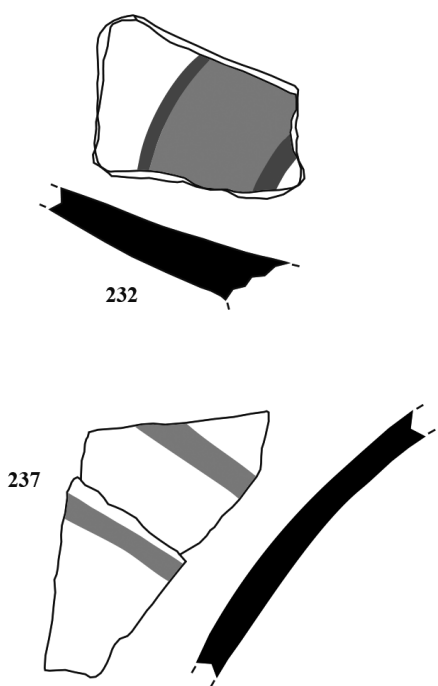
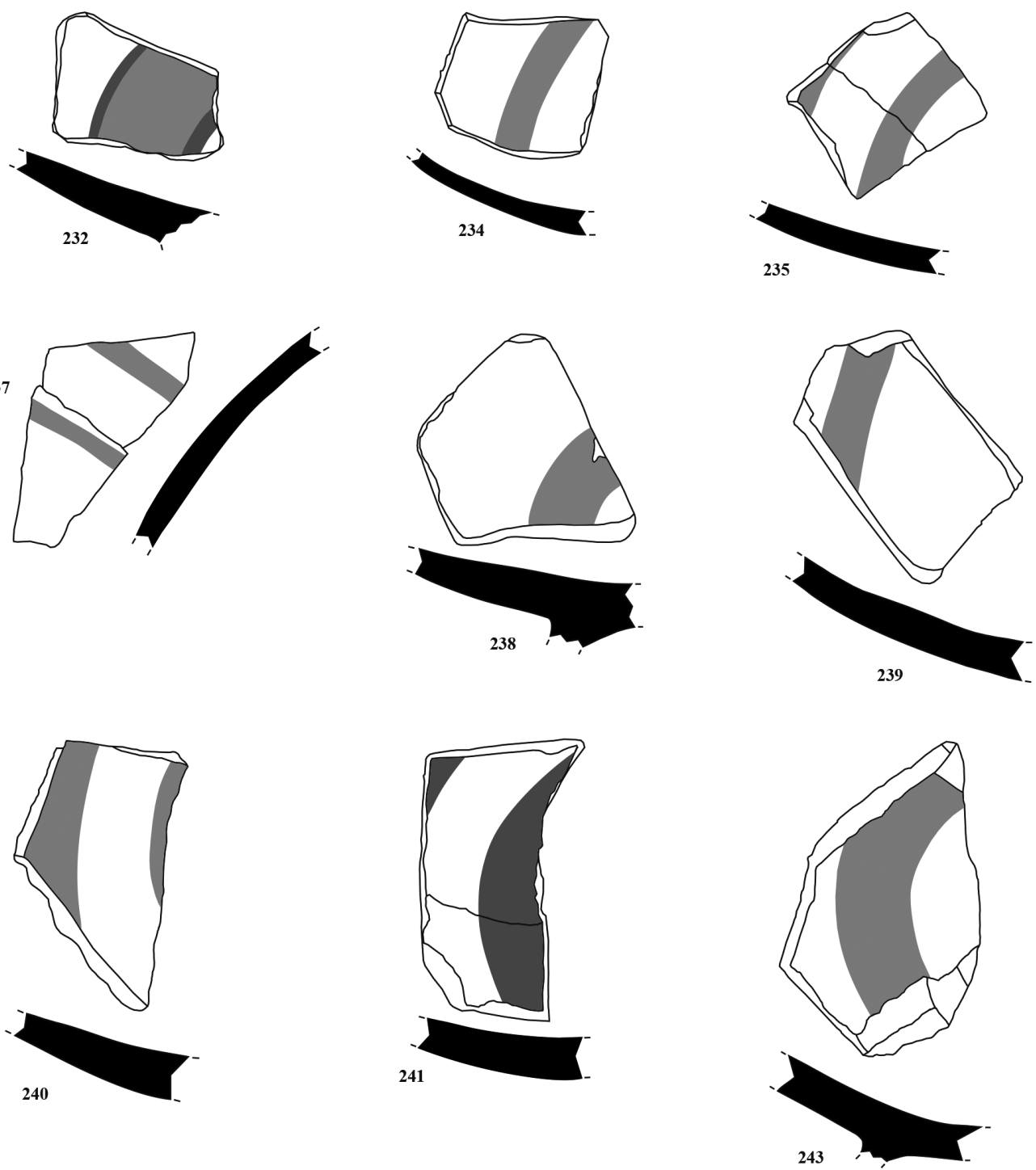

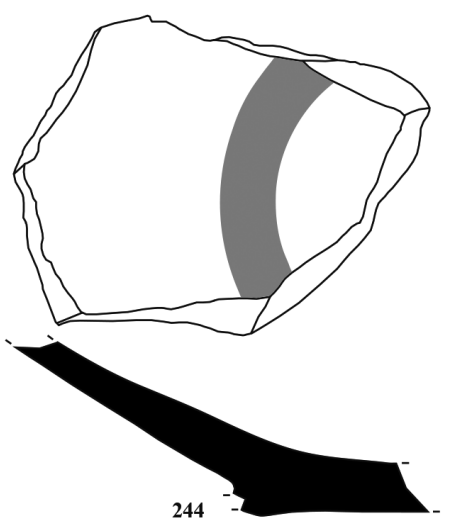


241. ( $\mathrm{N}^{\circ}$ 998): Body fragment; Kepez, found in 2005 . pl. 12/241 and pl. 31/241.

Max. h $1.5 \mathrm{~cm}$., max. w $6.8 \mathrm{~cm}$., max. th $1.1 \mathrm{~cm}$.

Very pale brown (10YR 7/4) unslipped surface on exterior and interior. Two bands in dark grayish brown (10YR 4/2) and light brown (7.5YR 6/4) on interior. Hard, thin paste; sparsely porous, fine, very pale brown (10YR 7/4) fabric with infrequent small lime and some medium grit inclusions.

242. ( $\mathrm{N}^{0} 760$ ): Body fragment; Kimistene, Acropolis, southern slope, just below of the summit of Deresemail creek, found in 2005.

pl. 31/242.

Max. h $5.5 \mathrm{~cm}$., max. w $6.6 \mathrm{~cm}$., max. th $0.9 \mathrm{~cm}$.

Very pale brown (10YR 7/4) unslipped surface on exterior. Smoothed surface on exterior; reddish brown (2.5YR 4/4) slip on interior. Hard, thin paste; non-porous, light brown (7.5YR 6/4) and pale brown (10YR 6/3) fabric with occasional lime, sand and rare quartz inclusions.

243. ( $\mathrm{N}^{\circ}$ 994): Body and base fragment; Kepez, found in 2005 .

pl. 12/243 and pl. 31/243.

Max. h $2.5 \mathrm{~cm}$., max. w $7.6 \mathrm{~cm}$., $\max$. th $1.1 \mathrm{~cm}$.

Pink (5YR 7/4) unslipped surface on exterior; reddish yellow (5YR 6/6) unslipped surface on interior. A concentric band in red (2.5YR 5/6) on interior. On the exterior some grooves. Average hardness; non-porous, thin paste; reddish brown (5YR 5/4) fabric with frequent sand and some lime inclusions.

244. ( $\mathrm{N}^{\circ}$ 1393): Body fragment; Kimistene, summit of the Acropolis, surface find, found in 2005.

pl. 12/244 and pl. 31/244.

Max. h $3.4 \mathrm{~cm}$., max. w $6.2 \mathrm{~cm}$., max. th $1.0 \mathrm{~cm}$.

Reddish yellow (7.5YR 7/6) slip on exterior and interior. A concentric band in red $(2.5 \mathrm{YR} 5 / 6)$ on interior. Hard, thin paste; sparsely porous, fine, reddish yellow (7.5YR 6/6) fabric with some tiny lime, sand inclusions.

Closed Forms (pl. 13, n ${ }^{\text {os }}$ 245-266)

Rim Fragments of Closed Forms

(pl. 13, $\mathrm{n}^{\text {os }} 245-247$ )

Pitcher or juglets with outcurved rims.

245. ( $\mathrm{N}^{\circ} 1101$ ): Rim fragment; Kepez, found in 2005. pl. 13/245 and pl. 32/245.

Max. h $2.1 \mathrm{~cm}$., max. w $2.5 \mathrm{~cm}$., max. th $0.4 \mathrm{~cm}$.

Red (10R 5/6) slip on exterior; matt reddish yellow (5YR 7/6), thin slip on interior rim. Hard, non-porous, thin paste; fine, reddish yellow (5YR 7/6) fabric with no visible inclusions.

246. ( $\left.\mathrm{N}^{\circ} 1002\right)$ : Rim fragment of a closed form; Kepez, found in 2005.

pl. 13/246 and pl. 32/246.

Max. h $4.4 \mathrm{~cm}$., max. w $4.3 \mathrm{~cm}$., max. th $0.9 \mathrm{~cm}$.
Very pale brown (10YR 8/4) slip on the exterior. Pink (5YR 7/4) unslipped surface on the interior. Red (10R 5/6) on exterior rim; its lower part has a black (5YR 2.5/1) horizontal band on the exterior. Average hardness; thin paste; very sparsely porous, reddish yellow (7.5YR 6/6) and light red (2.5YR 6/8) fabric with rare small grog and tiny lime; infrequent sand inclusions.

247. ( $\mathrm{N}^{\circ} 1083$ ): Rim fragment of a closed form; Kepez, found in 2005.

pl. 13/247 and pl. 32/247.

Max. h $2.4 \mathrm{~cm}$., d of rim $7.8 \mathrm{~cm}$., max. w $3.1 \mathrm{~cm}$., $\max$. th $0.6 \mathrm{~cm}$.

Light red (2.5YR 6/6) and red (2.5YR 5/6) mottled slip on exterior; red (2.5YR 5/6) slip on interior rim. Its lower part has a pink (7.5YR 7/4) unslipped surface. On the neck a weak red (2.5YR 4/2) band. Hard, thin paste; non-porous, fine, reddish yellow (5YR 6/6) fabric with frequent tiny lime inclusion.

\section{Handle Fragment of Closed Form} (pl. 13, n 377)

Vertical handle. 2005

248. ( $\mathrm{N}^{\circ} 1239$ ): Handle fragment; Kepez, found in

pl. 13/248 and pl. 32/248.

Max. h $1.3 \mathrm{~cm}$., max. w $2.2 \mathrm{~cm}$., max. th $1.3 \mathrm{~cm}$.

Red (10R 4/6) slip on all of surface. Average hardness; non-porous, fine, red (2.5YR 5/6) fabric with frequent tiny lime inclusions.

\section{Body Fragments of Closed Forms (pl. 13, $\mathrm{n}^{\text {os }}$ 256-266)}

Body fragments of unidentified closed shapes. Their interiors are unslipped; exterior decorated mostly with bands. 2005.

249. ( $\mathrm{N}^{\circ}$ 1042): Body fragment; Kepez, found in

pl. 32/249.

Max. h $3.0 \mathrm{~cm}$., max. w $1.7 \mathrm{~cm}$., $\max$. th $0.7 \mathrm{~cm}$.

Red (2.5YR 5/6) slip on exterior; pink (7.5YR 7/4) unslipped surface on interior. Soft, thin paste; non-porous, fine, red (2.5YR 5/8) fabric with frequent tiny lime inclusions.

250. ( $\mathrm{N}^{\mathrm{o}}$ 1186): Body fragment; Kepez, Cistern, found in 2005 .

pl. 32/250.

Max. h $1.8 \mathrm{~cm}$., max. w $2.6 \mathrm{~cm}$., max. th $0.7 \mathrm{~cm}$.

Red (2.5YR 5/8) slip on exterior; light gray (10YR $7 / 2$ ) unslipped surface on exterior. Average hardness; thin paste; non-porous, pale brown (10YR 6/3) mottled fabric with rare micaceous and sand inclusions. 
(i)
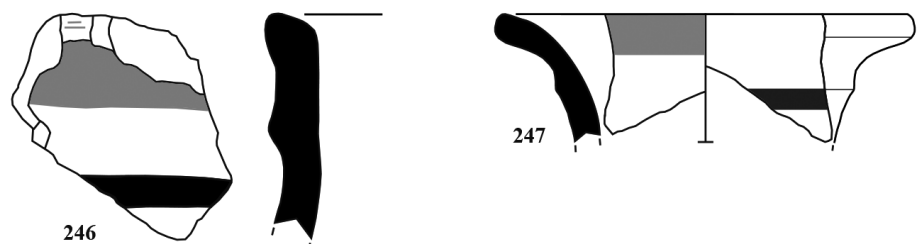

24
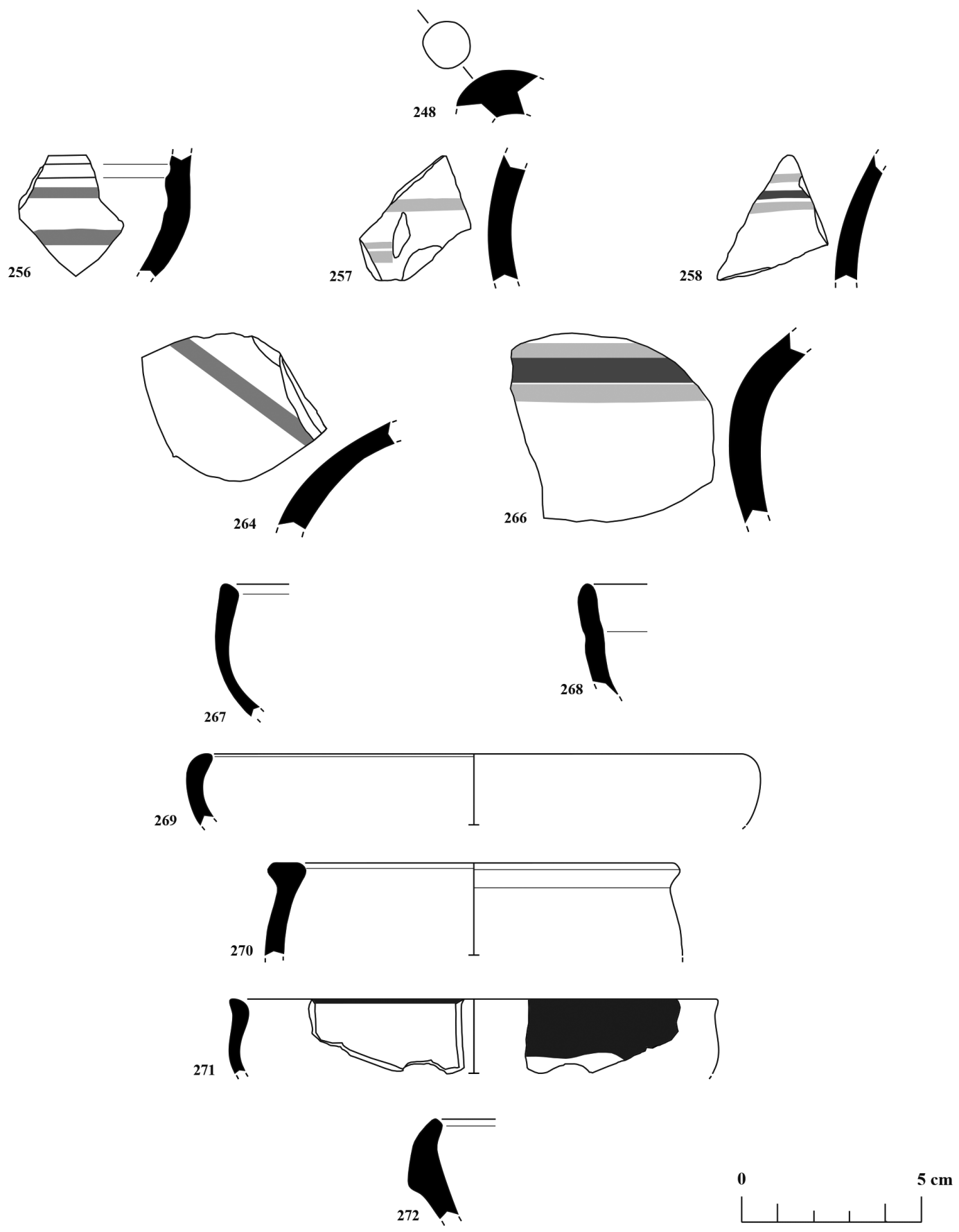

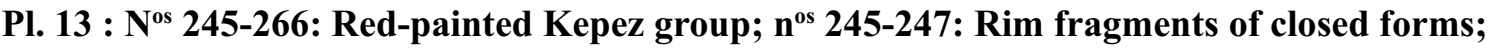
$n^{0}$ 248: A handle fragment of a closed form; $n^{\text {os }}$ 256-266: Body fragments of closed forms; $n^{\text {os }}$ 267-272:

Late Hellenistic-Early Roman gray ware; ${ }^{\text {os }}$ 267-269: Bowl form 1; ${ }^{\text {os }}$ 270-271: Bowl form 2; and $\mathrm{n}^{\circ}$ 272: Dish form 1. 
251. ( $\mathrm{N}^{\circ} 791$ ): Body fragment; Kimistene, Acropolis, southern slope, just below of the summit of Deresemail creek, found in 2005.

pl. 32/251.

Max. h $2.5 \mathrm{~cm}$., max. w $2.6 \mathrm{~cm}$., max. th $0.5 \mathrm{~cm}$.

Very pale brown (10YR 8/3) slip on exterior; yellowish red (5YR 5/6) on exterior slip. Reddish yellow (7.5YR $7 / 6$ ) unslipped surface on interior. Hard, thin paste; very sparsely porous, fine, pink (7.5YR 7/3) fabric with some sand and tiny lime inclusions. 2005 .

252. ( $\mathrm{N}^{\mathrm{o}}$ 1240): Body fragment; Kepez, found in

pl. 32/252.

Max. h $2.4 \mathrm{~cm}$., max. w $3.1 \mathrm{~cm}$., max. th $0.5 \mathrm{~cm}$.

Red (10R 5/8) slip on upper exterior. Its below part has a reddish yellow (5YR 7/6) unslipped surface. Pink (7.5YR 7/4) unslipped surface on interior. Hard, thin paste; non-porous, fine, reddish yellow (5YR 6/6) fabric with occasional small lime inclusions.

253. ( $\mathrm{N}^{\circ}$ 1174): Body fragment; Kepez, Cistern, found in 2005 .

pl. 32/253.

Max. h $1.6 \mathrm{~cm}$., max. w $3.2 \mathrm{~cm}$., max. th $0.5 \mathrm{~cm}$.

Red (10R 5/8) slip on exterior; reddish yellow (5YR $7 / 6$ ) unslipped surface on interior. A band in pinkish white (5YR 8/2) on exterior slip. Hard, non-porous, thin paste; reddish yellow (5YR 6/6) fabric with some small grit inclusions.

254. ( $\mathrm{N}^{\circ}$ 1411): Body fragment; Kepez, surface find, found in 2005 .

pl. 32/254.

Max. h $1.4 \mathrm{~cm}$., max. w $4.0 \mathrm{~cm}$., max. th $0.6 \mathrm{~cm}$.

Red (10R 5/6) slip on exterior; pink (7.5YR 7/4) unslipped surface on interior. Two bands in weak red (10R $4 / 2$ ) and white (5YR 8/1) on exterior slip. Hard, very sparsely porous, thin paste; reddish yellow (5YR 6/6) and light reddish brown (10YR 6/4) fabric with some sand, rare tiny lime inclusions.

255. ( $\mathrm{N}^{\mathrm{o}}$ 1038): Body fragment; Kepez, found in 2005

pl. 32/255.

Max. h $3.5 \mathrm{~cm} ., \max .2 .7 \mathrm{~cm}$., $\max$. th $0.6 \mathrm{~cm}$.

Red (2.5YR 4/6) slip on exterior; light brown (7.5YR 6/4) unslipped surface on interior. A band in light brown (7.5YR 6/4) on slip. Average hardness; thin paste; nonporous, fine, brown (7.5YR 4/4) fabric with some lime and sand inclusions.
256. ( $\mathrm{N}^{\circ} 1409$ ): Body fragment; Kepez, surface find, found in 2005.

pl. 13/256 and pl. 32/256.

Max. h $3.4 \mathrm{~cm}$. , max. w $2.9 \mathrm{~cm}$., max. th $0.6 \mathrm{~cm}$.

Grooves on neck ${ }^{44}$; pink (5YR 8/3) slip on exterior; pink (5YR 7/4) unslipped surface on interior. Three bands in black (7.5YR 2.5/1) and red (2.5YR 5/6) on exterior. Shallow grooves on the surface. Hard, thin paste; nonporous, fine, yellowish red (5YR 5/6) fabric with some sand, tiny lime inclusions.

257. ( No 523): Body fragment; Kimistene, Acropolis, southern slope, just below of the summit of Deresemail creek, found in 2005.

pl. $13 / 257$ and pl. $32 / 257$.

Max. h $3.5 \mathrm{~cm}$., max. w $3.1 \mathrm{~cm}$., max. th $0.7 \mathrm{~cm}$.

Red (10R 5/8) slip on upper exterior; light reddish brown (2.5YR 6/4) unslipped surface on interior. Two bands in pinkish white (7.5YR 8/2) on exterior slip. Hard, thin paste; non-porous, fine, reddish yellow (5YR 6/6) fabric with frequent tiny lime inclusions.

258. ( $\mathrm{N}^{\circ}$ 1327): Body fragment; Kimistene, Acropolis, southern slope, just below of the summit of Deresemail creek, found in 2005 .

pl. $13 / 258$ and pl. $32 / 258$.

Max. h $3.5 \mathrm{~cm}$. , max. w $3.1 \mathrm{~cm}$., max. th $0.7 \mathrm{~cm}$.

Red (2.5YR 4/6) slip on exterior; reddish yellow (7.5YR 7/6) unslipped surface on interior. Three bands in dusky red (2.5YR 3/2) and pinkish white (7.5YR 8/2) on exterior. Hard, thin paste; non-porous, fine, light brown (7.5YR 6/4) fabric with some tiny lime and sand inclusions.

259. (No 1468): Body fragment; Kimistene, Acropolis, southern slope, just below of the summit of Deresemail creek, found in 2005.

pl. 32/259.

Max. h $3.2 \mathrm{~cm}$., max. w $3.6 \mathrm{~cm}$., $\max$. th $0.7 \mathrm{~cm}$.

Red (2.5YR 5/8) slip on exterior; reddish yellow (5YR 7/6) unslipped surface on interior. Hard, thin paste; very sparsely porous, fine, light red (2.5YR 6/8) fabric with frequent tiny lime and rare sand inclusions.

260. ( $\mathrm{N}^{\circ}$ 1012): Body fragment; Kepez, found in 2005.

pl. 32/260.

Max. h 3.7 cm., max. w $3.6 \mathrm{~cm}$., max. th $0.6 \mathrm{~cm}$.

Reddish brown (5YR 5/4) slip on exterior; pink (7.5YR 7/4) unslipped surface on interior. Hard, thin paste; non-porous, fine, reddish yellow (7.5YR 6/6) fabric with frequent tiny lime inclusions. 
261. (No 890): Body fragment; Kimistene, Acropolis, southern slope, underground cave (cistern?), surface find, found in 2005 .

pl. 32/261.

Max. h $3.5 \mathrm{~cm}$., max. w $4.0 \mathrm{~cm}$., max. th $0.5 \mathrm{~cm}$.

Red $(2.5$ YR $5 / 6)$ shiny slip on exterior; very pale brown (10YR 8/4) unslipped surface on interior. Hard, thin paste; non-porous, fine, light brown (7.5YR 6/4) fabric with occasional tiny lime inclusions.

262. ( $\left.\mathrm{N}^{\circ} 1199\right)$ : Body fragment; Kepez, Cistern, found in 2005 .

pl. 32/262.

Max. h $3.2 \mathrm{~cm}$., max. w $4.0 \mathrm{~cm}$., $\max$. th $1.2 \mathrm{~cm}$.

Red (2.5YR 5/6) slip on exterior; reddish yellow (7.5YR 7/6) unslipped surface on interior. Two bands in weak red (2.5YR 4/2) and pinkish white (7.5YR 8/2) on exterior slip. Average hardness; porous, thin paste; fine, reddish yellow (5YR 6/6) fabric with some micaceous inclusions.

263. ( $\mathrm{N}^{\mathrm{0}}$ 1356): Body fragment; Kimistene, Cistern, eastern slope, found in 2005.

pl. 32/263.

Max. h 4.5 cm., max. w $4.0 \mathrm{~cm}$., max. th $0.8 \mathrm{~cm}$.

Red (2.5YR 5/6) slip on exterior; reddish yellow (7.5YR 7/6) unslipped surface on interior. Hard, thin paste; sparsely porous, fine, reddish yellow (5YR 6/6) fabric with frequent tiny lime and calsite inclusions.

264. (No 996): Body fragment; Kepez, found in 2005. pl. 13/264 and pl. 32/264.

Max. h $3.0 \mathrm{~cm}$., max. w $5.2 \mathrm{~cm}$., max. th $0.7 \mathrm{~cm}$.

Yellowish red (5YR 5/6) slip on exterior; very pale brown (10YR 7/4) unslipped surface on interior. Two bands in reddish brown (5YR 4/4) and pinkish white (7.5YR 8/2) on exterior slip. Average hardness; nonporous, thin paste; fine, light brown (7.5YR 6/4) fabric with some tiny lime and rare sand inclusions. 2005 .

265. ( $\mathrm{N}^{\mathrm{0}}$ 1008): Body fragment; Kepez, found in pl. 32/265.

Max. h $3.6 \mathrm{~cm}$., max. w $4.6 \mathrm{~cm}$., max. th $0.6 \mathrm{~cm}$.

Reddish brown (5YR 5/4) slip on exterior; light brown (7.5YR 6/4) unslipped surface on interior. A band in reddish yellow (7.5YR 6/6) on exterior slip. Hard, thin paste; very sparsely porous, brown (7.5YR 5/4) and reddish brown (5YR 5/4) fabric with rare tiny lime inclusions.
266. ( $\mathrm{N}^{\circ} 1163$ ): Body fragment; Kepez, Cistern, found in 2005 .

pl. $13 / 266$ and pl. $32 / 266$.

Max. h $5.3 \mathrm{~cm}$., max. w $5.7 \mathrm{~cm}$., max. th $0.8 \mathrm{~cm}$.

Brown (7.5YR 4/3) shiny slip on upper exterior; brown (7.5YR 5/4) matt slip on lower exterior. Light brown (7.5YR 6/4) unslipped surface on interior. Three bands in pinkish white (7.5YR 8/2) and dusky red (2.5YR $3 / 2$ ) on exterior. Hard, thin paste; very sparsely porous, fine, reddish yellow (7.5YR 6/6) fabric with frequent tiny lime inclusions.

\section{Late Hellenistic-Early Roman Gray Ware (pls. 13-16, $\mathrm{n}^{\text {os }}$ 267-307)}

In the Hellenistic period at Gordion nearly $75 \%$ of all vessels are gray ${ }^{45}$ and gray vessels appear in every general functional categories. ${ }^{46}$ At Hadrianopolis the earliest Roman fineware is represented by the gray ware (as well as brown-slipped ware), dating between the $1^{\text {st }}$ century B.C. to the $2^{\text {nd }}$ century A.D. (i.e., for proto-sigillata phase) which was almost exclusively locally produced, following the Late Iron Age (so-called 'Phrygian') tradition in production technics, i.e. manufacture as well as in the development of types. S. Mitchell believed there was no Hellenistic phase at Hadrianopolis ${ }^{47}$; but we have a few Late Hellenistic pottery sherds (i.e from the $1^{\text {st }}$ century B.C.) from Hadrianopolis. Through these finds it is possible to construct the first settlement at Hadrianopolis in the $1^{\text {st }}$ century B.C. Since Kimistene and other nearby settlements in Hadrianopolis's chora also yielded pottery of the Bronze and Iron Ages, it is surprizing to observe the physical similarity in appearance between Late Hellenistic-Early Roman gray ware in Hadrianopolis and earlier gray wares in its chora. During the Byzantine period there is a certain gray ware tradition in the region as well. The most important difference between this later gray ware and Late Hellenistic ones is speed of the wheel and its traces on the surface.

The paste of this ware is gray (10YR 5/1-6/1, $2.5 \mathrm{Y} 5 / 1-6 / 1$, Gley $15 / \mathrm{N})$, dark gray $(10 \mathrm{YR} 4 / 1$, $2.5 \mathrm{Y} 4 / 1$, Gley $14 / \mathrm{N})$, very dark gray $($ Gley $13 / \mathrm{N})$, grayish brown (10YR 5/2), black (Gley $12.5 / \mathrm{N}$ ), bluish gray (Gley $25 / 5 \mathrm{~PB})$, pale brown (10YR 6/3) and light brown (7.5YR 6/4). Fine and hard paste. Bad fired samples are mottled in gray, brown or dark grayish brown. Some samples have no inclusions; some of them have mica, lime and sand in medium sizes on their surface. Its fabric is similar to local 
sigillata of our study region. Slip is close to metallic tones, such as very dark gary (10YR 3/1, 2.5Y 3/1, Gley $13 / \mathrm{N})$, dark gray (10YR 4/1, 2.5Y 4/1, Gley 1 $4 / \mathrm{N})$, gray $(10 \mathrm{YR} 5 / 1,2.5 \mathrm{Y} 5 / 1-6 / 1$, Gley $16 / \mathrm{N})$, black $(2.5 \mathrm{Y} 2.5 / 1$, Gley $12.5 / \mathrm{N})$, dark reddish gray (5YR 4/2), grayish brown (10YR 5/2) and dark grayish brown (2.5Y 4/2). Slip had been applied in dipping position and in careless manner. Wall thickness differs between 0.3-1.4 cms. Most of the open vessels belong to a certain plate form.

55 sherds in total were collected; 26 of which are belonging to open and 29 to closed forms. Most of them were found at Hadrianopolis (22 from domus, 10 from the Bath A, 8 from the Bath B, 8 from western tomb and 2 from the absidal building) as well as Kimistene, Kepez and Boncuklar. This group of vessels could also be associated with grave traditions.

They could be dated between the $1^{\text {st }}$ century B.C. to $2^{\text {nd }}$ century A.D.

Open Forms (pls. 13-15, nos 267-289)

Bowl Form 1 (pl. 13, nos 267-269)

An incurved rim bowl form.

267. ( $\mathrm{N}^{\circ} 110$ ): Rim fragment; Bath B, Room 6, found in 2007.

pl. $13 / 267$.

Max. h 3.7 cm., max. w $4.2 \mathrm{~cm}$., max. th $0.3 \mathrm{~cm}$.

Dark gray (10YR 4/1) slip on exterior; very dark gray (Gley 13/N) slip on interior. Hard, thin paste; non-porous, fine, dark gray $(2.5 \mathrm{Y} 4 / 1)$ fabric with rare micaceous inclusion.

268. ( $\mathrm{N}^{\circ} 100$ ): Rim fragment; Bath $\mathrm{B}$, Room 6 , found in 2007.

pl. 13/268.

Max. h $3.1 \mathrm{~cm}$., max. w $4.6 \mathrm{~cm}$., max. th $0.5 \mathrm{~cm}$.

Very dark gray (Gley $13 / \mathrm{N})$ slip on exterior; very dark gray (2.5Y $3 / 1)$ slip on interior. Hard, thin paste; nonporous, fine, gray (10YR 5/1) fabric with rare lime inclusion.

269. (No 1208): Rim fragment; Kimistene, summit of the Acropolis, southern slope, found in 2005.

pl. 13/269.

Max. h $2.0 \mathrm{~cm}$., d of rim $14.8 \mathrm{~cm}$., max. w $4.8 \mathrm{~cm}$., $\max$. th $0.5 \mathrm{~cm}$.

Very dark gray $(2.5 \mathrm{Y} 3 / 1)$ slip on exterior and interior. Hard, non-porous, thin paste; brown $(7.5 \mathrm{YR} 5 / 3)$ and grayish brown (10YR 5/2) fabric with some micaceous inclusion.
Bowl Form 2 (pl. 13, n $\left.{ }^{\text {os }} 270-271\right)$

Outcurved rim bowl.

270. ( $\mathrm{N}^{\circ}$ 424): Rim fragment; apsidial building, found in 2007.

pl. 13/270.

Max. h $2.6 \mathrm{~cm}$. , d of rim $11.0 \mathrm{~cm}$., max. w $3.5 \mathrm{~cm}$, max. th $0.3 \mathrm{~cm}$.

Black (Gley $12.5 / \mathrm{N}$ ) slip on all of the surface. Hard, thin paste; non-porous, fine, light brown (7.5YR 6/4) fabric with no visible inclusion.

271. ( No 157): Rim fragment; domus, found in 2007. pl. 13/271.

Max. h $2.1 \mathrm{~cm}$. , d of rim $13.4 \mathrm{~cm}$., max. w $4.2 \mathrm{~cm}$., $\max$. th $0.3 \mathrm{~cm}$.

Dark gray (Gley $14 / \mathrm{N})$ slip on upper exterior; its below part and interior are slipped in gray (Gley $16 / \mathrm{N})$. Hard, thin paste; very sparsely porous, fine, gray (Gley 1 $5 / \mathrm{N}$ ) fabric with no visible inclusion.

Dish Form 1 (pls. 13-14, $\mathrm{n}^{\text {os }}$ 272-275)

Dull slipped.

272. ( $\left.\mathrm{N}^{\circ} 425\right)$ : Rim fragment; apsidial building, found in 2007.

pl. $13 / 272$.

Max. h $2.8 \mathrm{~cm}$., max. w $4.8 \mathrm{~cm}$., max. th $0.5 \mathrm{~cm}$.

Gray $(2.5 \mathrm{Y} 5 / 1)$ slip on exterior and interior. Hard, non-porous, thin paste; fine, gray $(2.5 \mathrm{Y} 6 / 1)$ fabric with no visible inclusions.

273. (No 158): Rim fragment; domus, found in 2007. pl. 14/273.

Max. h $3.4 \mathrm{~cm}$., d of rim $15.5 \mathrm{~cm}$., max. w $7.5 \mathrm{~cm}$., $\max$. th $0.4 \mathrm{~cm}$.

Gray (2.5Y 5/1) slip on exterior; dark gray (Gley 1 $4 / \mathrm{N})$ slip on interior. Hard, thin paste; very sparsely porous, fine, gray (10YR 6/1) fabric with no visible inclusions.

274. (№ 58): Rim fragment; domus, room 6 , level 1 , found in 2007.

pl. 14/274.

Max. h 3.9 cm., d of rim $20.8 \mathrm{~cm}$., max. w $9.1 \mathrm{~cm}$., max. th $0.6 \mathrm{~cm}$.

Dark gray (2.5Y 4/1) slip on exterior; gray (2.5Y 5/1) slip on interior. Hard, thin paste; very sparsely porous, fine, gray $(2.5 \mathrm{Y} 5 / 1)$ fabric with rare tiny lime inclusions. 

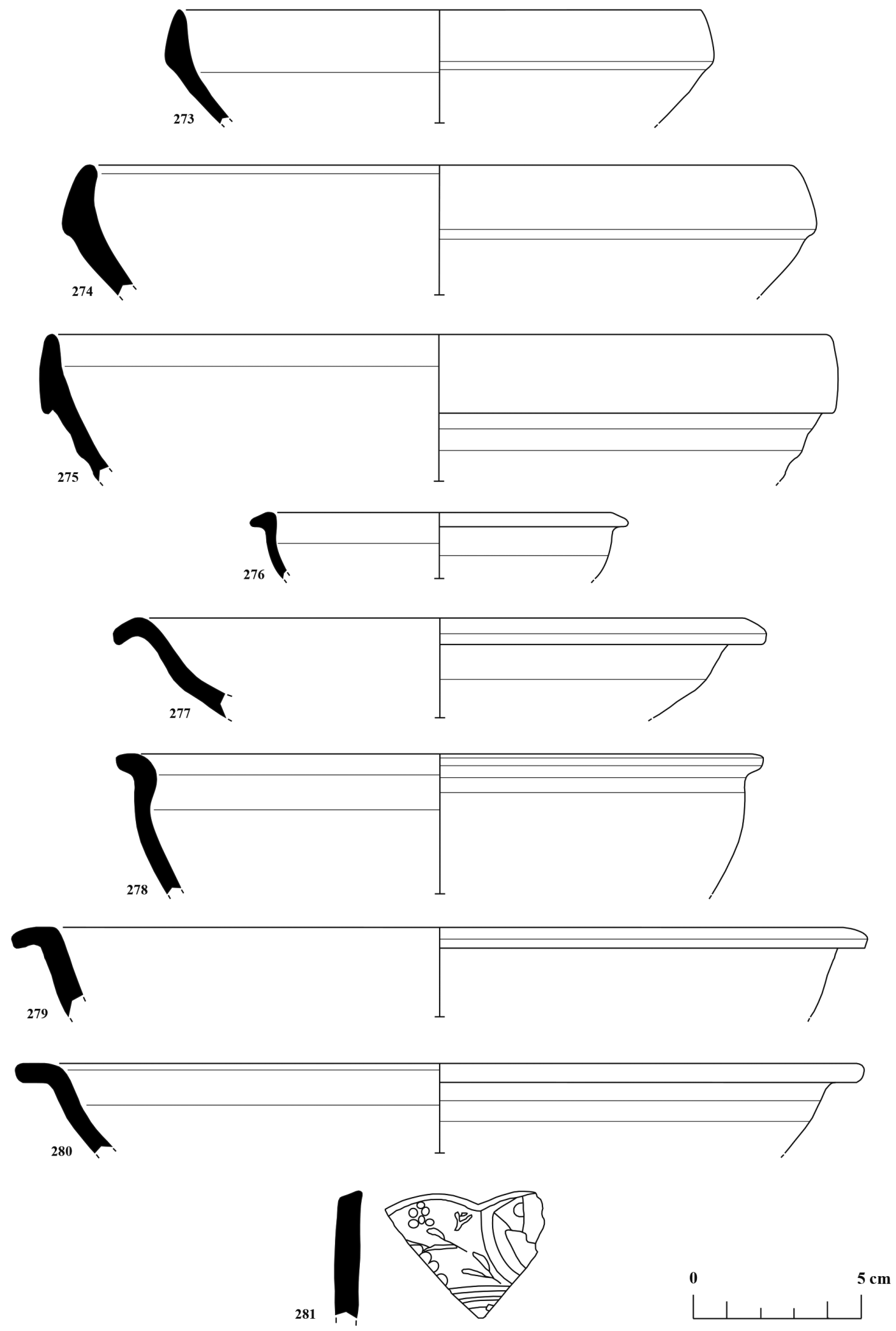

Pl. 14 : Nos 273-281: Late Hellenistic-Early Roman gray ware; $\mathbf{n}^{\text {os }}$ 273-275: Dish form 1; $n^{\text {os }}$ 276-280: Dish form 2; and no. 281: A rim fragment of a plate. 
275. ( $\mathrm{N}^{\circ} 251$ ): Rim fragment; western tomb, found 2007.

pl. 14/275.

Max. h $4.4 \mathrm{~cm}$. , d of rim $25.0 \mathrm{~cm}$., max. w $6.8 \mathrm{~cm}$., max. th $0.5 \mathrm{~cm}$.

Dark gray (Gley $14 / \mathrm{N})$ slip on exterior; very dark gray $(2.5 \mathrm{Y} 3 / 1)$ slip on interior. Hard, thin paste; very sparsely porous, brown (10YR 4/3) and dark gray (10YR 4/1) fabric with rare tiny lime inclusions.

Dish Form 2 (pl. 14, nos 276-280)

A downcurved rim dish. 2007.

276. ( $\mathrm{N}^{\circ} 249$ ): Rim fragment; western tomb, found

pl. 14/276.

Max. h $2.0 \mathrm{~cm}$., d of rim $10.2 \mathrm{~cm}$., max. w $5.3 \mathrm{~cm}$., max. th $0.3 \mathrm{~cm}$.

Dark gray (2.5Y 4/1) slip on exterior and interior. Average hardness; thin paste; very sparsely porous, fine, dark gray $(2.5 \mathrm{Y} 4 / 1)$ fabric with rare sand inclusions. 2007.

277. ( No 248): Rim fragment; western tomb, found in pl. 14/277.

Max. h $3.0 \mathrm{~cm}$. , d of rim $18.0 \mathrm{~cm}$., max. w $5.3 \mathrm{~cm}$., max. th $0.6 \mathrm{~cm}$.

Black (Gley $12.5 / \mathrm{N}$ ) slip on the exterior; dark reddish gray (5YR 4/2) slip on the interior. Hard, thin paste; nonporous, fine, gray (10YR 5/1) and dark grayish brown (10YR 4/2) fabric with rare tiny lime inclusion.

278. ( $\mathrm{N}^{\circ} 250$ ): Rim fragment; western tomb, found 2007.

pl. 14/278.

Max. h $4.2 \mathrm{~cm}$. , d of rim $18.4 \mathrm{~cm}$., max. w $3.4 \mathrm{~cm}$, max. th $0.5 \mathrm{~cm}$.

Black (Gley $12.5 / \mathrm{N}$ ) slip on exterior; very dark gray (Gley $13 / \mathrm{N}$ ) slip on interior. Hard, thin paste; non-porous, fine, dark gray (Gley $14 / \mathrm{N}$ ) fabric with occasional tiny lime inclusions.

279. (No 354): Rim fragment; monumental tomb, found in 2007.

pl. 14/279.

Max. h 2.7 cm., d of rim $24.0 \mathrm{~cm}$., max. w $6.6 \mathrm{~cm}$., $\max$. th $0.7 \mathrm{~cm}$.

Dark gray $(2.5 \mathrm{Y} 4 / 1)$ slip on exterior; very dark gray $(2.5 \mathrm{Y} 3 / 1)$ slip on interior. Hard, thin paste; very sparsely porous, fine, gray $(2.5 \mathrm{Y} 5 / 1)$ fabric with rare tiny lime inclusions.

280. ( $\mathrm{N}^{\circ} 196$ ): Rim fragment; Bath $\mathrm{A}$, room 5 , found in 2006 .

pl. 14/280.

Max. h 2.7 cm., d of rim 24.8 cm., max. w $5.8 \mathrm{~cm}$., max. th $0.3 \mathrm{~cm}$.
Very dark gray (Gley $13 / \mathrm{N}$ ) slip on the exterior and interior. Hard, thin paste; very sparsely porous, fine, bluish gray (Gley 2 5/5PB) fabric with no visible inclusion.

Rim Fragment of a Plate (pl. 14, nº 281)

Mottled exterior.

281. ( $\left.\mathrm{N}^{\circ} 254\right)$ : Rim fragment; western tomb, found 2007.

pl. 14/281.

Max. h $3.8 \mathrm{~cm}$., max. w $4.8 \mathrm{~cm}$., max. th $0.7 \mathrm{~cm}$.

Very dark gray (Gley $13 / \mathrm{N}$ ) slip on exterior; very dark gray $(2.5 \mathrm{Y} 3 / 1)$ slip on interior. Hard, thin paste; very sparsely porous, fine, gray (10YR 5/1) fabric with occasional sand inclusions.

\section{Base Fragments of Open Forms (pl. 15, $\mathrm{n}^{\text {os }} 282-289$ )}

Most of them have a shallow form. Their dimensions differ between 10.4 and $35.6 \mathrm{~cm}$.

282. ( $\left.\mathrm{N}^{\circ} 216\right)$ : Base fragment; Bath $\mathrm{A}$, room 1 , found 2006.

pl. 15/282.

Max. h $0.8 \mathrm{~cm}$., max. w $5.2 \mathrm{~cm}$., max. th $0.6 \mathrm{~cm}$.

Very dark gray (Gley $13 / \mathrm{N}$ ) slip on exterior and interior. Hard, thin paste; very sparsely porous, fine, gray (Gley $15 / \mathrm{N}$ ) fabric with some sand inclusions.

283. ( $\mathrm{N}^{\circ} 29$ ): Base fragment; domus, room 1 , level 1 , illegally excavated area, found in 2007.

pl. 15/283.

Max. h $2.5 \mathrm{~cm}$., d of base $10.4 \mathrm{~cm}$., max. w $3.2 \mathrm{~cm}$., max. th $0.7 \mathrm{~cm}$.

Grayish brown (10YR 5/2) slip on exterior; gray (10YR 5/1) slip on interior. Hard, thin paste; non-porous, fine, grayish brown (10YR 5/2) fabric with rare tiny lime inclusions.

284. ( $\mathrm{N}^{\circ} 151$ ): Base fragment; domus, found in 2007. pl. 15/284.

Max. h $2.7 \mathrm{~cm}$., d of base $13.6 \mathrm{~cm}$., max. w $6.7 \mathrm{~cm}$., $\max$. th $0.6 \mathrm{~cm}$.

Gray $(2.5 \mathrm{Y} 5 / 1)$ and very dark gray $(2.5 \mathrm{Y} 3 / 1)$ mottled slip on exterior; dark gray $(2.5 \mathrm{Y} 4 / 1)$ slip on interior. Hard, thin paste; non-porous, fine, gray (2.5Y 5/1) fabric with rare tiny lime and micaceous inclusions.

285. (№ 3): Base fragment; domus, room 1 , level 1 , found in 2007.

pl. 15/285.

Max. h $2.0 \mathrm{~cm}$., d of base $30.6 \mathrm{~cm}$., max. w $4.5 \mathrm{~cm}$., max. th $0.6 \mathrm{~cm}$.

Very dark gray (Gley $13 / \mathrm{N}$ ) slip on exterior and interior. Hard, thin paste; very sparsely porous, fine, dark 
282
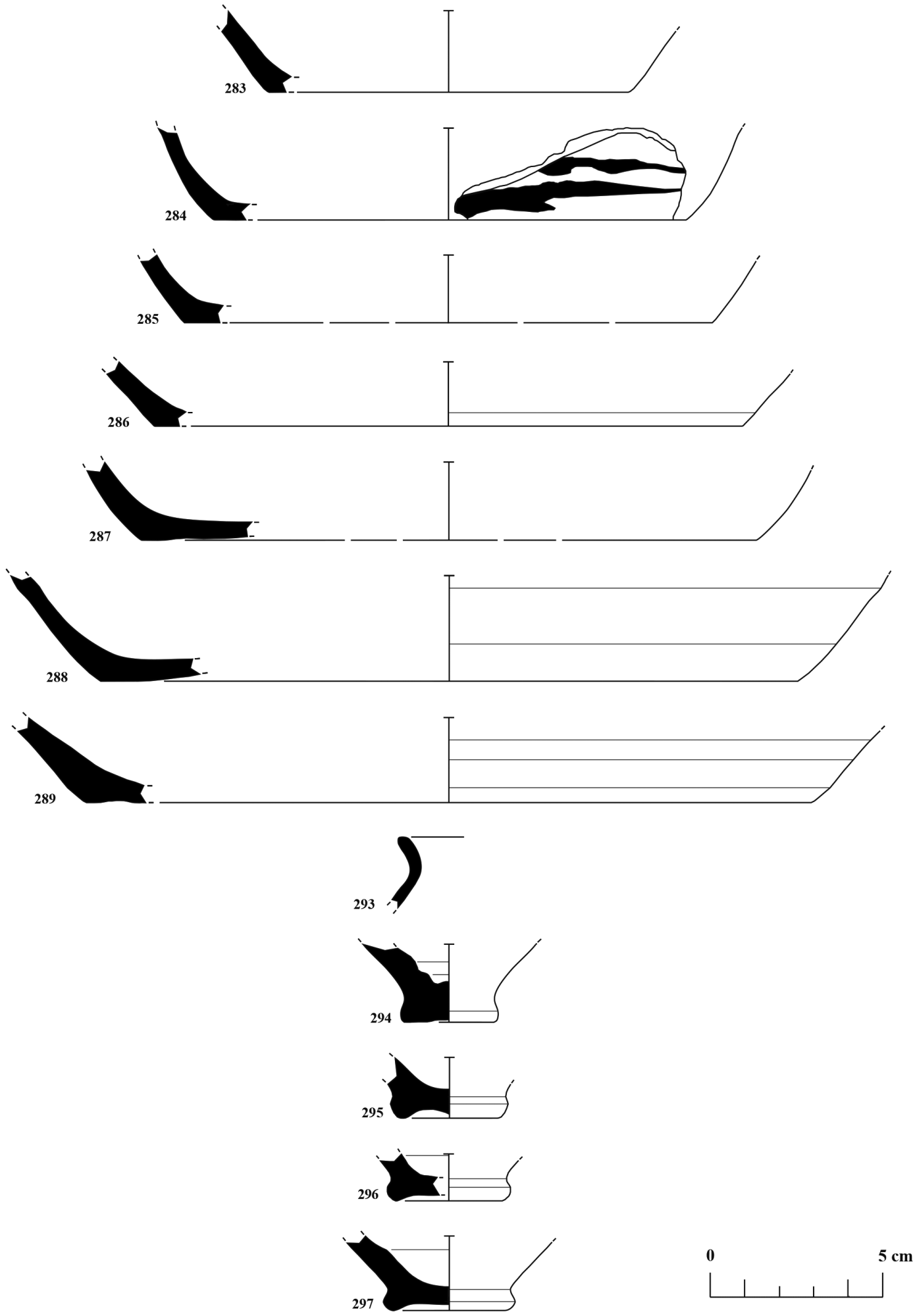

Pl. 15 : $\mathbf{N}^{\text {os }}$ 282-297: Late Hellenistic-Early Roman gray ware; $\mathbf{n}^{\text {os }}$ 282-289: Base fragments of open forms; no. 293: A rim fragment of a juglet; and $n^{\text {os }}$ 294-297: Base fragments of closed forms. 
gray $(2.5 \mathrm{Y} 4 / 1)$ fabric with occasional tiny lime inclusions.

286. ( $\left.\mathrm{N}^{\circ} 154\right)$ : Base fragment; domus, found in 2007. pl. 15/286.

Max. h $1.9 \mathrm{~cm}$., d of base $17.0 \mathrm{~cm}$., max. w $4.6 \mathrm{~cm}$., max. th $0.8 \mathrm{~cm}$.

Very dark gray (2.5Y 3/1) slip on exterior; dark gray $(2.5 \mathrm{Y} 4 / 1)$ slip on interior. Hard, thin paste; very sparsely porous, fine, gray $(2.5 Y 5 / 1)$ fabric with rare tiny lime inclusions.

287. ( $\left.\mathrm{N}^{\circ} 4\right)$ : Base fragment; domus, room 1, level 1, found in 2007 .

pl. 15/287.

Max. h $2.3 \mathrm{~cm}$., d of base $35.6 \mathrm{~cm}$., max. w $5.5 \mathrm{~cm}$., $\max$. th $0.7 \mathrm{~cm}$.

Dark gray (2.5Y 4/1) slip on exterior; gray (2.5Y 5/1) slip on interior. Hard, thin paste; very sparsely porous, fine, gray $(2.5 \mathrm{Y} 5 / 1)$ fabric with rare tiny lime inclusions.

288. ( $\left.\mathrm{N}^{\circ} 5\right)$ : Base fragment; domus, room 1, level 1, found in 2007.

pl. $15 / 288$.

Max. h $3.1 \mathrm{~cm}$., d of base $20.2 \mathrm{~cm}$., max. w $2.3 \mathrm{~cm}$., max. th $0.3 \mathrm{~cm}$.

Dark gray (2.5Y 4/1) slip on exterior; gray (2.5Y 5/1) slip on interior. Hard, thin paste; very sparsely porous, fine, gray $(2.5 \mathrm{Y} 5 / 1)$ fabric with rare tiny lime inclusions.

289. ( $\mathrm{N}^{\circ} 287$ ): Base fragment; domus, room 6 , level 1 , found in 2007.

pl. 15/289.

Max. h $2.5 \mathrm{~cm}$., d of base $21.0 \mathrm{~cm}$., max. w $5.3 \mathrm{~cm}$., $\max$. th $1.0 \mathrm{~cm}$.

Dark gray $(2.5 \mathrm{Y} 4 / 1)$ slip on exterior and interior. Hard, thin paste; non-porous, fine, gray (10YR 5/1) fabric with rare tiny lime inclusions.

\section{Body Fragments of Open Forms}

Undecorated fragments.

290. ( $\mathrm{N}^{0} 54$ ): Body fragment; domus, room 6 , level 1 , found in 2007.

Max. h $2.6 \mathrm{~cm}$., max. w $4.0 \mathrm{~cm}$., max. th $0.9 \mathrm{~cm}$.

Black (Gley $12.5 / \mathrm{N}$ ) slip on exterior and interior. Hard, thin paste; non-porous, fine, pale brown (10YR 6/3) fabric with no visible inclusions.

291. ( $\mathrm{N}^{\circ}$ 1378): Body fragment; Kepez, Necropolis, found 2005 .

Max. h $4.1 \mathrm{~cm}$., max. w $3.8 \mathrm{~cm}$., max. th $0.5 \mathrm{~cm}$.

Light brownish gray (10YR 6/2) unslipped surface on exterior; black (Gley $12.5 / \mathrm{N}$ ) slip on interior. Hard, thin paste; non-porous, brown (7.5YR 5/2) and very dark gray (Gley $13 / \mathrm{N}$ ) fabric with rare micaceous inclusions.

292. ( $\mathrm{N}^{\circ} 155$ ): Body fragment; domus, found in 2007. Max. h $3.6 \mathrm{~cm}$., max. w $7.5 \mathrm{~cm}$., max. th $0.7 \mathrm{~cm}$.

Dark gray $(2.5 \mathrm{Y} 4 / 1)$ and dark gray (Gley $14 / \mathrm{N})$ mottled slip both on exterior and interior. Hard, thin paste; very sparsely porous, fine, dark gray $(2.5 \mathrm{Y} 4 / 1)$ fabric with no visible inclusions.

Closed Forms (pls. 15-16, nos 293-307)

Rim Fragment of a Juglet (pl. 15, n² 293)

293. ( $\mathrm{N}^{\circ} 230$ ): Rim fragment; Bath $\mathrm{A}$, room 13 , found 2006.

pl. 15/293.

Max. h $2.1 \mathrm{~cm}$., max. w $2.3 \mathrm{~cm}$., max. th $0.3 \mathrm{~cm}$.

Very dark gray (2.5Y 3/1) slip on exterior; dark gray $(2.5 \mathrm{Y} 4 / 1)$ slip on interior. Hard, thin paste; very sparsely porous, gray $(2.5 \mathrm{Y} 5 / 1)$ fabric with no visible inclusions.

\section{Base Fragments of Closed Forms (pls. 15-16, nos 294-306)}

They belong to small forms for some certain liquids. Some of them could be belonging to juglets or unguentaria. They are ring bases.

294. ( $\mathrm{N}^{\circ} 68$ ): Base fragment; domus, room 6 , level 1 , found in 2007.

pl. 15/294.

Max. h $2.3 \mathrm{~cm}$., d of base $2.6 \mathrm{~cm}$., max. w $4.3 \mathrm{~cm}$., $\max$. th $0.7 \mathrm{~cm}$.

Gray (2.5Y 6/1) unslipped surface on exterior and interior, Average hardness; thin paste; very sparsely porous, fine, gray $(2.5 \mathrm{Y} 5 / 1)$ fabric with no visible inclusions.

295. ( $\mathrm{N}^{\circ} 366$ ): Base fragment; Bath $\mathrm{B}$, room 8 , illegally excavated area, found in 2007.

pl. 15/295.

Max. h $1.8 \mathrm{~cm}$., d of base $2.8 \mathrm{~cm}$., max. w $3.5 \mathrm{~cm}$., $\max$. th $0.8 \mathrm{~cm}$.

Gray (2.5Y 6/1) slip on exterior; gray (2.5Y 6/1) unslipped surface on interior. Hard, thin paste; very sparsely porous, fine, gray $(2.5 \mathrm{Y} 5 / 1)$ fabric with no visible inclusions.

296. ( $\mathrm{N}^{\circ} 90$ ): Base fragment; Bath $\mathrm{B}$, Room 5, found in 2007.

pl. $15 / 296$.

Max. h $1.4 \mathrm{~cm}$., d of base $3.1 \mathrm{~cm}$., max. w $3.3 \mathrm{~cm}$., $\max$. th $0.6 \mathrm{~cm}$.

Gray (2.5Y 5/1) slip on exterior; gray (2.5Y 5/1) unslipped surface on interior. Hard, thin paste; non-porous, fine, dark gray (Gley $14 / \mathrm{N}$ ) fabric with no visible inclusions. 

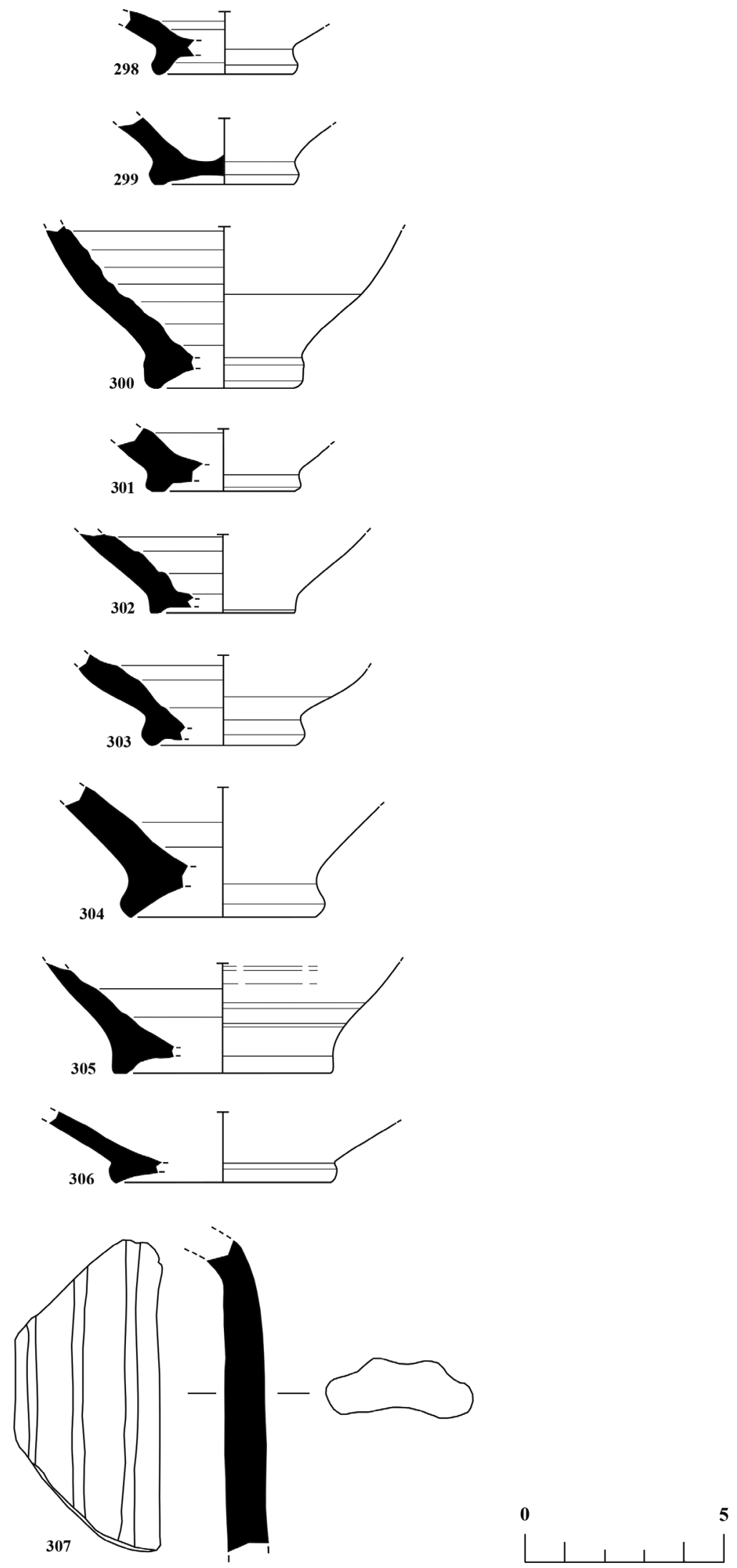

Pl. 16 : Nos 298-307: Late Hellenistic-Early Roman gray ware; $\mathbf{n}^{\text {os }}$ 298-306: Base fragments of closed forms; and $n^{0}$ 307: A handle fragment of a closed form. 
297. ( $\mathrm{N}^{\circ} 241$ ): Base fragment; western tomb, found 2007.

pl. 15/297.

Max. h $2.2 \mathrm{~cm}$., d of base $3.2 \mathrm{~cm}$., max. w $4.1 \mathrm{~cm}$., max. th $0.8 \mathrm{~cm}$.

Very dark gray (Gley $13 / \mathrm{N}$ ) slip on exterior; gray (2.5Y 6/1) unslipped surface on interior. Hard, thin paste; non-porous, fine, gray (2.5Y 5/1) fabric with no visible inclusions.

298. ( $\left.\mathrm{N}^{\circ} 92\right)$ : Base fragment; Bath $\mathrm{B}$, room 5 , found in 2007.

pl. 16/298.

Max. h $1.6 \mathrm{~cm}$., d of base $3.4 \mathrm{~cm}$., max. w $5.1 \mathrm{~cm}$., max. th $0.6 \mathrm{~cm}$.

Dark gray $(2.5 \mathrm{Y} 4 / 1)$ unslipped surface on exterior, gray $(2.5 \mathrm{Y} 5 / 1)$ unslipped surface on interior. Hard, thin paste; non-porous, fine, dark gray $(2.5 \mathrm{Y} 4 / 1)$ fabric with rare tiny lime inclusions.

299. ( $\left.N^{\circ} 107\right)$ : Base fragment; Bath $B$, room 6 , found in 2007.

pl. 16/299.

Max. h $1.7 \mathrm{~cm}$., d of base $3.5 \mathrm{~cm}$., max. w $4.8 \mathrm{~cm}$., max. th $0.6 \mathrm{~cm}$.

Dark gray (2.5Y 4/1) slip on exterior; dark gray (2.5Y 4/1) unslipped surface on interior. Hard, thin paste; nonporous, fine, dark gray $(2.5 \mathrm{Y} 4 / 1)$ fabric with no visible inclusions.

300. ( $\mathrm{N}^{\circ} 252$ ): Base fragment; western tomb, found 2007.

pl. 16/300.

Max. h $4.1 \mathrm{~cm}$., d of base $3.5 \mathrm{~cm}$., max. w $4.8 \mathrm{~cm}$., max. th $0.7 \mathrm{~cm}$.

Very dark gray (Gley $13 / \mathrm{N}$ ) slip on exterior; dark gray (Gley 14/N) unslipped surface on interior. Hard, thin paste; non-porous, fine, dark gray (Gley $14 / \mathrm{N})$ fabric with some tiny lime inclusions.

301. ( $\left.\mathrm{N}^{\circ} 8\right)$ : Base fragment; domus, room 1, level 1, found in 2007.

pl. 16/301.

Max. h $1.6 \mathrm{~cm}$., d of base $3.6 \mathrm{~cm}$., max. w $3.5 \mathrm{~cm}$., $\max$. th $0.8 \mathrm{~cm}$.

Gray $(2.5 \mathrm{Y} 6 / 1)$ unslipped surface on exterior; gray (2.5Y 5/1) unslipped surface on interior. Hard, thin paste; very sparsely porous, fine, dark gray $(2.5 \mathrm{Y} 4 / 1)$ fabric with rare tiny lime inclusions.

302. ( $\left.\mathrm{N}^{\circ} 36\right)$ : Base fragment; domus, room 6 , level 1 , found in 2007.

pl. 16/302.

Max. h $2.0 \mathrm{~cm}$., d of base $3.6 \mathrm{~cm}$., max. w $5.0 \mathrm{~cm}$., max. th $0.6 \mathrm{~cm}$.

Gray (2.5Y 5/1) slip on exterior; gray (2.5Y 6/1) unslipped surface on interior. Hard, thin paste; very sparsely porous, fine, gray $(2.5 \mathrm{Y} 5 / 1)$ fabric with rare micaceous inclusions.
303. ( $\left.\mathrm{N}^{\circ} 106\right)$ : Base fragment; Bath $\mathrm{B}$, room 6 , found in 2007.

pl. 16/303.

Max. h $2.3 \mathrm{~cm}$., d of base $3.6 \mathrm{~cm}$., max. w $5.1 \mathrm{~cm}$., $\max$. th $0.7 \mathrm{~cm}$.

Very dark gray (Gley $13 / \mathrm{N})$ slip on exterior; very dark gray (Gley $13 / \mathrm{N}$ ) unslipped surface on interior. Hard, thin paste; non-porous, fine, black (Gley $12.5 / \mathrm{N}$ ) fabric with some sand inclusions.

304. ( $\mathrm{N}^{\circ}$ 6): Base fragment; domus, room 1 , level 1 , found in 2007.

pl. 16/304.

Max. h $3.3 \mathrm{~cm}$. , d of base $4.6 \mathrm{~cm}$., max. w $4.4 \mathrm{~cm}$., $\max$. th $1.0 \mathrm{~cm}$.

Gray (2.5Y 5/1) slip on exterior; gray (2.5Y 6/1) unslipped surface on interior. Hard, thin paste; very sparsely porous, fine, dark gray $(2.5 \mathrm{Y} 4 / 1)$ fabric with rare micaceous inclusions.

305. (№ 37): Base fragment; domus, room 6 , level 1 , found in 2007.

pl. 16/305.

Max. h $2.8 \mathrm{~cm}$., d of base $5.4 \mathrm{~cm}$., max. w $5.5 \mathrm{~cm}$., max. th $0.6 \mathrm{~cm}$.

Black (Gley $12.5 / \mathrm{N}$ ) slip on exterior; dark gray (Gley $14 / \mathrm{N}$ ) unslipped surface on exterior and interior. Hard, thin paste; non-porous, fine, dark gray (Gley $14 / \mathrm{N})$ fabric with some tiny lime inclusions.

306. ( $\left.\mathrm{N}^{\circ} 174\right)$ : Base fragment; Domus, room 8 , floor level, found in 2007.

pl. 16/306.

Max. h $1.8 \mathrm{~cm}$. , d of base $5.4 \mathrm{~cm}$., max. w $4.5 \mathrm{~cm}$., $\max$. th $0.4 \mathrm{~cm}$.

Gray (10YR 6/1) unslipped surface on exterior; gray (2.5Y 6/1) unslipped surface on interior. Hard, thin paste; very sparsely porous, fine, gray $(2.5 \mathrm{Y} 5 / 1)$ fabric with no visible inclusions.

\section{A Handle Fragment of a Closed Form}

$$
\text { (pl. 16, n 307) }
$$

A rounded handle fragment of a small jug.

307. (No 371): Handle fragment; Bath $B$, room 6, illegally excavated area, found in 2007.

pl. 16/307.

Max. h 7.9 cm., max. w $3.7 \mathrm{~cm}$., max. th $1.4 \mathrm{~cm}$.

Dark gray (2.5Y 4/1) and gray (2.5Y 5/1) mottled slip on all of the surface. Hard, thin paste; very sparsely porous, fine, dark gray $(2.5 \mathrm{Y} 4 / 1)$ fabric with rare tiny lime inclusions. 


\section{Body Fragments of Closed Forms}

\section{Undecorated fragments ${ }^{48}$.}

308. ( $\mathrm{N}^{\circ} 214$ ): Body fragment; Bath A, room 1, found in 2006 .

Max. h $2.0 \mathrm{~cm}$., max. w $1.4 \mathrm{~cm}$., max. th $0.3 \mathrm{~cm}$.

Dark gray (Gley $14 / \mathrm{N})$ slip on exterior; gray $(2.5 \mathrm{Y}$ 6/1) unslipped surface on interior. Average hardness; thin paste; non-porous, fine, dark gray $(2.5 \mathrm{Y} 4 / 1)$ fabric with no visible inclusions.

309. ( $\mathrm{N}^{\circ} 473$ ): Body fragment; Bath $\mathrm{A}$, room $2 \mathrm{~b}$, found in 2006.

Max. h $2.6 \mathrm{~cm}$., max. w $2.5 \mathrm{~cm}$., max. th $0.3 \mathrm{~cm}$.

Very dark gray (2.5Y 3/1) slip on exterior; gray (2.5Y $5 / 1$ ) unslipped surface on interior. Hard, thin paste; very sparsely porous, fine, gray $(2.5 \mathrm{Y} 5 / 1)$ fabric with no visible inclusions.

310. ( $\mathrm{N}^{\circ} 211$ ): Body fragment; Bath $\mathrm{A}$, room 1, found in 2006 .

Max. h $2.5 \mathrm{~cm}$., max. w $2.9 \mathrm{~cm}$., max. th $0.4 \mathrm{~cm}$.

Black (Gley $12.5 / \mathrm{N}$ ) slip on exterior; very dark gray (Gley $13 / \mathrm{N}$ ) unslipped surface on interior. Hard, thin paste; non-porous, fine, very dark gray (Gley $13 / \mathrm{N}$ ) fabric with no visible inclusions.

311. ( $\left.\mathrm{N}^{\circ} 7\right)$ : Body fragment; domus, room 1, level 1 , found in 2007 .

Max. h $3.2 \mathrm{~cm}$., max. w $3.5 \mathrm{~cm}$., max. th $0.8 \mathrm{~cm}$.

Gray (2.5Y 6/1) slip on exterior; gray (2.5Y 6/1) unslipped surface on interior. Hard, thin paste; very sparsely porous, fine, gray $(2.5 \mathrm{Y} 5 / 1)$ fabric with some sand inclusions.

312. ( $\mathrm{N}^{\circ} 215$ ): Body fragment; Bath A, room 1, found in 2006.

Max. h $2.3 \mathrm{~cm}$., max. w $2.9 \mathrm{~cm}$., max. th $0.5 \mathrm{~cm}$.

Black (2.5Y 2.5/1) slip on exterior; light gray (2.5Y $7 / 1)$ unslipped surface on interior. Hard, thin paste; nonporous, fine, gray $(2.5 \mathrm{Y} 6 / 1)$ fabric with rare tiny lime inclusions.

313. ( $\left.\mathrm{N}^{\circ} 180\right)$ : Body fragment; domus, room 5 , found in 2007.

Max. h $3.6 \mathrm{~cm}$., max. w $3.5 \mathrm{~cm}$., max. th $0.6 \mathrm{~cm}$.

Very dark gray (10YR 3/1) slip on exterior; gray (2.5Y 6/1) unslipped surface on interior. Hard, thin paste; very sparsely porous, fine, gray $(2.5 \mathrm{Y} 5 / 1)$ fabric with rare tiny lime inclusions.

314. (No 894): Body fragment; Kimistene, Acropolis, southern slope, underground cave, surface find, found in 2005 .
Max. h $2.6 \mathrm{~cm}$., max. w $3.6 \mathrm{~cm}$., $\max$. th $0.6 \mathrm{~cm}$

Very dark gray (2.5Y 3/1) slip on exterior; gray (2.5Y $6 / 1$ ) unslipped surface on interior. Hard, thin paste; nonporous, fine, gray $(2.5 \mathrm{Y} 6 / 1)$ fabric with no visible inclusions.

315. ( $\mathrm{N}^{\mathrm{o}} 281$ ): Body fragment; Bath A, room 14 , found in 2006.

Max. h $2.9 \mathrm{~cm} ., \max$. w $4.1 \mathrm{~cm} ., \max$. th $0.5 \mathrm{~cm}$

Black (2.5Y 2.5/1) slip on exterior; gray (2.5Y 5/1) unslipped surface on interior. Hard, thin paste; nonporous, fine, dark gray $(2.5 \mathrm{Y} 4 / 1)$ fabric with occasional sand inclusions.

316. ( $\mathrm{N}^{\circ} 245$ ): Body fragment; western tomb, found in 2007.

Max. h $4.4 \mathrm{~cm}$. , max. w $2.6 \mathrm{~cm}$. , max. th $0.3 \mathrm{~cm}$

Very dark gray (Gley $13 / \mathrm{N})$ slip on exterior; gray (2.5Y 6/1) unslipped surface on interior. Hard, thin paste; non-porous, dark gray $(2.5 \mathrm{Y} 4 / 1)$ and gray $(2.5 \mathrm{Y} 5 / 1)$ fabric with no visible inclusions.

317. ( $\mathrm{N}^{\circ}$ 285): Body fragment; Bath A, room 14, found in 2006.

Max. h $2.7 \mathrm{~cm}$., $\max$. w $5.0 \mathrm{~cm}$., $\max$. th $0.4 \mathrm{~cm}$

Dark grayish brown (2.5Y 4/2) slip on upper exterior; dark gray (2.5Y 4/1) unslipped surface on interior. Hard, thin paste; very sparsely porous, dark gray $(2.5 \mathrm{Y} 4 / 1)$ fabric with rare tiny lime inclusions.

318. ( $\left.\mathrm{N}^{\mathrm{o}} 217\right)$ : Body fragment; Bath $\mathrm{A}$, room 1, found in 2006.

Max. h $3.1 \mathrm{~cm}$. , max. w $4.9 \mathrm{~cm}$., $\max$. th $0.6 \mathrm{~cm}$.

Dark gray (2.5Y 4/1) slip on exterior; gray (2.5Y 6/1) unslipped surface on interior. Hard, thin paste; nonporous, fine, gray $(2.5 \mathrm{Y} 5 / 1)$ fabric with no visible inclusions.

319. ( $\mathrm{N}^{\circ}$ 547): Body fragment; surface find from the Village Boncuklar, found in 2005.

Max. h $4.9 \mathrm{~cm}$., $\max$. w $5.0 \mathrm{~cm}$., $\max$. th $0.5 \mathrm{~cm}$

Black (Gley $12.5 / \mathrm{N}$ ) slip on exterior; light brownish gray $(10 \mathrm{YR} 6 / 2)$ unslipped surface on interior. Hard, thin paste; non-porous, fine, gray (10YR 5/1) fabric with no visible inclusions.

320. ( $\mathrm{N}^{\circ}$ 164): Body fragment; domus, found in 2007. Max. h 4.7 cm., max. w $6.3 \mathrm{~cm}$., max. th $0.6 \mathrm{~cm}$.

Very dark gray (2.5Y 3/1) slip on exterior; gray (2.5Y $6 / 1)$ unslipped surface on interior. Hard, thin paste; sparsely porous, fine, gray $(2.5 \mathrm{Y} 6 / 1)$ fabric with occasional sand inclusions. 
321. (No 142): Body fragment; domus, room 4 , found in 2007 .

Max. h $1.9 \mathrm{~cm}$., max. w $4.5 \mathrm{~cm}$., max. th $1.4 \mathrm{~cm}$.

Dark gray $($ Gley $14 / \mathrm{N})$ slip on exterior; gray $(2.5 \mathrm{Y}$ 6/1) unslipped surface on interior. Hard, thin paste; very sparsely porous, fine, gray (2.5Y 6/1) fabric with no visible inclusions.

\section{Late Hellenistic-Early Roman Brown- Slipped Ware (pls. 17-20, ${ }^{\text {os }} 322-396$ )}

Brown-slipped ware is a close relative of local sigillata in terms of fabric, shapes, slip techniques applied etc.: they are thin walled and consist of mostly open forms with brown and more matt slip. It is a hard, fine and non-porous fabric with less inclusions (sand, micaceous, lime and grit) in small sizes. Its production and firing technics are less careless than sigillata. Its paste is reddish yellow (5YR 6/6-7/6, 7.5YR 6/6-7/6), light brown (7.5YR 6/4), pink (5YR 7/4, 7.5YR 7/4), light yellowish brown (10YR 6/4, 2.5Y 6/3-6/4), red (2.5YR 5/6), brown (7.5YR 5/3-5/4), very pale brown (10YR 7/3-7/4), pale brown (10YR 6/3), yellowish red (5YR 5/6), light reddish brown (5YR 6/4), reddish brown (5YR 5/4) and light red (2.5YR 6/8-6/6). Slip is brown (7.5YR 4/2-4/3-4/4-5/3-5/4, 10YR 4/3-5/3), reddish brown (2.5 YR 4/3-4/4-5/4, 5YR 4/3-4/4-5/3-5/4), red (2.5YR 5/6-4/6-4/8), dark brown (7.5YR 3/23/3), black (7.5YR 2.5/1, 2.5Y 2.5/1), yellowish red (5YR 5/6), reddish yellow (5YR 6/6, 7.5YR 6/6$7 / 6$ ), dark grayish brown (10YR 4/2), dark reddish brown (5YR 3/2), weak red (2.5YR 4/2), light brown (7.5YR 6/4), dark reddish gray (5YR 4/2), very dark gray (10YR 3/1, 2.5Y 3/1), pale brown (10YR 6/3, $2.5 \mathrm{Y} 7 / 4-8 / 4)$, dark gray (2.5Y 4/1), pink (5YR 7/4), strong brown (7.5YR 5/6), very dark grayish brown (10YR 3/2) and yellow (10YR 7/6). Because of bad firing technics surface slip is frequently mottled in brown (7.5YR 4/3-4/2), dark reddish brown (5YR 3/3-3/2, 2.5YR 3/3), reddish brown (2.5YR 4/4, $5 \mathrm{YR}$ $5 / 3-5 / 4)$, dark gray (10YR 4/1), strong brown (7.5YR 5/6), dark reddish gray (5YR 4/2), very dark grayish brown (10YR $3 / 2)$, very dark gray (5YR $3 / 1$ ), black (5YR 2.5/1, 10YR 2.5/1), red (2.5YR $5 / 6)$, dark grayish brown (10YR 4/2), reddish yellow (5YR 6/6), duksy red (2.5YR 3/2) and yellowish brown (10YR 5/4). Their bases were left unslipped.

89 sherds were collected in total, 59 of which belong to the open and 30 to the closed forms. 22 of them were found in Bath A at Hadrianopolis, 17 in Kepez, 10 on the southern slope of the Acropolis at Kimistene and 3 in the western tomb at Hadrianopolis.

Two similar intact brown-slipped bowls (Fig. 1112) in two different shapes are today in the exhibi-

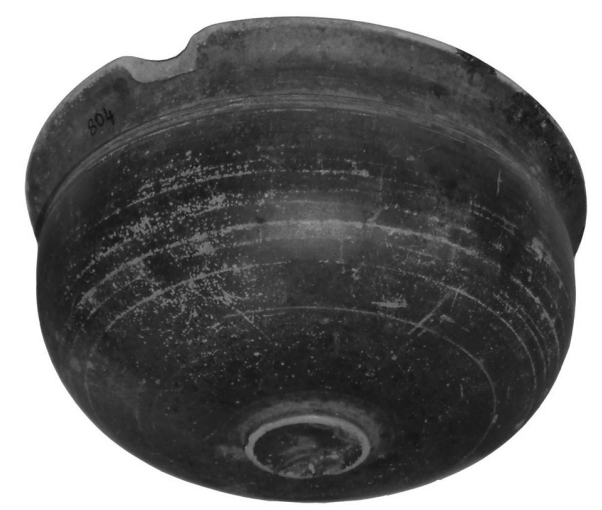

Fig. 11 : A Late Hellenistic-Early Roman brown-slipped bowl from the Museum of Kastamonu (inv. $n^{\circ}$ 804).

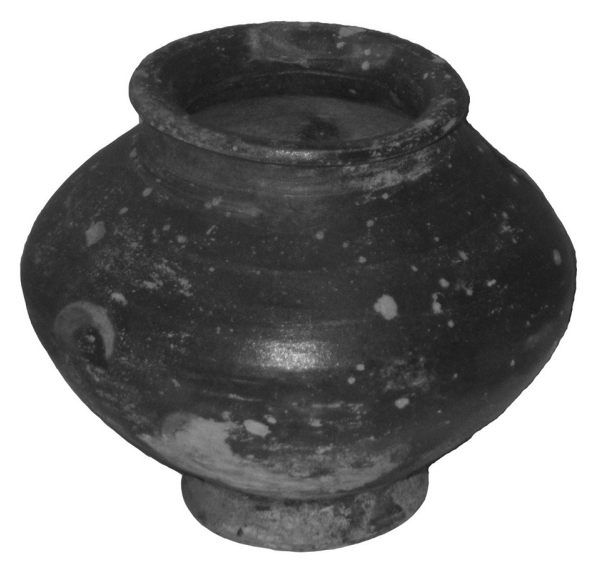

Fig. 12 : A $1^{\text {st }}$ cent. A.D. brown-slipped bowl from the Museum of Kastamonu, found in a sarcophagus by Fındıcak, near Araç, Kastamonu in 1971.

tion of the Museum of Kastamonu. They both originate from burials in the eastern part of Paphlagonia. This shows that this ware is also connected with the burial traditions.

They should be dated to the $1^{\text {st }}$ century B.C. and $1^{\text {st }}$ century A.D.

Open Forms (pls. 17-19, nos $322-363$ )

Most common form is the bowls.

Bowl Form 1 (pl. 17, $\mathrm{n}^{\text {os }} 322-327$ )

This is an incurved rim bowl form with a mottled surface.

322. ( $\left.\mathrm{N}^{\circ} 1413\right)$ : Rim fragment; Kepez, surface find, found in 2005 . 
pl. 17/322 and pl. 32/267.

Max. h $1.4 \mathrm{~cm}$., max. w $1.9 \mathrm{~cm}$., $\max$. th $0.3 \mathrm{~cm}$.

Brown (7.5YR 5/3) slip on exterior; yellowish red (5YR 5/6) slip on interior. Hard, thin paste; non-porous, fine, reddish yellow (5YR 6/6) fabric with rare tiny lime and sand inclusions.

323. ( $\left.\mathrm{N}^{\circ} 1104\right)$ : Rim fragment; Kepez, found in 2005. pl. 17/323 and pl. 32/268.

Max. h $1.5 \mathrm{~cm}$., max. w $2.0 \mathrm{~cm}$., max. th $0.4 \mathrm{~cm}$.

Reddish yellow (7.5YR 6/6) and brown (7.5YR 4/3) mottled slip on exterior; reddish yellow (7.5YR 7/6) unslipped surface on interior. Hard, thin paste; very sparsely porous, fine, reddish yellow (7.5YR 6/6) fabric with frequent tiny lime inclusions.

324. ( $\mathrm{N}^{\circ}$ 901): Rim fragment; Kimistene, Acropolis, southern slope, underground cave, surface find, found in 2005 .

pl. 17/324 and pl. 32/269.

Max. h $1.8 \mathrm{~cm}$., max. w $1.7 \mathrm{~cm}$., max. th $0.4 \mathrm{~cm}$.

Red (2.5YR 5/6) and reddish brown (2.5YR 4/4) mottled slip on exterior; reddish brown (5YR 4/3) and slip on interior. Hard, thin paste; non-porous, fine, reddish yellow (5YR 6/6) fabric with occasional sand and tiny lime inclusions.

325. ( $\mathrm{N}^{\circ}$ 1233): Rim fragment; Kepez, found in 2005. pl. $17 / 325$ and pl. $32 / 270$.

Max. h $2.0 \mathrm{~cm}$., max. w $3.4 \mathrm{~cm}$., max. th $0.5 \mathrm{~cm}$.

Weak red (2.5YR 4/2) slip on exterior and interior rim. Their below parts have red (2.5YR 5/6) slip; hard, thin paste; non-porous, fine, red $(2.5 \mathrm{YR} 5 / 6)$ fabric with rare medium sand inclusions.

326. ( No 343): Rim fragment; Bath B, Room 1, found in 2007.

pl. 17/326 and pl. 32/271.

Max. h $2.2 \mathrm{~cm}$., d of rim $11.5 \mathrm{~cm}$., $\max$. w $3.7 \mathrm{~cm}$., max. th $0.4 \mathrm{~cm}$.

Dark brown (7.5YR 3/2) slip on exterior rim and interior. Its below part has a reddish yellow (7.5YR 7/6) unslipped surface on exterior. Hard, thin paste; non-porous, fine, reddish yellow (7.5YR 6/6) fabric with some tiny lime inclusions.

327. ( $\mathrm{N}^{\circ}$ 931): Rim fragment; Kimistene, Acropolis, found in 2005 .

pl. 17/327 and pl. 32/272.

Max. h $2.6 \mathrm{~cm}$., d of rim $13.6 \mathrm{~cm}$., max. w $4.0 \mathrm{~cm}$. $\max$. th $0.5 \mathrm{~cm}$.

Brown (7.5YR 5/3) slip on exterior and interior. Hard, thin paste; non-porous, fine, brown (10YR 6/4) fabric with occasional sand inclusions.
Bowl Form 2 (pl. 17, nos 334-339)

An outcurved rim bowl, sometimes with a groove on the rim.

328. ( $\mathrm{N}^{\circ}$ 297): Rim fragment; Bath A, Room 2b, found in 2006.

pl. 32/273.

Max. h $0.8 \mathrm{~cm}$., max. w $1.3 \mathrm{~cm}$., max. th $0.3 \mathrm{~cm}$.

Brown (7.5YR 4/2) and pale brown (2.5Y 7/4) slip on exterior; red (2.5YR 4/6) slip on interior. Average hardness; thin paste; non-porous, fine, reddish yellow (7.5YR 7/6) fabric with no visible inclusions.

329. (No 591): Rim fragment; Kimistene, Acropolis, southern slope, just below of the summit of Deresemail creek, found in 2005.

pl. 32/274.

Max. h $1.6 \mathrm{~cm}$., max. w $2.1 \mathrm{~cm}$., max. th $0.5 \mathrm{~cm}$.

Red (2.5YR 5/6) slip on exterior; light brown (7.5YR 6/4) slip on interior. Average hardness; thin paste; nonporous, fine, pink (7.5YR 7/4) fabric with rare sand and micaceous inclusions.

330. (No 584): Rim fragment; Kimistene, Acropolis, southern slope, just below of the summit of Deresemail creek, found in 2005.

pl. 32/275.

Max. h $1.6 \mathrm{~cm}$., max. w $1.5 \mathrm{~cm}$., max. th $0.4 \mathrm{~cm}$.

Reddish brown (5YR 5/4), eroded slip both on exterior and interior. Average hardness; thin paste; nonporous, fine, light brown (7.5YR 6/4) fabric with frequent tiny lime inclusions.

331. ( $\mathrm{N}^{\circ} 1060$ ): Rim fragment; Kepez, found in 2005. pl. 32/276.

Max. h $2.3 \mathrm{~cm}$., max. w $1.5 \mathrm{~cm}$., max. th $0.4 \mathrm{~cm}$.

Reddish brown (5YR 5/4), mottled slip both on exterior and interior. Hard, thin paste; non-porous, fine, very pale brown (10YR 7/4) fabric with some tiny lime and sand inclusions.

332. ( $\mathrm{N}^{\circ}$ 520): Rim fragment; Kimistene, Acropolis, southern slope, just below of the summit of Deresemail creek, found in 2005 .

pl. 32/277.

Max. h $1.5 \mathrm{~cm}$., max. w $2.2 \mathrm{~cm}$., max. th $0.5 \mathrm{~cm}$.

Red (2.5YR 5/6) slip on exterior; dark reddish brown (5YR 3/3) and red (2.5YR 5/6) mottled slip on interior. Hard, thin paste; non-porous, fine, yellowish red (5YR 5/6) fabric with no visible inclusions.

333. ( $\left.\mathrm{N}^{\circ} 1374\right)$ : Rim fragment; Kimistene, Acropolis, southern slope, just below of the summit of Deresemail creek, found in 2005.

pl. 32/278.

Max. h $1.8 \mathrm{~cm}$., max. w $1.7 \mathrm{~cm}$., max. th $0.5 \mathrm{~cm}$. 

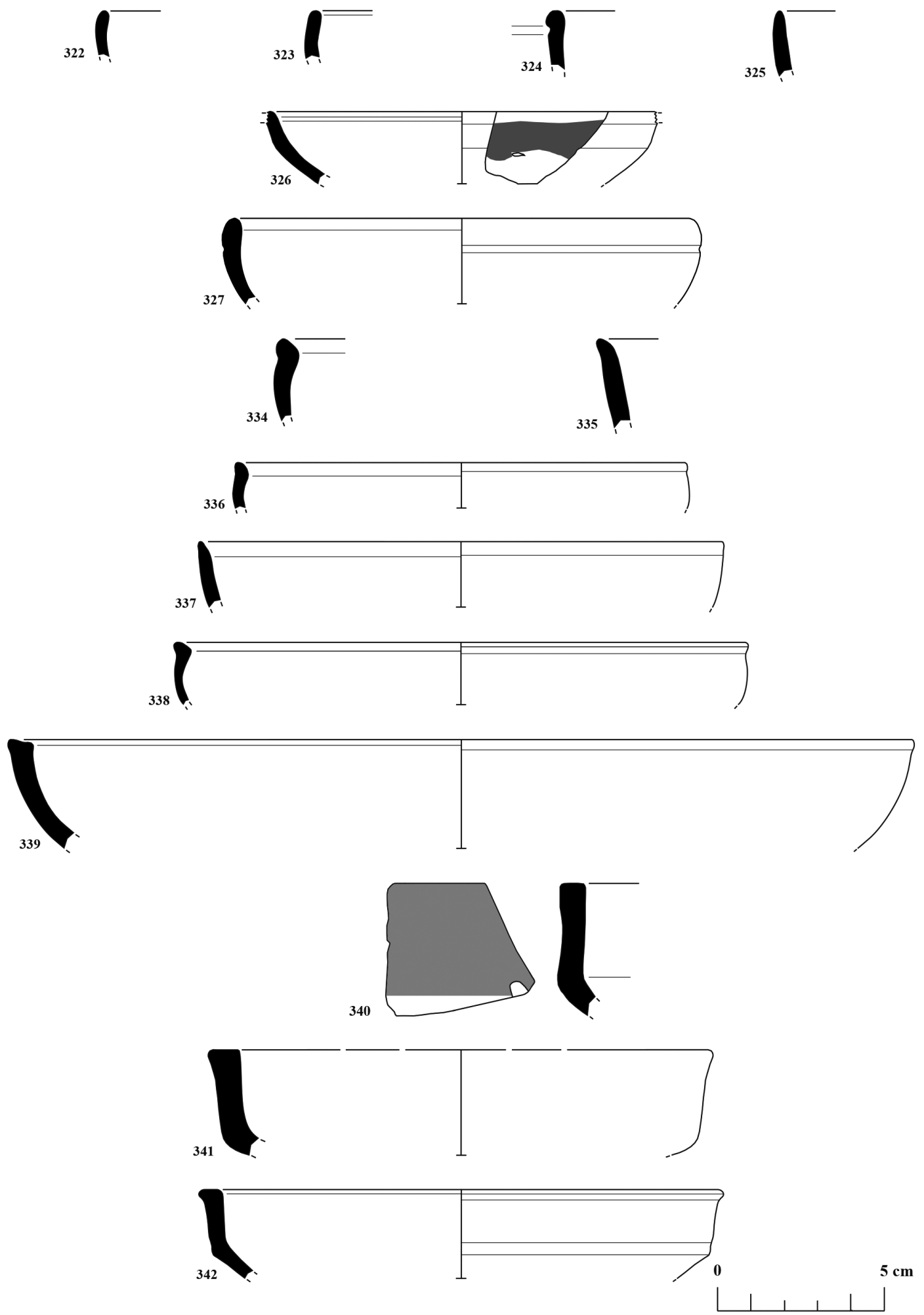

Pl. 17 : Nos 322-342: Late Hellenistic-Early Roman brown-slipped ware; $\mathbf{n}^{\text {os }}$ 322-327:

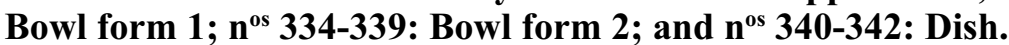


Red (2.5YR 5/8) and dark reddish brown (2.5YR 3/3) mottled slip on exterior; reddish brown (5YR 4/3) slip on interior rim. Its below part has a pink (5YR 7/4) unslipped surface on interior. Hard, thin paste; non-porous, fine, reddish yellow (5YR 6/6) fabric with no visible inclusions.

334. ( $\mathrm{N}^{\circ} 851$ ): Rim fragment; Kimistene, surface find, found in 2005 .

pl. 17/334 and pl. 32/279.

Max. h $2.5 \mathrm{~cm}$., max. w $2.5 \mathrm{~cm}$., max. th $0.5 \mathrm{~cm}$.

Brown (7.5YR 4/2) abrasion slip on exterior and interior. Average hardness; thin paste; very sparsely porous, fine, light brown (7.5YR 6/4) fabric with tiny lime inclusions.

335. ( $\mathrm{N}^{\circ}$ 1362): Rim fragment; Kimistene, Cistern, eastern slope, found in 2005.

pl. 17/335 and pl. 33/280.

Max. h $2.6 \mathrm{~cm}$., max. w $2.7 \mathrm{~cm}$., max. th $0.5 \mathrm{~cm}$.

Yellowish red (5YR 5/6) slip on exterior and interior. Hard, thin paste; very sparsely porous, fine, reddish yellow (5YR 7/6) fabric with rare tiny lime inclusions.

336. (No 952): Rim fragment; Kimistene, Acropolis, found in 2005 .

pl. 17/336 and pl. 33/281.

Max. h $1.4 \mathrm{~cm}$., d of rim $13.4 \mathrm{~cm}$., max. w $2.7 \mathrm{~cm}$., $\max$. th $0.3 \mathrm{~cm}$.

Dark gray (10YR 4/1) and brown (10YR 5/3) mottled slip on exterior; dark gray $(2.5 \mathrm{Y} 4 / 1)$ slip on interior. Hard, thin paste; non-porous, grayish brown (10YR 5/2) fabric with no visible inclusions.

337. (No 1102): Rim fragment; Kepez, found in 2005. pl. 17/337 and pl. 33/282.

Max. h $2.0 \mathrm{~cm}$., d of rim $15.6 \mathrm{~cm}$., max. w $3.0 \mathrm{~cm}$., max. th $0.4 \mathrm{~cm}$.

Dark reddish gray (5YR 4/2) slip on exterior; reddish brown (5YR 4/3) slip on interior. Average hardness; thin paste; very sparsely porous, fine, very pale brown (10YR 7/4) fabric with rare micaceous, tiny lime and sand inclusions.

338. ( $\left.\mathrm{N}^{\circ} 411\right)$ : Rim fragment; Kimistene, surface find, found in 2005 .

pl. 17/338 and pl. 33/283.

Max. h 1.9 cm., d of rim $17.0 \mathrm{~cm}$., max. w $2.5 \mathrm{~cm}$., $\max$. th $0.3 \mathrm{~cm}$.

Reddish yellow (7.5YR 6/6) slip on exterior; dark reddish gray (5YR 4/2) and light brown (7.5YR 6/4) slip on interior. Hard, thin paste; non-porous, pink (7.5YR 7/4) fabric with rare sand inclusions. in 2006 .

339. ( $\mathrm{N}^{\circ} 238$ ): Rim fragment; Bath $\mathrm{A}$, room 12 , found pl. 17/339 and pl. 33/284.

Max. h $3.3 \mathrm{~cm}$., d of rim $27.0 \mathrm{~cm}$., max. w $6.8 \mathrm{~cm}$., $\max$. th $0.6 \mathrm{~cm}$.
Red (2.5YR 5/6) slip on exterior; strong brown (7.5YR 5/6) slip on interior. Hard, thin paste; very sparsely porous, fine, light brown (7.5YR 6/4) fabric with no visible inclusions.

$$
\text { Dish (pl. 17, } \left.\mathrm{n}^{\text {os }} 340-342\right)
$$

A dish form with a flattened rim.

340. ( $\left.\mathrm{N}^{\circ} 356\right)$ : Rim fragment; western tomb, found in 2007.

pl. 17/340 and pl. 33/285.

Max. h $4.0 \mathrm{~cm}$., max. w $4.6 \mathrm{~cm}$., max. th $0.7 \mathrm{~cm}$.

Red (2.5YR 5/6) slip on exterior rim and interior; pink (5YR 7/4) slip on lower exterior. Hard, thin paste; non-porous, fine, red $(2.5 \mathrm{YR} 5 / 6)$ fabric with some lime inclusions.

341. ( $\mathrm{N}^{\circ} 422$ ): Rim fragment; apsidial building, found in 2007.

pl. 17/341 and pl. 33/286.

Max. h $3.2 \mathrm{~cm}$., d of rim $29.6 \mathrm{~cm}$., max. w $4.2 \mathrm{~cm}$., $\max$. th $0.7 \mathrm{~cm}$.

Reddish brown (2.5YR 5/4) slip on exterior and interior. Hard, thin paste; non-porous, fine, light red $(2.5 \mathrm{YR}$ 6/8) fabric with some lime inclusions.

342. ( $\mathrm{N}^{\circ} 222$ ): Rim fragment; Bath $\mathrm{A}$, room 13, found in 2006.

pl. $17 / 342$ and pl. 33/287.

Max. h $2.7 \mathrm{~cm}$., d of rim $15.4 \mathrm{~cm}$., max. w $4.1 \mathrm{~cm}$., $\max$. th $0.5 \mathrm{~cm}$.

Brown (10YR 4/3) slip on exterior; very dark gray (10YR 3/1) slip on interior. Hard, thin paste; very sparsely porous, fine, light brown (7.5YR 6/4) fabric with no visible inclusions.

\section{Other Rim Fragments \\ (pl. 18, $\mathrm{n}^{\text {os }} 344-346$ )}

Some of them are thickened rim forms and some have mottled slips.

343. ( $\mathrm{N}^{\circ}$ 834): Rim fragment; Kimistene, Cistern, eastern slope, found in 2005.

pl. 33/288.

Max. h $2.0 \mathrm{~cm}$., max. w $4.1 \mathrm{~cm}$., max. th $0.4 \mathrm{~cm}$.

Red (2.5YR 5/6) slip on exterior; red (2.5YR 4/6) slip on interior. Hard, thin paste; non-porous, fine, reddish yellow (5YR 6/6) fabric with no visible inclusions.

344. ( $\mathrm{N}^{\circ} 227$ ): Rim fragment; Bath $\mathrm{A}$, room 13, found in 2006.

pl. 18/344 and pl. 33/289.

Max. h $4.4 \mathrm{~cm}$., max. w $6.5 \mathrm{~cm}$., max. th $0.5 \mathrm{~cm}$.

Brown (7.5YR 4/3) and very dark grayish brown (10YR 3/2) mottled slip both on exterior and interior. Hard, thin paste; non-porous, very dark gray (Gley $13 / \mathrm{N}$ ) fabric with some tiny lime inclusions. 
345. ( $\left.\mathrm{N}^{\circ} 242\right)$ : Rim fragment; western tomb, found in 2007.

pl. 18/345 and pl. 33/290.

Max. h $3.6 \mathrm{~cm}$., d of rim $18.8 \mathrm{~cm}$., max. w $5.4 \mathrm{~cm}$., $\max$. th $0.4 \mathrm{~cm}$.

Brown (7.5YR 4/2-4/3) slip on exterior; brown (7.5YR 4/2) slip on interior. Average hardness; thin paste; non-porous, fine, light brown (7.5YR 6/4) fabric with no visible inclusions.

346. ( $\mathrm{N}^{\circ}$ 1259): Rim fragment; Kimistene, Necropolis, surface find, found in 2005.

pl. 18/346 and pl. 33/291.

Max. h $3.0 \mathrm{~cm}$., d of rim $24.0 \mathrm{~cm}$., $\max$. w $4.8 \mathrm{~cm}$., max. th $0.6 \mathrm{~cm}$.

Reddish brown (5YR 4/4) slip both on exterior and interior. Hard, thin paste; non-porous, fine, red (2.5YR 5/6) fabric with frequent tiny lime inclusions.

\section{Base Fragments of Open Forms (pls. 18-19, $\mathrm{n}^{\text {os }} 349-363$ )}

High based fragments; exterior surfaces left unslipped. Traces of slips are mottled.

347. ( $\mathrm{N}^{\circ} 373$ ): Base fragment; Bath $\mathrm{A}$, room $2 \mathrm{~b}$, found in 2006 .

pl. 33/292.

Max. h $1.3 \mathrm{~cm}$, max. w $1.2 \mathrm{~cm}$., $\max$. th $0.2 \mathrm{~cm}$.

Pink (5YR 7/4) unslipped surface on exterior; brown (7.5YR 4/3) slip on interior. Average hardness; thin paste; non-porous, reddish yellow (5YR 6/6) and light brown (7.5YR 6/4) fabric with no visible inclusions.

348. $\left(\mathrm{N}^{\circ} 372\right)$ : Base fragment; Bath $\mathrm{A}$, room $2 \mathrm{~b}$, found in 2006 .

pl. 33/293.

Max. h $1.3 \mathrm{~cm}$., max. w $1.2 \mathrm{~cm}$., max. th $0.2 \mathrm{~cm}$.

Pink (7.5YR 7/4) unslipped surface on exterior; brown (7.5YR 4/3) slip on interior. Average hardness; thin paste; non-porous, reddish yellow (5YR 6/6) and light brown (7.5YR 6/4) fabric with no visible inclusions.

349. ( $\mathrm{N}^{\circ}$ 529): Base fragment; Kimistene, Acropolis, southern slope, just below of the summit of Deresemail creek, found in 2005 .

pl. 18/349 and pl. 33/294.

Max. h $1.5 \mathrm{~cm}$., max. w $1.8 \mathrm{~cm}$., max. th $0.4 \mathrm{~cm}$.

Reddish yellow (5YR 6/6) and reddish brown (5YR 5/4) mottled slip on exterior; brown (7.5YR 4/3) slip on interior. Hard, thin paste; non-porous, fine, pink (7.5YR 7/4) fabric with no visible inclusions.

350. ( $\mathrm{N}^{\circ}$ 984): Base fragment; Hadrianopolis, surface find, found in 2005 .

pl. 18/350 and pl. 33/295.

Max. h $1.4 \mathrm{~cm}$., max. w $3.0 \mathrm{~cm}$., max. th $0.5 \mathrm{~cm}$.
Pink (7.5YR 7/4) unslipped surface on exterior; reddish brown (2.5YR 4/4) slip on interior. Hard, thin paste; non-porous; very pale brown (10YR 7/4) and pink (7.5YR $7 / 4$ ) fabric with no visible inclusions.

351. ( $\mathrm{N}^{\circ} 95$ ): Base fragment; Bath $\mathrm{B}$, room 5 , found in 2007.

pl. 18/351 and pl. 33/296.

Max. h $1.6 \mathrm{~cm}$., d of base $2.8 \mathrm{~cm}$., max. w $3.0 \mathrm{~cm}$., max. th $0.4 \mathrm{~cm}$.

Reddish brown (5YR 4/4) slip on exterior; dark reddish brown (5YR 3/2) slip on interior. Hard, thin paste; non-porous, fine, red (2.5YR 5/6) fabric with no visible inclusions.

352. ( $\mathrm{N}^{\circ} 293$ ): Base fragment; Bath $\mathrm{A}$, room $2 \mathrm{~b}$, found in 2006.

pl. 18/352 and pl. 33/297.

Max. h $0.7 \mathrm{~cm}$., d of base $4.0 \mathrm{~cm}$., max. w $2.9 \mathrm{~cm}$., $\max$. th $0.3 \mathrm{~cm}$.

Pink (7.5YR 7/4) unslipped surface on exterior; brown (7.5YR 5/4) slip on interior. Hard, thin paste; very sparsely porous, fine, pink (7.5YR 7/4) fabric with no visible inclusions.

353. ( $\mathrm{N}^{\circ}$ 367): Base fragment; Bath $\mathrm{B}$, room 8 , from the illegally excavated area in the southeast, found in 2007.

pl. 18/353 and pl. 33/298.

Max. h $1.2 \mathrm{~cm}$., d of base $4.4 \mathrm{~cm}$., max. w $2.7 \mathrm{~cm}$., $\max$. th $0.4 \mathrm{~cm}$.

Pink (7.5YR 7/4) unslipped surface on exterior; reddish brown (5YR 5/4) slip on interior. Hard, thin paste; very sparsely porous, fine, light reddish brown (5YR 6/4) fabric with some tiny lime inclusions.

354. ( $\mathrm{N}^{\circ}$ 519): Base fragment; Kimistene, Acropolis, southern slope, just below of the summit of Deresemail creek, found in 2005.

pl. 18/354 and pl. 33/299.

Max. h $1.1 \mathrm{~cm}$., d of base $4.6 \mathrm{~cm}$., max. w $4.6 \mathrm{~cm}$., $\max$. th $0.3 \mathrm{~cm}$

Pink (7.5YR 7/4) unslipped surface on exterior; brown (7.5YR 5/4) and very dark grayish brown (10YR $3 / 2$ ) mottled slip on interior. Hard, thin paste; very sparsely porous, fine, reddish yellow (5YR 6/6) fabric with occasional tiny lime inclusions.

355. ( $\mathrm{N}^{\circ}$ 284): Base fragment; Bath $\mathrm{A}$, room 14 , found in 2007.

pl. 18/355 and pl. 33/300.

Max. h $1.2 \mathrm{~cm}$., d of base $5.2 \mathrm{~cm}$., $\max$. w $5.4 \mathrm{~cm}$., $\max$. th $0.4 \mathrm{~cm}$.

Reddish yellow (5YR 6/6) and brown (7.5YR 4/2) mottled slip on exterior; brown (10YR 5/3) and reddish yellow (5YR 6/6) mottled slip on interior. Average hardness; thin paste; very sparsely porous, fine, reddish yellow (5YR 6/6) fabric with infrequent lime, sand and occasional micaceous inclusions. 

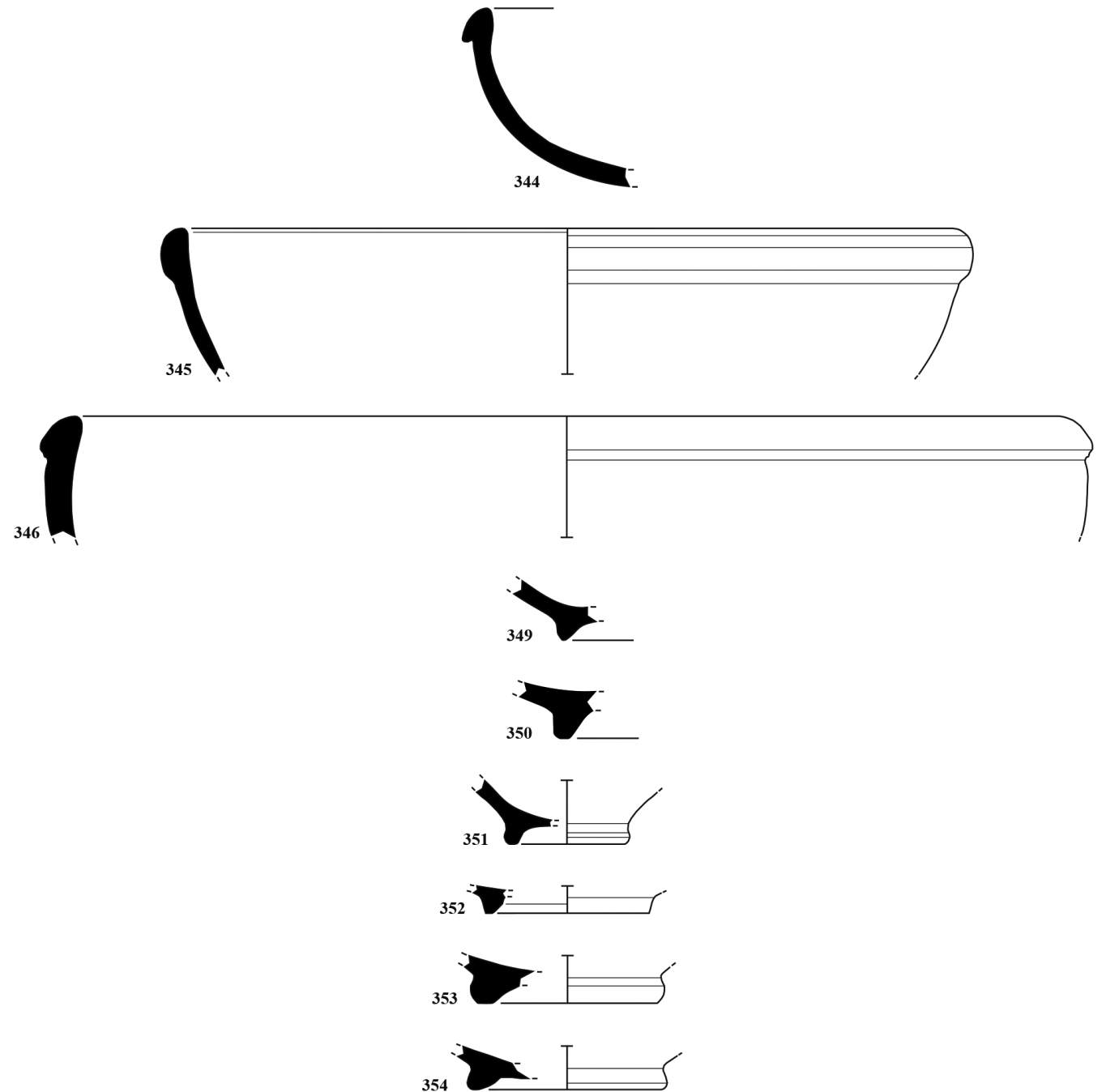

2
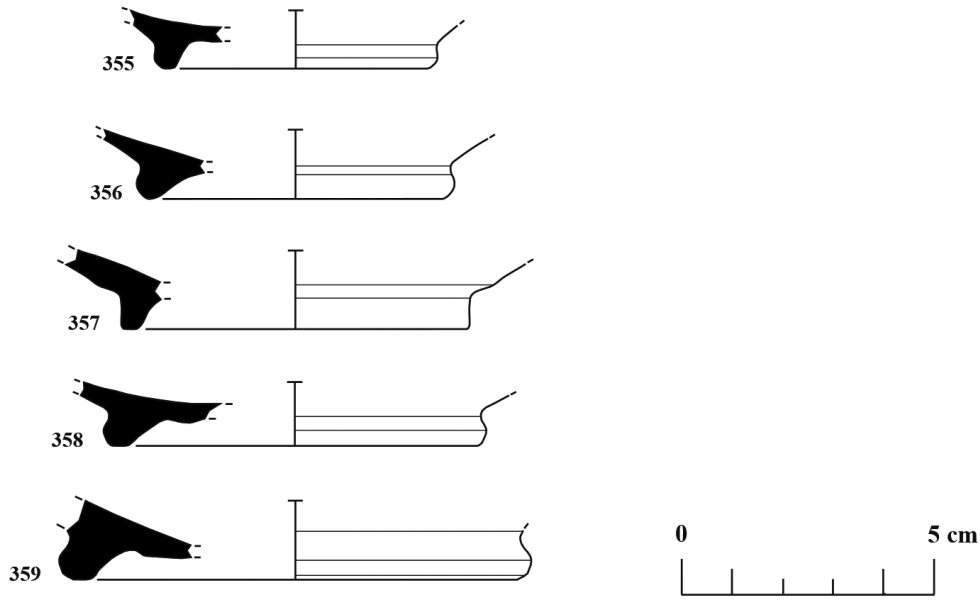

PI. 18 : Nos 344-359: Late Hellenistic-Early Roman brown-slipped ware; ${ }^{\text {os }}$ 344-346: Other rim forms; and $n^{\text {os } 349-359: ~ B a s e ~ f r a g m e n t s ~ o f ~ o p e n ~ f o r m s . ~}$ 
356. ( $\mathrm{N}^{\circ}$ 206): Base fragment; Bath $\mathrm{A}$, room 1 , found in 2006 .

pl. 18/356 and pl. 33/301.

Max. h $1.5 \mathrm{~cm}$., d of base $5.8 \mathrm{~cm}$., max. w $4.2 \mathrm{~cm}$., max. th $0.4 \mathrm{~cm}$.

Light yellowish brown $(2.5 \mathrm{Y} 6 / 3)$ unslipped surface on exterior; brown (10YR 5/3) slip on interior. Hard, thin paste; very sparsely porous, fine, light yellowish brown (2.5Y 6/4) fabric with occasional sand inclusions.

357. ( $\mathrm{N}^{\circ}$ 279): Base fragment; Bath $\mathrm{A}$, room 14, found in 2007 .

pl. 18/357 and pl. 33/302.

Max. h $1.6 \mathrm{~cm}$., d of base $6.8 \mathrm{~cm}$., $\max$. w $4.6 \mathrm{~cm}$., max. th $0.6 \mathrm{~cm}$.

Dark grayish brown (10YR 4/2) and brown (10YR 4/3) mottled slip on exterior; dark grayish brown (10YR 4/2) slip on interior. Hard, thin paste; non-porous, fine, light brown (7.5YR 6/4) fabric with no visible inclusions.

358. ( $\mathrm{N}^{\circ} 355$ ): Base fragment; monumental tomb, found in 2007.

pl. 18/358 and pl. 33/303.

Max. h $1.3 \mathrm{~cm}$., d of base $7.2 \mathrm{~cm}$., max. w $2.5 \mathrm{~cm}$., $\max$. th $0.5 \mathrm{~cm}$.

Pink (7.5YR 7/4) unslipped surface on exterior; reddish brown (5YR 5/4) slip on interior. Hard, thin paste; very sparsely porous, fine, pink (7.5YR 7/4) fabric with occasional micaceous inclusions.

359. ( $\mathrm{N}^{\circ} 253$ ): Base fragment; western tomb, found in 2007 .

pl. 18/359 and pl. 33/304.

Max. h $1.6 \mathrm{~cm}$., d of base $8.8 \mathrm{~cm}$., max. w $8.2 \mathrm{~cm}$., $\max$. th $0.6 \mathrm{~cm}$.

Pink (5YR 7/4) unslipped surface on the exterior; reddish brown (5YR 4/3) slip in the interior. Hard, thin paste; very sparsely porous, fine, pink (5YR 7/4) fabric with tiny lime inclusion.

360. ( $\mathrm{N}^{\circ}$ 1384): Base fragment; surface find from Göletarkas1, found in 2005.

pl. 19/360 and pl. 33/305.

Max. h $2.6 \mathrm{~cm}$., d of base $13.6 \mathrm{~cm}$., max. w $6.8 \mathrm{~cm}$., max. th $1.0 \mathrm{~cm}$.

Reddish brown (5YR 5/4) slip on exterior and interior. Exterior surface is burnished. Hard, thin paste; very sparsely porous, fine, reddish brown (5YR 5/4) fabric with some sand inclusions.

361. ( $\left.\mathrm{N}^{\circ} 1469\right)$ : Base fragment; surface find from the Village Boncuklar, found in 2005 .

pl. 19/361 and pl. 33/306.

Max. h $1.7 \mathrm{~cm}$. , d of base $14.6 \mathrm{~cm} .$, max. w $4.2 \mathrm{~cm}$., $\max$. th $0.7 \mathrm{~cm}$.

Pale brown (10YR 6/3) slip on exterior; reddish brown (5YR 4/3) slip on interior. Exterior surface is burnished. Hard, thin paste; non-porous, gray (2.5Y 5/1) fabric with sand and occasional micaceous inclusions.
362. ( $\mathrm{N}^{\circ}$ 932): Base fragment; Kimistene, Acropolis, found in 2005 .

pl. 19/362 and pl. 34/307.

Max. h $1.6 \mathrm{~cm}$., d of base $14.8 \mathrm{~cm}$., max. w $4.3 \mathrm{~cm}$., $\max$. th $0.7 \mathrm{~cm}$.

Red (2.5YR 4/8) slip on exterior; brown (7.5YR 4/4) slip on interior. Three thin bands in very dark gray (7.5YR 3/1) on interior. Hard, thin paste; non-porous, fine, reddish brown (5YR 5/4) fabric with no visible inclusions.

363. ( $\mathrm{N}^{\circ}$ 650): Base fragment; Kimistene, Cistern, found in 2005 .

pl. 19/363 and pl. 34/308.

Max. h $4.0 \mathrm{~cm} ., \mathrm{d}$ of base $18.0 \mathrm{~cm}$., $\max . \mathrm{w} 6.8 \mathrm{~cm}$., $\max$. th $0.7 \mathrm{~cm}$.

Light brown (7.5YR 6/4) slip on exterior; reddish brown (5YR 4/3) slip on interior. Hard, thin paste; nonporous, fine, yellowish red (5YR 5/6) fabric with some sand inclusion.

\section{Body Fragments of Open Forms \\ (pl. 34, $\mathrm{n}^{\text {os }} 309-324$ )}

Fragments, mostly with mottled slip.

364. (No 1144): Body fragment; Kimistene, Acropolis, found in 2005.

pl. 34/309.

Max. h $1.0 \mathrm{~cm}$. , max. w $1.4 \mathrm{~cm}$., max. th $0.3 \mathrm{~cm}$.

Black (2.5Y 2.5/1) slip on exterior; reddish brown (2.5YR 4/4) slip on interior. Hard, thin paste; non-porous, fine, pale brown (10YR 6/3) fabric with no visible inclusions.

365. (No 1139): Body fragment; Kimistene, Acropolis, found in 2005 .

pl. 34/310.

Max. h $1.5 \mathrm{~cm}$, max. w $1.6 \mathrm{~cm}$., max. th $0.5 \mathrm{~cm}$.

Light brownish gray $(2.5 \mathrm{Y} 6 / 2)$ unslipped surface on exterior; reddish brown (2.5YR 4/4) slip on interior. Hard, thin paste; non-porous, fine, light red (2.5YR 6/6) fabric with rare sand inclusions.

366. ( $\left.\mathrm{N}^{\circ} 1141\right)$ : Body fragment; Kimistene, Acropolis, found in 2005 .

pl. 34/311.

Max. h 1.9 cm., max. w $1.7 \mathrm{~cm}$., max. th $0.4 \mathrm{~cm}$.

Reddish brown (2.5YR 4/4) and red (2.5YR 5/6) mottled slip on exterior; reddish brown (2.5YR 4/4) slip on interior. Hard, thin paste; non-porous, fine, pink (5YR 7/4) fabric with no visible inclusions.

367. ( $\mathrm{N}^{\circ} 522$ ): Body fragment; Kepez, found in 2005. pl. 34/312.

Max. h $2.1 \mathrm{~cm}$., max. w $2.4 \mathrm{~cm}$., max. th $0.5 \mathrm{~cm}$.

Red (2.5YR 5/6) and reddish brown (2.5YR 5/4) slip on exterior; reddish yellow (5YR 6/6) slip on interior. Hard, thin paste; sparsely porous, fine, reddish yellow (5YR 6/6) fabric with no visible inclusions. 
368. ( $\left.\mathrm{N}^{\circ} 1194\right)$ : Body fragment; Kepez, surface find in the Cistern, found in 2005 .

pl. 34/313.

Max. h $1.5 \mathrm{~cm}$., max. w $3.0 \mathrm{~cm}$., max. th $0.5 \mathrm{~cm}$.

Yellowish red (5YR 5/6) slip on exterior; brown (7.5YR 5/3) slip on interior. Exterior surface is burnished. Hard, thin paste; non-porous, pale brown (10YR 6/3) and reddish brown (5YR 5/4) fabric with sand and rare micaceous inclusions.

369. ( $\mathrm{N}^{\circ}$ 1039): Body fragment; Kepez, found in 2005 .

pl. 34/314.

Max. h $2.3 \mathrm{~cm}$., max. w $2.3 \mathrm{~cm}$., max. th $0.4 \mathrm{~cm}$.

Red (2.5YR 4/6) slip on exterior; reddish brown (2.5YR 4/4) slip on interior. Hard, thin paste; very sparsely porous, fine, light reddish brown (5YR 6/4) fabric with frequent tiny lime inclusions.

370. (No 1037): Body fragment; Kepez, found 2005.

pl. 34/315.

Max. h 2.4 cm., max. w $2.4 \mathrm{~cm}$., max. th $0.5 \mathrm{~cm}$.

Very dark gray (5YR 3/1) slip on exterior; red (2.5YR $5 / 6)$ slip on interior. Soft, thin paste; very sparsely porous, fine, brown (7.5YR 5/4) fabric with occasional lime inclusions.

371. ( $\mathrm{N}^{\circ}$ 693): Body fragment; Kimistene, Acropolis, southern slope, just below of the summit of Deresemail creek, found in 2005.

pl. 34/316.

Max. h $2.6 \mathrm{~cm}$., max. w $2.5 \mathrm{~cm}$., $\max$. th $0.5 \mathrm{~cm}$.

Dusky red (2.5YR 3/2) and red (2.5YR 4/6) mottled slip on exterior; reddish brown $(2.5 \mathrm{YR} 4 / 3)$ slip on interior. Hard, thin paste; very sparsely porous, fine, reddish yellow (5YR 6/6) fabric with infrequent lime and sand inclusions.

372. ( $\mathrm{N}^{\circ} 33$ ): Body fragment; domus, room 2 , found in 2007.

pl. 34/317.

Max. h $3.0 \mathrm{~cm}$., max. w $2.5 \mathrm{~cm}$., $\max$. th $0.5 \mathrm{~cm}$.

Weak red (2.5YR 4/2) slip on exterior and interior. Hard, thin paste; very sparsely porous, light brown (7.5YR 6/3-6/4) mottled fabric with infrequent lime inclusions.

373. ( $\mathrm{N}^{\circ}$ 1041): Body fragment; Kepez, found in 2005 .

pl. 34/318.

Max. h $2.7 \mathrm{~cm}$., max. w $2.9 \mathrm{~cm}$., max. th $0.6 \mathrm{~cm}$.

Dark grayish brown (10YR 4/2) and yellowish brown (10YR 5/4) mottled slip on exterior. Brown (10YR 4/3) slip on interior. Hard, thin paste; sparsely porous, light yellowish brown (10YR 6/4) fabric with no visible inclusions.
374. ( $\mathrm{N}^{\circ} 570$ ): Body fragment; surface find from the Village Boncuklar, found in 2005.

pl. 34/319.

Max. h $3.4 \mathrm{~cm}$. , max. w $1.5 \mathrm{~cm}$., max. th $0.5 \mathrm{~cm}$.

Dark brown (7.5YR 4/2) slip on exterior; black (7.5YR 2.5/1) slip on interior. Hard, thin paste; nonporous, fine, light brown (7.5YR 6/4) fabric with rare sand inclusions.

375. ( $\left.\mathrm{N}^{\circ} 1377\right)$ : Body fragment; Kepez, Necropolis, found in 2005.

pl. 34/320.

Max. h $3.1 \mathrm{~cm}$., max. w $3.2 \mathrm{~cm}$., max. th $0.7 \mathrm{~cm}$.

Dark brown (7.5YR 3/2) slip on exterior; reddish brown (5YR 4/4) slip on interior. Slip is shiny on all of the surface. Hard, thin paste; non-porous, fine, reddish yellow (7.5YR 6/6) fabric with frequent tiny lime inclusions.

376. ( No 435): Body fragment; Kimistene, Acropolis, slope, found in 2005.

pl. 34/321.

Max. h 2.7 cm., max. w $4.5 \mathrm{~cm}$., max. th $0.7 \mathrm{~cm}$.

Pink (7.5YR 7/4) unslipped surface on exterior; brown (7.5YR 4/3) slip on interior. Average hardness; thin paste; non-porous, fine, reddish yellow (7.5YR 6/6) fabric with no visible inclusions.

377. ( $\mathrm{N}^{\circ} 1410$ ): Body fragment; Kepez, surface find, found in 2005.

pl. 34/322.

Max. h $4.3 \mathrm{~cm}$. , max. w $4.3 \mathrm{~cm}$. , max. th $0.6 \mathrm{~cm}$.

Dark reddish gray (5YR 4/2) slip on exterior; reddish brown (5YR 5/4) slip on interior. Hard, very sparsely porous, thin paste; light red (2.5YR 6/6) and reddish yellow (7.5YR 6/6) mottled fabric with some tiny lime inclusions. 2005 .

378. ( $\mathrm{N}^{\circ}$ 1044): Body fragment; Kepez, found in pl. 34/323.

Max. h $3.3 \mathrm{~cm}$., max. w $3.5 \mathrm{~cm}$., max. th $0.5 \mathrm{~cm}$.

Very pale brown (10YR 8/3) unslipped surface on upper exterior. The below part of the exterior is slipped in dark grayish brown (10YR 4/2). Red (2.5YR 5/6) slip on interior. Hard, thin paste; very sparsely porous, fine, very pale brown (10YR 7/3) fabric with some tiny lime inclusions.

379. ( $\mathrm{N}^{\mathrm{N}} 162$ ): Body fragment; Domus, found in 2007.

pl. 34/324.

Max. h $5.0 \mathrm{~cm}$. , max. w $4.9 \mathrm{~cm}$., max. th $1.2 \mathrm{~cm}$.

Brown (7.5YR 5/3) slip on exterior; dark brown (7.5YR 3/2) slip on interior. Hard, non-porous, thin paste; fine, brown (7.5YR 5/3) fabric with occasional tiny lime inclusions. 

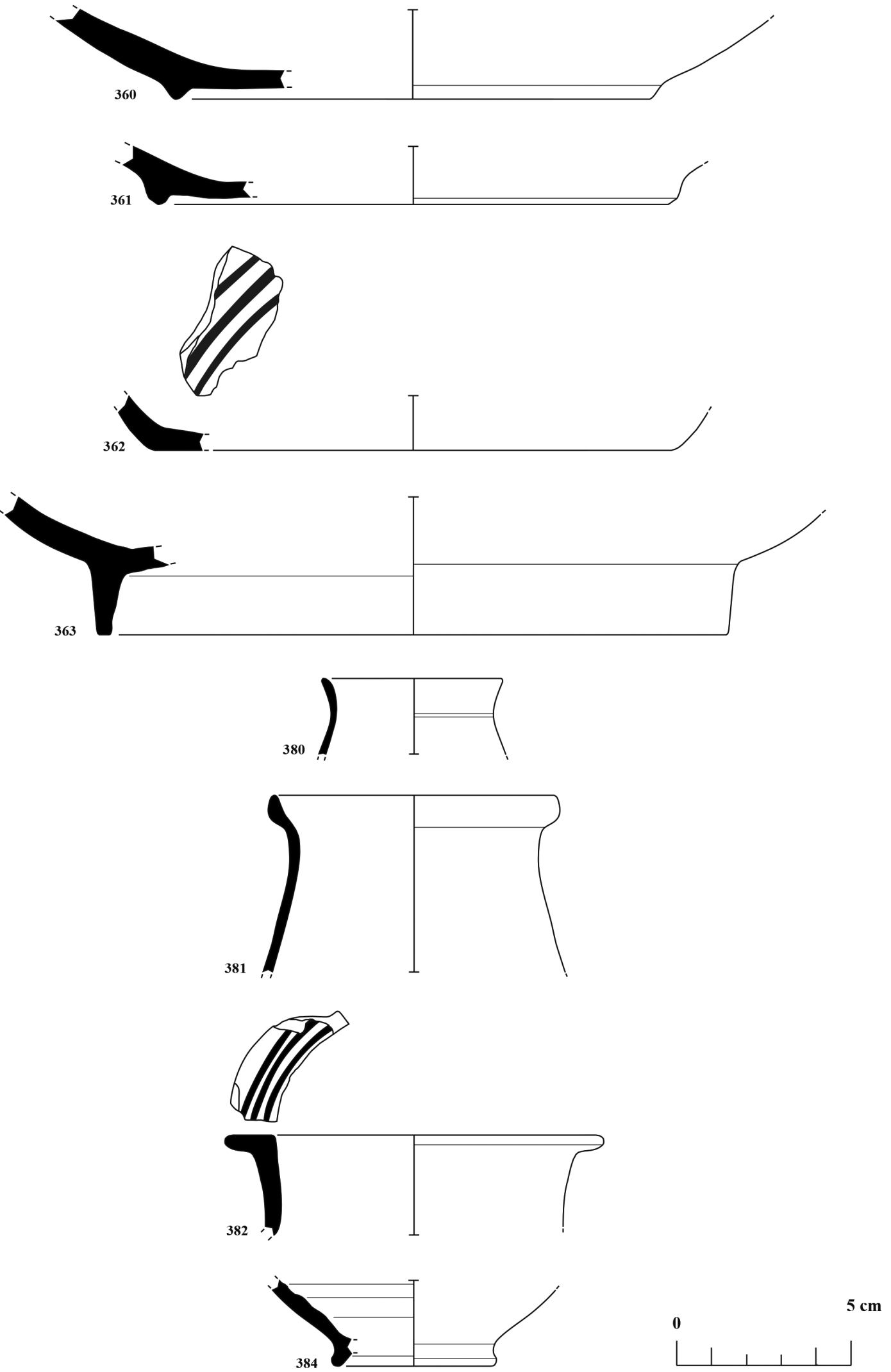

Pl. 19 : Nos 360-384: Late Hellenistic-Early Roman brown-slipped ware; $\mathbf{n}^{\text {os }}$ 360-363: Base fragments of open forms; $n^{\text {os }}$ 380-382: Juglet; and $n^{\circ} 384$ : A base fragment of a closed form. 
Closed Forms (pls. 19-20, $\left.{ }^{\text {os }} 380-396\right)$

Juglet (pl. 19, nos 380-382)

Mostly thin-walled forms with blackish or mottled slip. Possibly drinking vessels. in 2006 .

380. ( $\mathrm{N}^{\circ} 205$ ): Rim fragment; Bath $\mathrm{A}$, room 1 , found

pl. 19/380 and pl. 34/325.

Max. h $2.2 \mathrm{~cm}$., d of rim $5.2 \mathrm{~cm}$., $\max$. w $2.9 \mathrm{~cm}$., max. th $0.2 \mathrm{~cm}$.

It might be belonging to a kind of juglet with splayed mouth. Black (7.5YR 2.5/1) slip on exterior; reddish brown (5YR 5/3) slip on interior. Hard, non-porous, thin paste; fine, reddish yellow (5YR 6/6) fabric with no visible inclusions. in 2006

381. ( $\left.\mathrm{N}^{\circ} 192\right)$ : Rim fragment; Bath $\mathrm{A}$, room 2 , found pl. 19/381 and pl. 34/326.

Max. h $5.1 \mathrm{~cm}$., d of rim $8.0 \mathrm{~cm}$., $\max$. w $7.3 \mathrm{~cm}$., $\max$. th $0.3 \mathrm{~cm}$.

Offset rim; black (7.5YR 2.5/1) slip on exterior; dark brown (7.5YR 3/2) slip on interior. Pink (7.5YR 7/4) unslipped surface on lower interior. Hard, non-porous, thin paste; fine, pink (7.5YR 7/4) fabric with no visible inclusions.

382. (№ 1178): Rim fragment; Kimistene, Acropolis, southern slope, just below of the summit of Deresemail creek, found in 2005 .

pl. 19/382 and pl. 34/327.

Max. h $2.9 \mathrm{~cm}$., d of rim $10.4 \mathrm{~cm}$., max. w $3.2 \mathrm{~cm}$., max. th $0.6 \mathrm{~cm}$.

Very dark gray (10YR 3/1) slip on exterior rim; yellow (10YR 7/6) slip on lower exterior. Pale brown (2.5Y $8 / 4)$ slip and very dark gray $(2.5 \mathrm{Y} 3 / 1)$ thin band on its rim. Black (10YR 2.5/1) and very dark grayish brown (10YR 3/2) mottled slipn the interior rim. Reddish yellow (7.5YR 6/6) unslipped surface on the lower interior. Hard, thin paste; non-porous, fine, reddish yellow (7.5YR 6/6) fabric with no visible inclusions.

\section{Base Fragments of Closed Forms} (pls. 19-20, $\mathrm{n}^{\text {os }} 384-389$ )

Mostly unslipped, ring bases.

383. ( $\mathrm{N}^{\circ} 1489$ ): Base fragment; surface find from the Village Boncuklar, found in 2005.

pl. 34/328.

Max. h $1.3 \mathrm{~cm}$., max. w $1.8 \mathrm{~cm}$., max. th $0.3 \mathrm{~cm}$.

Pink (7.5YR 8/4) unslipped surface on exterior and interior. Average hardness; thin paste; non-porous, fine, reddish yellow (5YR 7/6) fabric with no visible inclusions.
384. ( $\mathrm{N}^{\circ} 1201$ ): Base fragment; Kepez, surface find in the Cistern, found in 2005.

pl. 19/384 and pl. 34/329.

Max. h $2.5 \mathrm{~cm}$., d of rim $4.4 \mathrm{~cm}$., max. w $5.0 \mathrm{~cm}$., $\max$. th $0.5 \mathrm{~cm}$.

Reddish yellow (7.5YR 7/6) unslipped surface on exterior and interior. Hard, thin paste; non-porous, reddish yellow (5YR 6/6) and pale brown (10YR 6/3) fabric with occasional micaceous inclusions.

385. ( $\left.\mathrm{N}^{\circ} 1492\right)$ : Base fragment; surface find from the Village Boncuklar, found in 2005.

pl. 20/385 and pl. 34/330.

Max. h $1.6 \mathrm{~cm}$., d of base $5.0 \mathrm{~cm}$., max. w $3.8 \mathrm{~cm}$., max. th $0.4 \mathrm{~cm}$.

Light brownish gray (10YR 6/2) unslipped surface on exterior and interior. Hard, thin paste; very sparsely porous, gray $(2.5 \mathrm{Y} 5 / 1)$ fabric with occasional tiny lime inclusions.

386. ( No 946): Base fragment; Kimistene, Acropolis, found in 2005 .

pl. 20/386 and pl. 34/331.

Max. h $1.1 \mathrm{~cm}$., d of base $5.8 \mathrm{~cm}$., $\max$. w $4.5 \mathrm{~cm}$., $\max$. th $0.3 \mathrm{~cm}$.

Brown (7.5YR 4/2) eroded slip on exterior; pink (5YR 7/4) unslipped surface on interior. Hard, thin paste; non-porous, fine, pink (5YR 7/4) fabric with no visible inclusions.

387. (№ 948): Base fragment; Kimistene, Acropolis, found in 2005.

pl. 20/387 and pl. 34/332.

Max. h $1.4 \mathrm{~cm}$., d of base $6.0 \mathrm{~cm}$., $\max . \mathrm{w} 4.9 \mathrm{~cm}$., $\max$. th $0.4 \mathrm{~cm}$.

Reddish yellow (5YR 6/6) unslipped surface on exterior; reddish yellow (7.5YR 7/6) unslipped surface on interior. Hard, thin paste; very sparsely porous, reddish yellow (5YR 6/6) and (7.5YR 6/6) mottled fabric with some tiny lime inclusions.

388. ( $\left.\mathrm{N}^{\circ} 1420\right)$ : Base fragment; Basilica A found in 2005.

pl. 20/388 and pl. 34/333.

Max. h $2.2 \mathrm{~cm}$., d of base $8.6 \mathrm{~cm}$., $\max$. w $7.3 \mathrm{~cm}$., $\max$. th $0.8 \mathrm{~cm}$.

Red (2.5YR 5/6) slip on exterior; pink (5YR 7/4) unslipped surface on interior. Hard, thin paste; very sparsely porous, pink (5YR 7/4) and light reddish brown (2.5YR 6/4) fabric with no visible inclusions.

389. ( $\mathrm{N}^{\circ}$ 787): Base fragment; Kimistene, Acropolis, southern slope, just below of the summit of Deresemail creek, found in 2005 .

pl. 20/389 and pl. 34/334.

Max. h $3.5 \mathrm{~cm}$., d of base $11.4 \mathrm{~cm}$., max. w $3.1 \mathrm{~cm}$., $\max$. th $0.9 \mathrm{~cm}$.

Reddish brown (5YR 4/3) slip on exterior; pink (7.5YR 7/4) unslipped surface on interior. Hard, thin 

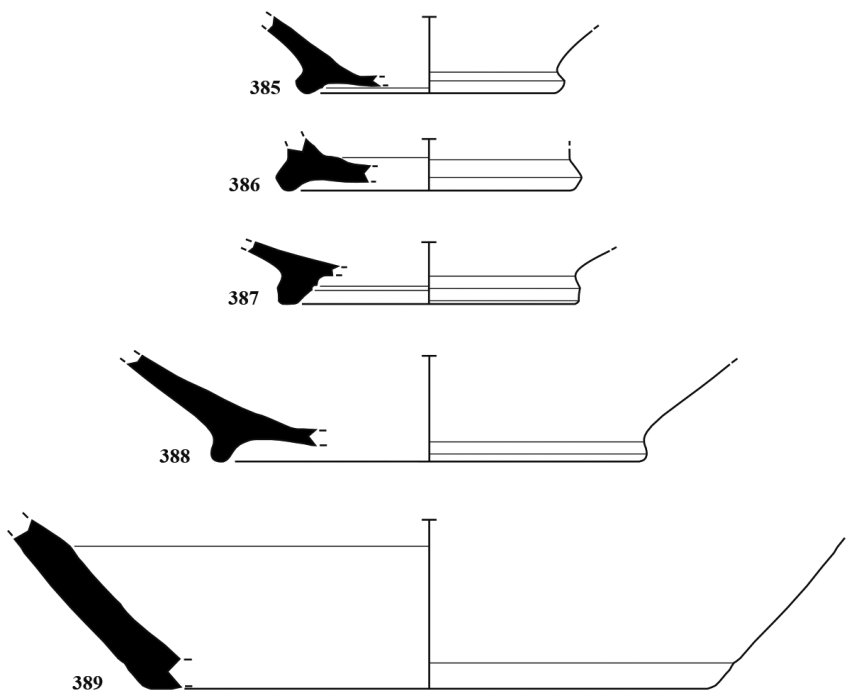

389
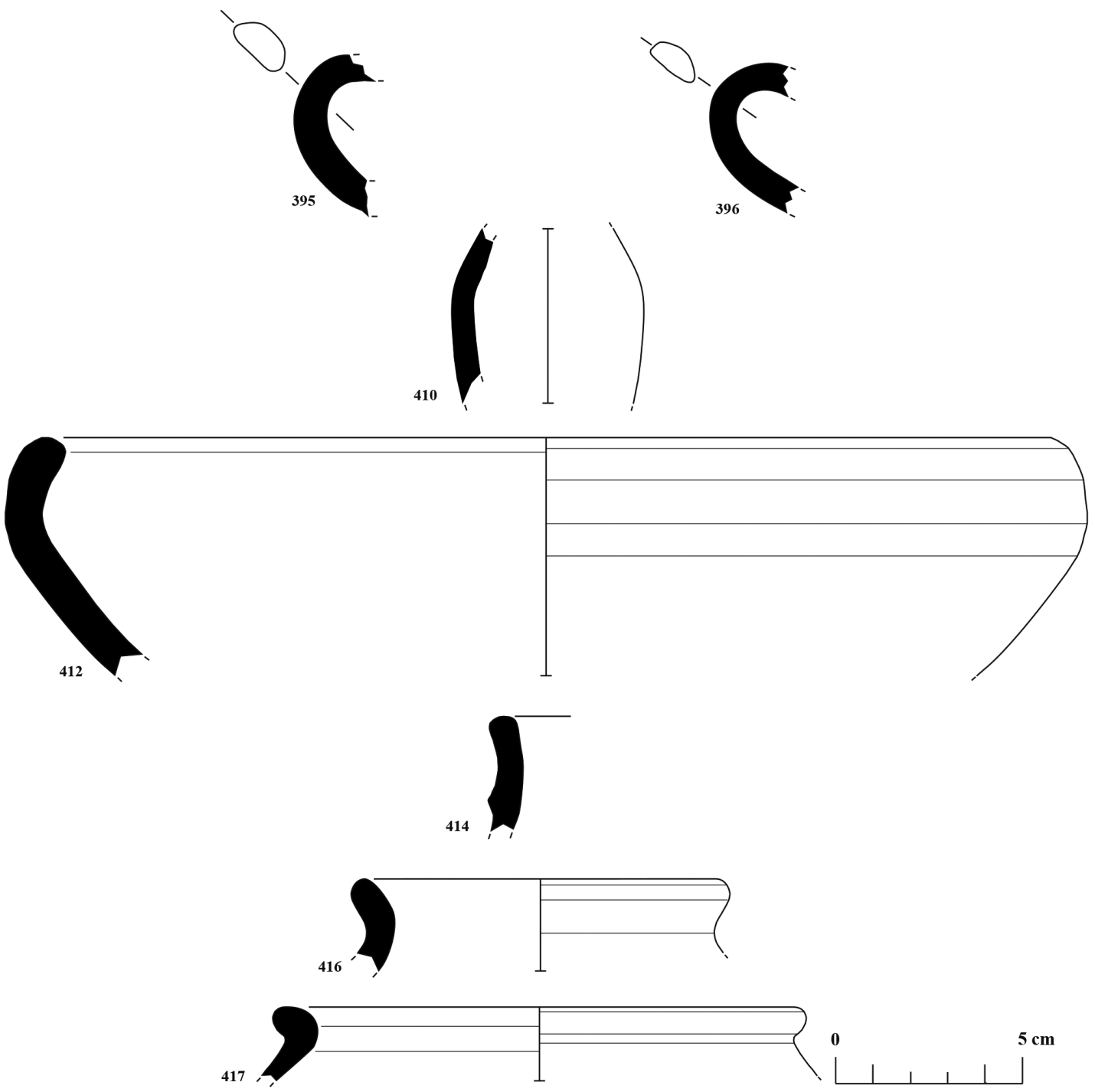

Pl. 20 : Nos 385-396: Late Hellenistic-Early Roman brown-slipped ware; $\mathbf{n}^{\text {os }}$ 385-389: Base fragments of closed forms; $n^{\text {os }}$ 395-396: Handle fragments of closed forms; no. 410: An unguentarium fragment; $n^{\text {os }}$ 412-417: Hellenistic coarse ware; $n^{0}$ 412: A rim fragment of an open form; and $n^{\text {os }}$ 414-417: Rim fragments of closed forms. 
paste; non-porous, reddish yellow (7.5YR 6/6) fabric with frequent tiny lime inclusions.

\section{Handle Fragments of Closed Forms (pl. 20, $\left.\mathrm{n}^{\text {os }} 395-396\right)$}

Vertical handles with mottled surfaces.

390. ( $\mathrm{N}^{\circ} 1134$ ): Handle fragment; Kimistene, Acropolis, found in 2005 .

pl. $35 / 335$.

Max. h $1.6 \mathrm{~cm}$., max. w $1.3 \mathrm{~cm}$., $\max$. th $0.7 \mathrm{~cm}$.

Dark reddish gray (5YR 3/2) and black (5YR 2.5/1) mottled slip both on exterior and interior. Average hardness; thin paste; non-porous, fine, reddish yellow (5YR 6/6) fabric with occasional tiny lime inclusions.

391. ( $\mathrm{N}^{\circ} 412$ ): Handle fragment; Hadrianopolis, surface find, found in 2005.

pl. 33/336.

Max. h $1.5 \mathrm{~cm}$., max. w $1.4 \mathrm{~cm}$., $\max$. th $0.6 \mathrm{~cm}$.

Red (2.5YR 5/6) and very dark gray (5YR 3/1) mottled slip both on exterior and interior. Hard, thin paste; non-porous, fine, reddish yellow (5YR 6/6) fabric with no visible inclusions.

392. ( $\mathrm{N}^{\circ}$ 240): Handle fragment; Bath A, room 12, found in 2006.

pl. $35 / 337$.

Max. h $2.0 \mathrm{~cm}$., max. w $1.7 \mathrm{~cm}$., max. th $0.6 \mathrm{~cm}$.

Red (2.5YR 5/6) and dark reddish brown (5YR 3/2) mottled slip both on exterior and interior. Average hardness; thin paste; very sparsely porous, fine, reddish yellow (5YR 6/6) fabric with no visible inclusions.

393. ( $\mathrm{N}^{\circ}$ 201): Handle fragment; Bath $\mathrm{A}$, room 13a, below the floor, found in 2006 .

pl. 35/338.

Max. h $1.0 \mathrm{~cm}$., max. w $2.3 \mathrm{~cm}$., max. th $0.6 \mathrm{~cm}$.

Reddish brown (5YR 4/4) and very dark gray (5YR $3 / 1$ ) mottled slip both on exterior and interior. Hard, thin paste; non-porous, reddish yellow (5YR 6/6) and light red (2.5YR 6/6) mottled fabric with rare micaceous and tiny lime inclusions.

394. ( $\mathrm{N}^{\circ}$ 224): Handle fragment; Bath A, Room 13, found in 2006 .

pl. 35/339.

Max. h $2.5 \mathrm{~cm}$., max. w $1.2 \mathrm{~cm}$., $\max$. th $0.6 \mathrm{~cm}$.

Black (7.5YR 2.5/1) slip on exterior and interior. Hard, thin paste; very sparsely porous, fine, reddish yellow (7.5YR 6/6) fabric with occasional micaceous and tiny lime inclusions.

395. ( $\mathrm{N}^{\circ}$ 207): Handle fragment; Bath A, Room 1, found in 2006 . pl. 20/395 and pl. 35/340.

Max. h 4.3 cm., max. w $1.7 \mathrm{~cm}$., max. th $0.8 \mathrm{~cm}$.

Brown (7.5YR 5/4) slip on exterior and interior. Hard, thin paste; very sparsely porous, fine, light yellowish brown (10YR 6/4) fabric with no visible inclusions.

396. ( $\left.\mathrm{N}^{\circ} 191\right)$ : Handle fragment; Bath A, Room 4, found in 2006.

pl. 20/396 and pl. 35/341.

Max. h $4.0 \mathrm{~cm}$., max. w $1.6 \mathrm{~cm}$., max. th $0.7 \mathrm{~cm}$.

Strong brown (7.5YR 5/6) and dark brown (7.5YR $3 / 2$ ) mottled slip both on exterior and interior. Average hardness; thin paste; non-porous, fine, light brown (7.5YR 6/4) fabric with frequent tiny lime inclusions.

\section{A Lamp Fragment (pl. 35, $\mathrm{n}^{\circ}$ 342)}

A fragment of the middle part of the lamp.

397. ( $\mathrm{N}^{\circ} 25$ ): Body fragment; domus, room 1, level 1 , found in 2007 .

pl. 35/342.

Max. h $1.9 \mathrm{~cm} .$, max. w $2.8 \mathrm{~cm}$., max. th $0.4 \mathrm{~cm}$.

Dark brown (7.5YR 3/2) slip on exterior; pink (7.5YR 7/4) unslipped surface on interior. Average hardness; thin paste; very sparsely porous, fine, reddish yellow (7.5YR 6/6) fabric with frequent sand inclusions.

\section{Body Fragments of Closed Forms (pl. $\left.35, n^{\text {os }} 343-354\right)$}

Some with very intensive wheel-marks.

398. ( $\left.\mathrm{N}^{\circ} 568\right)$ : Body fragment; surface find from the Village Boncuklar, found in 2005.

pl. 35/343.

Max. h $1.5 \mathrm{~cm}$. , max. w $1.4 \mathrm{~cm}$., $\max$. th $0.3 \mathrm{~cm}$.

Dark brown (7.5YR 3/3) slip on exterior; grayish brown (10YR 3/2) unslipped surface on interior. Average hardness; thin paste; non-porous, fine, pale brown (10YR $6 / 3$ ) fabric with no visible inclusions.

399. ( $\mathrm{N}^{\circ}$ 478): Body fragment; Bath $\mathrm{A}$, room $2 \mathrm{~b}$, found in 2006.

pl. 35/344.

Max. h $2.0 \mathrm{~cm}$., max. w $2.5 \mathrm{~cm}$., max. th $0.2 \mathrm{~cm}$.

Yellowish red (5YR 5/6) slip on exterior; pale brown (2.5Y $7 / 3)$ and dark gray $(2.5 \mathrm{Y} 4 / 1)$ mottled unslipped surface on interior. Hard, thin paste; non-porous, light brownish gray (2.5Y 6/2) and reddish yellow (7.5YR 7/6) fabric with no visible inclusions.

400. ( $\mathrm{N}^{\circ}$ 1267): Body fragment; Kimistene, Necropolis, surface find, found in 2005. 
pl. 35/345.

Max. h $1.5 \mathrm{~cm}$., max. w $2.4 \mathrm{~cm}$., $\max$. th $0.3 \mathrm{~cm}$.

Reddish brown (5YR 5/4) slip on exterior; pink (7.5YR 7/4) unslipped surface on interior, Average hardness; thin paste; non-porous, fine, reddish yellow (7.5YR $7 / 6$ ) fabric with no visible inclusions.

401. ( $\mathrm{N}^{\circ}$ 1326): Body fragment; Kimistene, summit of the Acropolis, found in 2005.

pl. 35/346.

Max. h 2.4 cm., max. w $3.4 \mathrm{~cm}$., max. th $0.4 \mathrm{~cm}$.

Brown (7.5YR 4/3) slip on exterior; pink (7.5YR 7/4) unslipped surface on interior, Hard, thin paste; nonporous, fine, reddish yellow (7.5YR 7/6) fabric with no visible inclusions.

402. ( $\mathrm{N}^{\circ}$ 554): Body fragment; surface find from the Village Boncuklar, found in 2005.

pl. 35/347.

Max. h $2.7 \mathrm{~cm}$., max. w $2.9 \mathrm{~cm}$., max. th $0.3 \mathrm{~cm}$.

Brown (10YR 5/3) slip on exterior; very pale brown (10YR 7/3) unslipped surface on interior. Average hardness; thin paste; non-porous, fine, very pale brown (10YR 7/3) fabric with no visible inclusions.

403. ( No 55): Body fragment; Domus, room 6, level 1 , found in 2007.

pl. 35/348.

Max. h $3.2 \mathrm{~cm}$., max. w $2.7 \mathrm{~cm}$., max. th $0.3 \mathrm{~cm}$.

Dark grayish brown (10YR 4/2) slip on exterior; light yellowish brown (2.5Y 6/3) and dark gray (2.5Y 4/1) mottled unslipped surface on interior. Hard, thin paste; nonporous, light yellowish brown $(2.5 \mathrm{Y} 6 / 3)$ and dark gray $(2.5 \mathrm{Y} 4 / 1)$ mottled fabric with no visible inclusions.

404. ( $\mathrm{N}^{\mathrm{0}}$ 1455): Body fragment; Bath $\mathrm{A}$, room 1 , found in 2006 .

pl. 35/349.

Max. h $3.6 \mathrm{~cm}$., max. w $3.3 \mathrm{~cm}$., max. th $0.6 \mathrm{~cm}$.

Reddish brown (2.5YR 4/4) shiny slip on exterior; light red (2.5YR 6/6) unslipped surface on interior, Hard, thin paste; non-porous, fine, yellowish red (5YR 5/6) fabric with rare lime and sand inclusions.

405. ( $\mathrm{N}^{\circ} 218$ ): Body fragment; Bath A, room 1, found in 2006.

pl. 35/350.

Max. h $4.1 \mathrm{~cm}$., max. w $2.6 \mathrm{~cm}$., max. th $0.5 \mathrm{~cm}$.

Dark brown (7.5YR 3/2) slip on exterior; pink (7.5YR 7/4) unslipped surface on interior. Hard, thin paste; non-porous, fine, light brown (7.5YR 6/4) fabric with no visible inclusions.
406. ( $\mathrm{N}^{\mathrm{o}} 275$ ): Body fragment; Bath A, Room 14, found in 2007.

pl. 35/351.

Max. h $4.3 \mathrm{~cm}$., max. w $3.4 \mathrm{~cm}$., max. th $0.3 \mathrm{~cm}$.

Dark reddish brown (5YR 3/2) slip on exterior; red (2.5YR 4/6) slip on upper exterior. The below part of the interior has a light red (2.5YR 6/6) unslipped surface. Hard, thin paste; non-porous, light red (2.5YR 6/6) and reddish yellow (5YR 6/6) mottled fabric with no visible inclusions.

407. ( $\mathrm{N}^{\mathrm{o}} 338$ ): Body fragment; Bath A, room 1, found in 2007.

pl. $35 / 352$.

Max. h 3.4 cm., max. w $4.5 \mathrm{~cm}$., max. th $0.5 \mathrm{~cm}$.

Brown (7.5YR 4/2) slip on exterior; reddish yellow (7.5YR 7/6) unslipped surface on interior. Average hardness; thin paste; very sparsely porous, fine, reddish yellow (7.5YR 6/6) fabric with some tiny lime and rare micaceous inclusions.

408. ( $\left.\mathrm{N}^{\circ} 1200\right)$ : Body fragment; Kepez, surface find in the Cistern, found in 2005.

pl. 35/353.

Max. h 3.7 cm., max. w $4.8 \mathrm{~cm}$., $\max$. th $0.6 \mathrm{~cm}$.

Brown (7.5YR 4/3) and reddish yellow (5YR 6/6) mottled slip on exterior; pink (7.5YR 7/3) unslipped surface on interior. Hard, thin paste; very sparsely porous, fine, pink (7.5YR 7/4) fabric with infrequent calsite, sand and tiny lime inclusions.

409. ( $\left.\mathrm{N}^{\circ} 1408\right)$ : Body fragment; Kepez, surface find, found in 2005 .

pl. 35/354.

Max. h 7.8 cm., max. w 7.9 cm., $\max$. th $0.8 \mathrm{~cm}$.

Dark brown (7.5YR 3/2) slip on exterior; pink (7.5YR 7/4) unslipped surface on interior. Hard, thin paste; non-porous, fine, reddish yellow (5YR 6/6) fabric with some small grit, sand and lime inclusions.

\section{An Unguentarium}

$$
\text { (pl. 20, no 410) }
$$

Fragment of the upper body with non-porous walls $^{49}$.

410. ( $\mathrm{N}^{\circ} 1370$ ): Body fragment of a fusiform unguentarium $^{50}$; Kimistene, Necropolis 1, found in 2005.

pl. 20/410 and pl. 35/355.

Max. h $4.7 \mathrm{~cm}$, max. w $4.0 \mathrm{~cm}$, max. th $0.6 \mathrm{~cm}$.

Yellowish red (5YR 5/6) slip on exterior; reddish brown (5YR 5/4) unslipped surface on exterior. Nonporous paste; fine, reddish brown (5YR 5/4) fabric with rare tiny lime inclusions.

Late Hellenistic ( $1^{\text {st }}$ cent. B.C.)

49) Parallels: Rotroff 1997: 175-178, $\mathrm{n}^{\text {os }}$ 1163-1172. A similar unguentarium fragment was found in Apollonia Pontica; its upper body profile is, however, wider than $\mathrm{n}^{\circ} 410$. It is dated to the third quarter of the $3^{\text {rd }}$ century B.C.: Bechtold and Docter 2008: 72, fig. 25 .

50) This sherd has been published at: Laflı and Kan Şahin 2013: 462 


\section{Hellenistic Coarse Ware \\ (pls. 20-22, $\mathrm{n}^{\text {os }} 412-450$ )}

One of the largest groups of Hellenistic surface finds comprises of the wheel-made cooking and plain ware that is classified as 'Hellenistic coarse ware'. Their typological and clay differences to Roman coarse ware, however, is not very distinctive. Most common forms have a large plain body without any decoration. They should be locally manufactured.

Most common paste tones are reddish yellow (5YR 6/6-6/8-7/6, 7.5YR 6/6-7/6), yellowish red (5YR 5/6-5/8), red (2.5YR 5/6-5/8), light red (2.5YR 6/6-6/8), brown (7.5YR 5/4, 10YR 5/3), pale brown (10YR 6/3), gray (Gley $15 / \mathrm{N}, 10 \mathrm{YR} 6 / 1,7.5 \mathrm{YR} 4 / 1$, 5YR 5/1), reddish brown (5YR 5/4), pink (7.5YR $7 / 4$ ) and light yellowish brown (10YR 6/4). Fine and hard fabric with grit, sand, lime, micaceous and grog in large sizes, visible even on the surface. Nonporous fabric with reddish yellow (5YR 6/6-7/6, 7.5YR 6/6-7/6), very pale brown (10YR 8/2-8/3$7 / 3$ ), pink (7.5YR 8/3-8/4-7/4), light red (2.5YR $6 / 8$ ), red (2.5YR 5/6), light reddish brown (5YR $6 / 4)$, gray $(2.5 \mathrm{Y} 6 / 1)$ and light yellowish brown (10YR 6/4) slips. Wall thickness differs between 4 and $10 \mathrm{~mm}$.

3 of 47 fragments belong to open and 44 to closed forms. 24 of them were found at Kepez, and the rest from Kimistene. It is interesting to note that there is no Hellenistic coarse ware find from Hadrianopolis.

$2^{\text {nd }}-1{ }^{\text {st }}$ centuries B.C.

$$
\text { Open Forms (pl. 20, n 412) }
$$

Rim Fragments (pl. 20, n 412)

It was not possible to assign sherds of open forms to any known typologies. Anyhow they belong to wide and large forms, probably for necessary household tasks such as mixing and preparing food; thus perhaps large kitchen bowls.

411. ( $N^{\circ}$ 1117): Rim fragment; Kimistene, Acropolis, found in 2005 .

pl. 35/356.

Max. h $3.8 \mathrm{~cm}$., max. w $4.6 \mathrm{~cm}$., max. th $1.3 \mathrm{~cm}$.

Reddish yellow (5YR 6/6) slip on exterior and interior. Hard, non-porous, fine, reddish yellow (5YR 6/6) fabric with frequent large grit and sand inclusions.
412. ( $\mathrm{N}^{\circ}$ 828): Rim fragment; Kimistene, Cistern, eastern slope, found in 2005.

pl. 20/412 and pl. 35/357.

Max. h $6.4 \mathrm{~cm}$., d of rim $27.0 \mathrm{~cm}$., max. w $12.8 \mathrm{~cm}$., max. th $1.1 \mathrm{~cm}$.

Reddish yellow (5YR 6/6) slip on exterior and interior. Hard, non-porous, fine, red (2.5YR 5/8) fabric with frequent tiny lime inclusions.

413. (No 1067): Rim fragment; Kepez, found in 2005. pl. 35/358.

Max. h $5.5 \mathrm{~cm}$., d of rim $31.0 \mathrm{~cm}$., max. w $8.7 \mathrm{~cm}$., $\max$. th $1.5 \mathrm{~cm}$.

Light brown (7.5YR 6/4) unslipped surface on exterior and interior. Soft, sparsely porous fine, yellowish red (5YR 5/6) fabric with frequent small grit inclusions.

Closed Forms (pls. 20-22, ${ }^{\text {os }} 414-452$ )

Rim Fragments (pls. 20-21, n ${ }^{\text {os }} 414-418$ )

They should be associated with storage or pouring activities in the household. Most of them are smaller sherds belonging to deep vessel forms with a globular or ovoid body, a constricted neck, a slightly thickened everted or outcurved rim and a flat or slightly rounded base. Thus, they could be cooking pots or jugs with a variation in size from 9.4 to $24 \mathrm{~cm}$ in rim diameter.

414. ( $\left.\mathrm{N}^{\circ} 1052\right)$ : Rim fragment of a jug; Kepez, found in 2005 .

pl. 20/414 and pl. 36/359.

Max. h $3.1 \mathrm{~cm}$., max. w $2.7 \mathrm{~cm}$., max. th $0.7 \mathrm{~cm}$.

Very pale brown (10YR 8/2) slip on exterior and interior. Average hardness; non-porous, fine, reddish yellow (7.5YR 6/6) fabric with frequent tiny lime inclusions.

415. (No 594): Rim fragment; Kimistene, Acropolis, southern slope, just below of the summit of Deresemail creek, found in 2005.

pl. 36/360.

Max. h $5.0 \mathrm{~cm}$., max. w $4.6 \mathrm{~cm}$., max. th $1.0 \mathrm{~cm}$.

Very pale brown (10YR 7/3) slip on exterior and interior rim. Reddish yellow (5YR 6/6) unslipped surface on lower interior. Hard, very sparsely porous, fine, reddish yellow (5YR 6/6) fabric with frequent tiny lime and some sand inclusions.

416. ( No 949): Rim fragment; Kepez, the surface find in the Cistern, found in 2005.

pl. 20/416 and pl. 36/361.

Max. h $2.5 \mathrm{~cm}$., d of rim $9.4 \mathrm{~cm}$., max. w $3.5 \mathrm{~cm}$., $\max$. th $0.7 \mathrm{~cm}$.

Reddish yellow (5YR 6/6) slip on exterior and interior. Average hardness; non-porous, fine, light brown (7.5YR 6/6) fabric with some sand inclusions. 

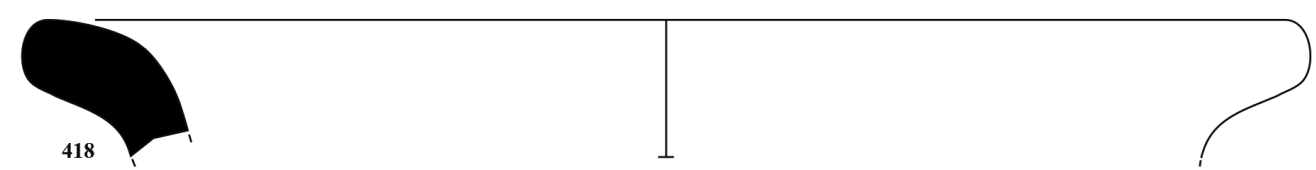

419
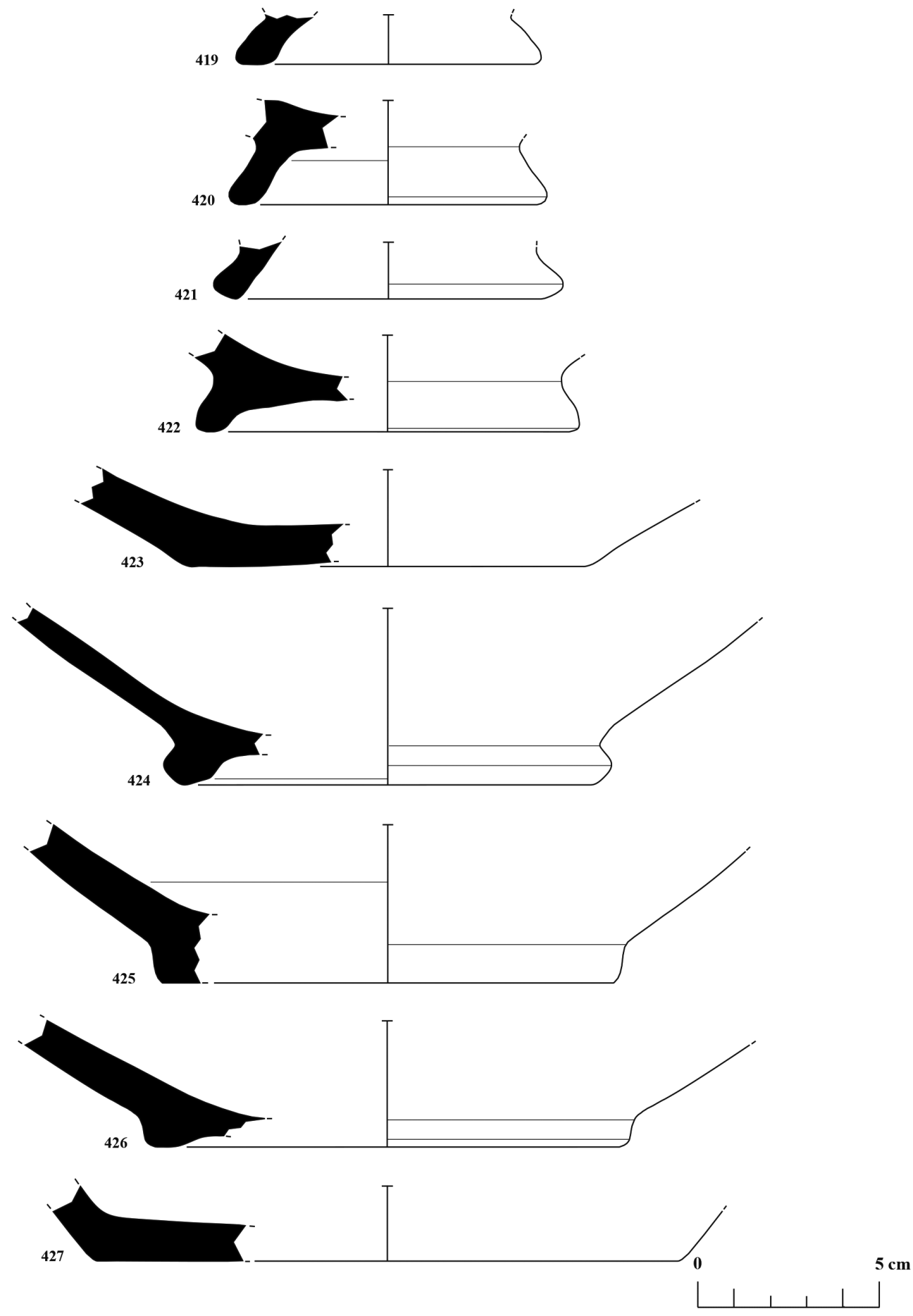

Pl. 21 : $\mathbf{N}^{\text {os }}$ 418-427: Hellenistic coarse ware; $n^{0}$ 418: A rim fragment of a closed form; and $n^{\text {os }}$ 419-427: Base fragments of closed forms. 
417. ( $\left.\mathrm{N}^{\circ} 1156\right)$ : Rim fragment; Kepez, the surface find in the Cistern, found in 2005.

pl. 20/417 and pl. 36/362.

Max. h $2.0 \mathrm{~cm}$., d of rim $13.6 \mathrm{~cm}$., max. w $4.8 \mathrm{~cm}$., max. th $0.4 \mathrm{~cm}$.

Gray (2.5Y 6/1) slip on exterior; light gray (2.5Y 7/1) unslipped surface on interior. Hard, non-porous, fine, gray (10YR 6/1) fabric with some lime and large grit inclusions.

418. ( $\left.\mathrm{N}^{\circ} 1273\right)$ : Rim fragment of a casserole (?); Kimistene, Necropolis, found in 2005.

pl. 21/418 and pl. 36/363.

Max. h $2.7 \mathrm{~cm}$., d of rim $24.0 \mathrm{~cm}$., max. w $4.2 \mathrm{~cm}$., max. th $1.3 \mathrm{~cm}$.

Everted rim $^{51}$; gray $(2.5 \mathrm{Y} 6 / 1)$ unslipped surface on exterior; gray (Gley $16 / \mathrm{N}$ ) unslipped surface on interior. Hard, sparsely porous, fine, gray (Gley $15 / \mathrm{N}$ ) fabric with frequent lime and sand inclusions.

\section{Base Fragments of Closed Forms (pl. 21, $n^{\text {os }} 419-427$ )}

Ring base fragments of juglets or table amphorae.

419. ( $\left.\mathrm{N}^{\circ} 1108\right)$ : Base fragment; Kepez, surface find in the Cistern, found in 2005 .

pl. 21/419 and pl. 36/364.

Max. h $1.4 \mathrm{~cm}$., d of base $8.0 \mathrm{~cm}$., max. w $6.5 \mathrm{~cm}$., max. th $1.0 \mathrm{~cm}$.

Reddish yellow (5YR 7/6) unslipped surface on exterior and interior. Average hardness; non-porous, fine, yellowish red (5YR 5/6) fabric with frequent tiny lime inclusions.

420. ( $\mathrm{N}^{\circ}$ 992): Base fragment; Kepez, found in 2005. pl. 21/420 and pl. 36/365.

Max. h $2.9 \mathrm{~cm}$., d of base $8.2 \mathrm{~cm}$., max. w $4.3 \mathrm{~cm}$., max. th $1.2 \mathrm{~cm}$.

Very pale brown (10YR 7/3) slip on exterior; light brownish gray (10YR 6/2) unslipped surface on interior. Average hardness; very sparsely porous, dark gray (10YR 4/1) and pale brown (10YR 6/3) fabric with occasional tiny lime and sand inclusions. 2005 .

421. ( $\mathrm{N}^{\circ}$ 1072): Base fragment; Kepez, found in

pl. 21/421 and pl. 36/366.

Max. h $1.6 \mathrm{~cm}$., d of base $8.4 \mathrm{~cm}$., max. w $4.5 \mathrm{~cm}$., $\max$. th $1.0 \mathrm{~cm}$.

Whole surface is unslipped. Average hardness; nonporous, reddish yellow (5YR 6/6) fabric with infrequent tiny lime inclusions.
422. ( $\mathrm{N}^{\circ}$ 1228): Base fragment; Kepez, found in 2005.

pl. 21/422 and pl. 36/367.

Max. h $2.7 \mathrm{~cm}$., d of base $10.0 \mathrm{~cm}$., max. w $8.8 \mathrm{~cm}$., max. th $1.2 \mathrm{~cm}$.

Reddish yellow (7.5YR 7/6) unslipped surface on exterior and interior. Pink (7.5YR 7/4) unslipped surface on interior. Average hardness; very sparsely porous, fine, reddish yellow (7.5YR 7/6) fabric with infrequent small grit inclusions.

423. ( $\mathrm{N}^{\circ}$ 1113): Base fragment; Kepez, surface find in the Cistern, found in 2005.

pl. 21/423 and pl. 36/368.

Max. h $2.7 \mathrm{~cm}$., d of base $10.8 \mathrm{~cm}$., max. w $8.3 \mathrm{~cm}$., $\max$. th $1.4 \mathrm{~cm}$.

Reddish yellow (7.5YR 6/6) slip on exterior. Exterior surface is burnished. Reddish yellow (5YR 6/6) slip on interior. Hard, very sparsely porous, yellowish red (5YR $5 / 6)$ and gray (7.5YR 6/1) fabric with frequent tiny lime inclusions.

424. ( No 997): Base fragment; Kimistene, Acropolis, found in 2005 .

pl. 21/424 and pl. 36/369.

Max. h $4.9 \mathrm{~cm}$., d of base $11.2 \mathrm{~cm}$., max. w $8.8 \mathrm{~cm}$., max. th $1.2 \mathrm{~cm}$

Light yellowish brown (10YR 6/4) unslipped surface on exterior; light brown (7.5YR 6/4) unslipped surface on interior. Soft, very sparsely porous, brown (10YR 5/3) fabric with some sand inclusions.

425. ( $\left.\mathrm{N}^{\circ} 1155\right)$ : Base fragment; Kepez, surface find in the Cistern, found in 2005.

pl. 21/425 and pl. 36/370.

Max. h $4.4 \mathrm{~cm}$., d of base $12.4 \mathrm{~cm}$., $\max$. w $11.7 \mathrm{~cm}$., max. th $1.4 \mathrm{~cm}$.

Light yellowish brown (10YR 6/4) thin slip on exterior; light brown (7.5YR 6/4) unslipped surface on interior. Hard, porous, light yellowish brown (10YR 6/4) and brown $(10$ YR 4/2) fabric with some tiny lime and sand inclusions.

426. ( $\mathrm{N}^{\circ}$ 1367): Base fragment; Kimistene, Acropolis, found in 2005 .

pl. 21/426 and pl. 36/371.

Max. h $3.5 \mathrm{~cm}$., d of base $12.8 \mathrm{~cm}$., max. w $6.9 \mathrm{~cm}$., $\max$. th $1.1 \mathrm{~cm}$.

Reddish yellow (5YR 6/6) slip on exterior; reddish yellow (5YR 6/6) unslipped surface on interior. Average hardness; sparsely porous, fine, reddish yellow (5YR 6/8) fabric with frequent tiny lime inclusions. 
427. ( $\left.\mathrm{N}^{\circ} 1110\right)$ : Base fragment; Kepez, surface find in the Cistern, found in 2005.

pl. 21/427 and pl. 36/372.

Max. h $2.1 \mathrm{~cm}$., d of base $16.0 \mathrm{~cm}$., max. w $7.5 \mathrm{~cm}$., max. th $1.0 \mathrm{~cm}$.

Very pale brown (10YR 8/3) slip on exterior; brown (7.5YR 5/3) unslipped surface on interior. Average hardness; non-porous, fine, brown (7.5YR 5/4) fabric with some tiny lime and occasional micaceous inclusions.

\section{A Handle Fragment of a Closed Form} (pl. 36, $\mathrm{n}^{\circ} 373$ )

A vertical handle.

428. ( $\left.\mathrm{N}^{\circ} 448\right)$ : Handle fragment; Kimistene, Acropolis, southern slope, just below of the summit of Deresemail creek, found in 2005 .

pl. 36/373.

Max. h $8.0 \mathrm{~cm}$., max. w $3.9 \mathrm{~cm}$., max. th $2.9 \mathrm{~cm}$.

Pink (7.5YR 8/3) slip on all of surface. Hard, porous, fine, reddish yellow (5YR 6/6) fabric with some lime and occasional grog inclusions.

\section{Body Fragments of Closed Form (pl. 22, $\mathrm{n}^{\text {os }} 450-551$ )}

Some of them are decorated with simple painting or reliefing.

429. (No 761): Body fragment; Kimistene, Acropolis, temple's terrace, illegally excavated area under the temple's podium, found in 2005 .

pl. $37 / 374$.

Max. h $1.6 \mathrm{~cm}$., max. w $1.9 \mathrm{~cm}$., max. th $0.6 \mathrm{~cm}$.

Unslipped surface on exterior and interior. Hard, nonporous, fine, reddish yellow (5YR 6/6) fabric with frequent tiny lime and rare grog inclusions.

430. ( $\mathrm{N}^{\circ} 748$ ): Body fragment; Kimistene, Acropolis, temple's terrace, illegally excavated area under the temple's podium, found in 2005 .

pl. 37/375.

Max. h $1.9 \mathrm{~cm}$., max. w $2.2 \mathrm{~cm}$., max. th $0.7 \mathrm{~cm}$.

Pink (7.5YR 8/4) slip on exterior; light red (2.5YR 7/6) unslipped surface on interior. Hard, non-porous, fine, yellowish red (5YR 5/8) fabric with rare lime inclusions.

431. ( $\mathrm{N}^{\circ} 770$ ): Body fragment; Kimistene, Acropolis, temple's terrace, illegally excavated area under the temple's podium, found in 2005 .

pl. 37/376.

Max. h $2.7 \mathrm{~cm}$., max. w $2.2 \mathrm{~cm}$., max. th $0.6 \mathrm{~cm}$.

Unslipped surface on exterior and interior. Hard, very sparsely porous, fine, reddish yellow (5YR 7/6) fabric with rare medium lime inclusions.
432. ( $\mathrm{N}^{\circ}$ 1055): Body fragment; Kepez, found in 2005.

pl. 37/377.

Max. h 2.9 cm., max. w $3.2 \mathrm{~cm}$., max. th $0.6 \mathrm{~cm}$.

$\mathrm{U}$ nslipped surface on exterior and interior. Hard, non-porous, fine, red (2.5YR 5/6) fabric with some lime and rare medium grit inclusions.

433. (№ 779): Body fragment; Kimistene, Acropolis, temple's terrace, illegally excavated area under the temple's podium, found in 2005 .

pl. 37/378.

Max. h $2.7 \mathrm{~cm}$., max. w $3.1 \mathrm{~cm}$., max. th $0.6 \mathrm{~cm}$.

Unslipped surface on exterior and interior. Hard, nonporous, fine, reddish yellow (5YR 6/8) fabric with some lime, medium grit and rare micaceous inclusions.

434. ( $\mathrm{N}^{0}$ 785): Body fragment; Kimistene, Acropolis, temple's terrace, illegally excavated area under the temple's podium, found in 2005 .

pl. 37/379.

Max. h $3.3 \mathrm{~cm}$., max. w $3.3 \mathrm{~cm}$., max. th $0.7 \mathrm{~cm}$.

Unslipped surface on exterior and interior. Hard, nonporous, fine, reddish yellow (5YR 6/8) fabric with some lime, small grit and rare micaceous inclusions.

435. ( $\mathrm{N}^{\circ} 729$ ): Body fragment; Kimistene, Acropolis, temple's terrace, illegally excavated area under the temple's podium, found in 2005 .

pl. 37/380.

Max. h $2.5 \mathrm{~cm}$., max. w $3.6 \mathrm{~cm}$., max. th $1.2 \mathrm{~cm}$.

Unslipped surface on exterior and interior. Average hardness; non-porous, fine, yellowish red (5YR 5/6) fabric with some sand inclusions.

436. (No 1177): Body fragment; Kepez, surface find in the Cistern, found in 2005.

pl. 37/381.

Max. h $2.8 \mathrm{~cm}$., max. w $3.7 \mathrm{~cm}$., max. th $1.0 \mathrm{~cm}$.

Reddish yellow (7.5YR 7/6) slip on exterior; pink (7.5YR 7/4) unslipped surface on interior. Average hardness; non-porous, fine, reddish yellow (5YR 6/8) fabric with infrequent tiny lime inclusions.

437. (No 778): Body fragment; Kimistene, Acropolis, temple's terrace, illegally excavated area under the temple's podium, found in 2005 .

pl. 37/382.

Max. h $4.2 \mathrm{~cm}$., max. w $2.8 \mathrm{~cm}$., max. th $0.6 \mathrm{~cm}$.

Unslipped surface on exterior and interior. Hard, nonporous, fine, reddish yellow (5YR 6/8) fabric with some lime, small grit and rare micaceous inclusions.

438. ( $\mathrm{N}^{\circ}$ 777): Body fragment; Kimistene, Acropolis, temple's terrace, illegally excavated area under the temple's podium, found in 2005 .

pl. 37/383.

Max. h $3.9 \mathrm{~cm}$., max. w $3.6 \mathrm{~cm}$., max. th $0.7 \mathrm{~cm}$.

Light red (2.5YR 6/8) slip on exterior; unslipped sur- 
face on interior. Hard, thin paste; non-porous, fine, reddish yellow (5YR 6/6) fabric with frequent tiny lime inclusions.

439. ( $\mathrm{N}^{\circ}$ 1196): Body fragment; Kimistene, Acropolis, southern slope, just below of the summit of Deresemail creek, found in 2005.

pl. 37/384.

Max. h $4.6 \mathrm{~cm}$., max. w $4.0 \mathrm{~cm}$., max. th $0.9 \mathrm{~cm}$.

Pink (7.5YR 7/4) slip on exterior; unslipped surface on interior. Exterior surface is burnished. Hard, nonporous, reddish yellow (5YR 6/6) and gray (7.5YR 5/1) fabric with occasional micaceous and rare lime inclusions. 2005 .

440. ( $\mathrm{N}^{\circ}$ 1230): Body fragment; Kepez, found in

pl. $37 / 385$.

Max. h $5.0 \mathrm{~cm}$., max. w $4.7 \mathrm{~cm}$., $\max$. th $1.0 \mathrm{~cm}$.

Reddish yellow (7.5YR 7/6) slip on exterior; unslipped surface on interior. Hard, non-porous, yellowish red $(5 \mathrm{YR} 5 / 6)$ fabric with frequent tiny lime inclusions.

441. ( $\mathrm{N}^{\circ}$ 1289): Body fragment; Kimistene, Acropolis, found in 2005 .

pl. 37/386.

Max. h $4.1 \mathrm{~cm}$., max. w $5.1 \mathrm{~cm}$., max. th $1.0 \mathrm{~cm}$.

Unslipped surface on exterior and interior. Hard, nonporous, fine, yellowish red (5YR 5/6) fabric with infrequent tiny lime and sand inclusions.

442. ( $\mathrm{N}^{\circ} 1137$ ): Body fragment; Kimistene, Acropolis, southern slope, just below of the summit of Deresemail creek, found in 2005.

pl. 37/387.

Max. h 4.9 cm., max. w $5.6 \mathrm{~cm}$., max. th $1.0 \mathrm{~cm}$.

Painted band decoration on shoulder; pink (7.5YR $7 / 4$ ) unslipped surface on upper exterior. Its below part has a very pale brown (10YR 8/2) slip. Reddish yellow (2.5YR 6/6) unslipped surface on interior. A band in red $(2.5 Y R$ 5/6) on exterior. Exterior surface is burnished. Hard, non-porous, fine, red (2.5YR 5/6) fabric with rare lime inclusions.

443. ( $\mathrm{N}^{\circ}$ 989): Body fragment; Kepez, found in 2005 . pl. 37/388.

Max. h $5.1 \mathrm{~cm}$., max. w $5.3 \mathrm{~cm}$., max. th $0.4 \mathrm{~cm}$.

Reddish yellow (5YR 7/6) slip on exterior; reddish yellow (5YR 6/6) unslipped surface on interior. Hard, very sparsely porous, red $(2.5 \mathrm{YR} 5 / 8)$ and pale brown (10YR 6/3) fabric with infrequent tiny lime, rare sand inclusions.

444. ( $\mathrm{N}^{\circ}$ 1229): Body fragment; Kepez, surface find in the Cistern, found in 2005.

pl. 37/389.

Max. h $6.8 \mathrm{~cm}$., max. w $4.2 \mathrm{~cm}$., $\max$. th $1.2 \mathrm{~cm}$.

Reddish yellow (5YR 6/6) unslipped surface on exterior and interior. Hard, sparsely porous, fine, reddish yellow (5YR 6/6) fabric with some tiny lime, medium grit inclusions.
445. ( $\mathrm{N}^{\mathrm{o}} 463$ ): Body fragment; Kimistene, Acropolis, southern slope, just below of the summit of Deresemail creek, found in 2005.

pl. 37/390.

Max. h 3.0 cm., max. w $8.2 \mathrm{~cm}$., max. th $0.9 \mathrm{~cm}$.

Red (2.5YR 5/6) slip on exterior; reddish yellow (5YR 6/4) unslipped surface on interior. A band in pinkish white $(7.5 \mathrm{YR} 8 / 2)$ on exterior slip. Hard, very sparsely porous, fine, reddish yellow (7.5YR 6/6) fabric with some tiny lime inclusions.

446. ( $\mathrm{N}^{\circ}$ 1297): Body fragment; Kimistene, Acropolis, temple slope, illegally excavated pit, found in 2005 .

pl. $37 / 391$.

Max. h $7.1 \mathrm{~cm}$. , max. w $4.7 \mathrm{~cm}$. , $\max$. th $0.8 \mathrm{~cm}$.

Reddish yellow (5YR 6/6) slip on exterior; pink (5YR $7 / 4$ ) unslipped surface on interior. Exterior surface is burnished. Hard, non-porous, fine, light reddish brown (5YR $6 / 4$ ) fabric with frequent tiny lime, occasional sand inclusions.

447. ( $\mathrm{N}^{\circ} 863$ ): Body fragment; Kimistene, Acropolis, temple slope, illegal excavation area, altar with boucranion, found in 2005 .

pl. $37 / 392$.

Max. h $7.3 \mathrm{~cm}$. , max. w $5.8 \mathrm{~cm}$., max. th $0.8 \mathrm{~cm}$.

Pink (7.5YR 7/4) slip on exterior; very pale brown (10YR 7/4) unslipped surface on interior. Exterior surface is burnished. Hard, non-porous, very pale brown (10YR $7 / 4)$ and light red (2.5YR 6/8) fabric with frequent tiny lime and occasional sand inclusions.

448. ( $\left.\mathrm{N}^{\circ} 1164\right)$ : Body fragment; Kepez, surface find in the Cistern, found in 2005.

Max. h $6.6 \mathrm{~cm}$., max. w $7.9 \mathrm{~cm}$., max. th $0.9 \mathrm{~cm}$

Reddish yellow (5YR 6/6) thin slip on exterior; reddish yellow (7.5YR 7/6) unslipped surface on interior. Exterior surface is burnished. Hard, non-porous, yellowish red (5YR 5/6) and reddish yellow (7.5YR 6/6) fabric with some tiny lime and micaceous inclusions.

449. ( $\left.\mathrm{N}^{\circ} 1379\right)$ : Body fragment; Kepez, Necropolis, found in 2005 .

Max. h $6.5 \mathrm{~cm} ., \max$. w $8.2 \mathrm{~cm}$., $\max$. th $1.1 \mathrm{~cm}$ pl. 37/394.

Light brown (7.5YR 6/3) unslipped surface on exterior; light red (2.5YR 6/8) unslipped surface on interior. Traces of carbon on exterior. Hard, non-porous, light red (2.5YR 6/6) fabric with frequent tiny lime and occasional sand inclusions.

450. ( $\left.\mathrm{N}^{\circ} 1151\right)$ : Body fragment; Kepez, surface find in the Cistern, found in 2005.

pl. 22/450 and pl. $38 / 395$.

Max. h $6.7 \mathrm{~cm}$., max. w $9.5 \mathrm{~cm}$., max. th $1.0 \mathrm{~cm}$.

Very pale brown (10YR 8/2) slip on exterior; reddish yellow (7.5YR 6/6) unslipped surface on interior. Hard, very sparsely porous, reddish yellow (7.5YR 6/6) and 

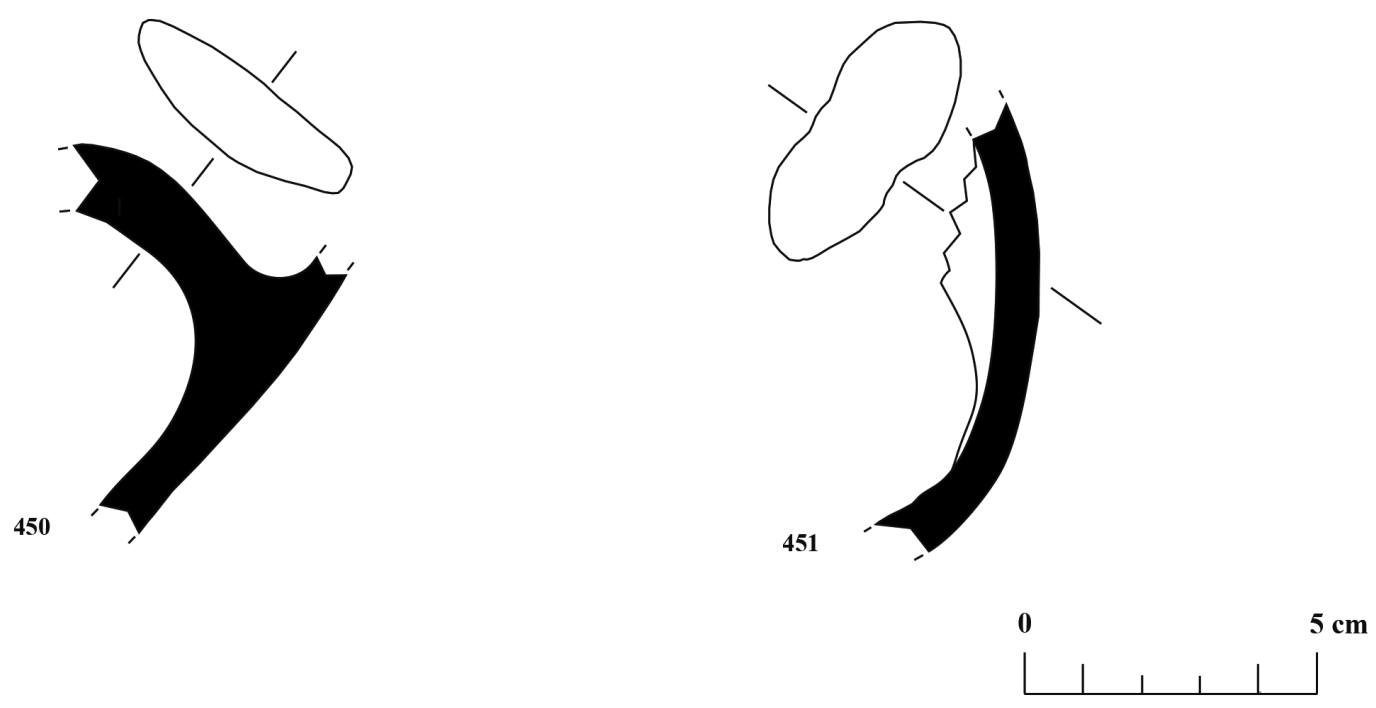

PI. 22: Nos 450-451: Hellenistic Coarse Ware, body fragments of closed forms.

brown (7.5YR 4/2) fabric with some tiny lime, medium grit and micaceous inclusions.

451. ( $\mathrm{N}^{\circ}$ 726): Body fragment; Kimistene, Acropolis, temple's terrace, illegally excavated area under the temple's podium, found in 2005 .

pl. 22/451 and pl. $38 / 396$.

Max. h $7.7 \mathrm{~cm}$., max. w $8.5 \mathrm{~cm}$., max. th $1.0 \mathrm{~cm}$.

Reddish yellow (5YR 7/6) slip on exterior; reddish yellow (5YR 6/6) unslipped surface on interior. Hard, non-porous, fine, reddish yellow (5YR 6/8) fabric with frequent tiny lime, medium grit and micaceous inclusions. 2005 .

452. ( $\mathrm{N}^{\mathrm{o}}$ 1293): Body fragment; Kepez, found in pl. 38/397.

Max. h $6.4 \mathrm{~cm}$., max. w $9.9 \mathrm{~cm}$., max. th $0.9 \mathrm{~cm}$.

Very pale brown (10YR 8/3) slip on exterior; light reddish brown (5YR 6/4) unslipped surface on interior. Hard, non-porous, fine, yellowish red (5YR 5/6) fabric with frequent tiny lime inclusions.

453. ( $\mathrm{N}^{\circ}$ 1162): Body fragment; Kepez, surface find in the Cistern, found in 2005.

pl. 38/398.

Max. h $7.5 \mathrm{~cm}$., max. w $10.1 \mathrm{~cm}$., max. th $0.9 \mathrm{~cm}$.

Very pale brown (10YR 8/2) slip on exterior; reddish yellow (7.5YR 6/6) unslipped surface on interior. Average hardness; very sparsely porous, fine, reddish yellow (5YR 6/6) fabric with frequent tiny lime, medium grit and micaceous inclusions.

454. ( $\mathrm{N}^{\mathrm{o}}$ 1154): Body fragment; Kepez, surface find in the Cistern, found in 2005.

pl. 38/399.

Max. h $11.2 \mathrm{~cm}$., max. w $8.4 \mathrm{~cm}$., max. th $0.6 \mathrm{~cm}$.

Very pale brown (10YR 8/2) slip on exterior; pink
(7.5YR 7/4) unslipped surface on interior. Hard, porous, fine, pink (7.5YR 7/4) fabric with frequent tiny lime, rare micaceous and sand inclusions.

455. ( $\mathrm{N}^{\circ}$ 697): Body fragment; Kimistene, Acropolis, temple's eastern slope, surface find, found in 2005.

pl. 38/400.

Max. h $9.2 \mathrm{~cm}$., $\max$. w $9.2 \mathrm{~cm}$., max. th $0.3 \mathrm{~cm}$

Reddish yellow (5YR 6/6) slip on exterior; pink (7.5YR 7/4) unslipped surface on interior. Hard, very sparsely porous, yellowish red (5YR 5/6) and gray (5YR $5 / 1$ ) fabric with frequent large grit and lime inclusions.

456. ( $\mathrm{N}^{\mathrm{o}}$ 1474): Body fragment; Kepez, in the rockcut grave, found in 2005 .

pl. 38/401.

Max. h $4.6 \mathrm{~cm} .$, max. w $10.3 \mathrm{~cm}$., max. th $1.4 \mathrm{~cm}$.

Light brown (7.5YR 6/4) unslipped surface on exterior and interior. Soft, sparsely porous, fine, brown (7.5YR 5/4) fabric with frequent tiny lime, sand and some medium grit inclusions.

457. ( $\mathrm{N}^{\circ}$ 1153): Body fragment; Kepez, surface find in the Cistern, found in 2005.

Max. h $9.4 \mathrm{~cm}$., max. w $8.4 \mathrm{~cm}$., max. th $1.5 \mathrm{~cm}$

Very pale brown (10YR 8/3) slip on exterior; reddish yellow (5YR 7/6) unslipped surface on interior. Hard, non-porous, fine, light red (2.5YR 6/8) fabric with frequent tiny lime and some large grit inclusions in its interior surface. 


\section{CONCLUSIONS}

As Matthews indicates ${ }^{52}$, Alexander's march and the progress of the Hellenistic age across Anatolia had no significant material impact upon the inhabitants of Inner Paphlagonia. Beside that, our knowledge about Hellenistic Paphlagonia is extremly limited: Strabo wrote that before his time Paphlagonia was ruled by several kings (12.3.41). In alliance with the Bithynian king, Nicomedes III Euergetes, Mithradates VI conquered Paphlagonia in 108/7 B.C. It seems that during the Hellenistic period the Kimistene region had almost no contact with the coastal Greek cities, although the first Greek influences should had began in this period. Thus, we should expect a closed and isolated administration in southwestern Paphlagonia during this period. In the Hellenistic period imported pottery in southwestern Paphlagonia is therefore very rare; most of the products should be locally manufactured. Our Iron Age and Hellenistic surface material shows a continuity of form and decoration from the preceding Iron Age into the Hellenistic era, as also attested on the Konya plain and in the Amasya region ${ }^{53}$.

Most of our Hellenistic pottery results depend on Kimistene. Hellenistic material from this hill-top site proves that this site was settled beginning at least in the Iron Age and continued through the entire Hellenistic period without a break. It should have had a specific (religious?) function during the Hellenistic period; perhaps the Roman temple in Kimistene had an Iron Age and Hellenistic predeccessor in wooden form. During the Hellenistic period Kepez was definetely a mountain-top necropolis, but the use of this site continued until the Early Byzantine period.

Since Hellenistic settlements in the hinterland of Paphlagonia are rare, Hellenistic surface material from the surveys at Devrek is important: A small number of fine ware was discovered which was mostly locally produced and imitated Eastern Sigillata forms during the Late Hellenistic period ${ }^{54}$.

Two further similar sites with their Hellenistic pottery could be Ankyra in the south and Hattusha in the southeast which are being currently studied by Sven Kühn (Tübingen) and Cem Küncü (Ankara).

In the Hellenistic period locally manufactured pottery in southwestern Paphlagonia was very conservative in terms of typology and decoration and this did not change for a long time. Their clay characteristics with either red or brown fabric are very homogeneous. They mostly consist of basic open forms, such as semi-fine dining vessels (incurved rim bowls, fish plates, everted rim bowls, dishes etc.), imitated western and northern typologies, sometimes with banded decoration.

As in the Iron Age, Hellenistic finds from southwestern Paphlagonia are also connected with Central and Northern Anatolian Hellenistic pottery traditions. Hellenistic sherds from Kimistene are similar to the finds from Oluz Höyük in Amasya. The pottery from Kimistene and the rest of southwestern $\mathrm{Pa}$ phlagonia, especially the painted examples, indicates religious-ritual activities. Most of the Hellenistic fine ware and forms were grave goods and they were not for daily domestic use. They were obviously related to the burial traditions of this landscape, as the same phenomen is observable at local sigillata. The domestic use should had been executed by perishable wooden vessels. Thus, the pottery presented here do not really reflect daily Hellenistic life of this part of the ancient world.

Transportation among the landscapes between the coastline and the hinterland of Paphlagonia was very limited, perhaps due to the lack of metals and transportation vehicles. This should have had a reflection in material culture; lack of imported material and unique as well as less-developed local ware is perhaps its evidence.

\section{Notes and Acknowledgements}

This group of pottery was presented on May 9 , 2009 at the $8^{\text {th }}$ Scientific Meeting on Hellenistic Pottery in Ioannina (with B. Gürler; $c f$. Laflı and Kan Şahin 2015, in print), on October 12, 2010 at Izmir Workshop on Hellenistic Ceramics in Anatolia, on February 4, 2012 at the Fünfter Archäologischer Workshop für junge Wissenschaftler/Innen in Hamburg (with G. Kan Şahin) and on November 10, 2013 at the International Conference of 'Traditions and Innovations. Tracking the Development of Pottery from the Late Classical to the Early Imperial Periods' in Berlin. All the plates of this paper were drawn by G. Kan Şahin who also took the photographs with C. Şahin (Çanakkale). The maps were produced by S. Patac1 (Ardahan). In the catalogue section the numbers in brackets indicate find numbers of the field project. Abbreviations in the catalogue: th: thickness; h: height; w: width; d: diameter; and max.: maximum. For this article The Munsell Soil Color 
Charts (2009) has been used. These sherds are being stored today in the Museum of Amasra as well as at the container of the excavation site in Eskipazar. Figs. 10a-b are by Dr William Anderson (Mel- bourne), to whom we are very grateful. We also would like to thank to A. Tibet (Istanbul) and other editors of Anatolia Antiqua.

E.L. and G.K.Ş.

\section{REFERENCES}

Abadie-Reynal, C., 2003: "La céramique du HautEmpire a Porsuk", in Abadie-Reynal, C. (ed.), Les ceramiques en Anatolie aux époques héllenistique et romaine [Varia Anatolica XV]: Paris/Istanbul: 101-109.

Alexandropoulou, A., 2012: "A Late Classical and Hellenistic Pottery of Sinope and Amisos", in Tsetskhladze, G.R., Laflı, E., Hargrave, J. and Anderson, W. (eds.), The Black Sea, Paphlagonia, Pontus and Phrygia in Antiquity. Aspects of Archaeology and Ancient History [B.A.R., Int. Ser. 2432], Oxford: 9-12.

Anderson, W., 2008: "Preliminary Report on Pottery from the Avkat Archaeological Project, 2007-08: Prehistoric to Roman", The Avkat Archaeological Project, The Second Season, July-August 2008: Preliminary Summary Report, in < http://www.princeton.edu/avkat/reports/ 2008fieldworkreport.pdf $>(24 / 02 / 2014)$.

Atasoy, S., 2012: "New Exploration of the Southern Black Sea Coast: Filyos-Tios", in Tsetskhladze, G.R., Laflı, E., Hargrave, J. and Anderson, W. (eds.), The Black Sea, Paphlagonia, Pontus and Phrygia in Antiquity. Aspects of Archaeology and Ancient History [B.A.R., Int. Ser. 2432], Oxford: 29-34.

Bakan, C., and Şerifoğlu, T.E., in print: "Cide (Kytoros) Hellenistik Dönem Çalışmaları", in Laflı, E. and Patac1, S. (eds.), Recent Studies on the Archaeology of Anatolia [Colloquia Anatolica et Aegaea, Acta congressus communis omnium gentium Smyrnae I, B.A.R., Int. Ser.], Oxford.

Barat, Cl., 2014: "La Paphlagonie : histoire et peuplement", in Bru, H. and Labarre, G. (eds.), L'Anatolie des peuples, des cités et des cultures (II ${ }^{e}$ millénaire av. J.-C. - V siècle ap. J.-C.). Colloque international de Besançon - 26-27 novembre 2010. Vol. II: Autour d'un projet d'atlas historique et archéologique de l'Asie Mineure. Méthodologie et prospective, Besançon: 151-166.

Barat, Cl., Dalaison, J., Delrieux, F., Pichonneau, J.Fr. and Rémy, B., 2009: "Prospection et inventaire archéologiques dans la vallé du Gökırmak. Premier rapport préliminaire: région de Taşköprü', Anatolia Antiqua XVII: 393-409.

Bechtold, B. and Docter, R., 2010: "Preliminary Observations on the Plain and Cooking Ware Fragments", in Docter, R., Panayotova, K., de Boer, J., Donnellan, L., van de Put, W. and Bechtold, B. (eds.), Apollonia Pontica 2007, Gent 2008 (second revised edition 2010): 47-98.

Bilde, P. G., 2010: "Mouldmade Bowls", in Lejpunskaja, N.A., Bilde, P.G., Højte, J.M., Krapivina, V.V. And Kryžickij, S.D. (eds.), The Lower City of Olbia (Sector
NGS) in the $6^{\text {th }}$ Century B.C. to the $4^{\text {th }}$ Century A.D., Vol. 1, Aarhus: 269-288, pls. 168-195.

Bilgi, Ö. 1999: "Íkiztepe in the Late Iron Age", AnatSt 49: 27-54.

Darbyshire, G., Mitchell, S. and Vardar, L., 2000:

"The Galatian Settlement in Asia Minor", AnatSt 50: 75-97.

Doksanalt1, E. and Karauğuz, G., 2012: "The Hellenistic and Roman Ceramics from Field Surveys at Devrek and its Environs, West Black Sea Region of Turkey", in Tsetskhladze, G. R., Laflı, E., Hargrave, J. and Anderson, W. (eds.), The Black Sea, Paphlagonia, Pontus and Phrygia in Antiquity. Aspects of Archaeology and Ancient History [B.A.R., Int. Ser. 2432], Oxford: 53-66.

Doonan, O., 2004: Sinop Landscapes, Exploration Connection in a Black Sea Hinterland, Philadelphia, PA.

Dönmez, Ş., 2005: "Amasya Province in the Iron Age", in Çilingiroğlu, A. and Darbyshire, G. (eds.), Anatolian Iron Ages 5 [British Institute at Ankara Monograph 31], London: 65-74.

- 2010: Kašku Ülkesi'nin Önemli Kenti Amasya-Oluz Höyük 2007 ve 2008 Dönemi Çalışmaları Genel Değerlendirmeler ve Ön Sonuçlar [T.C. Amasya Valiliği Yayın No: 48], Ankara.

- 2014, in print: "A New Excavation in Pontic Cappadocia: Amasya-Oluz Höyük. Preliminary Results for the Hellenistic Period and Iron Age Layers", in Laflı, E. and Patac1, S. (eds.), Recent Studies on the Archaeology of Anatolia [Colloquia Anatolica et Aegaea, Acta congressus communis omnium gentium Smyrnae I, B.A.R., Int. Ser.], Oxford.

Düring, B. and Glatz, C., 2010: "The Cide Archaeological Project 2009: First Results", Anatolia Antiqua XVIII: 203-213.

Grave, P., Kealhofer, L., Marsh, B., Sivas, T. and Sivas, H., 2012: "Reconstructing Iron Age Community Dynamics in Eskişehir Province, Central Turkey", Journal of Archaeological Method and Theory 19/3: 377-406.

Karaca, E., 2010: "Filyos-Tios Kazı Çalışmaları2009”, Türk Eskiçağ Bilimleri Enstitüsü Haberler, 29: 25 26.

Lafl1, E., 2006: "Hellenistic and Roman Ceramic Archaeology on the Southern Black Sea Coast: An Overview of the Turkish Archaeological Literature related to Ceramic Archaeology of Paphlagonia and Pontus", in Erciyas, B. D., and Kopraman, E. (eds.), Black Sea Studies Symposium Proceedings 2004 Ankara, Istanbul: 189-202. 
Laflı, E. and Christof, E., 2011: "Der kaiserzeitliche Tempel von Asartepe/Kimistene in der Chora des paphlagonischen Hadrianopolis - Ergebnisse der Prospektion von 2005", IstMitt 61: 233-285.

- 2012a: Hadrianopolis I: Inschriften aus Paphlagonia [B.A.R., Int. Ser. 2366], Oxford.

- 2012b: "Drei neu entdeckte Phallossteine aus der Chora von Hadrianopolis", in Tsetskhladze, G.R., Laflı, E., Hargrave, J. and Anderson, W. (eds.), The Black Sea, Paphlagonia, Pontus and Phrygia in Antiquity. Aspects of Archaeology and Ancient History [B.A.R., Int. Ser. 2432], Oxford: 163-170.

Laflı, E. and Kan Şahin, G., 2011: "Iron Age and Hellenistic Ceramics from Southwestern Paphlagonia", Arheologija i prirodne nauke/Archaeology and Science 7: 9-165.

- 2012: "Terra Sigillata and Red-Slipped Ware from Hadrianopolis in Southwestern Paphlagonia", Anatolica Antiqua XX: 45-120.

- 2013: "Pottery from Southwestern Paphlagonia II: Unguentaria and Lamps", in Ramminger, B., Stilborg, O. and Helfert, M. (eds.), Naturwissenschaftliche Analysen vor- und frühgeschichtlicher Keramik III. Methoden, Anwendungsbereiche, Auswertungsmöglichkeiten [Universitätsforschungen zur prähistorischen Archäologie aus der Abteilung Vor- und Frühgeschichtliche Archäologie der Universität Hamburg, Band 238], Bonn: 353-378.

- 2015, in print: "A Preliminary Report on the Iron Age and Hellenistic Ceramics from southwestern Pa-

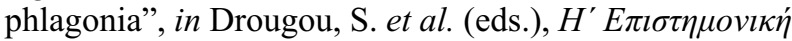

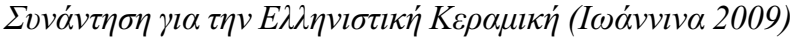
/ H’Scientific Meeting on Hellenistic Pottery, Ioannina 2009. Proceedings, Athens.

Laflı, E., Kan Şahin, G. and Patacı, S., 2013: "Iron Age Ceramics from Southwestern Paphlagonia", Anatolia Antiqua XXI: 33-68.

Magie, D., 1950: Roman Rule in Asia Minor to the End of the Third Century after Christ, Princeton, NJ.

Marro, C., Özdoğan, M., and Tibet, A., 1996: "Prospection archéologique franco-turque dans la région de Kastamonu (Mer Noire). Premier rapport préliminaire", Anatolia Antiqua IV: 273-290.

Matthews, R., 2009: “A Dark Age, Gray Ware and Elusive Empirs: Paphlagonia through the Iron Age, 1200330 B.C.", in Matthews, R. and Glatz, C. (eds.), At Empire's Edge: Project Paphlagonia. Regional Survey in North-Central Turkey [British Institute in Ankara, BIAA Monograph 44], London: 149-171.

Matthews, R., Metcalfe, M. and Cottica, D., 2009: "Landscapes with Figures: Paphlagonia through the Hellenistic, Roman and Byzantine Periods, 330 B.C.-A.D. 1453", in Matthews, R. and Glatz, C. (eds.), At Empire's Edge: Project Paphlagonia. Regional Survey in North-
Central Turkey [British Institute in Ankara, BIAA Monograph 44], London: 173-199 and 216-226.

Meriç, R., 2000: Späthellenistische-römische Keramik und Kleinfunde aus einem Schachtbrunnen am Staatsmarkt in Ephesos [Forschungen in Ephesos IX/3], Vienna.

Mitchell, S., 1993: Anatolia: Land, Men, and Gods in Asia Minor, Vol. 1: The Celts in Anatolia and the Impact of Roman Rule, Oxford.

Özsait, M. and Özsait, N., 2014: "Prospections en Cappadoce pontique", in Bru, H. and Labarre, G. (eds.), L'Anatolie des peuples, des cités et des cultures (II' millénaire av. J.-C. - Ve siècle ap. J.-C.). Colloque international de Besançon - 26-27 novembre 2010. Vol. II: Approches locales et régionales, Besançon: 171-188.

Rotroff, S.I., 1997: Hellenistic Pottery, Athenian and Imported Wheelmade Table Ware and Related Material, The Athenian Agora XXIX, Part 1-2, Princeton, NJ: 1575, figs. 1-106, pls. 1-148.

- 1982: Hellenistic Pottery: Athenian and Imported Moldmade Bowls, The Athenian Agora XXII, Princeton, NJ: 1-136, pls. 1-99.

Sagona, A. and Sagona, C., 2004: Archaeology at the North-East Anatolian Frontier, I: An Historical Geography and Field Survey of the Bayburt Provience [Ancient Near Eastern Studies, Supplement Series 14], Louvain.

Sönmez, İ.F., and Öztürk, B. 2008: "Batı Karadeniz'de Bir Antik Kent Kazısı: Tios (Filyos)", Arkeoloji ve Sanat Dergisi 127: 133-146.

Stewart, S.M., 2010: Gordion after the Knot: Hellenistic Pottery and Culture (Unpubl. Diss.; University of Cincinnati).

Vanhaverbeke, H., Waelkens, M., Vyncke, K., De Laet, V., Aydal, S., Mušič, B., De Cupere, B., Poblome, J., Braekmans, D., Degryse, P., Marinova, E., Verstraeten, G., Van Neer, W., Šlapšak, B., Medaric, I., Ekinci, H.A. and Erbay, M.O., 2010: "Pisidian' Culture? The Classical-Hellenistic Site at Düzen Tepe near Sagalassus (southwest Turkey)", AnatSt 60: 105-128.

Voigt, M.M., DeVries, K., Henrickson, R.C., Lawall, M., Marsh, B., Gürsan-Salzmann, A. and Young, T.C., 1997: "Fieldwork at Gordion: 1993-1995", Anatolica 23: $1-38$.

Zolotarev, M.I., 2005: “A Hellenistic Ceramic Deposit from the North-eastern Sector of Chersonesos", in Stolba, V.F. and Hannestad, L. (eds.), Chronologies of the Black Sea Area in the Period c. 400-100 BC, Aarhus: 193216.

Zoroğlu, L., 1979: “Eskiyapar'da Bulunan Kızılırmak Havzası (Galat Denilen) Boyalı Seramikleri”, in VIII. Türk Tarih Kongresi, I. Cilt, Ankara: 345-354, pls. 1-6, figs. 1-5. 

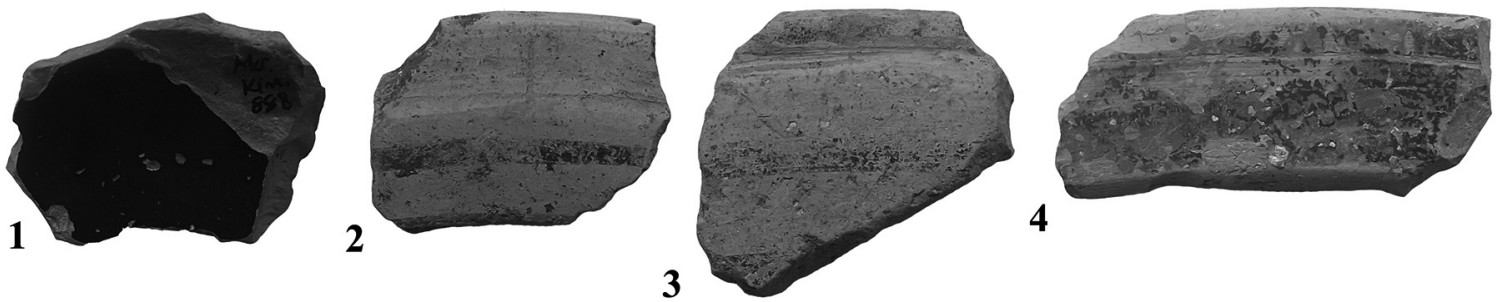

5
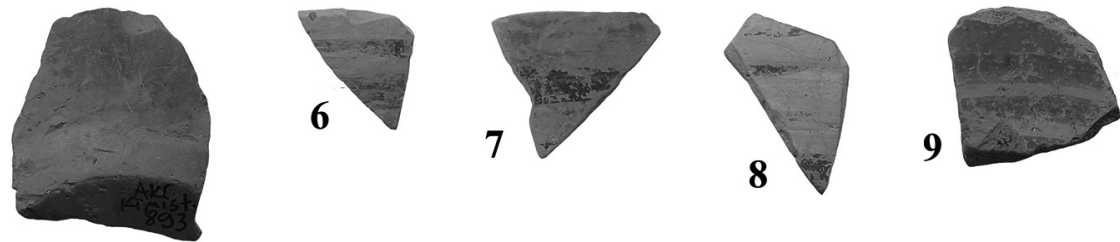

10

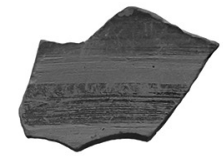

11

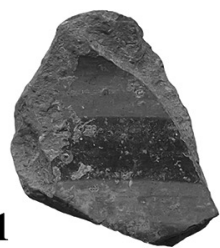

12

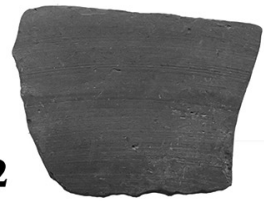

13
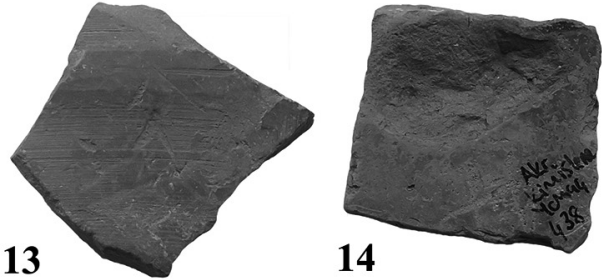

14

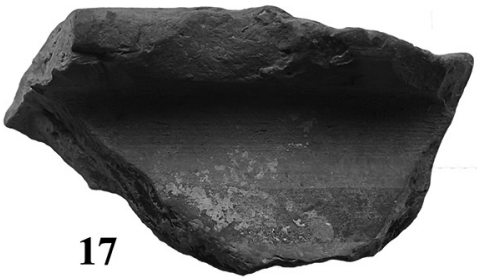

18

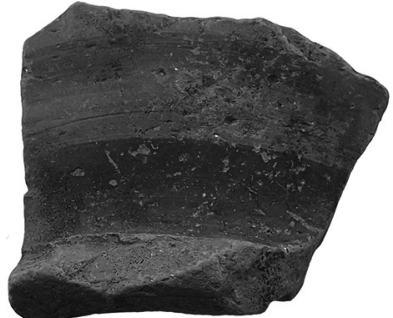

19
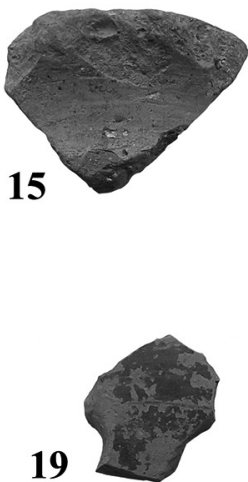
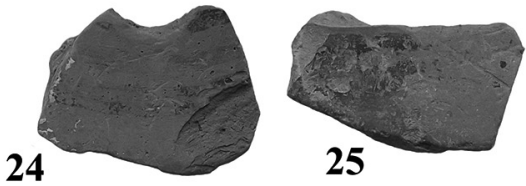

23
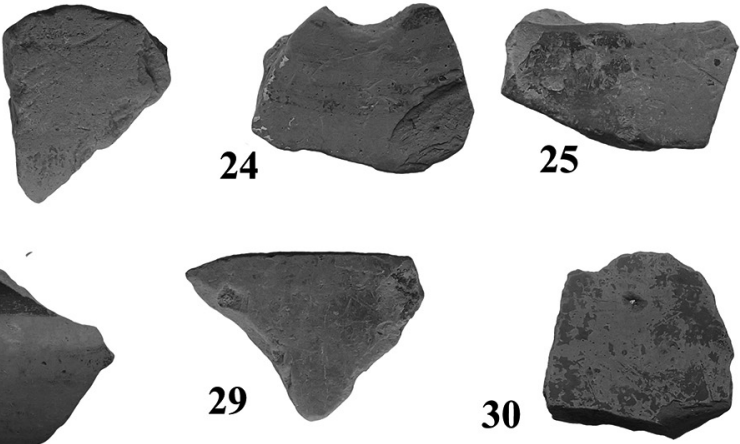

26

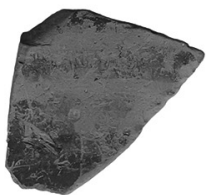

27
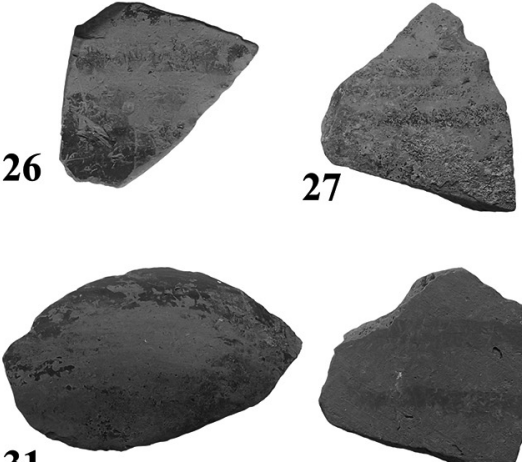

31

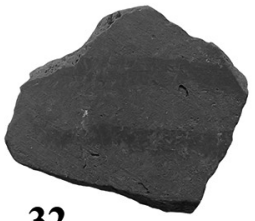

32
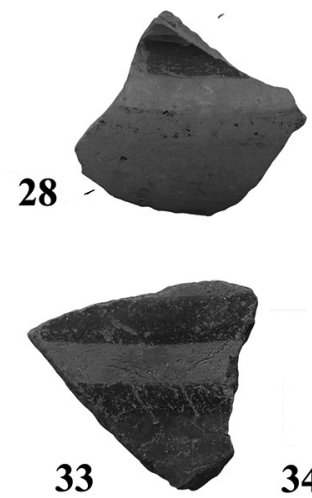

34

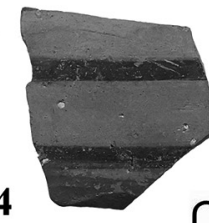

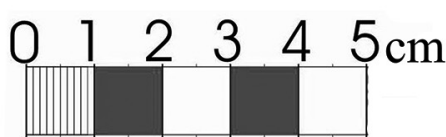

Pl. 23 : $\mathbf{N}^{\circ} 1$ : A Pontic skyphos fragment; ${ }^{\text {os }}$ 2-34: Hellenistic painted ware; $\mathbf{n}^{\text {os }}$ 2-4: Rim fragments of open forms; $n^{\circ} 5$ : A base fragment of an open form; and $n^{\text {os }}$ 6-14: Body fragments of open forms;

$n^{\text {os }}$ 15-17: Rim fragments of closed forms; $n^{\circ} 18$ : A base fragment of a closed form; and $n^{\text {os } 19-34: ~ B o d y ~ f r a g m e n t s ~ o f ~ c l o s e d ~ f o r m s . ~}$ 

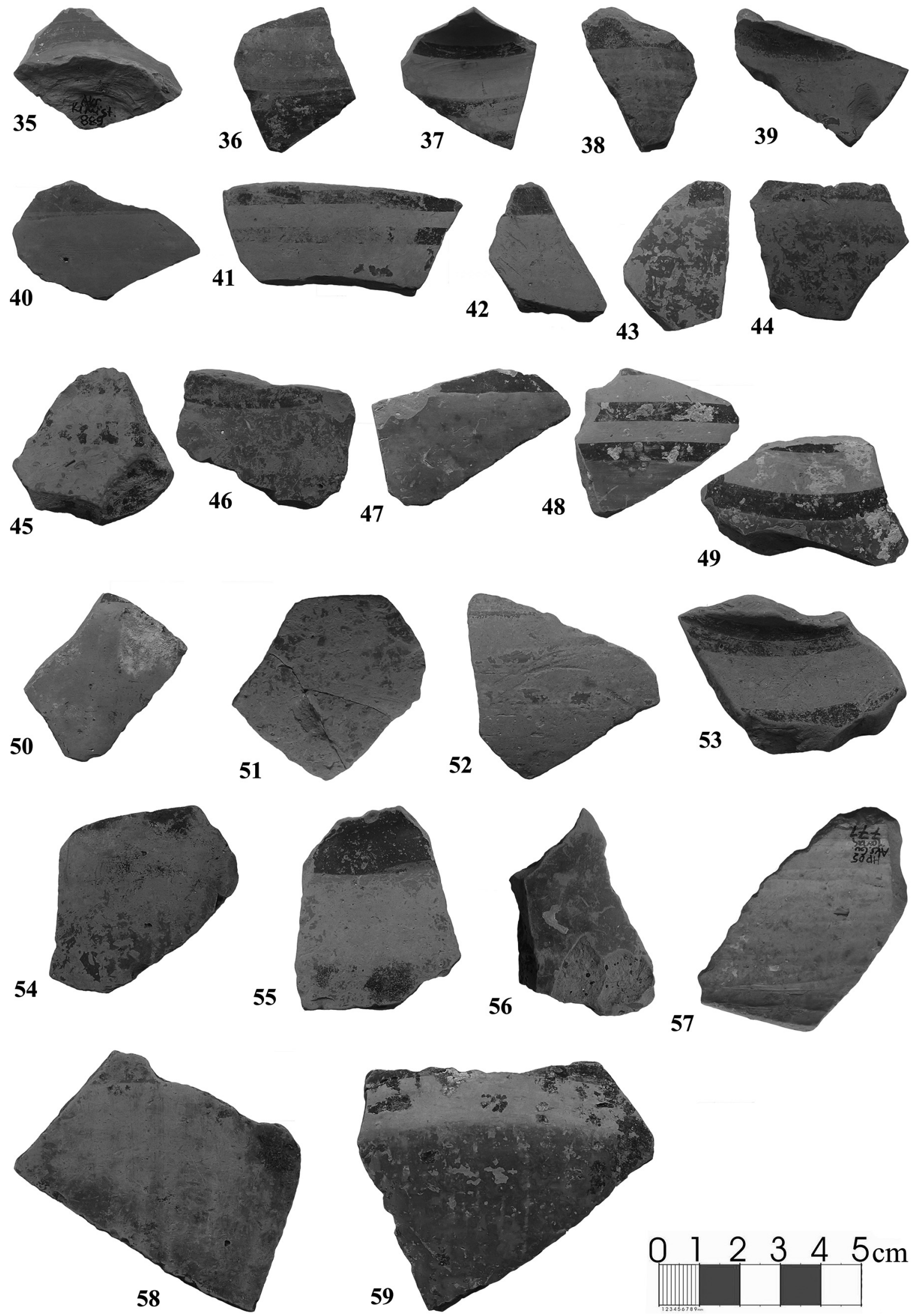

Pl. 24 : $\mathrm{N}^{\text {os }}$ 35-59: Hellenistic painted ware, body fragments of closed forms. 

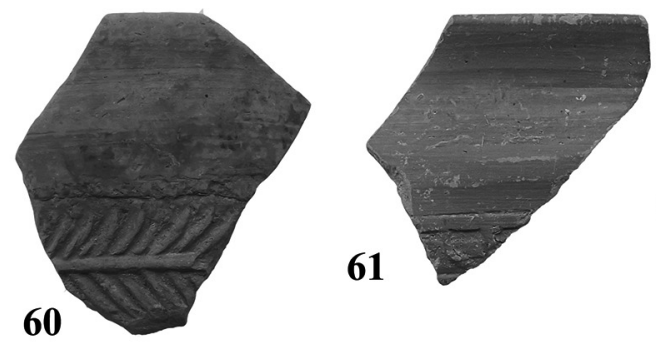

62

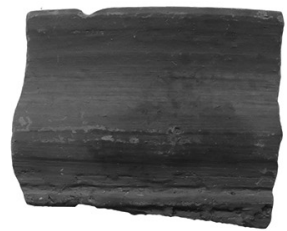

63
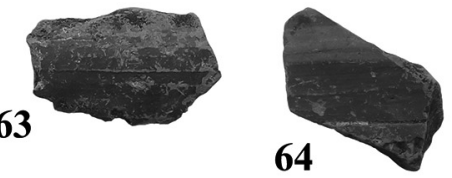

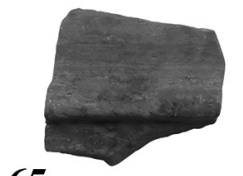

65
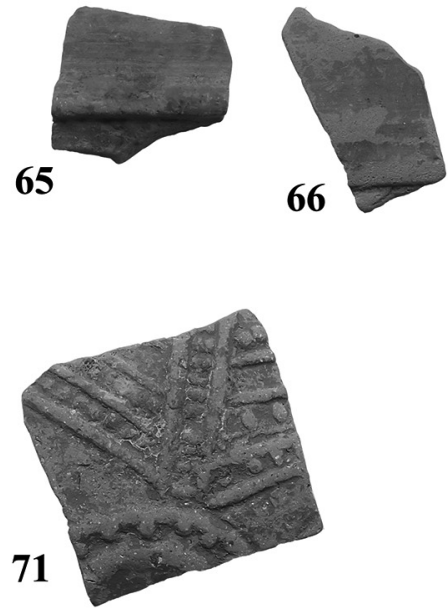

72

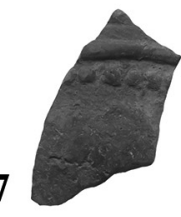

68

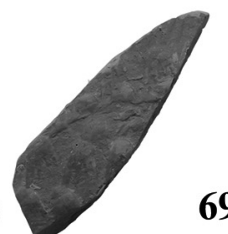

69
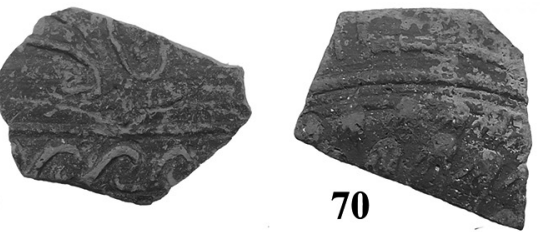

73
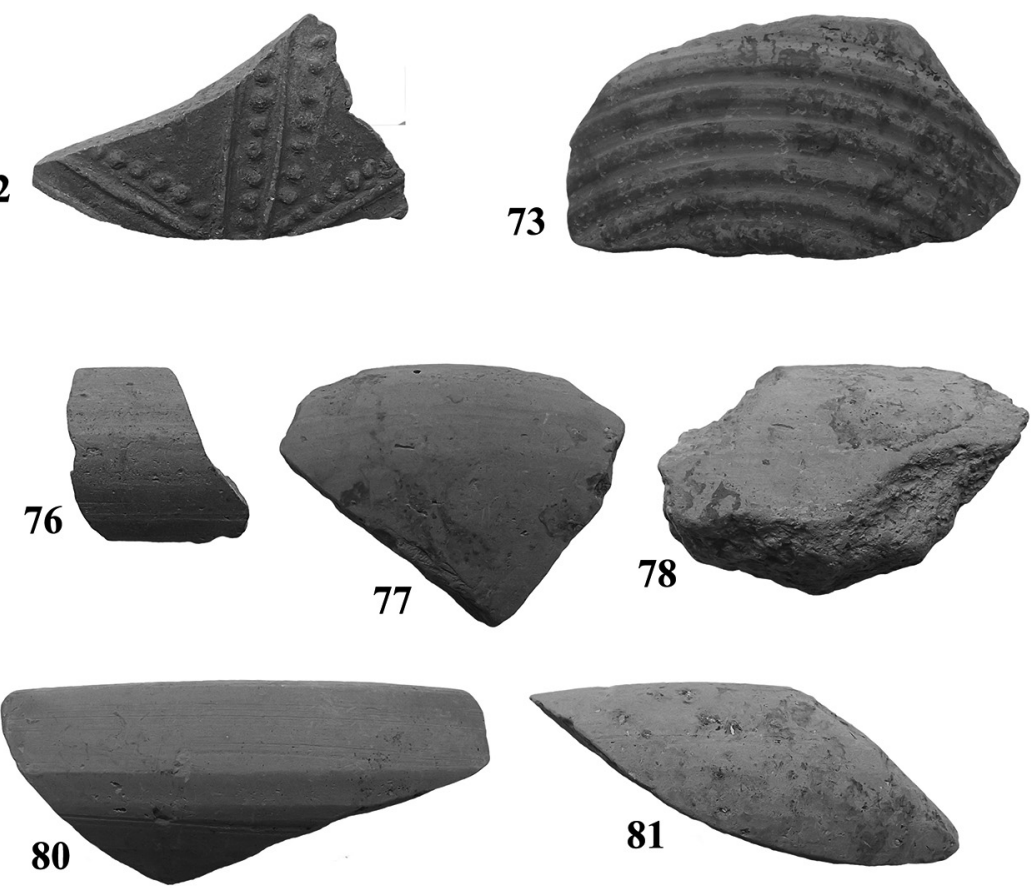

79
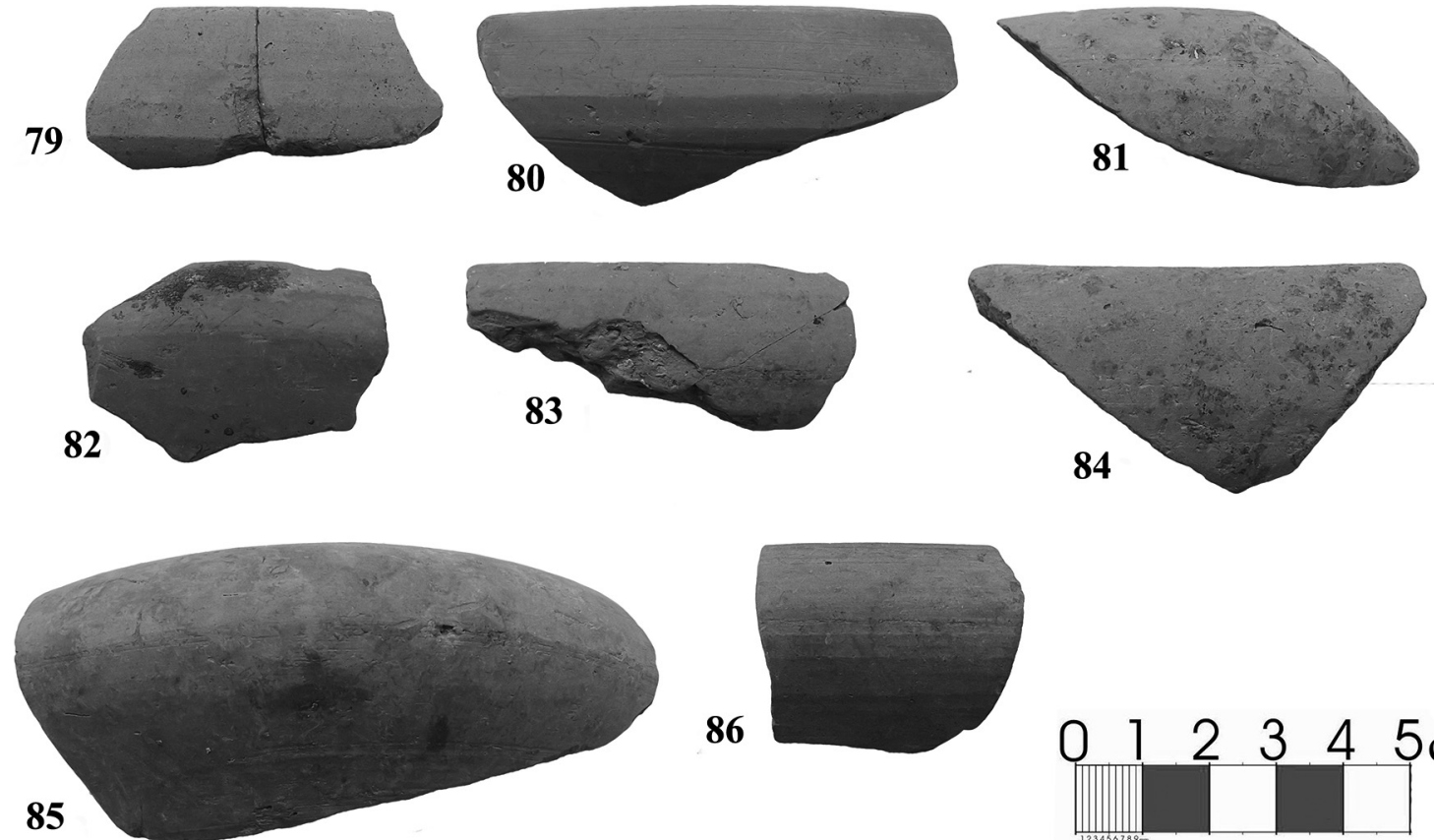

86
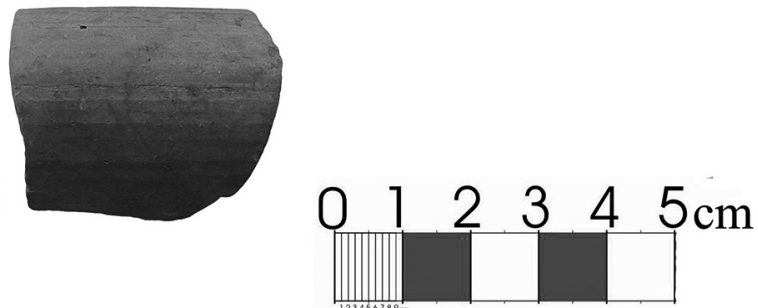

Pl. 25 : $\mathrm{N}^{\text {os }}$ 60-73: Hellenistic relief ware; $\mathrm{n}^{\text {os }}$ 60-62: Rim fragments of a bowl form; and $\mathrm{n}^{\text {os }}$ 63-73: Body fragments of open forms; and $n^{\text {os }}$ 74-86: Hellenistic burnished ware, rim fragments of a bowl form. 

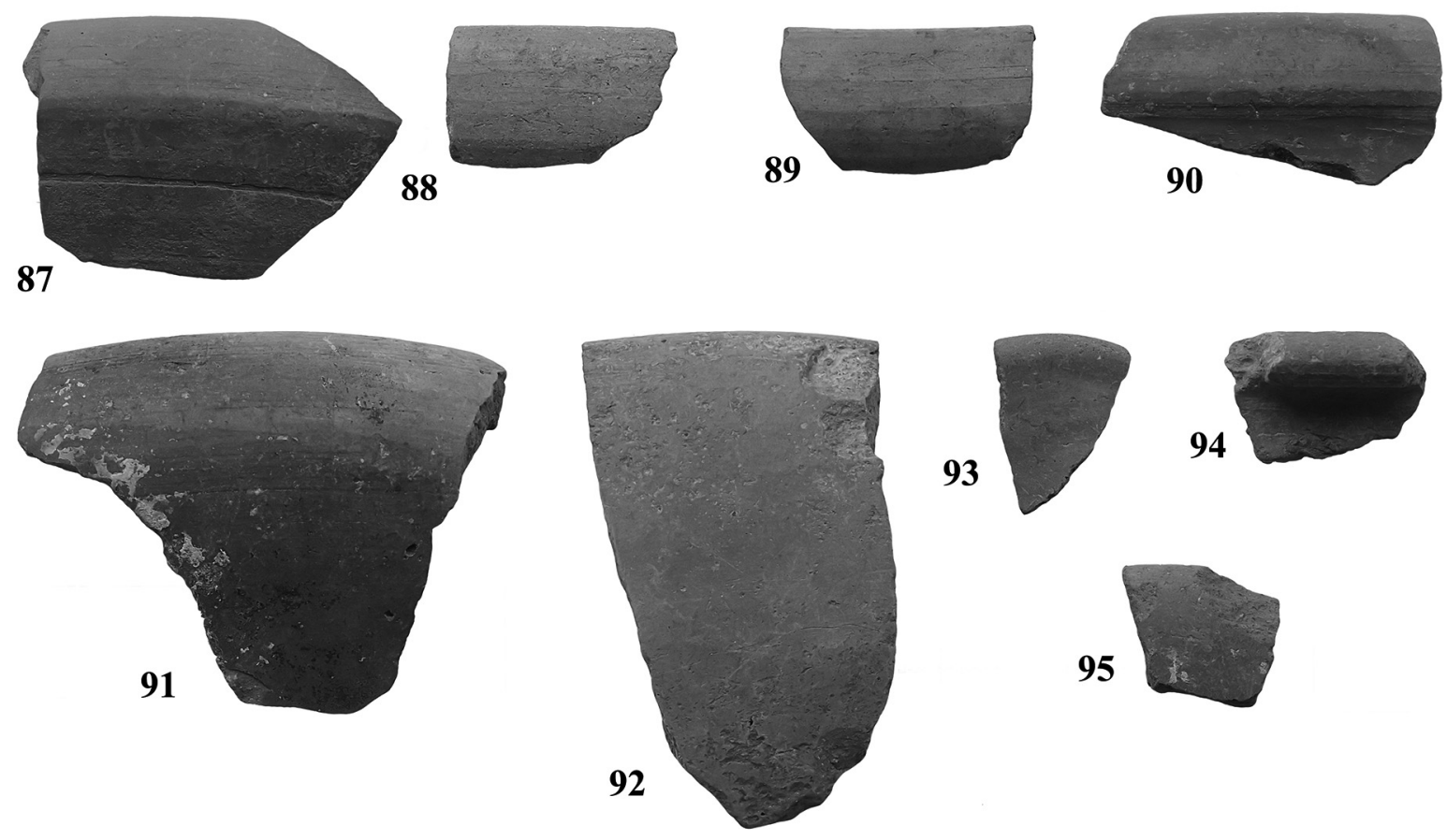

93

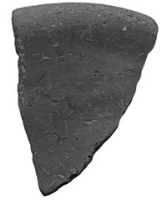

94

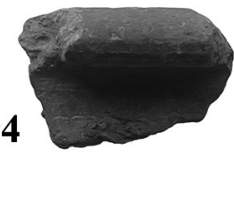

95
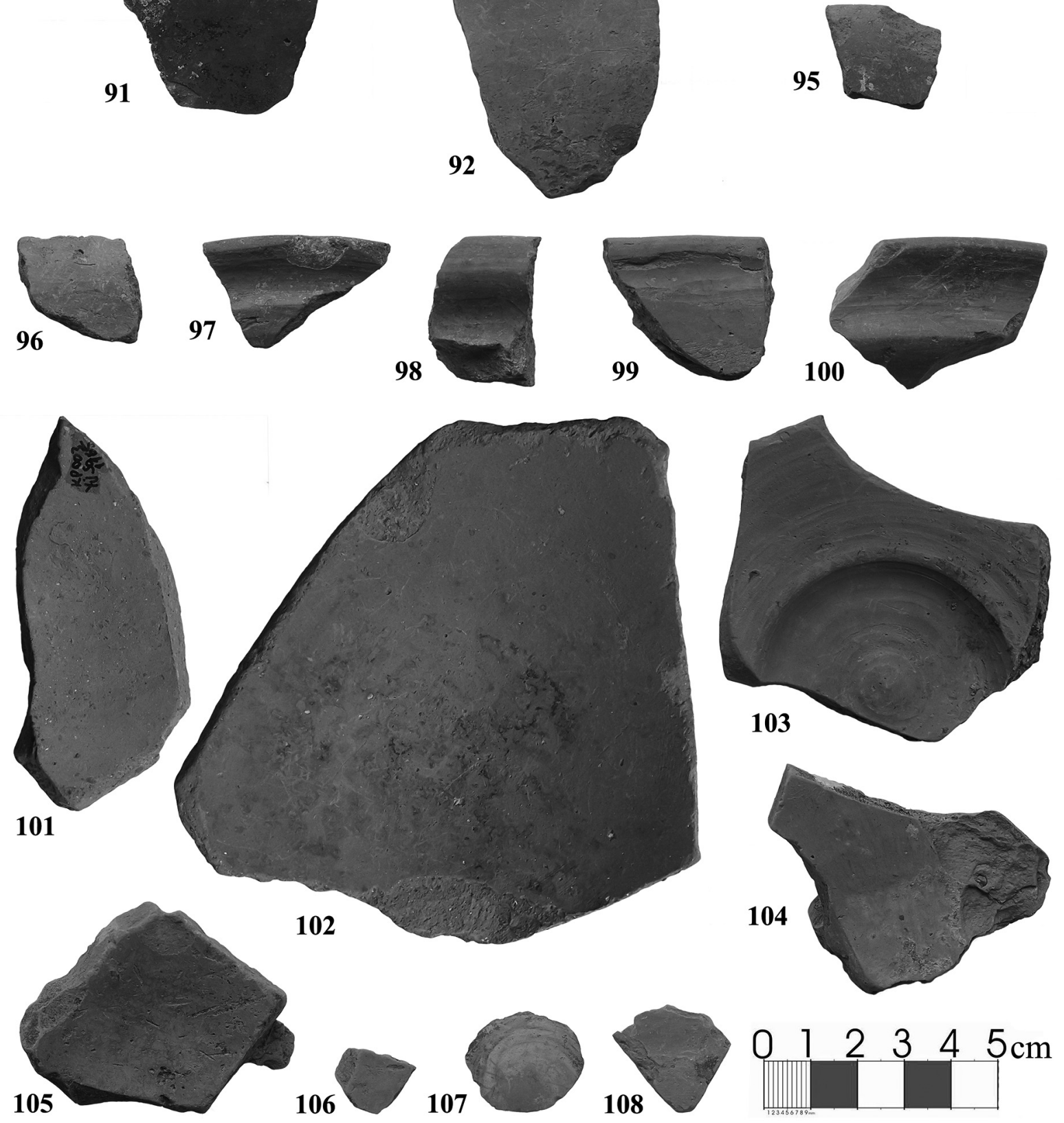

Pl. 26 : $\mathbf{N}^{\text {os }}$ 87-108: Hellenistic burnished ware; $n^{\text {os }}$ 87-92: Rim fragments of a bowl form;

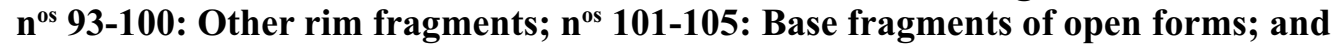
$n^{\text {os }}$ 106-108: Body fragments of open forms. 

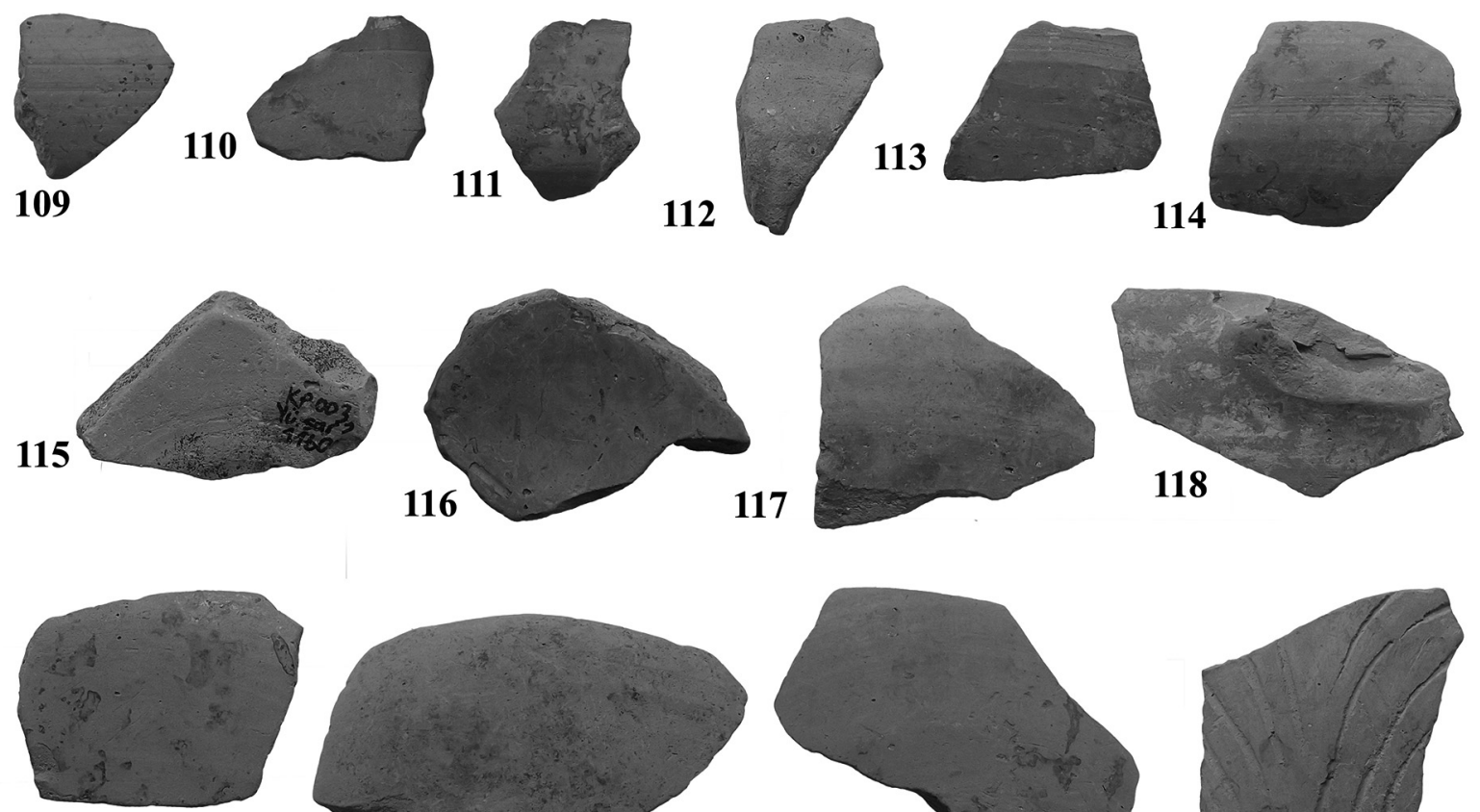

119
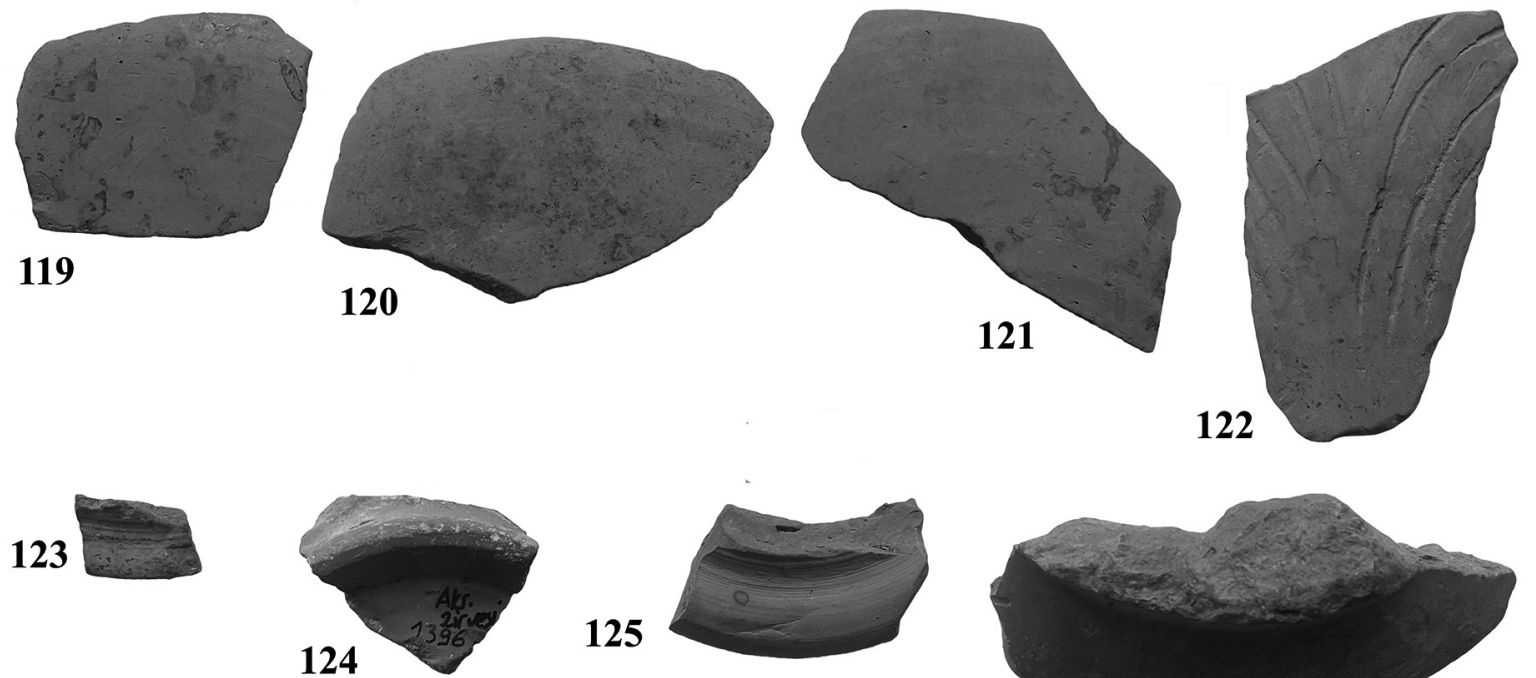

125
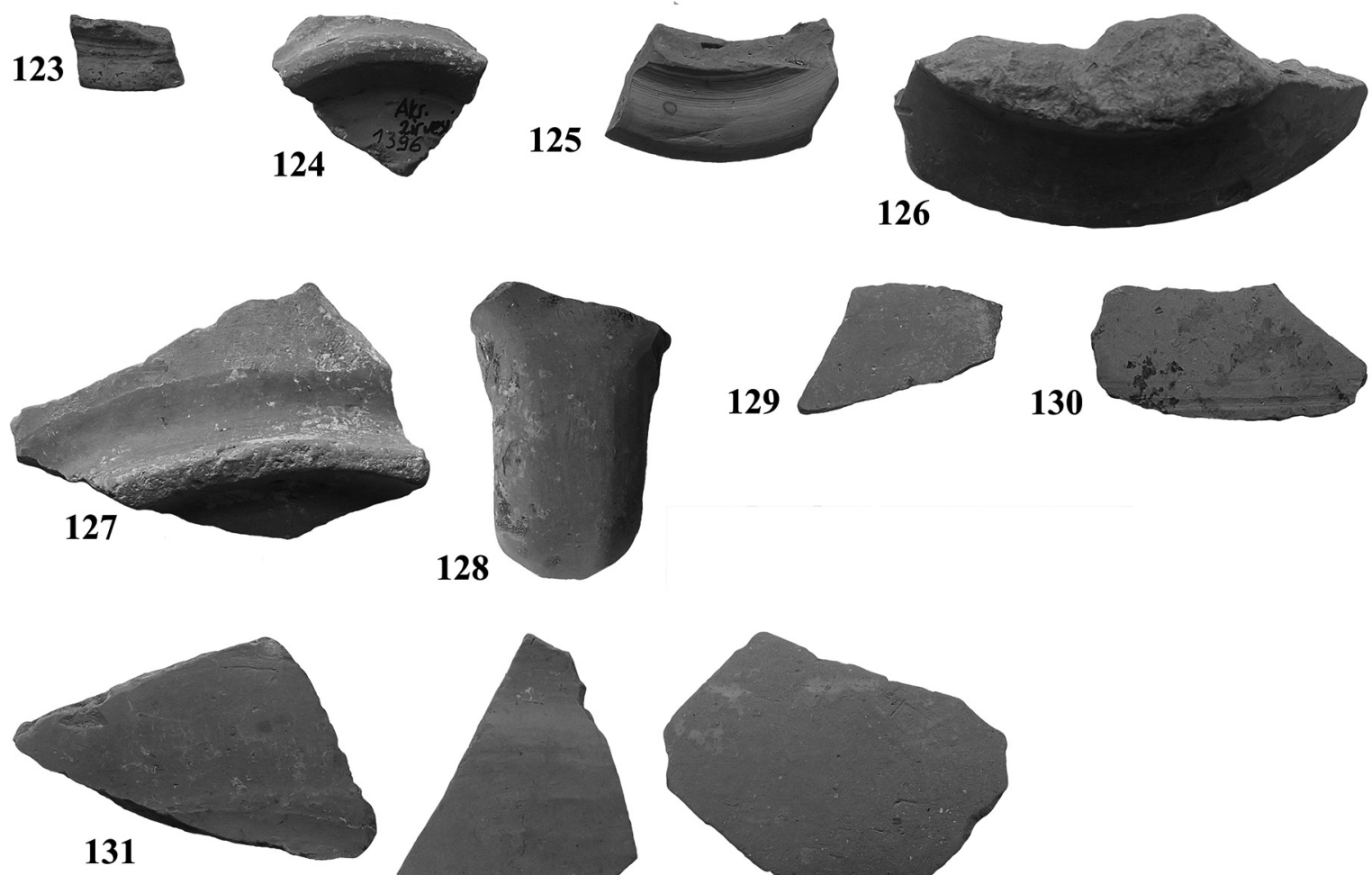

132
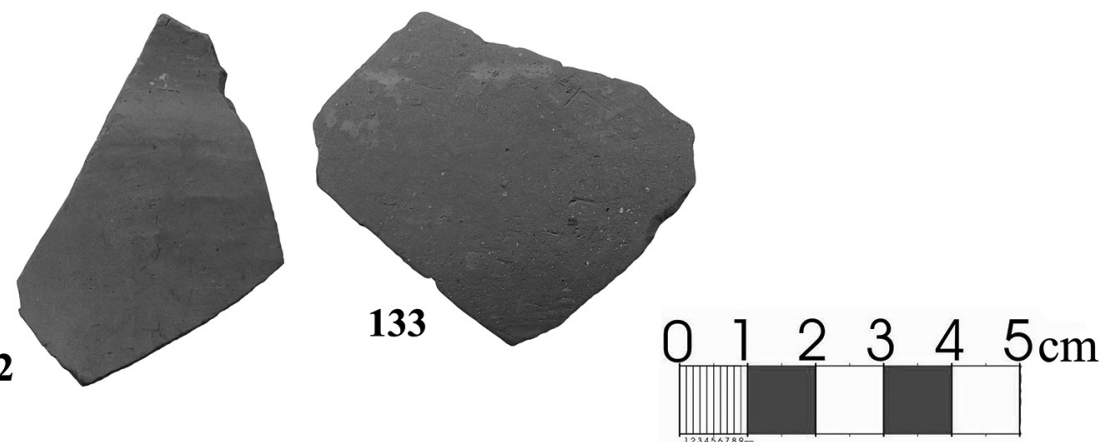

Pl. 27 : $N^{\text {os }}$ 109-133: Hellenistic burnished ware; $n^{\text {os }}$ 109-121: Body fragments of open forms;

no. 122: A body fragment of a rhyton; $\mathrm{n}^{\mathrm{os}}$ 123-127: Base fragments of closed forms;

$n^{0}$ 128: A handle fragment of a closed form; and $n^{\text {os }}$ 129-133: Body fragments of closed forms. 

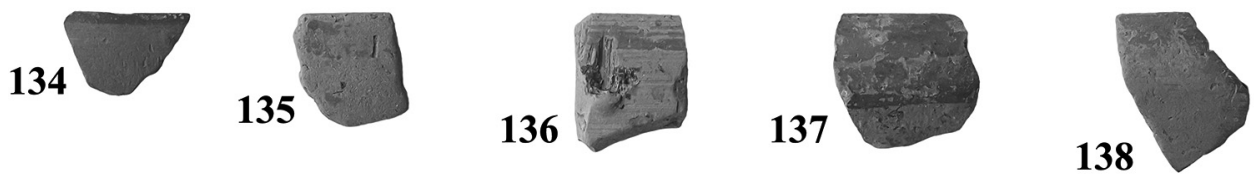

139
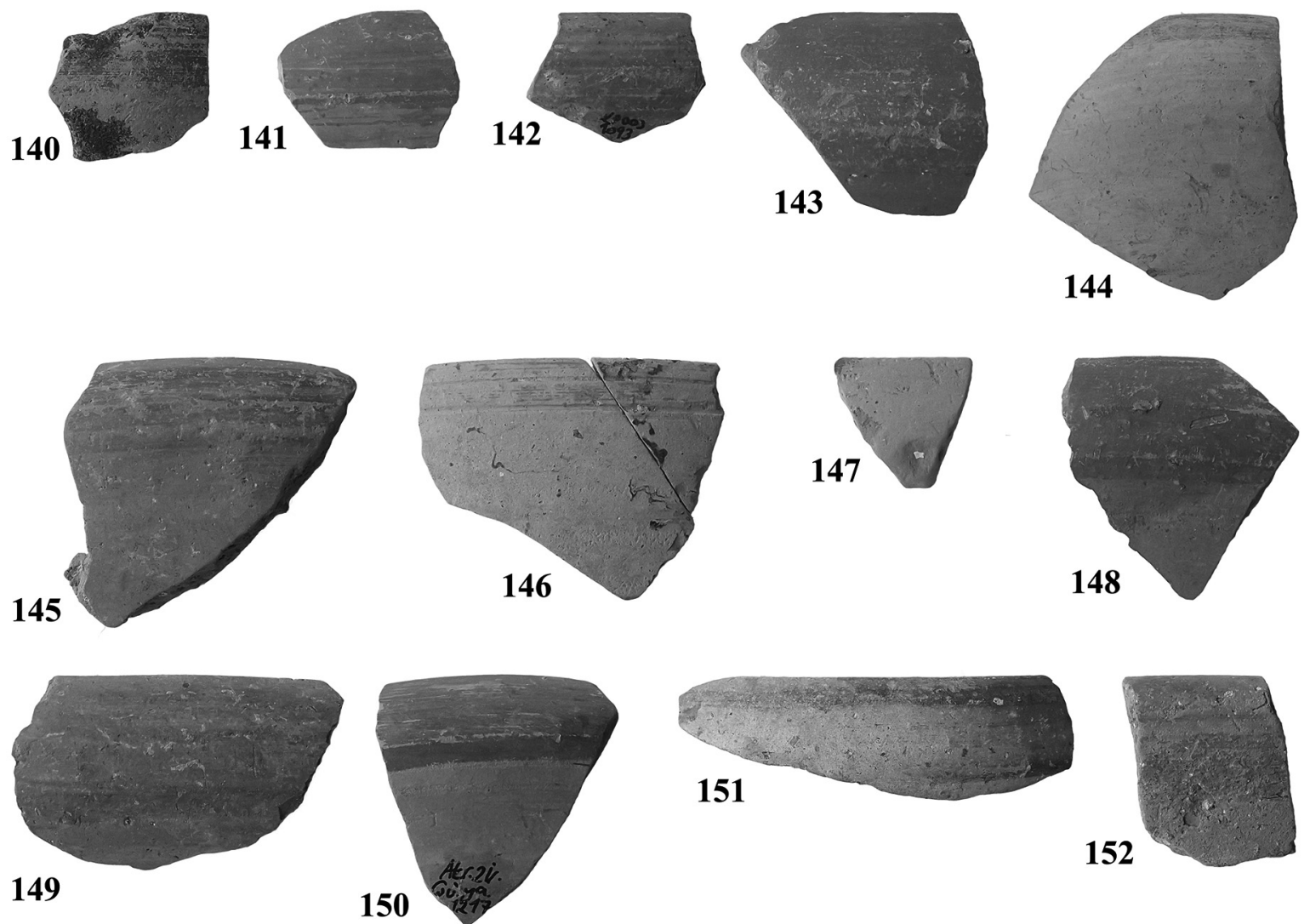

152

149

150
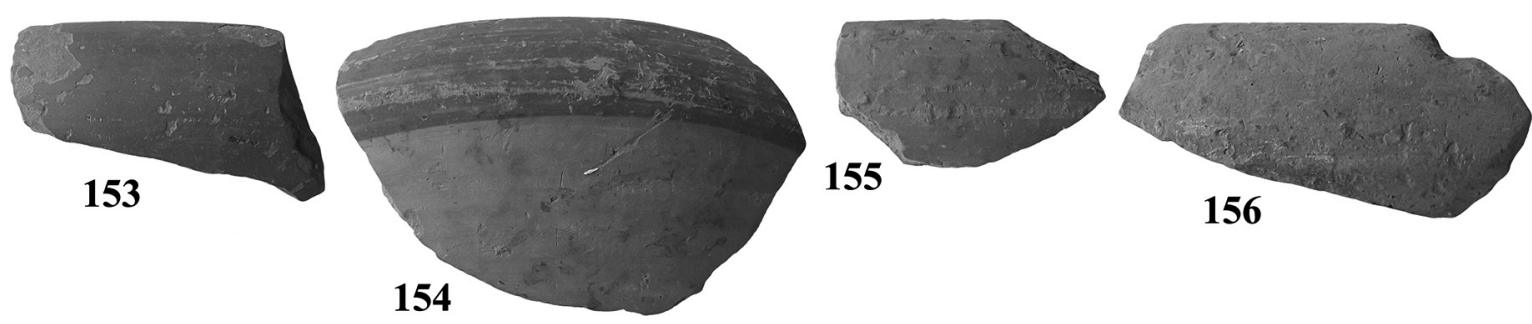

157
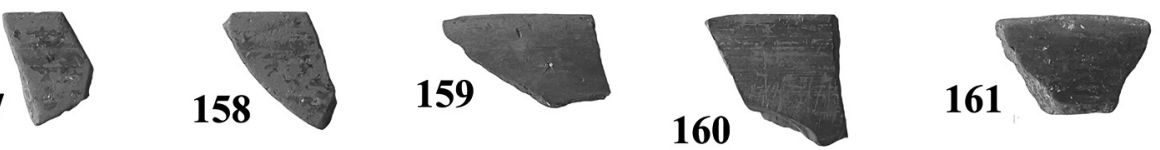

162
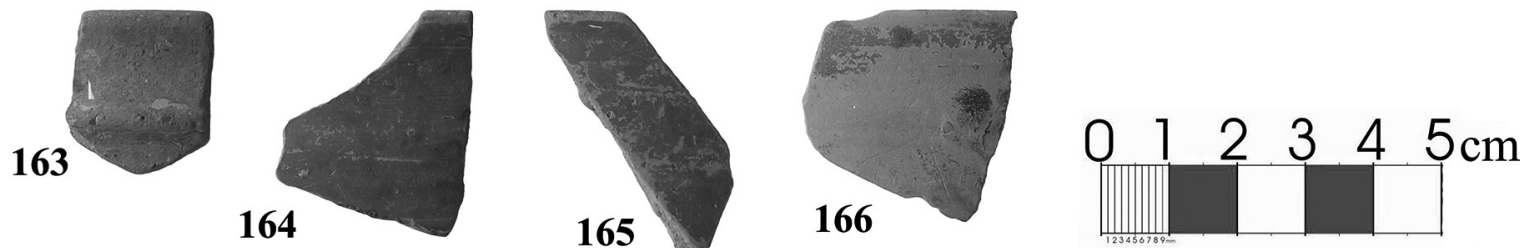

Pl. 28 : Nos 134-166: Red-painted Kepez group; ${ }^{\text {os }}$ 134-156: Bowl form 1; and $\mathrm{n}^{\text {os }}$ 157-166: Bowl form 2. 


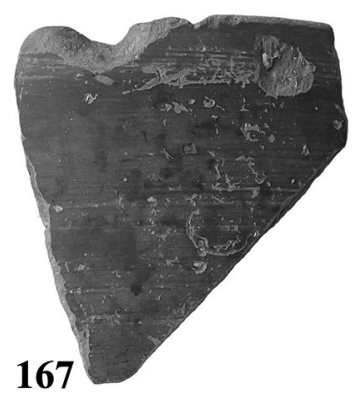

171

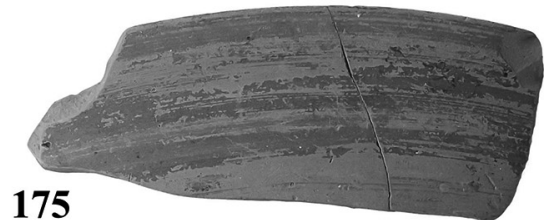

176
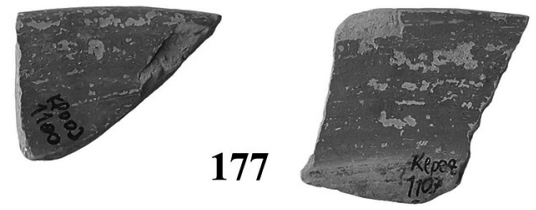

178

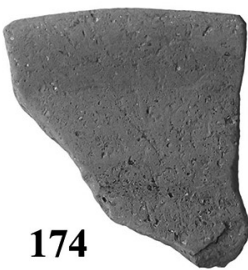

173

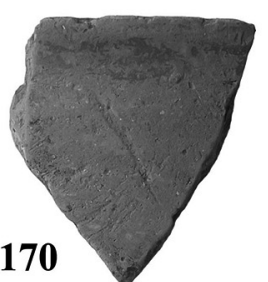

172
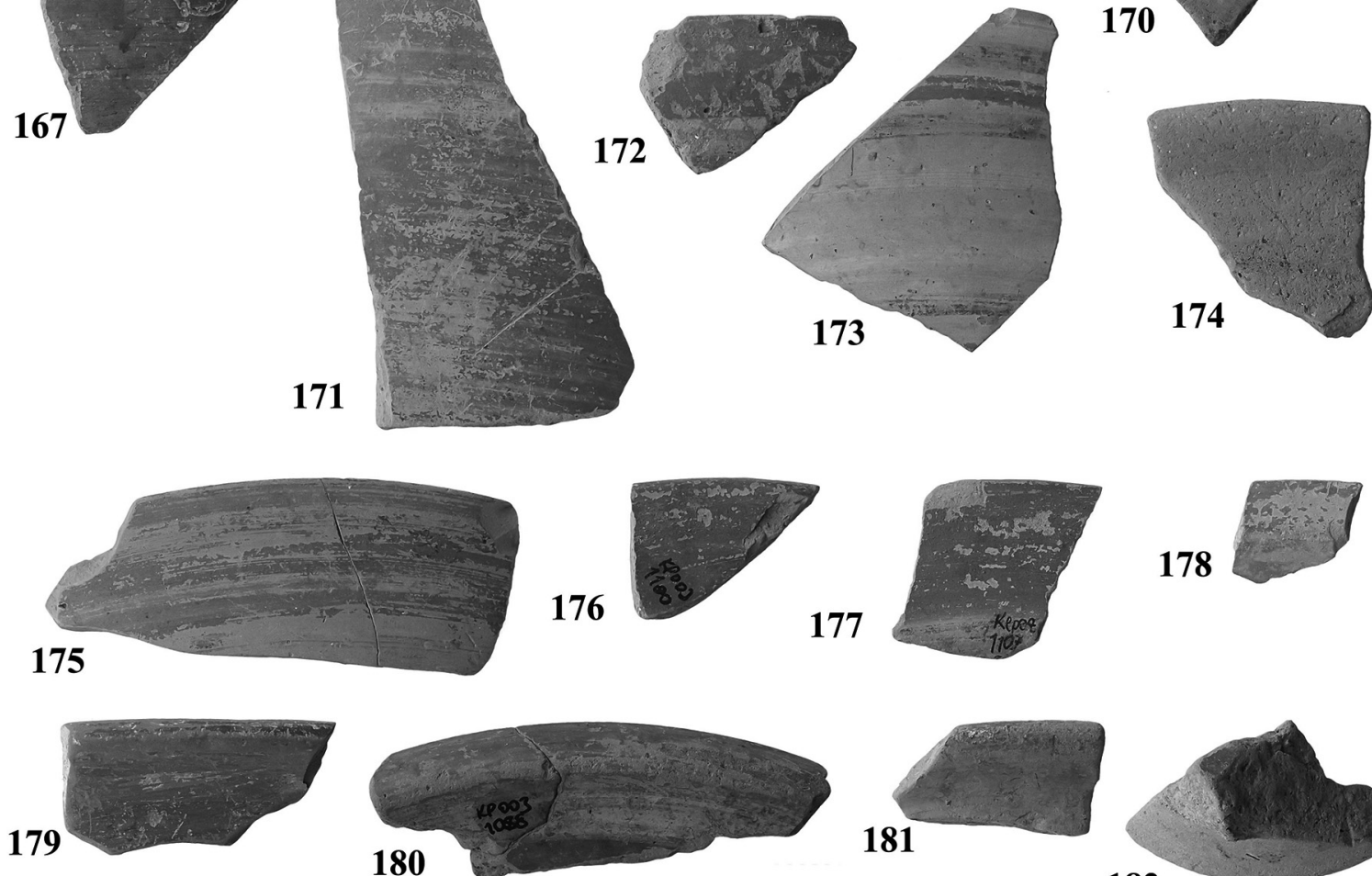

181

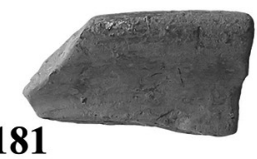

182
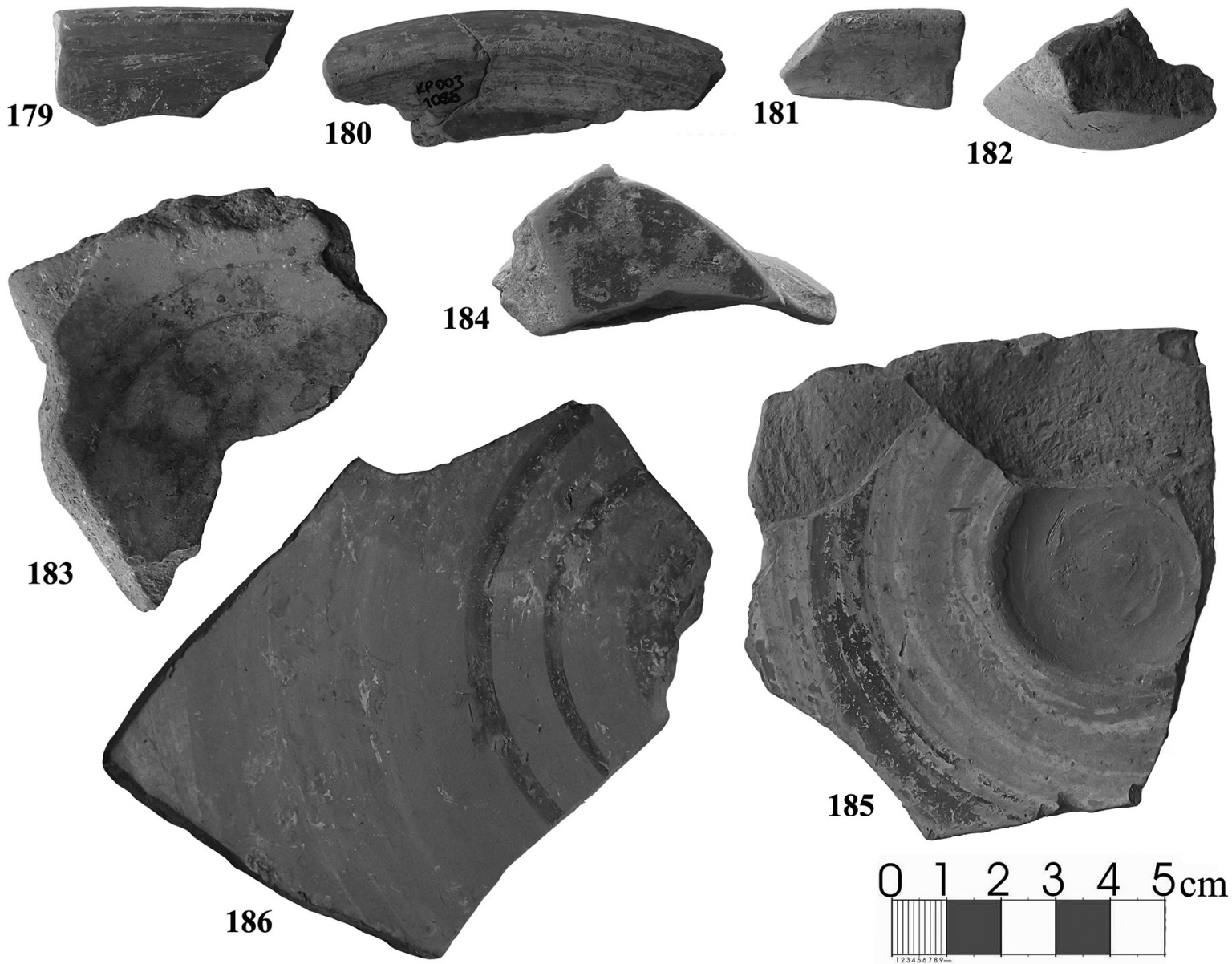

Pl. 29 : Nos 167-186: Red-painted Kepez group; $\mathbf{n}^{\text {os }}$ 167-172: Bowl form 2; $\mathbf{n}^{\text {os }}$ 173-175: Dish form 1; $n^{\text {os }}$ 176-177: Dish form 2; $n^{\text {os }}$ 178-181: Plate; and $n^{\text {os }}$ 182-186: Base fragments of open forms. 

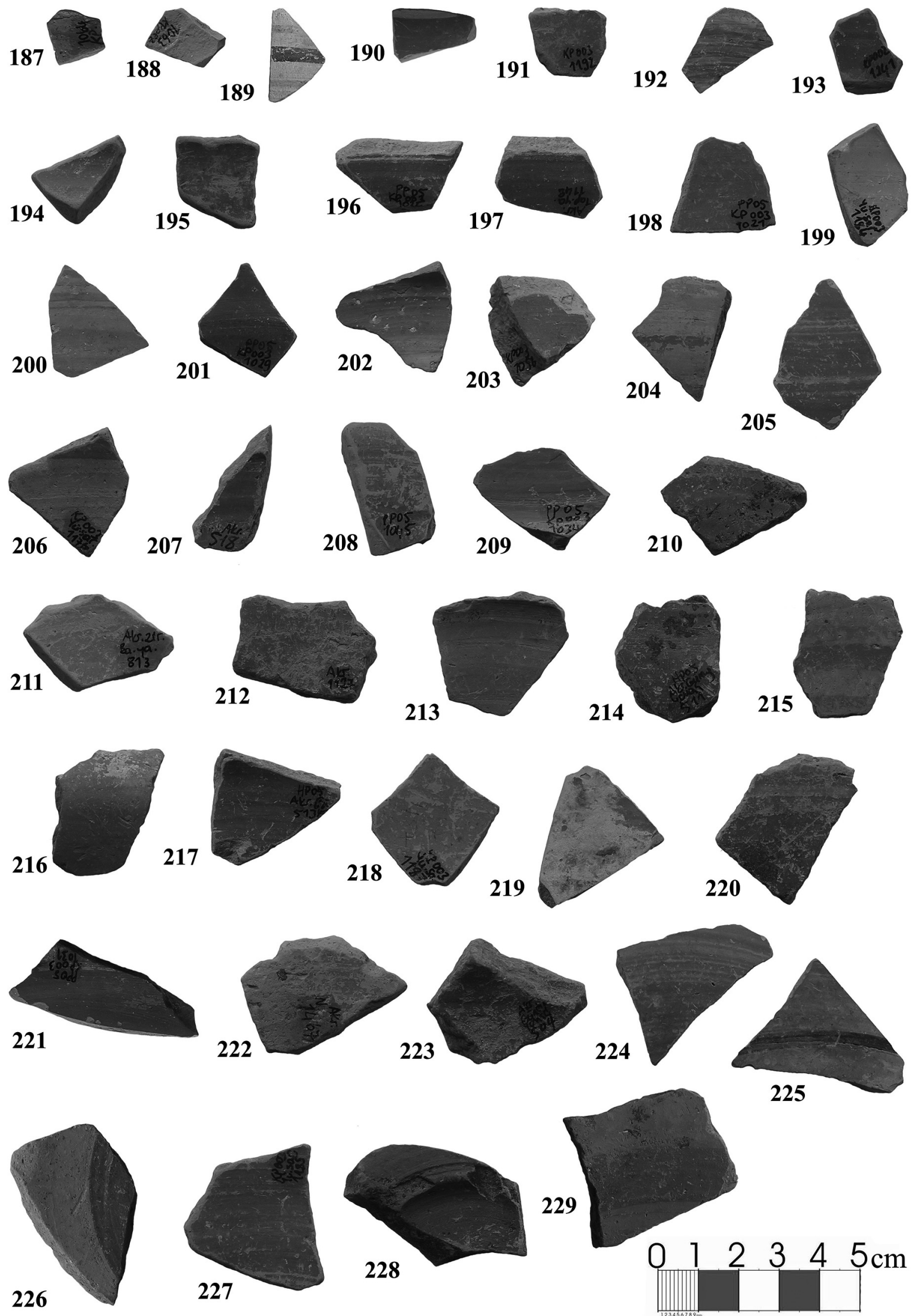

Pl. 30 : Nos 187-229: Red-painted Kepez group, body fragments of open forms. 

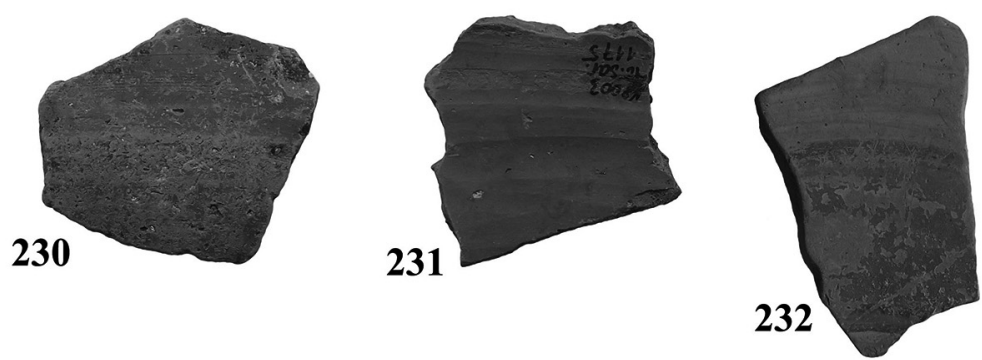

233
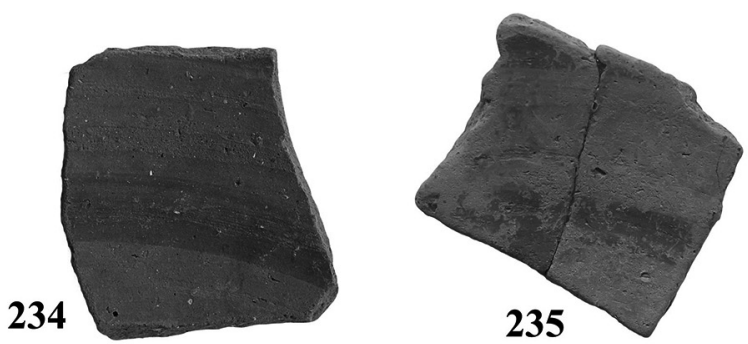

236
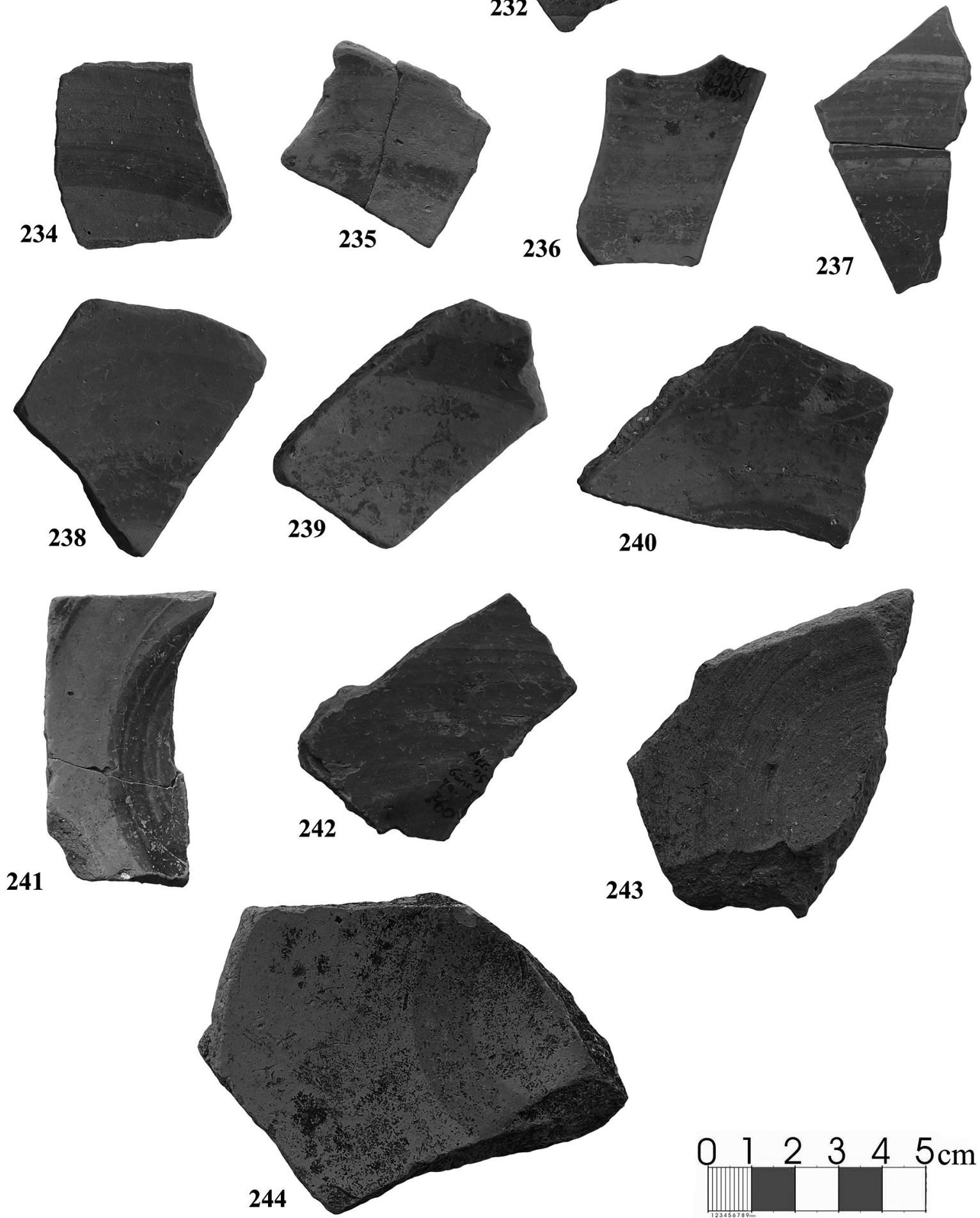

Pl. 31 : Nos 230-244: Red-painted Kepez group, body fragments of open forms. 

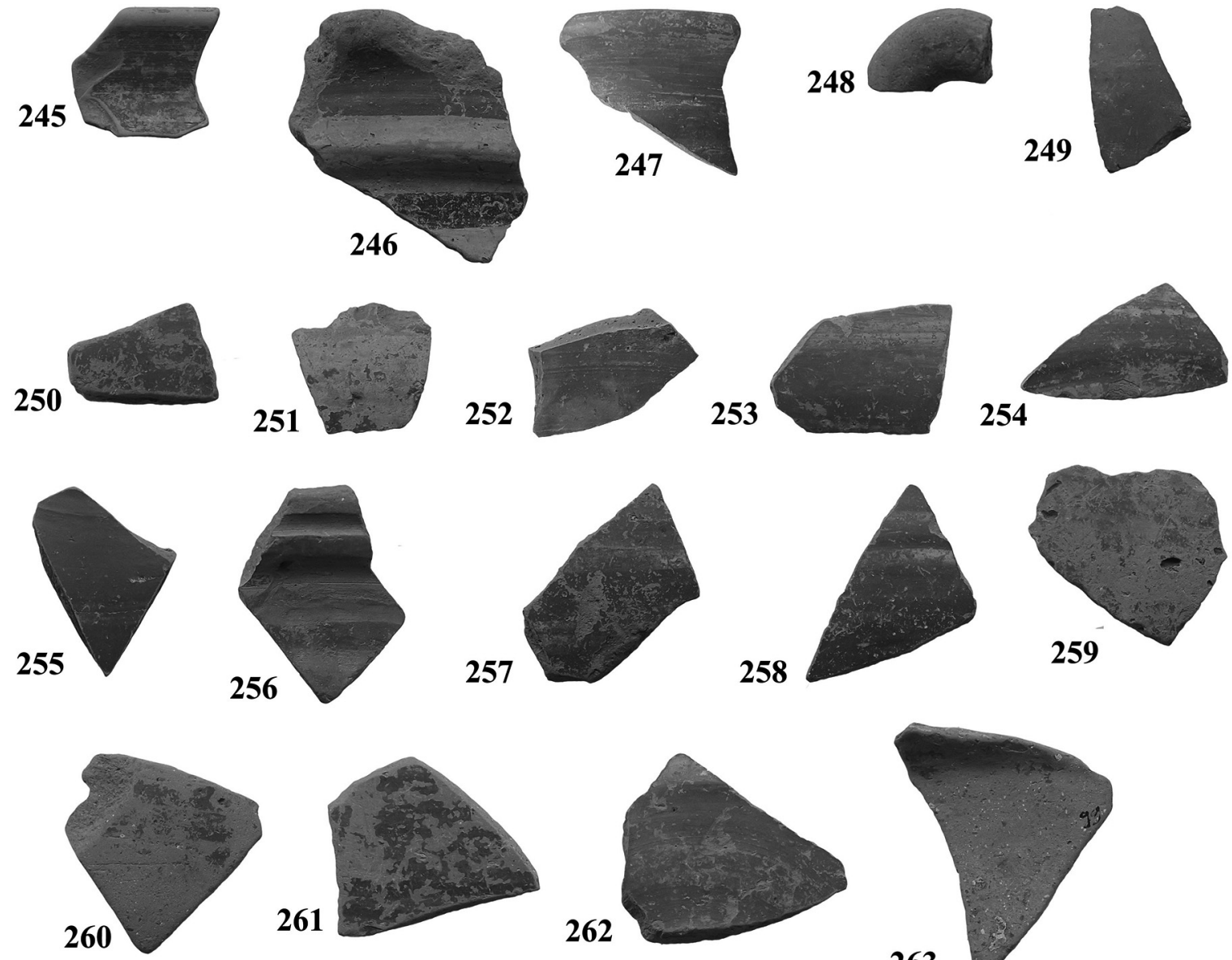

262
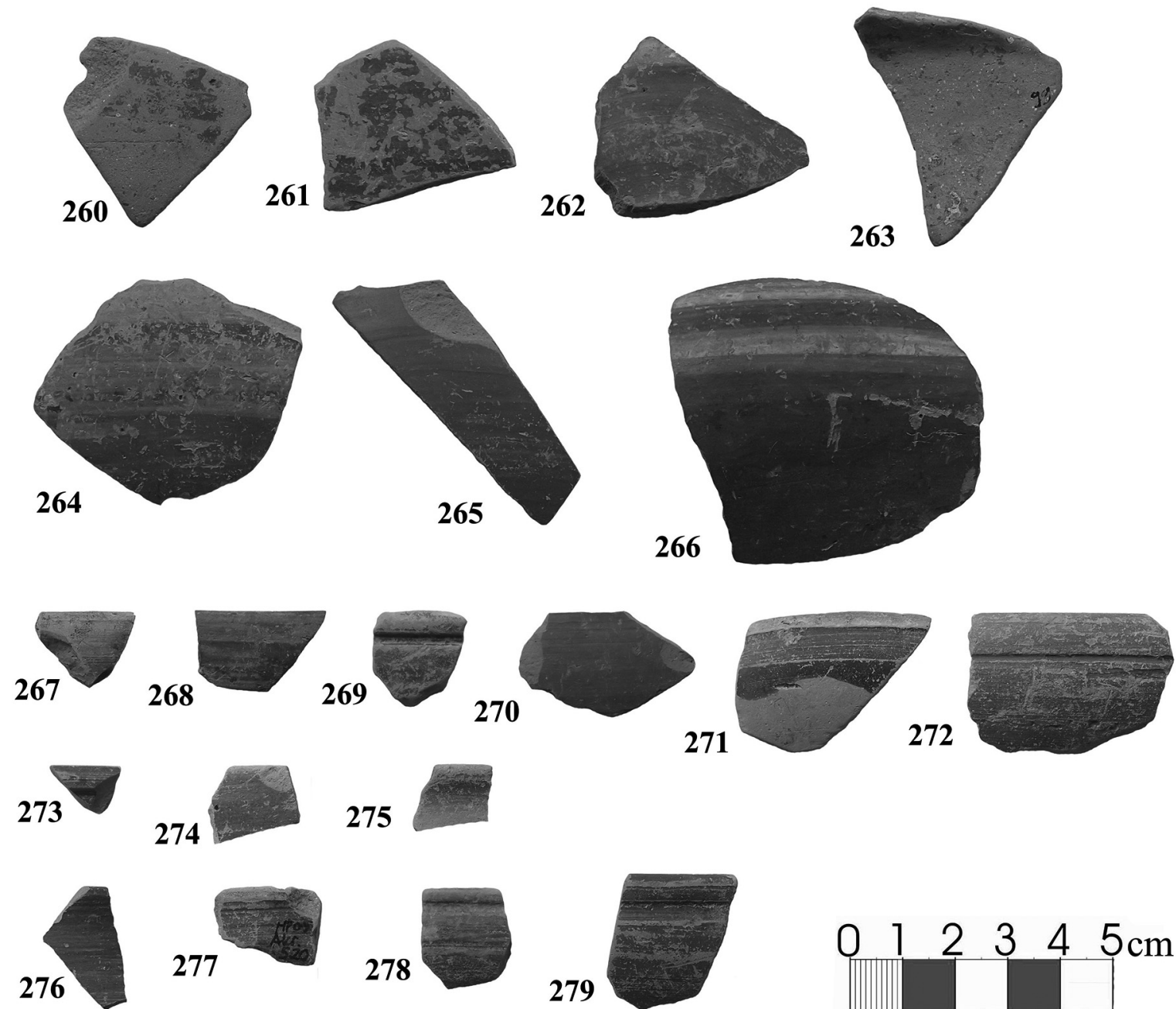

274
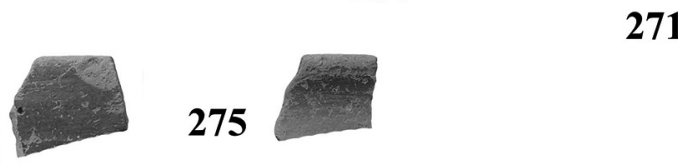

272

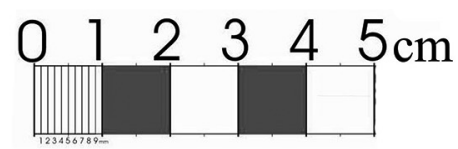

Pl. 32 : Nos 245-266: Red-painted Kepez group; $n^{\text {os }}$ 245-247: Rim fragments of closed forms; no. 248: $A$ handle fragment of a closed form; $n^{\text {os }}$ 249-266: Body fragments of closed forms; $n^{\text {os }}$ 267-279: Late

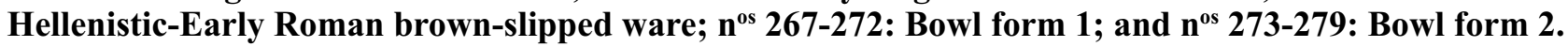



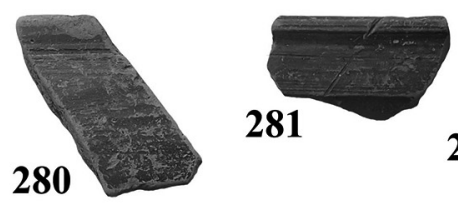

282

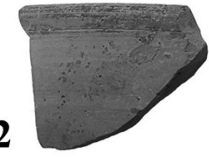

283
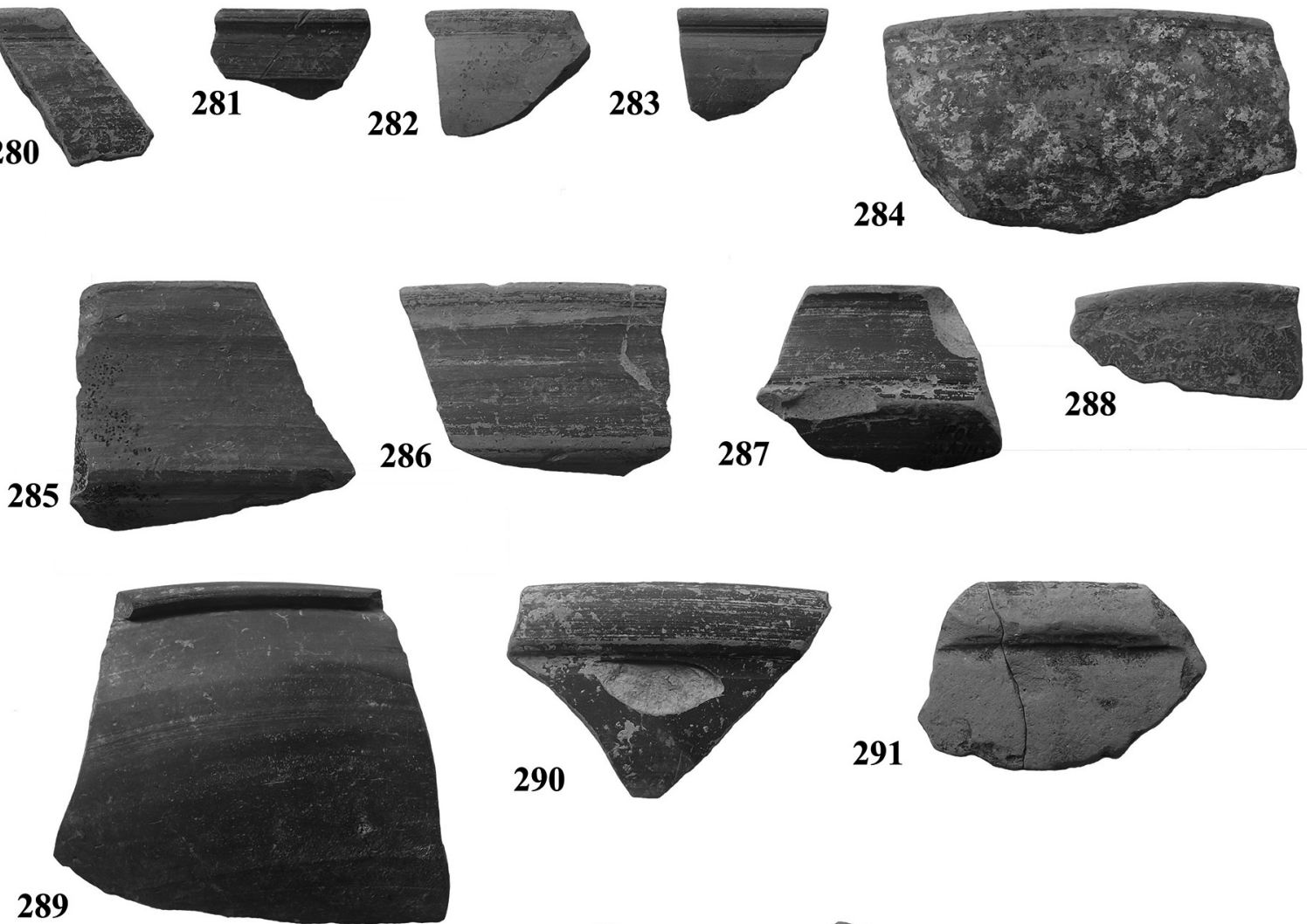

292

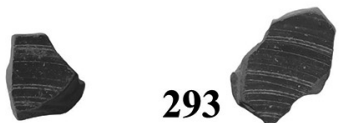

294
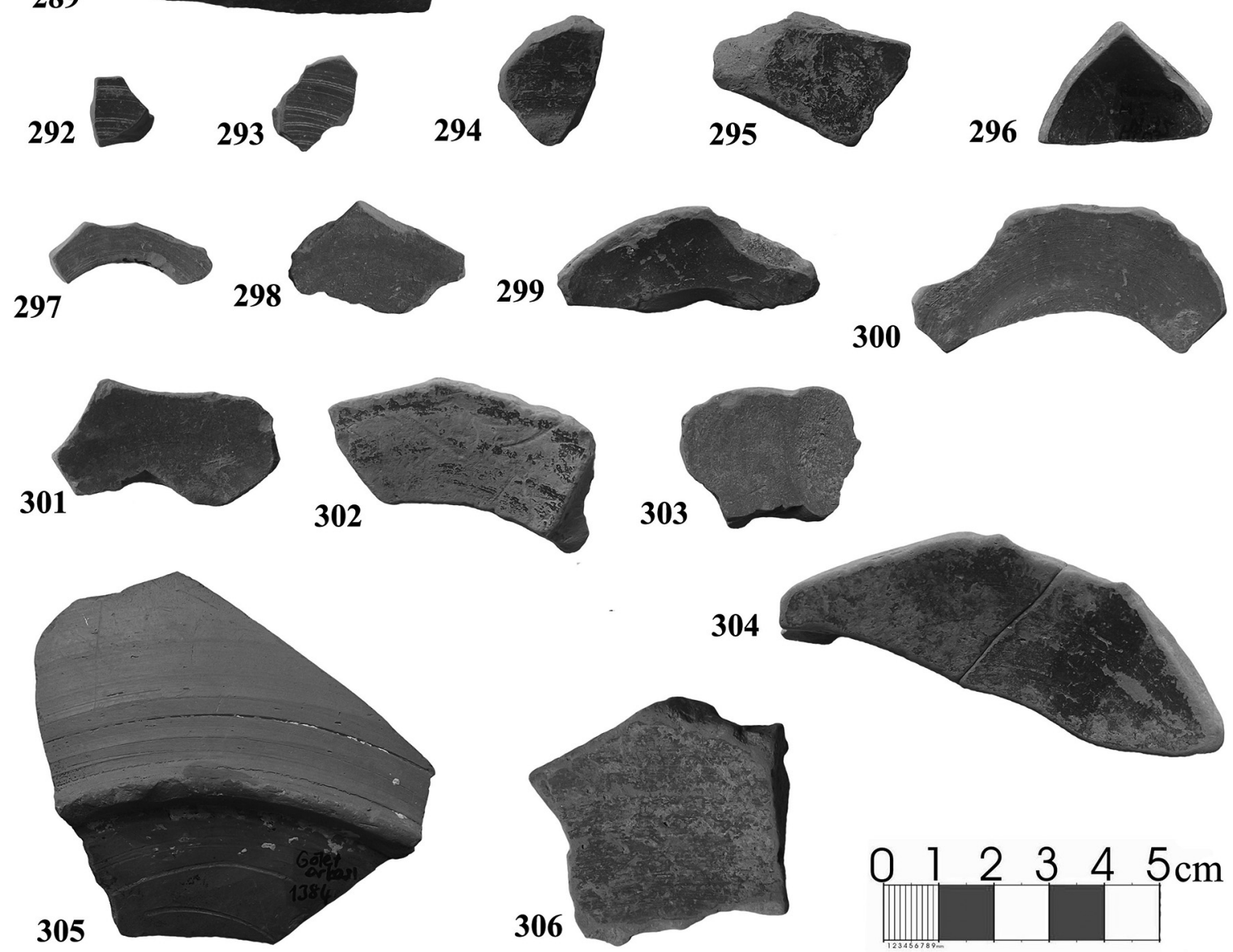

Pl. 33 : Nos 280-306: Late Hellenistic-Early Roman brown-slipped ware; ${ }^{\text {os }}$ 280-284: Bowl form 2; $n^{\text {os } 285-287: ~ D i s h ; ~}{ }^{\text {os }}$ 288-291: Other rim forms; and $n^{\text {os }}$ 292-306: Base fragments of open forms. 

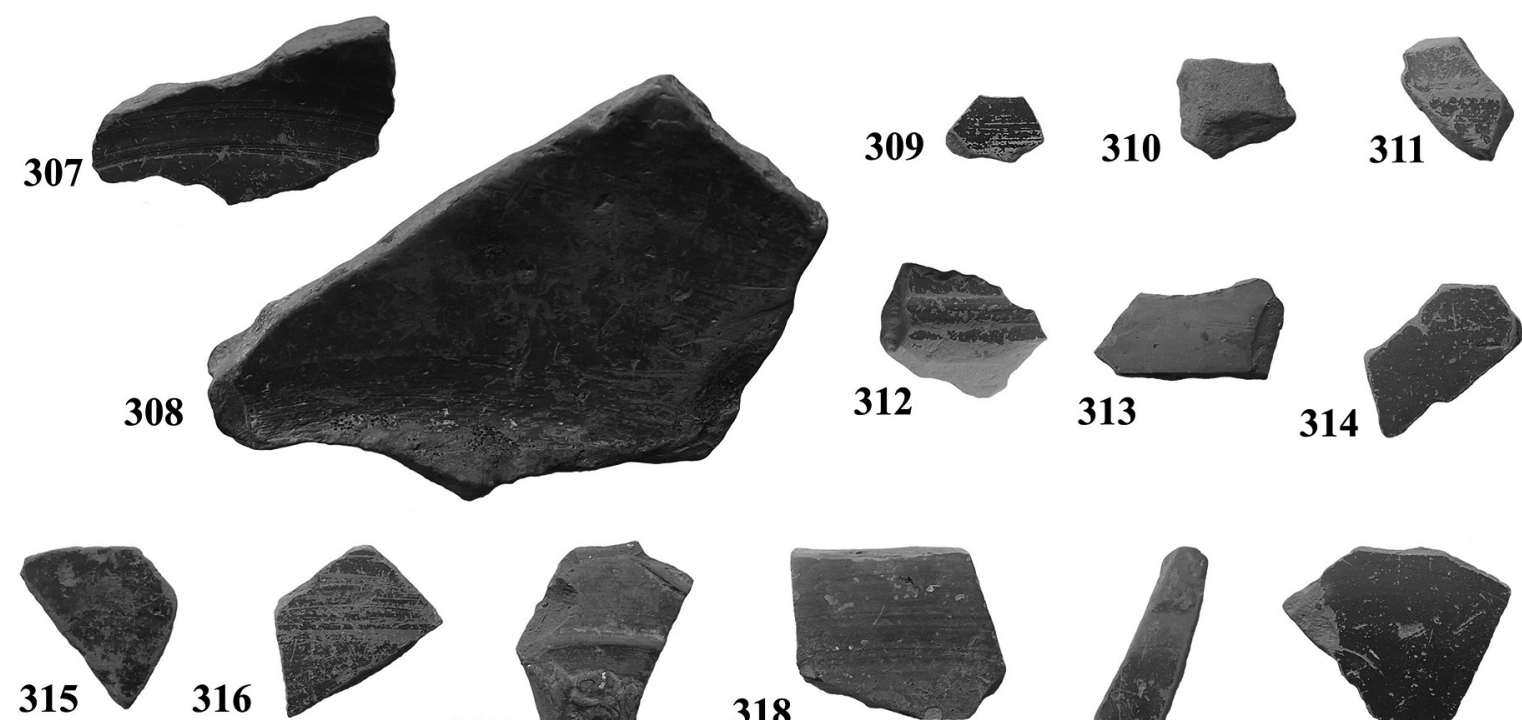

317
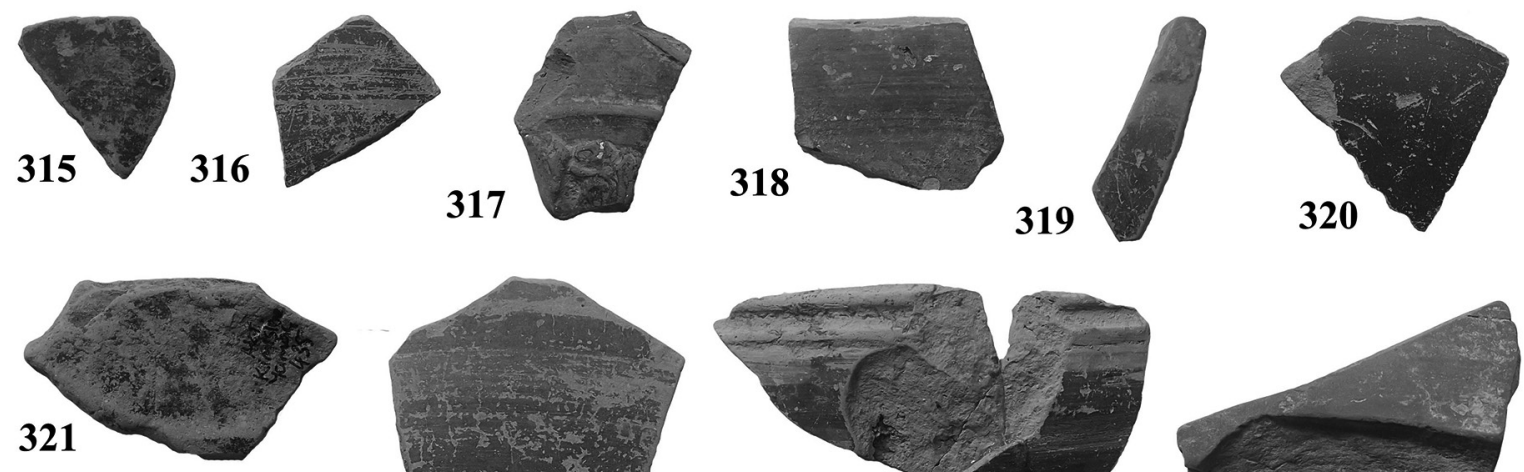

322
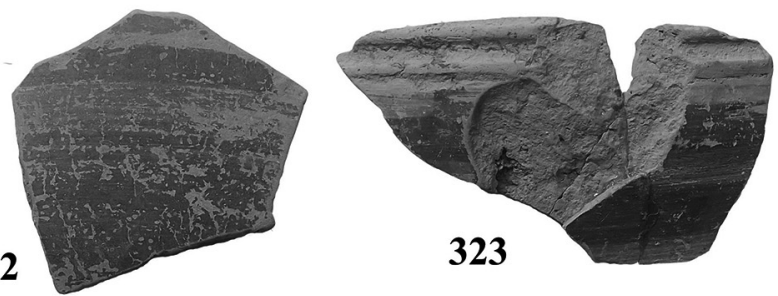

323
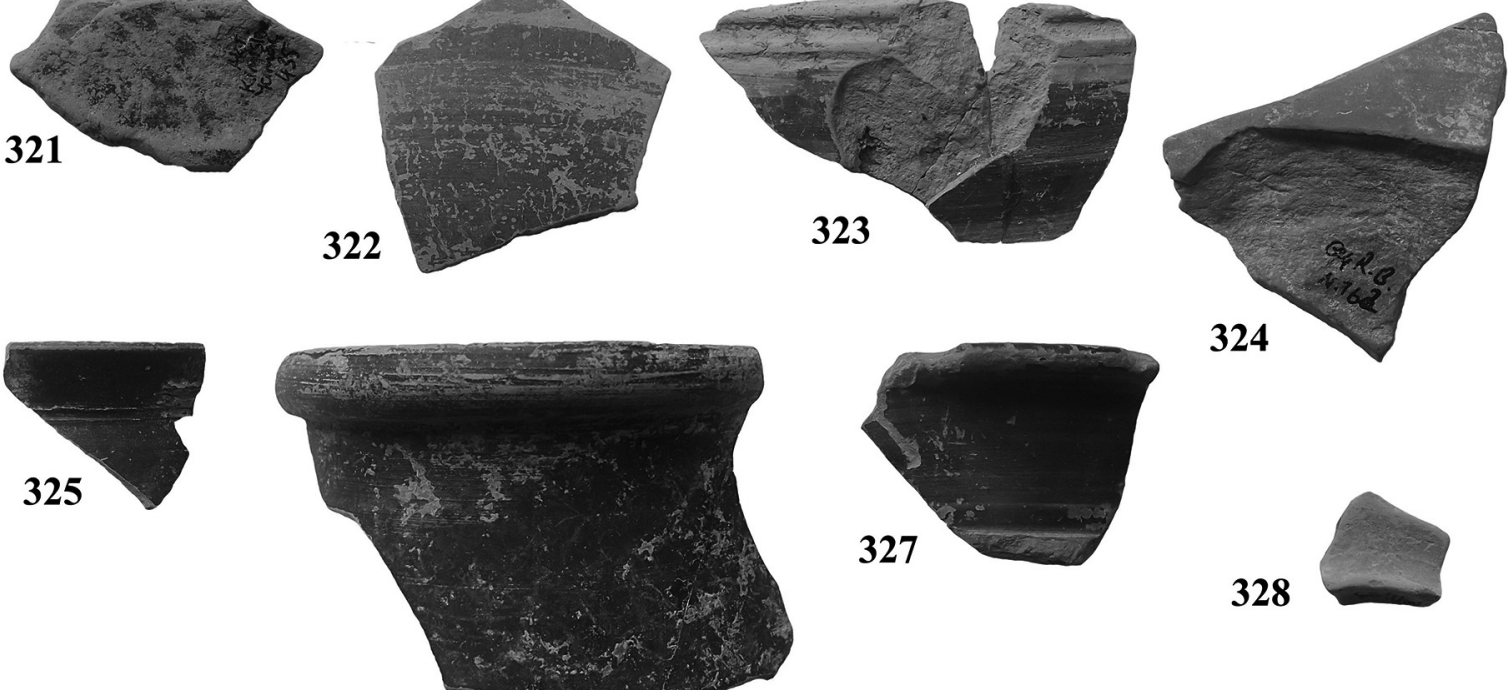

324

328
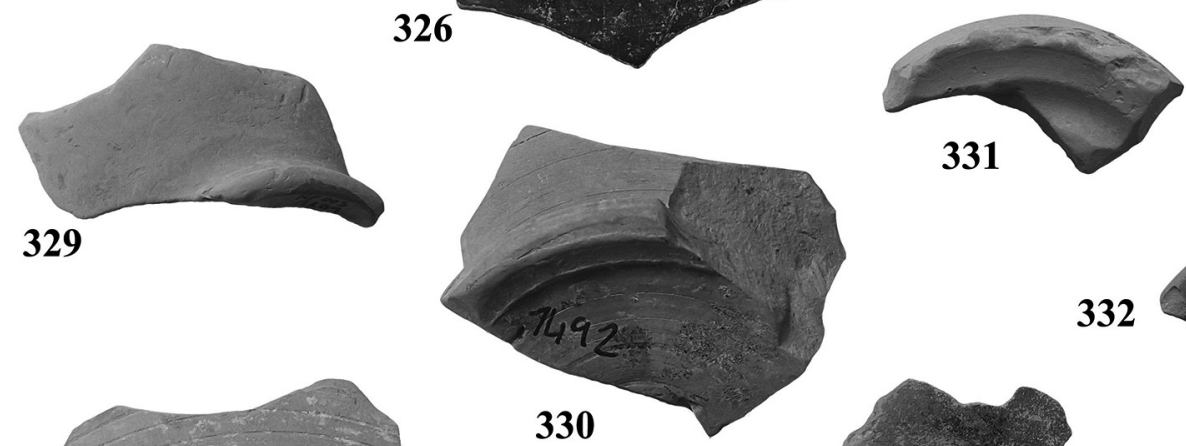

332
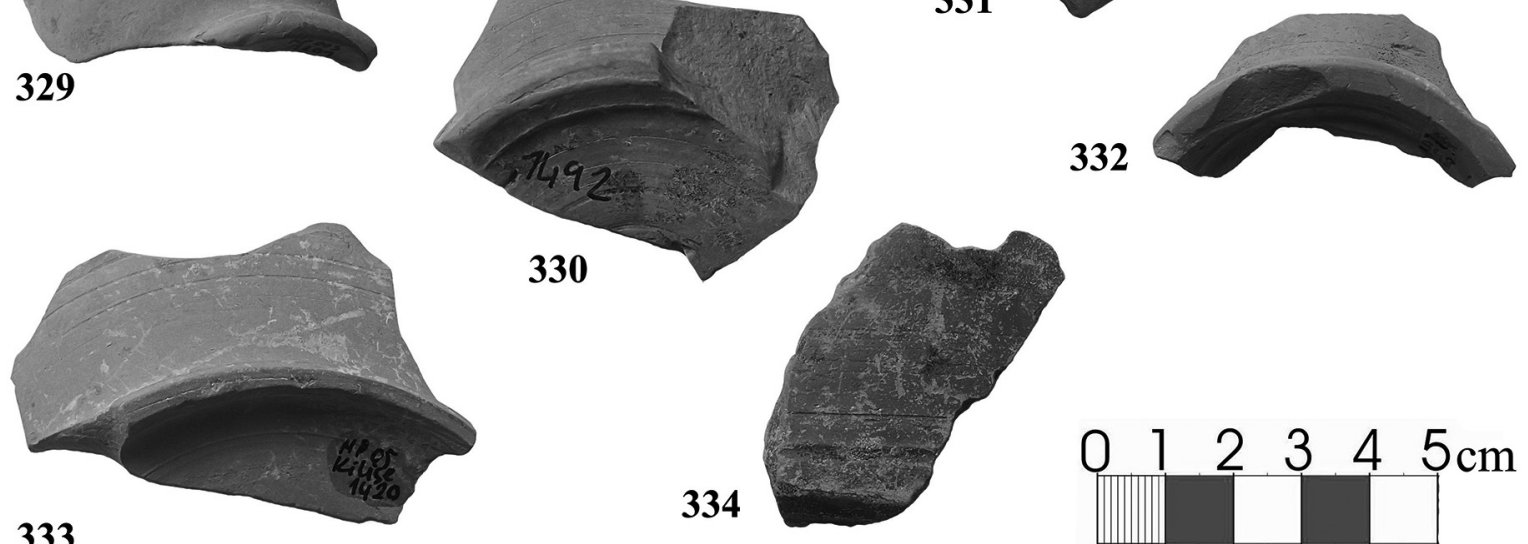

330
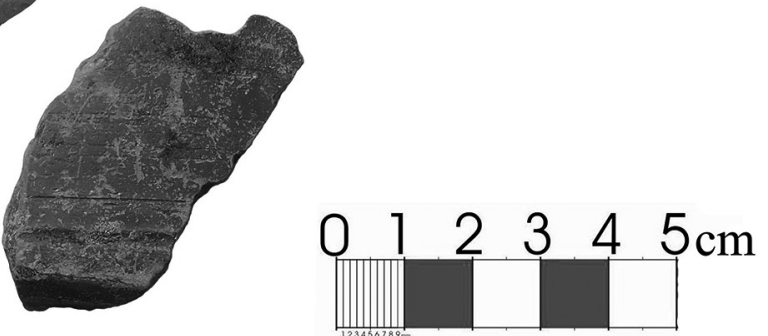

Pl. 34 : Nos 307-334: Late Hellenistic-Early Roman brown-slipped ware; $\mathbf{n}^{\text {os }}$ 307-308: Base fragments of open forms; $n^{\text {os }}$ 309-324: Body fragments of open forms; $n^{\text {os }} 325-327$ : Juglet; and $n^{\text {os }} 328-344$ :

Base fragments of closed forms. 


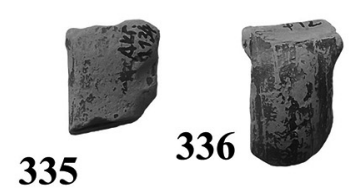

337

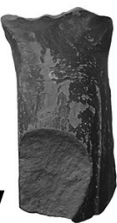

338

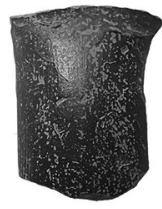

339

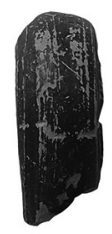

340

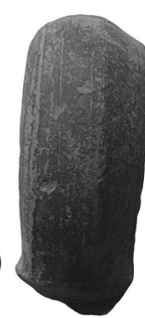

341

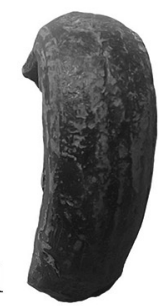

345

\section{3}

342

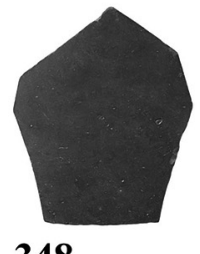

348
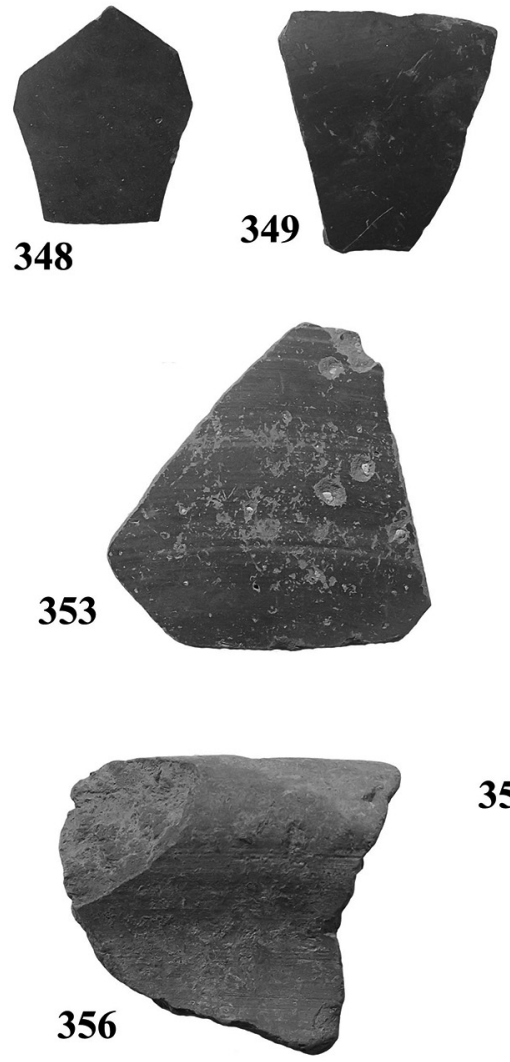

354
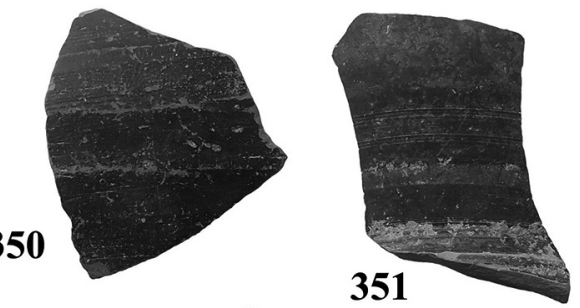

352

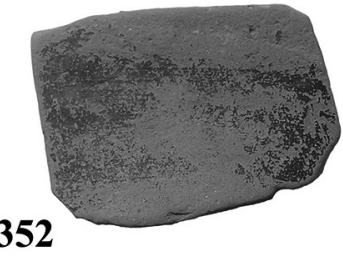

346
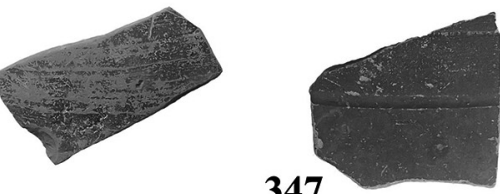

347 

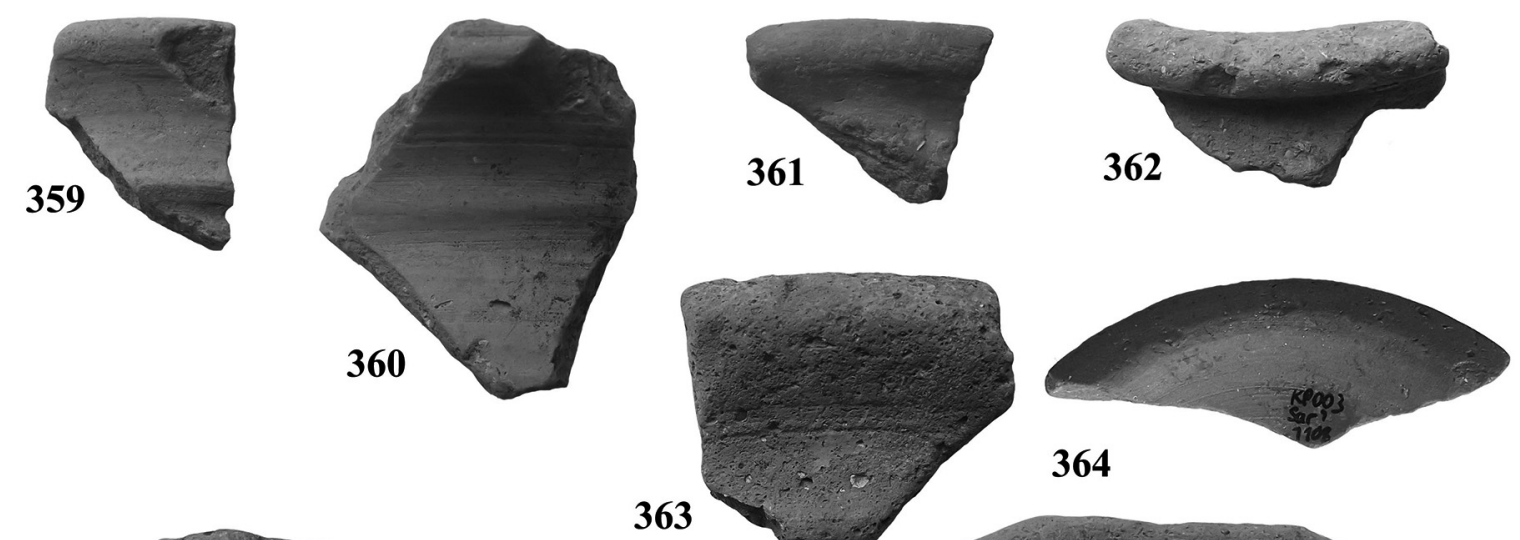

365
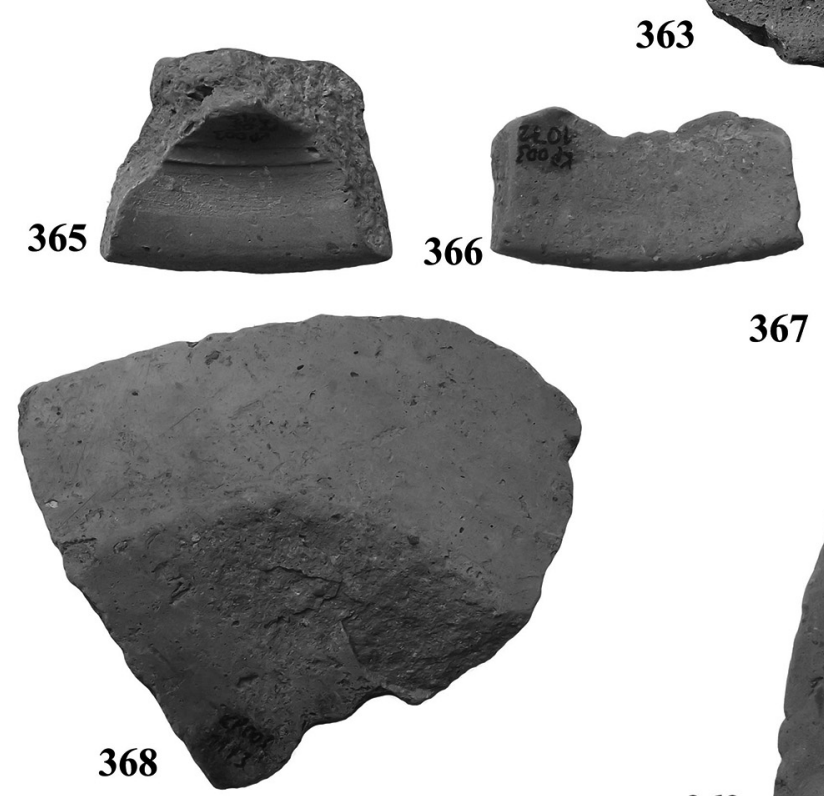

367
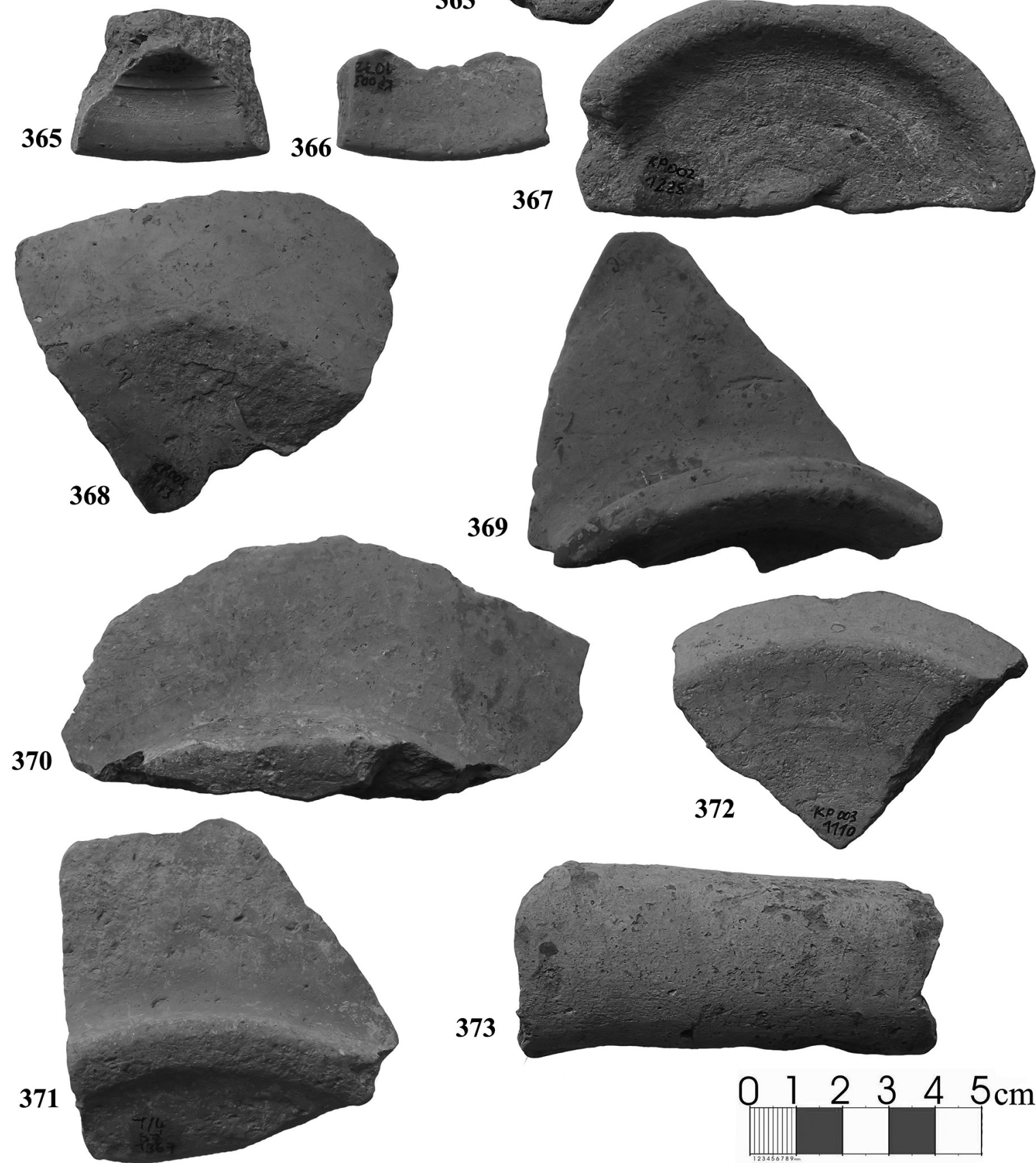

Pl. 36 : $\mathrm{N}^{\text {os }}$ 359-373: Hellenistic coarse ware; $\mathbf{n}^{\text {os }}$ 359-363: Rim fragments of closed forms; $\mathbf{n}^{\text {os }} 364-372$ : Base fragments of closed forms; and $n^{\circ} 373$ : A handle fragment of a closed form. 

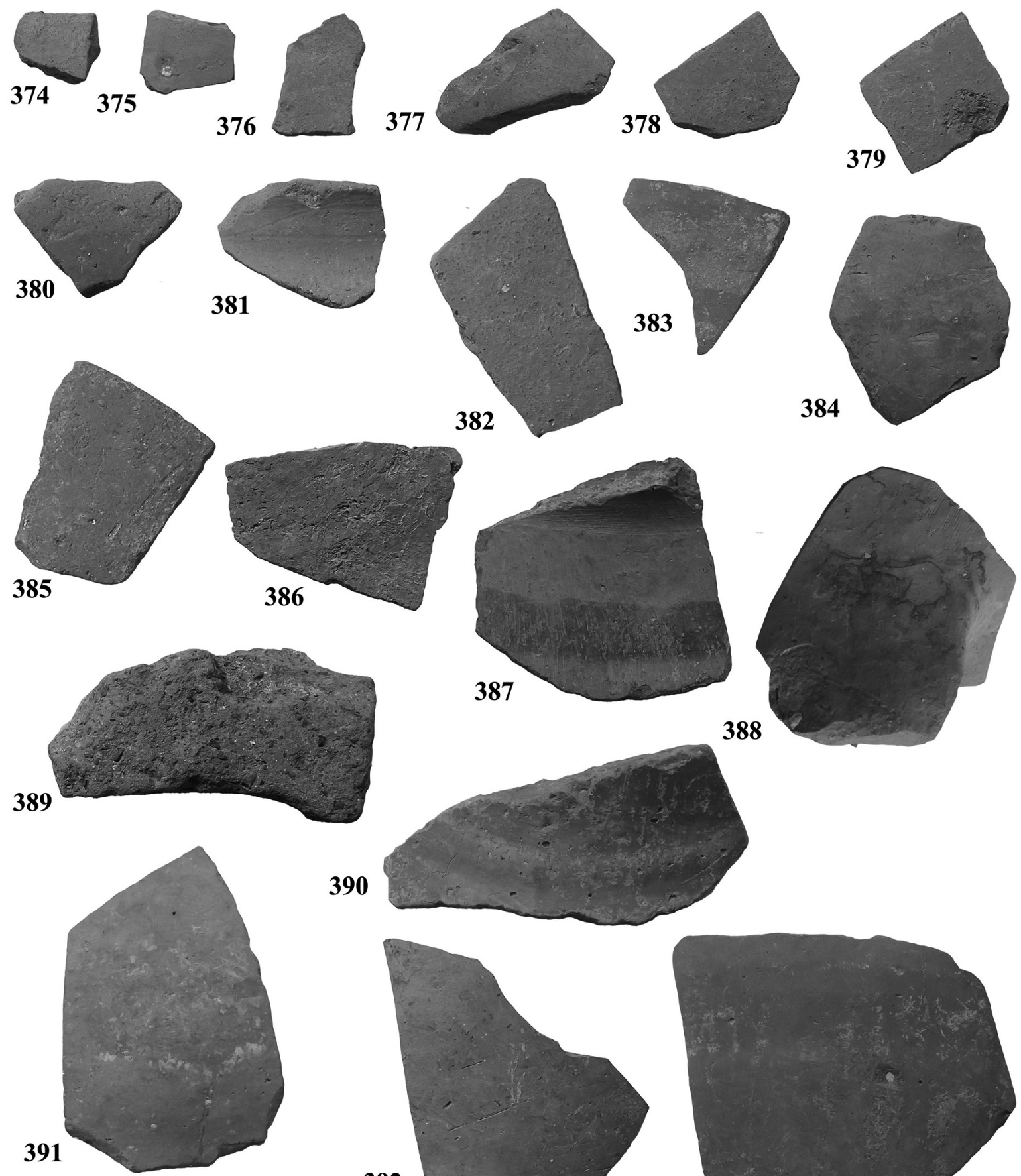

390
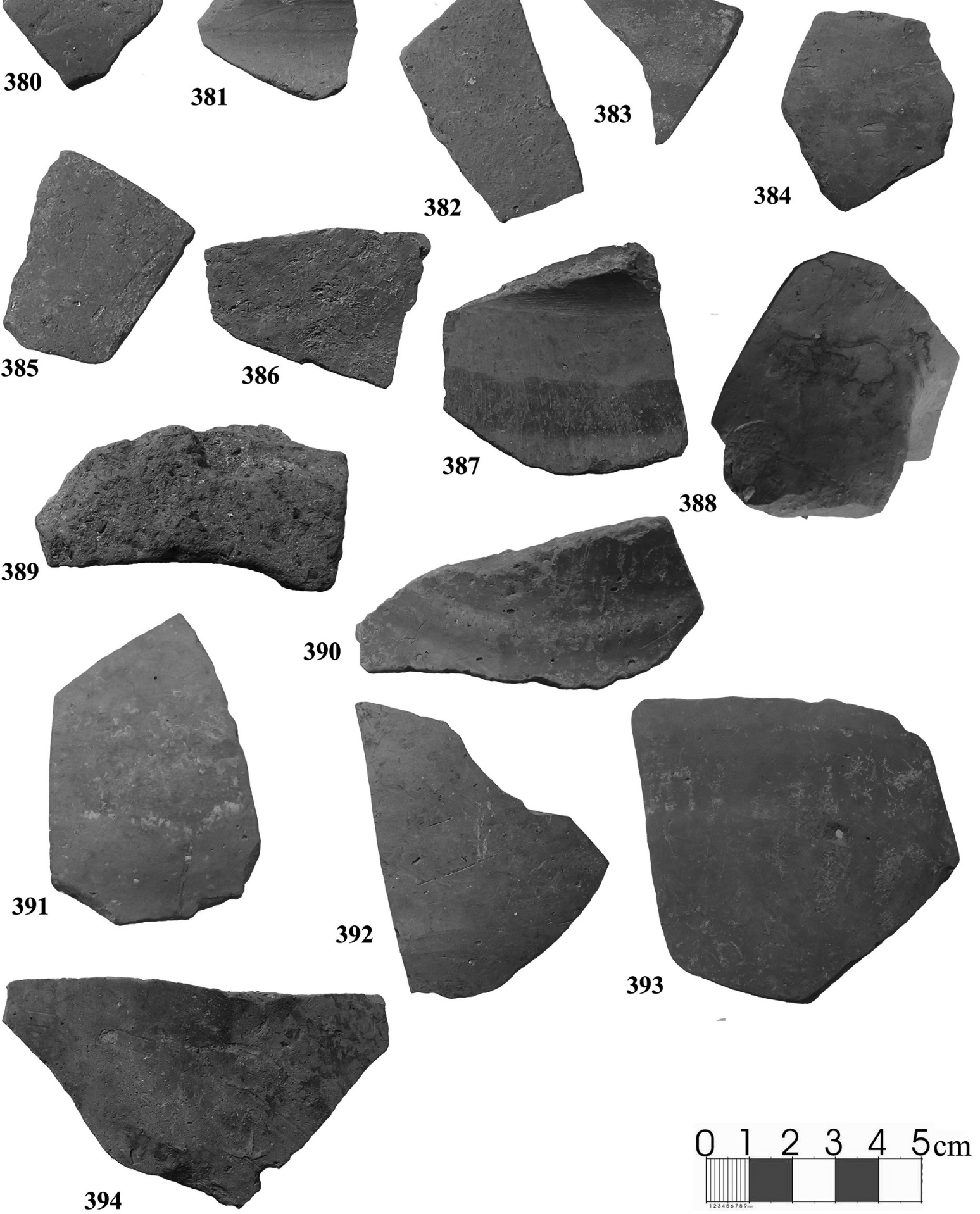

PI. 37 : Nos 374-394: Hellenistic coarse ware, body fragments of closed forms. 


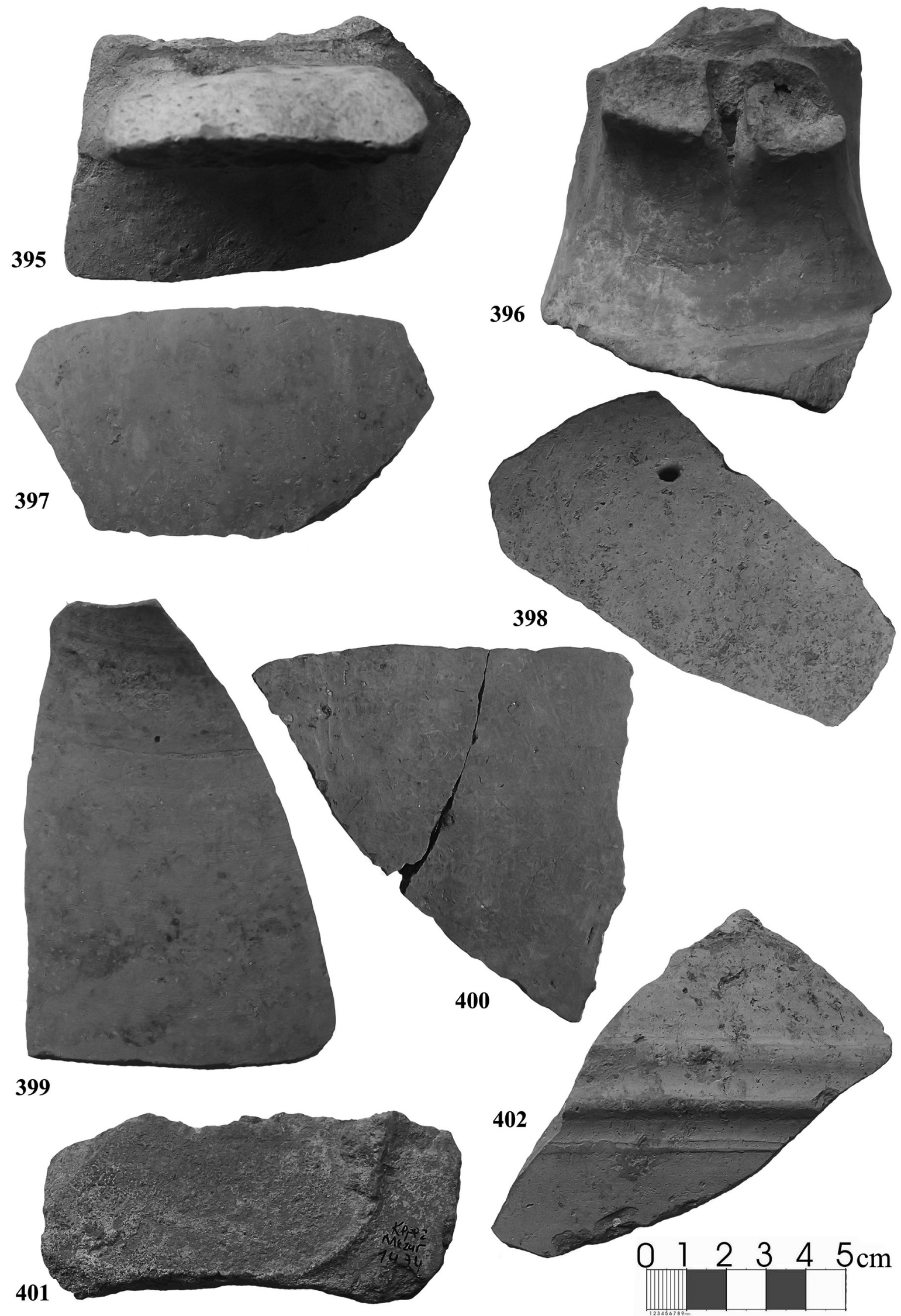

Pl. 38 : Nos 395-402: Hellenistic coarse ware, body fragments of closed forms. 


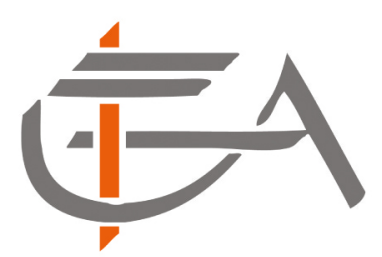

Institut Français

d'Etudes Anatoliennes

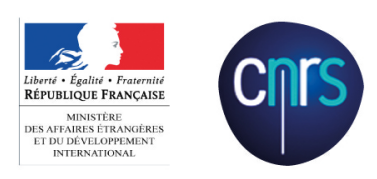

Peinture rupestre préhistorique, Sağlık Köy, près d'Alabanda, Turquie (cliché Suat Ateşlier). 